“I JUST FIND IT AWKWARD”: GIRLS' NEGOTIATIONS OF SEXUALISED POP MUSIC MEDIA

BY

SARAH ANN GODDARD

\begin{abstract}
A thesis
submitted to Victoria University of Wellington

in fulfilment of the requirements of the degree of

Doctor of Philosophy
\end{abstract}

Victoria University

(2016) 
Acknowledgements

There is a long list of people who have encouraged, supported and propped me up on this long journey. Firstly, thank you to my supervisor Dr Sue Jackson. You know more than perhaps anyone else that this journey has been far from straightforward. I am so incredibly grateful for your guidance, patience, time, wisdom, your feedback and most importantly, your belief in my ability to complete this thesis even when I did not believe I could. I know that this thesis, and in many ways who I have developed into as a feminist researcher would not be the same without you. Thank you for pushing me and for seeing in me what I sometimes could not see in myself. Your passion for this area of work and the lives that this important research touches has inspired me since before the conceptualisation of this project. It is this inspiration and my own passion which I see reflected in the pages of this thesis and that I wish to take forward with me into my future work.

Thank you also to my secondary supervisor, Anita Brady. Your encouragement and feedback have been extremely valuable. Thank you for the time you have invested in this project to give detailed feedback, especially of the final draft. Your interest and enthusiasm throughout this process has been extremely helpful.

Thank you to the girls who took the time to take part in this research. Your smiling, laughing, faces and enthusiastic and bubbly contributions to this project are written throughout the pages of this thesis and instilled in my mind.

Thank you to my postgrad friends at Victoria University for your kind words of encouragement. Thank you to David for the stress relieving laughs over lunch and coffee. Thank you to Clara for being there for me amidst your own $\mathrm{PhD}$ stress and for repeatedly assuring me and telling me to "just let it go".

Thank you to my friends and family and two people who fit in both of those categories, my queens, Harriet and Chelsea. Thank you for your unwavering support, your belief in me and for encouraging me to finish even when it seemed impossible. Thank you for putting up with stressy, unpredictable Sarah for so so long. I love you both so much and know that none of this would have been possible without you. 
Thank you to Liz for being there for coffee and listening to me rant and cry over the phone. Coping with the emotional stress of completing this thesis would have been impossible without you. Thank you to my "fur" parents for always having a bed and a cat available to me.

Thank you to my wonderful parents. Mum and dad, thank you for your unconditional love and support over all these years. Thank you for helping me to become someone who asks questions and to be a strong and proud woman. I love you both so much and am so grateful to have you in my life.

Thank you to my na-na. I really don't know how I would have coped with the last few years of this journey without you. You are the most wonderful sister and friend and I am so grateful to have you in my life. To my grandad John, thank you for all your love and support. Finally, to my late nana Bernadette, thank you for all your love and encouragement and for looking down on me all these years. 


\begin{abstract}
This thesis examines girls' relationship with and consumption of female pop stars' music media. It is contextualised within a period of extensive academic and media debate about girls' engagement with what has been termed the sexualisation of culture. Much of the alarm concerning girls' premature sexualisation is underpinned by the presumption of girls as passive media consumers who are uniformly influenced by sexually saturated female pop music, particularly its ubiquitous representation of hyper (hetero) sexually desiring femininity. The notion of girls as precociously sexualised by hypersexual female pop music media has gained homogenous status within mainstream media and popular psychology texts. Girls' pleasurable consumption and negotiation of a sexually laden media landscape is approached in this research as complicated by their contradictory positioning as savvy consumers within the postfeminist girlhood consumer market and simultaneously as victims within mainstream media and academic literature.
\end{abstract}

Grounded in feminist poststructuralist understandings of girls' subjectivity, the thesis explores the possibilities of self that representations within female pop music media enable and constrain for girls. Furthermore, the thesis explores ways in which girls make sense of these discourses while carefully managing their positioning as consumers. The research upon which this thesis is based has two parts. Part one of the research involved focus groups within which 30 pre-teen girls, identifying as 'Kiwis' or 'New Zealanders' discussed their engagement with female popular music media. The second part comprises a thematic discursive and semiotic analysis of girls' selfrecorded group video performances to a favourite pop song by a female artist. Discursive analysis of the professional music videos on which girls' performances were based accompanied analyses of girls' videos. The thesis contributes to a growing body of critical feminist research which responds to sexualisation claims that underpin hegemonic understandings of contemporary girlhood.

The analyses presented in the research challenge moralistic notions of girls as uniformly influenced by pop music media by highlighting their navigation of this media as a contradictory process of appropriation and rejection. This complex negotiation, while seen in previous feminist literature, is uniquely captured within this thesis through the innovative employment of a performance method that extends 
feminist theorisations that problematize binary assumptions of girls' engagement with sexualised media. This research identifies girls' meaning making as a contradictory and plural process and provides novel insights about girls' negotiation of postfeminist femininities in their own self-making in relation to self. Crucially, the thesis highlights the way in which girls' navigation of sexualised media can be understood as occurring through both rejection and reproduction of postfeminist femininity ideals. Contextualised in New Zealand, the research extends knowledge about girls' navigation of sexualised media beyond a US/UK social context. It also advances the small body of New Zealand literature about girls' media engagement broadly and about the ways they experience sexualised media in particular. 


\section{Preface}

My interest in development and studying young peoples' experiences with their own growing, changing, bodies, minds and place in the world has been with me since high school. My enthusiasm for studying girlhood centre's most prominently on my own experience of this time, and particularly my relationship with popular culture and love of popular music. The majority of my memories as a girl revolve around pop music. Though I didn't know it at the time (but have come to know and understand through the process of this thesis) my tween years occurred during a particularly notable increase of female pop music in the early to mid-1990's. My love of music and growing up during this time cemented female popular music and pop music stars as a central medium in my life, one which has continued to be a part of who I am and how I express myself in the years since. By far my favorite activity as a girl was planning and choreographing 'shows', dances and general performances to music. I would produce these shows by myself, performing for my toys or inviting my parents into my room to watch what I had cultivated. My most memorable performances at this time were to Spice Girls songs and involved intensive and very serious choreography sessions and practices with friends, all of which was done safely away from the intruding adult eye. Privacy was central to these practices where, in my stripy tights and baggy white t-shirts, I would sing and move to music up on my tip toes, imagining that I was wearing the heeled shoes and a sparkly outfit.

In acknowledging the influence that my own experiences have had on my research I think it is paramount to highlight that in the increase in female pop music artists, the central discourses within this shift including neoliberalism and most importantly to the current research, postfeminism, have been a context within which I have been raised. In exploring the sexualisation of culture and particularly the role of postfeminist discourse within contemporary culture, it is important to highlight that I have not lived in a time where ideal postfeminist femininity didn't saturate mainstream culture. For me, I have never experienced a time where strong, independent, loud and attractive women weren't visible in popular culture. Ideal femininity was modelled (a notion which will be explored and problematised in the thesis) to me through the likes of the Spice Girls and in many ways continues to be modelled (or maybe more accurately, pressured) for me through pop music celebrities like Nicki Minaj, Rihanna and Beyoncé. Growing up in this cultural context where hypersexuality rules and sexually behaving bodies are given 'attention', the 
contemporary 'situation', as it is often described in literature, as a problem seems somewhat 'normal' to me outside of a research context.

Given my own experience with pop music during girlhood, making sense of this relationship within a research context has been difficult. Particularly, in entering tertiary education with an interest in studying childhood development and particularly girls' development, many of the ways in which I was interested in investigating girls' lives were not reflected through the experimental paradigms which dominate undergraduate psychology degrees. My interests in looking beyond the experimental paradigm and focussing on girls' experiences led me to a critical feminist approach to the study of girlhood. Investigating girls' pop music engagement in a time in which this relationship is so profoundly problematised has at times been a difficult and frustrating venture. Although my own memory of engaging with pop music as a girl (rose coloured as it may be) laid some of the foundations of how I experience myself now, as strong, opinionated and female, the majority of the mainstream psychological literature which I encountered in investigating the sexualisation of girls literature was largely absent of girls' voices.

For me, then, studying girls' engagement with pop music media in a social context within which it is almost universally problematised has been a journey which at times I have found enraging, saddening and always personal. Influenced by my own thoughts and feelings about growing up as a girl in a society that is saturated with images of powerful, independent and sexually savvy women, this thesis marks my first major academic exploration into how this context might influence girls' subjectivity work. Most importantly however, this research represents my first endeavour to provide a voice for girls and to respect and hold up that voice in a cultural environment where girls' voices are most commonly ignored, rejected or silenced. 


\section{Contents}

Acknowledgements 2

$\begin{array}{ll}\text { Abstract } & 4\end{array}$

Preface 6

$\begin{array}{lll}\text { Chapter One: } & \text { Introducing the Research }\end{array}$

$\begin{array}{ll}\text { New Zealand as a cultural context } & 15\end{array}$

$\begin{array}{ll}\text { Research questions and contribution } & 17\end{array}$

$\begin{array}{lll}\text { Chapter Two: } & \text { The Sexualisation of Culture }\end{array}$

What is the sexualisation of culture? 22

Feminist approaches to the sexualisation of culture 24

$\begin{array}{lr}\text { Feminist 'porn wars' } & 25\end{array}$

$\begin{array}{ll}\text { Contemporary feminist understandings } & 27\end{array}$

Towards a 'nuanced' approach

Sexuality as a postfeminist phenomenon 33

Centrality of the female body 35

$\begin{array}{ll}\text { The new desiring subject } & 37\end{array}$

Celebrity as a postfeminist text 39

Postfeminist absences in pop music media 43

Chapter Summary $\quad 45$

Chapter Three: $\quad$ The Sexualisation of Girlhood 47

Contextualising the sexualisation of girls 48

Unpacking the sexualisation of girls literature 49

Girls and sexuality: A socio-historical account 53

The sexualised 'at-risk' girl $\quad 57$ 
The smart, sassy 'can-do' girl. $\quad 58$

Complications of Girls' Sexual Agency and Empowerment 61

Girls and Pop Music: A place for Sexual Agency? 67

$\begin{array}{ll}\text { Chapter Summary } & 71\end{array}$

$\begin{array}{lll}\text { Chapter Four: } & \text { Methodological Framework }\end{array}$

$\begin{array}{ll}\text { Critical approaches } & 74\end{array}$

$\begin{array}{ll}\text { Poststructuralist theories } & 76\end{array}$

$\begin{array}{ll}\text { Discourse } & 77\end{array}$

Language, knowledge and power $\quad 78$

$\begin{array}{lr}\text { Subjectivity } & 80\end{array}$

$\begin{array}{ll}\text { Feminist approaches } & 82\end{array}$

$\begin{array}{ll}\text { Feminist poststructuralism } & 84\end{array}$

$\begin{array}{ll}\text { Audience studies } & 86\end{array}$

Approaching the child audience $\quad 91$

$\begin{array}{ll}\text { Girls as Media Producers } & 93\end{array}$

$\begin{array}{ll}\text { Approaching celebrity as a discursive text } & 94\end{array}$

Ethical Issues in the Research $\quad 98$

Feminist ethics of practice and care $\quad 98$

$\begin{array}{ll}\text { Conducting research with children } & 101\end{array}$

Reflexive Considerations of the Research 102

$\begin{array}{lr}\text { Researcher reflectivity } & 102\end{array}$

$\begin{array}{ll}\text { Chapter Summary } & 102\end{array}$

Chapter Five: $\quad$ General and Focus Group Study Method 106 
$\begin{array}{ll}\text { Participants } & 106\end{array}$

Recruitment 106

$\begin{array}{ll}\text { Participant descriptions } & 107\end{array}$

$\begin{array}{ll}\text { The Focus Group Study Method } & 107\end{array}$

$\begin{array}{ll}\text { Focus Group Study Process } & 108\end{array}$

$\begin{array}{ll}\text { Transcription } & 110\end{array}$

$\begin{array}{ll}\text { Focus Group Analysis } & 111\end{array}$

$\begin{array}{ll}\text { Thematic analysis } & 111\end{array}$

Discourse analysis 113

Chapter Six: $\quad$ Girls Negotiating Female Pop Music Media 115

$\begin{array}{ll}\text { Constructing the 'Real' Celebrity } & 115\end{array}$

$\begin{array}{ll}\text { Authenticity } & 116\end{array}$

$\begin{array}{lr}\text { Maturity } & 123\end{array}$

Negotiating Pop Music Consumption 129

The sexually knowing consumer $\quad 129$

The responsible media consumer $\quad 135$

The awkward viewer $\quad 138$

Chapter Summary 143

Chapter Seven: $\quad$ Music Video Study Method 145

$\begin{array}{ll}\text { Music video study process } & 145\end{array}$

$\begin{array}{ll}\text { Music Video Analysis } & 147\end{array}$

$\begin{array}{ll}\text { Thematic analysis } & 147\end{array}$

$\begin{array}{ll}\text { Semiotics and discourse analysis } & 149\end{array}$

Follow-up Interviews 151 
Chapter Summary

Chapter Eight: $\quad$ Girls Media Production 153

Case Study One 155

Katy Perry, official music video analysis 155

Girls' video analysis: performing 'the bitch' 157

$\begin{array}{ll}\text { Case Study Two } & 161\end{array}$

Jessie J, official music video analysis $\quad 161$

Girls' video analysis: performing 'pop star' 166

$\begin{array}{ll}\text { Case Study Three } & 168\end{array}$

Lady Gaga, official music video analysis $\quad 168$

Girls' video analysis: performing 'extreme versions of us' 172

$\begin{array}{ll}\text { Chapter Summary } & 174\end{array}$

Chapter Nine: $\quad$ Synthesis: Girls' Negotiation and Rupture 177

Girls, Pop Music and 'Sexualisation' 177

Girls' negotiation of sexualised pop music 178

Girls' discursive rupture of sexualisation discourses $\quad 181$

$\begin{array}{ll}\text { Final Reflections } & 184\end{array}$

$\begin{array}{ll}\text { References } & 192\end{array}$

$\begin{array}{ll}\text { Appendices } & 230\end{array}$

Appendix A 230

Appendix B $\quad 232$

Appendix C 233

Appendix D 235

Appendix E 236

$\begin{array}{ll}\text { Appendix F } & 237\end{array}$

$\begin{array}{ll}\text { Appendix G } & 239\end{array}$

Appendix H 240

Appendix I 241 


\section{Chapter One:}

\section{Approaching Contemporary Girlhood: Culture, Discourse and the Moral Panic}

The sexualised child is a potent (and possibly seductive) figure whose supposed actions and subjectivity reveal fissures of gender, sexuality, race, class, and age - a monstrous outcome that must be brought under control. (Egan, 2013, p. 48)

Over the past decade popular culture has increasingly produced hyper-sexy celebrity identities aimed at tween audiences (Jackson \& Vares, 2011, 2015b; Kennedy, 2014). According to news media and popular psychology texts, images of 'barely dressed' celebrities such as Beyoncé, Katy Perry and Miley Cyrus, represent a 'dangerous' hypersexual femininity that contaminates girls' innocence and thrusts them into precocious sexuality (Hamilton, 2009; Levin \& Kilbourne, 2008). Popular online media blogs and forums regularly present articles describing the negative influences that these stars are apparently having on young girls. The Daily Mail, for example, asserts that "raunchy, hypersexualised pop stars like Miley Cyrus and Rihanna damage girls' self-esteem - and could harm education and job prospects" (Cox, 2013). In this way, news media have been identified as playing a significant role in shaping contemporary moral panics and anxieties surrounding sexualisation (McRobbie \& Thornton, 1995).

As technological advances have transformed the possibilities for communication, the structure and the dissemination of moral panics such as the sexualisation of girls has also increased dramatically (Gill, 2012b; Juffer, 1998; McRobbie \& Thornton, 1995; Paasonen Nikunen \& Saarenmaa, 2007). New media technologies, in particular, have seemingly enabled the rapid spread of sexual representations said to negatively influence girls, while simultaneously enabling the proliferation of opinions expressing concern at this shift (Gill, 2012b). As observed by McRobbie and Thornton (1995: see also Gill, 2012b), contemporary media provide a multimodal site where sexualisation is both demonstrated and commented on. The relationship between contemporary media and sexualisation debates can be approached as intertwined where, as Gill (2012b) asserts, the media functions as "a key site of concerns about concerns about sexualisation" (p. 484). The increased saturating circulation of foreboding perspectives concerning the sexualisation of girls 
has also been understood as leading to a sensitisation to sexualising material. Gill (2012b) argues, for example, that extensive media coverage of the sexualisation of girls has led to a sensitisation wherein "ordinary, innocent and everyday activities become criminalised because of a 'moral panic' about sexualisation" (p. 484). In order to demonstrates this sensitisation, Gill cites the example of parents taking photos of their children in the bath as a contemporary concern within public debates.

The media's participation in both the dissemination of sexualised content and the heightened panic regarding the sexualisation of girls can be seen through the ongoing criticism of girls' representation within sexualised culture. In 2006, for example, the New Zealand based fashion/trend magazine Pavement released a special issue, dedicated to teens, titled "Lost Youth". The issue included a photo spread featuring a number of young (tween to teenage) girls and young women wearing makeup while posed in what was suggested to be adult styled, sexualised clothing, settings and situations (Cook, 2006). Of particular concern in this shoot was the inclusion of an 11-year-old girl who was described in the media as heavily made up and appeared alongside semi-naked models in 'adult' poses and situations (Cook, 2006). The public criticism concerning this publication included a formal complaint by the child advocacy group End Child Prostitution, Child Pornography and Trafficking of Children for Sexual Purposes (ECPAT) who claimed that many of the images, including the image of the 11-year-old girl, were in breach of the 1993 Films, Videos and Publications Classifications Act (see New Zealand Legislation, 1993). In addition, a New Zealand company refused to display the magazine issue, selling it only under the counter and by request (Cook, 2006). While no formal action was taken against the magazine (which ceased production later in 2006 for commercial reasons), this event did position the sexualisation of girls as a central concern within New Zealand society. It also sparked widespread debate in news media and academia about the effects of a contemporary sexualised culture on girls (Bloore, 2011, Clark, 2008, Gilbert, 2010).

Concern regarding the sexualisation of girls has also been seen globally in response to the growing representation of girls as sexually desiring or desirable within mainstream media and advertising. In 2008 Vanity Fair magazine released its June issue featuring then 15 year old teen Disney star Miley Cyrus. In the magazine, Cyrus posed semi-nude in the images which were shot by photographer Annie Liebovitz. The photo-shoot (for which Cyrus later issued a public apology to her fans, see 
Aswad, 2008) sparked much criticism within mainstream media. The New York Times, for example, described the photographs as sexually suggestive and Cyrus as "draped in a sheet, bare backed, hair tousled, with a come-hither smile" (Barnes, 2008). In 2011 another wave of sexualisation stories began in the media concerning the release of the latest cover of Paris Vogue and details concerning the photo shoot. As with the 2008 Miley Cyrus Vanity Fair shoot, described above, the four-page spread featuring ten-year-old model Thylane Lena-Rose Blondeau was the focus of intense public and online criticism. Blondeau was dressed and posed in what was claimed to be an inappropriate and highly sexualised manner (see Daily Mail, 2011 article "Far too much, far too young: Outrage over shocking images of the 10-YEAROLD model who has graced the pages of Vogue").

As well as the media attention that these publications have received, the representation of young girls in adult-styled clothing and poses within popular media content has also been problematised by many Western academics. Rush and LaNauze (2006, 2006b), for example, deployed the term 'corporate paedophilia' to describe both the increased production of such imagery in popular media and, more particularly, to describe an increase in advertising campaigns for products aimed at young girls. These authors, and many other critics (e.g. Hamilton, 2009; Papadopolus, 2010; Tankard Reist, 2009), argue that such representations of girls encourage the paedophilic gaze, therefore putting girls in danger. In addition, Rush and LaNauze (2006, 2006b) claim that exposure to increasingly sexualised representations in the media and the proliferation of 'sexualised' goods marketed to girls, pressures girls to present themselves as sexually knowing at a young (and inappropriate) age (see also, Walter, 2011). This pressure, as well as girls' presumed mimicry of the sexualised representation of other girls and women in the media, underpins the contemporary construction of an increasingly sexualised culture as dangerous to girls' development.

This thesis is a critical examination of girls' negotiation of hypersexual female pop music media. This media is one site of the sexualisation of culture which has been repeatedly highlighted as problematic for girls within literature and mainstream media concerned with the sexualisation of girlhood (Bailey, 2011; Hamilton, 2009; Papadopoulos, 2010). The thesis approaches female pop music media as a complex discursive resource which makes available and restrains possibilities of self for girls. It investigates girls' negotiation of these possibilities of self, through their discussion of and performance to this media, alongside dominant and problematic constructions 
of girls as uniformly sexualised by pop music representations. The increased accessibility of sexualised popular culture and media to girls, coupled with a strong entrenchment of the traditional childhood discourses which emphasise sexual innocence and naivity, makes for an often contradictory maze of discourses and subjectivities that girls must negotiate (Griffin, 2004, 2004b; Jackson \& Vares, 2015, 2015b; Jackson, Vares \& Gill, 2013; Renold \& Ringrose, 2011; Ringrose, 2008, 2011). The saturating nature of hypersexualised female representations within popular media, and the entrenchment of protectionist discourses which construct girls as inherently vulnerable to such media present an important context for continued feminist enquiry. Although hypersexual representations are increasingly aimed at young girls within contemporary popular culture, they are simultaneously positioned as dangerous to young girls' development. In addressing girls as an audience to this media however, this thesis moves outside of binaries and sexualisation assumptions concerning girls' media engagement. Instead, the research approaches girls as thoughtful consumers who are engaging with this media through complex processes of appropriation, rejection and disruption of various girlhood discourses and subjectivities. This thesis offers a timely and important investigation into the ways in which girls manage their own pleasurable consumption and production of pop music media. It presents important insights into the ways in which girls' pleasurable consumption is carefully managed alongside problematic constructions of them as sexually desiring and desirable subjects within postfeminist media and as over-sexed and victimised 'Lolitas' in mainstream psychology and news media texts.

\section{New Zealand as a Research Context}

This thesis is based on research which was conducted in Aotearoa New Zealand. While an in-depth investigation of the cultural complexities of New Zealand society are outside of the scope of this thesis, as a small nation with an increasingly complex cultural identity, media influence from larger more globally powerful country's such as the United States of America and the United Kingdom are an important consideration in exploring girls' media consumption (Dunleavy, 2005; Goode \& Zuberi, 2004; Horrocks, 2004). The notion of the sexualisation of girls as problematic within New Zealand can also, arguably, be approached as globally influenced. Despite a very small number of research projects which have directly addressed girls and sexualisation within a New Zealand context (such as Jackson \& 
Vares, 2011, Jackson, Vares \& Gill, 2013) the proposed 'sexualising effects' of contemporary culture asserted within sexualisation literature are often universalised and discussed as a global phenomenon (e.g., Hamilton, 2009; Levin \& Kilbourne, 2008; Tankard Reist, 2009). Unlike larger countries such as Australia and the United Kingdom, which have increased the regulation of sexualised media and products marketed to girls and put in place regulatory legislation aimed at 'containing' the sexualisation 'problem', there have been no regulatory or legislative changes in New Zealand (Bailey, 2011; Papadopolus, 2010; Rush \& La Nauze, 2006, 2006b). Despite this, mainstream publications and public campaigns (such as Melissa Tankard Reist's tour around New Zealand discussing the dangers of sexualisation on young girls, see RadioNZ, 2015) which describe the sexualisation of girls phenomenon as a concern in New Zealand often draw on literature which is produced outside of a New Zealand context (Tankard Reist, 2009). This investigation responds to the problematic and universalised construction of girls' media consumption within the sexualisation of girls discourse. Unpacking these assumptions, the research explores girls' engagement with hypersexual popular culture within a New Zealand context, paying particular attention to their complex negotiations and meaning making of pop music media. Further, and moving beyond sexualisation assumptions, this thesis recognises the dangers in overstating and universalising the 'effects' of sexualised media. Rather, it acknowledges the importance of moving past media effects models which conceptualise girls' media consumption as a uniform process of internalisation and reproduction (Goode \& Zuberi, 2004).

In approaching girls' pop music media engagement within a New Zealand context, the country's unique media landscape needs to be briefly addressed. As a small country New Zealand has struggled to create a media culture of its own which, as Horrocks (2004) explains, is due to "its size, economic dependency, and deeply engrained sense of inferiority or "cultural cringe"” (p. 9, see also Dunleavy, 2005, p. 5-7). Horrocks (2004) identified New Zealand as having one of the lowest rates of local production in the world. Dunleavy (2005) describes New Zealand's limited local media production as the result of its economic restrictions for the funding and support of local content and also as due to the country's positioning as a central importer of content produced and distributed from larger countries such as the USA and UK.

Given the quantity of imported content, New Zealand's mediascape is usefully described by Goode \& Zuburi as combining "elements of local production and culture 
with images, texts, programmes and formats imported from various locations around the world" (2004, p. 4). As well as emphasising local media production, this description highlights the centrality of imported content in New Zealand's media culture. In this way, New Zealand's media culture must be conceptualised as a negotiation (Horrocks, 2004) between locally produced and imported media content rather than as entirely free from global influence or, perhaps even more problematically, as entirely dominated by global influences such as the sexualisation of culture.

Due to New Zealand's small music industry (comparatively to larger countries such as the USA and UK) much of the pop music content made available for girls to consume (on television channels such as MTV or JuiceTV) is by artists from the USA and UK. Although the New Zealand music industry has produced a number of locally successful female pop music artists (such as Brooke Fraser, Kimbra and Ladyhawke) a very small number of these acts have reached the global level that has recently been achieved by female pop artist Lorde. Despite Lorde's positioning within the same hypersexual female pop music industry that features artists such as Miley Cyrus and Beyoncé, her music content and representations sit in stark contrast to the other artists. Instead Lorde has publically denounced the trend of hypersexual representation in female popular music and has declared herself a feminist in many interviews (Overell, 2014). Aligning with the high volume of imported content within New Zealand media culture, the pop music media representations and artists that girls in the research spoke of were largely from the USA and UK. For example, all of the extracts selected for analysis in the thesis's focus group analysis chapter are from discussions about artists from the USA. Alongside this, all of songs selected by the girls for their performances and analysed in the second analytical chapter are by artists from the USA or artists who are signed with USA based record labels.

\section{Research Questions and Contribution}

This thesis is about girls' negotiation of female pop music media. Female pop music media is conceptualised in the research as making available contradictory versions of femininity, mixing feminist ideals and aims with hypersexuality and an obsession with the heterosexually desiring female body. In addition, this research approaches popular music and media by female artists as replete with constricting and enabling possibilities of self for girl consumers. Contrary to hegemonic 
understandings of girlhood as passively influenced by this media, sexually saturated feminine subjectivities within popular music are constructed as neither inherently positive nor negative for young girls' development. Unpacking the regulatory constructions of girls as at risk to hypersexual pop music representations, the present thesis moves away from sexualisation assumptions towards a conceptualisation which engages with girls as complex media consumers. From this perspective, the current research explores the ways in which girls negotiate their own pleasurable consumption and production of pop music media in a socio-historical setting that regularly positions girlhood as 'in trouble'.

The analyses presented in this dissertation contribute to the area of girlhood studies and critical feminist psychology in a number of important ways. Firstly, the research contributes new perspectives about girls' pop music media consumption, providing a valuable contribution to the study of contemporary girlhood. This contribution is achieved primarily through the use of an innovative research method involving girls' creative production of music videos. Using this performance method provided a way of gathering understandings that extend beyond girls' consumption of pop music to how they may use and negotiate it in practice. Thus, this research contributes to a growing body of critical feminist literature which addresses girls as both media consumers and media producers. Second, this thesis contributes to and extends upon contemporary literature that theorises girls' media engagement as complex and outside of problematic, dualistic understandings. Finally, conducted in New Zealand, this thesis provides an important contribution to the international scholarship of girlhood studies by way of investigating girls' media engagement outside of larger countries such as the USA and UK (where the majority of sexualisation research has taken place). At the same time, the thesis contributes to New Zealand produced research within which there is somewhat limited audience research and an especially small research literature that explores girls' understanding and meaning making about female pop music media.

The thesis is guided by the following four broad research questions. These questions guide an open-minded, critical feminist poststructuralist investigation into girls' engagement with female popular music media: 
1. What are the gendered discourses that are made available to young girls in mainstream media, and within these discourses what subjectivities are made available or unavailable to girls?

2. How do girls make meaning and develop understandings of femininity from the increasingly sexualised music media which they consume?

3. How might the discourses of femininity produced in female pop music media inform girls' understanding of their own development?

4. In what ways do these girls reproduce, transform, negotiate or reject the subjectivities that are made available to them within mainstream music media?

Grounded in a rich history of critical feminist poststructuralist research and guided by the research questions above, this thesis presents a critical feminist investigation into the ways in which girls make sense of female pop music media representations and the saturation of postfeminist discourses within them. In addition to exploring girls' meaning making, their negotiation (through talk about and performance to female pop music media) is contextualised within problematic discourses of girlhood sexuality which have historically and, as this thesis asserts, continue to be defined via dichotomous understandings of innocence and deviance in regard to feminine sexuality development. In approaching this research and what has been a contentious topic over the last decade, the thesis draws on a number of interdisciplinary approaches including girlhood studies, feminist psychology and audience studies.

The exploration of girls' engagement with hypersexual pop music media unfolds through the following six chapters of this thesis. Chapter Two will introduce the research context by locating the sexualisation of culture historically and discursively within contemporary Western culture. In Chapter Three, the focus shifts to the sexualisation of girlhood, specifically its relation to the sexualisation of culture. Chapter Four of the thesis provides an overview of the theoretical understandings that underpin the critical feminist approach employed in this research and guide the analysis of the focus group and music video study. A short focus group method (Chapter Five) precedes the analysis in Chapter Six of data gathered from in-depth 
focus group interviews. This chapter uses Foucauldian discourse analysis to investigate girls' meaning making of hypersexual representations of femininity within female pop music media. Chapter Seven describes the method and the process of the music video analysis presented in Chapter Eight. Semiotic and Foucauldian discourse analysis is used to explore the ways in which girls' meaning making can be understood as both consumptive and productive practices in Chapter Eight. In addition, Chapter Eight incorporates thematic analysis of professional music videos (of the songs selected by the girls for their own performances). Lastly, Chapter Nine summarises and synthesises the analytical chapters through the lense of the research questions and feminist poststructuralist theoretical framework. Implications of the findings for the current research are discussed as well as consideration of the application of these findings to future research. 


\title{
Chapter Two:
}

\section{The Sexualisation of Culture}

\begin{abstract}
Beyoncé is seen in the back of a limo with her husband, Jay-Z, as the tempo of the song Partition increases. Beyoncé wears a sequined jacket and fingerless gloves. Her hair is down and she wears suspenders and lace stockings. Beyoncé's face is almost completely obscured as repeated shots of Jay-Z's hand rubbing and moving up her thigh, removing her clothing and exposing her cleavage are shown. Beyoncé's profile is seen briefly as she kisses her husband's neck but her cleavage and thighs (as they are touched by Jay-Z's hands) are central to this scene's lyrics: "Now my mascara running, red lipstick smudged, oh he's so horny yeah he want to fuck. He popped all my buttons and he ripped my blouse, he Monica Lewinsky'd all on my gown”. Partition, Knowles-Carter (2014, 0:54 - 1:10).
\end{abstract}

The scene described above is from the video for Beyoncé's 2014 single Partition. The video begins by introducing a woman (Beyoncè) sitting at a table with her seemingly disinterested husband. The sexualised scenes in the music video, such as the one above, are the woman's fantasy while she is watching her husband read the newspaper, paying no attention to her. The video typifies the hypersexualised performances of femininity that have been argued to have become commonplace within contemporary popular culture (Gill, 2003, 2007, 2007c, 2008b).

Hypersexuality in this thesis follows Gill's (2007) employment of the term to describe an ever increasing use of sexual imagery in media and advertising. Gill explains that hypersexual images have become "regular parts of the iconography of advertising in the early 21 st century" wherein contemporary culture has become saturated with "ever more arresting and stimulating images in order to get consumers' attention" (2007, p. 94). Beyoncé's performance in the music video described above illustrates one of the central tenants of contemporary hypersexual culture, the idealisation of hypersexual femininity. In the music video, Beyoncé demonstrates many of the traits of this 'new' femininity namely, objectification of the self, performative hyper-sexy femininity, and the consistently sexually desiring construction of this apparently empowered and free female sexuality (Amy-Chinn, 2006; Gill, 2007, 2007c).

This chapter unpacks the sexualisation of culture by exploring shifts in mainstream media representations of sexuality, and the influence this shift has had on media and academic understandings of sex and sexuality within contemporary culture. 
Feminist debate concerning the legislation of pornography, and the ensuing feminist 'porn wars' literature will be explored. Understanding Beyoncé's performance above through the feminist theorisation of postfeminist media culture (Gill, 2007, 2007c, 2008b, 2011), the current chapter will also explore the ways in which postfeminist media has produced a 'new' hyper-(hetero)-sexual femininity which saturates contemporary popular culture. The marketing and representation of this commodified, hypersexualised femininity will be explored broadly as it is seen in contemporary culture and, more specifically, as it saturates the representations within female pop music media.

\section{What is the Sexualisation of Culture?}

The sexualisation, 'pornification' and 'raunching' up of culture all refer to a perceived social shift in the contemporary West which is characterised by an increase in hypersexual representations in mainstream media and popular culture (Levy, 2005; McNair, 2002). Central to this shift is the postulation that pornographic representations, traditionally proscribed from the public sphere, are now penetrating and increasingly influencing mainstream popular culture (Attwood, 2006, 2010, 2011, 2014; Evans, Riley \& Shankar, 2010; Gavey, 2012; Gill, 2003, 2007, 2008b, 2012b). Evidence for this perceived shift is seen through the transformation and widening of contemporary sexuality discourses and an increased divergence from traditional and chaste sexual 'norms'. Changes in the contemporary conceptualisation of public and private are also evident within in this social shift through the saturation of (and arguably public obsession with) sexualised representations, revelations and public exposures (particularly from celebrities) in the media (Attwood, 2006; Gill, 2007, $2012 b)$. In addition to an increase in sexual representations in the media and popular culture, hypersexuality is understood as becoming common place. Attwood, for example, explains that "products and services are becoming more accessible to a wider group of consumers, and the development of new communication technologies to support, replace or reconfigure sexual encounters are increasingly part of ordinary people's everyday lives" (Attwood, 2006, p. 82).

Given the broad scope of the proposed influences of the sexualisation of culture, the term itself is variously employed to describe complex and increasingly contradictory understandings and interpretations of this cultural shift (Attwood, 2006; Gill; 2007, 2008b, 2012b; Levy, 2005; McNair, 1996, 2002). The 'mainstreaming' of 
pornographic representation and its persistent representations within popular culture has been discussed as leading to a popularisation of the sexually explicit wherein sexual stylisation and performances have become idealised. As Attwood expands, sexuality, and particularly "sexiness", has become "central to the way we mark what is significant, good and worthwhile about contemporary life" (2014, p. XVI).

Although the increased emphasis on sexual representation can be seen across many forms of contemporary Western culture, feminist academics have highlighted that the sexualisation of culture is predominantly evidenced through the shift from traditionally passive to hypersexual representations of women (Attwood, 2006, 2014; Gill, 2007, 2007c, 2008b, 2009; Evans, Riley \& Shankar, 2010; McNair, 2002; McRobbie, 2004, 2007). In as much as the possibilities of agentic sexual identities for females have greatly increased and in many ways become normalised within popular culture representations (even mandatory, according to Gill, 2007, 2007c; McRobbie, 2007, 2008), there has been a simultaneous increase in sex related moral panics and scandals concerning the sexualisation of culture which are regularly circulated within contemporary news media (Egan, 2013; Egan \& Hawkes, 2008, 2008b, 2012; McRobbie \& Thornton, 1995).

Although the current cultural context is regularly presented in news media and popular psychology texts (e.g., Levy, 2005) as unprecedented and new, changes in public discourses of sexuality and sexual representation have been seen throughout history. In his historical examination of sex and western culture for example, Foucault identifies a "discursive explosion" in the Victorian period in which sex was "put into discourse" (1978/1980, p. 11). Foucault's assertion highlights a shift in Western culture which saw sex become an object of knowledge whereby, through the process of confession, exploration and surveillance, sex became linked to the individual's production of the self. Foucault argues that through the proliferation of these knowledges, sexuality in contemporary times has become central to the classification of human behaviours and the trajectory of the self (Beck, 1992; Giddens, 1991). Foucault (1978/1980) contends that making sense of our sexuality through surveillance and measurement has become central in the modern task of discovering 'who we are' (Giddens, 1991). What makes the current moment more concerning to theorists than previous shifts is that the contemporary situation involves the permeation of pornography into the mainstream to an unprecedented degree (Attwood, 2006, 2014, Gill, 2012b). As such, contemporary sexualised 
representations and practices previously only associated with the sex industry have arguably become normalised and commonplace in the public sphere and especially in mainstream media (Gill, 2012b). In exploring the sexualisation of culture, feminist approaches are organised around varied and often contradictory positions. These approaches, which are largely linked to individual understandings of women's engagement with hypersexual culture, will be explored next.

\section{Feminist Approaches to the Sexualisation of Culture}

Feminist literature examining the sexualisation of culture seems to primarily support the view of a saturation of sexual representations within Western popular culture and media (Attwood, 2006, 2014; Gill, 2007, 2008, 2009, 2011; Smith, 2010). Gill for example describes the permeation of sex and pornography in mainstream media as a time in which:

pornstars have emerged as bestselling authors and celebrities; a 'porno chic' aesthetic can be seen in music videos and advertising; and practices once associated with the sex industry - for example lap dancing and pole dancing have become newly 'respectabilised', promoted as regular corporate entertainment or recreational activity. (Gill, 2012b, p. 484)

Feminist poststructuralist approaches largely understand the sexualisation of culture as more than just a perceived increase in the representation of sex. Instead it is understood as related to a broader shift in the transformation of traditional gender norms particularly in relation women's rights and opportunities for social participation. Following the second wave feminist movement (Genz, 2006;

McRobbie, 2000, 2004, 2007, 2009) women are viewed as benefitting from increased opportunities, including involvement in the workforce and political sphere (McNair, 2002). Subsequently, women's social involvement has contributed to the substantial increase in marketing targeted directly at this population and the image of the consuming female subject as agentic, independent and sexually desiring has replaced traditional notions of passive and domestic femininity (Attwood, 2014; Gill, 2003, 2007b, 2007c, 2009).

Although feminist literature is largely in agreement about the increase in sexual representation in mainstream culture and its attendant shifts in contemporary femininity, understandings of women's engagement with sexualised culture are diverse. The broad application, meanings and values associated with sex and sexiness within contemporary culture have for the most part represented a contentious area for 
feminist engagement. Specifically, the commercialisation of sex and its frivolous and saturating representations within public domains (described by Attwood, 2014 as signalling contemporary sex as detached from it traditionally serious conceptualisation), has led many feminist commentators to contest that contemporary sex is empty and cheap in nature (see Levy, 2005). The sexualisation of culture, then, has most commonly been approached as a problem (see Charles, 2012). This problematic view means that contemporary sexualised culture has repeatedly been conceptualised as putting society, particularly women, at risk (McRobbie, 2004), offering cheap thrills (Levy, 2005) which in 'reality' reflect a dangerous internalisation of traditional gender norms (Amy-Chinn, 2006; Gill, 2007, 2008, 2009, 2011; McRobbie; 2004, 2007) and a retro-sexism (Whelehan, 2000) in contemporary times.

In order to engage with these disparate views, feminist engagement with contemporary sexualised culture needs to be contextualised within a historical location of the so-called "feminist sex wars" and, more specifically, the "porn wars" (Hunter \& Duggan, 1995). Historical feminist debate concerning women and sexuality is relevant within the research and can be approached as underpinning many of the contemporary positions and disagreements concerning women's engagement with contemporary sexualised culture. Feminist engagement with the porn wars, for example, has been described as a "maddening deadlock" (Segal, 2004, p. 59), which Munford (2009) asserts is underpinned by "a tendency to narrativize feminist debates about sexual politics along the dichotomous axes of anti- and pro-sex feminisms" ( $p$. 184). The dichotomous debates within the feminist porn wars of the 1970's described by Munford are approached in this research as related to (and arguably underpinning) much of the feminist contention within contemporary feminist theorisation. For this reason, feminist theorisation of the 'porn wars' will be discussed next.

The porn wars. Contested feminist perspectives on the implications of the sexualisation of culture for women (for example Attwood, 2006; Attwood \& Smith, 2014; Gill, 2012b; Smith, 2010) resonate with similarly conflicting perspectives over the so-called 'porn wars', which refers to a period from the 1970's to 1990's. The porn wars are best understood as situated more broadly within the sex wars of the 1970's and 1980's in which as Henry (2004) explains, "feminists argued over pornography, sex work, censorship, sadomasochism and other sexual practices, and 
what constituted "good" feminist sex - or whether that should even be a concept in the first place" (p. 89). Focussing on pornography debates specifically, many feminist groups emerged with numerous approaches and understandings of women's participation in pornography, women's sexuality, and women's oppression (Duggan \& Hunter, 1995; Paasonen, Nikunen \& Saarenma, 2007). While this debate included a myriad of feminist positions and conceptualisations in regards to pornography, broadly speaking, much of the contention has been represented by two opposing feminist groups with conflicting views concerning the legislation of pornography.

The 1970's saw the formation of a group of anti-pornography lobbyists within the feminist movement. Headed by feminist theorists Andrea Dworkin and Catherine MacKinnon this movement gathered (and has maintained) much attention for its radical conservative lobbying for anti-pornography legislation. MacKinnon (1987) asserts that women who participate in pornography are not seen as human, rather, in this context, "women exist to the end of male pleasure" (p. 158). Aligning with the slogan 'Pornography is the theory, rape is the practice' (Morgan, 1980), the antipornography faction understands pornography as victimizing and objectifying women through the reproduction and celebration of patriarchal male-female power relations (Dworkin, 1985; Dworkin \& MacKinnon, 1988). MacKinnon (1987) argues that genres such as pornography work to further legitimise the social construction of women as objects for male pleasure. In this way, the anti-pornography position conceptualises pornography as promoting and glamorising rape (Dworkin \& MacKinnon 1988).

In asserting these ideas, the anti-pornography movement aligned with traditional 'media effects' focussed psychological research (Dworkin \& MacKinnon 1988). The problematic nature of such research that attempts to make causal links between males viewing pornography and violence against women (e.g. Seto, Maric \& Barbaree, 2001) has been criticised by feminist scholars (Boyle, 2000; Ciclitira, 2002, 2004). For example, the methodological shortcomings within media effects focussed research include experimental issues such as the inability to operationalise pornography and population biases, namely that its subjects are largely white, middleclass, male university students (see Ciclitira, 2002, p. 192 on "Inadequacy of the Experimental Approach"). Although many studies have since weakened or retracted historical claims that pornography is a direct cause of male violence against females 
(for example, Donnerstein, Linz \& Penrod, 1987 and Kutchinsky, 1991), the antipornography movement continues to vehemently argue that men's consumption of pornography causes an increase in male-on-female sexual violence and rape (Dines, 2010; Dines, 2012; Dines \& Jenson, 2005).

The anti-censorship position developed in direct opposition to the antipornography position. The anti-censorship position initially held the aim of defeating anti-pornography legislation for a more liberal and public discourse about female sexuality (Hunter \& Duggan, 1995; Segal, 1998). Feminists such as Ann Russo (1987) describe the anti-censorship position as conceptualising female repression as the result of enforced sexual passivity. She goes on to highlight that from an anticensorship position, "male supremacy and female sexual passivity are due, in part, to repression of women's sexual expression and potential sexual power" (Russo, 1987, p. 107). Patriarchal conceptualisations of women as sexually passive are therefore understood as reinforced through the repeated rejection of agentic and empowered understandings of women's engagement with pornography and sexualised culture (Segal, 1998; Hunter \& Duggan, 1995). Although anti-censorship feminists acknowledge that pornography is often male-centric and that representations of sexual practices are often sexist and compulsively heterosexual, this movement also recognises pornography as a medium with the potential to expand the possibilities for female sexual expression rather than singularly inhibit them (Ciclitira, 2002, 2004; Jess Butler, 2013; Segal, 1998). The anti-censorship position therefore emphasises the need to counter anti-pornography positions, which emphasise an internalisation and naturalisation of women's engagement with pornography as victimising.

\section{Contemporary feminist understandings of sexualisation. Contemporary}

feminist theorisation of the possibility of agency in women's engagement with sexualised culture, in particular its hypersexual practices, may be approached as a continuation of pornography debates. Contemporary debates concerning the sexualisation of culture refer to a 'mainstreaming' of 'porno-esque' representations (Gill, 2007, 2012b) rather than the pornography genre specifically. However, contemporary feminist debates about the possibilities of engagement with hypersexualised culture for women may be approached as underpinned by the same 'pro' or 'anti' pornography dichotomy which has been described above as inflecting the feminist porn wars (Hunter \& Duggan, 1995). In addition to conceptualising 
hypersexual representations of women as harmful, many feminists critiquing the sexualisation of culture understand contemporary hypersexual femininity not as liberation from traditional passive constructions of femininity but as "a tidal wave of invidious insurgent patriarchalism which is hidden beneath the celebrations of female freedom” (McRobbie, 2008, p. 539, see also Dunshinsky, 2013; Genz, 2006). Research within this perspective often asserts that women's engagement with sexualised culture, such as beautification practices (Lazar, 2009), the purchasing of 'sexy' lingerie (Amy-Chinn, 2006) and Brazilian waxing (Gill, 2007, 2007c, 2008b, 2009), signals an internalisation of patriarchal ideas, a revival and repackaging of sexism (Whelehan, 2000) and is simply "objectification in [a] new and even more pernicious guise" (Gill, 2003, p. 105) rather than women's emancipation from such traditional controls. For example, in her exploration into women's involvement in 'raunch culture' Levy (2005), warns that the new provocative female identity does not lead to or signal women's emancipation from patriarchal binds, rather it, "has diluted the effect of radicals and feminists, who've seen their movement's images polarised while their ideals forgotten" (p. 196). Women's engagement with sexualised culture within this literature is regularly constructed as a betrayal (McRobbie, 2008) or famously, in the case of Faludi (1992), as a backlash against the gains of feminism.

In contrast to these denunciatory views, other feminist scholars understand the sexualisation of culture and women's engagement with it as a positive and liberating social shift. These academics conceptualise the increase in pornographic representations and the sexualisation of culture as signifying a democratisation of sex within western societies (Attwood, 2014; Ciclitira, 2004; McNair, 2002; Smith, 2010). The democratisation of sex position celebrates the new 'pornsphere', proclaiming that the mainstreaming of pornography and increased representation of hypersexual femininity signifies the end of female sexual repression (McNair, 2002; Smith, 2010). McNair (2002), for example, describes the sexualisation of culture as "the collision of ideological shifts caused by decades of sex-political struggle with a postmodern intellectual climate in which the meaning of the pornographic can be remade, and its perverse pleasures recognised" (p. 81). This assertions highlights McNair's (see also Attwood, 2006, 2014; Smith, 2010) understanding of the sexualisation of culture as a positive force due to the potential for transgression of traditional and restrictive sexual boundaries. The breakdown of the public versus private boundary within contemporary culture, along with the mainstreaming of 
previously taboo sexual pleasures and practices is conceptualised within this theorisation as positively benefitting those who have been excluded from public sexual discourses such as the LGBTQ community and, importantly to this thesis, increasing sexual possibilities for women.

Central to an understanding of contemporary sexualised culture as a form of sexual democratisation (Attwood, 2014; McNair, 2002; Smith, 2010) is the role of technological advancements of the last decade. Smith (2010, reflecting on McNair, 2002) describes the sexual possibilities brought about by new media technologies as positively enabling, "access to the means of sexual expression and the pluralising of sexual cultures to include those (for example, gays, lesbians, trans-people and other so-called 'perverts') who [have] been specifically excluded from sexual selfdefinition" (p. 104). Paasonen, Nikunen and Sarenmaa (2007), also assert that the advent of the internet has opened the possibilities for sexuality through the increased accessibility of pornographic material. Juffer (1998) also takes this view and explains that the emersion of pornography into mainstream culture and the construction of pornography consumption as 'normal' has led to an unprecedented accessibility to pornography through new media technologies, which she contends, has brought pornography into people's daily lives.

The notion of the sexualisation of culture as providing a 'democratisation of desire' emphasises the potential of this social shift to provide women of all ages, ethnicities and abilities the agency (previously only afforded to men) to be both consumers and producers of pornographic and/or other hypersexual material (Ciclitira, 2004; Smith \& Attwood, 2014). In addition, democratising positions understand women's engagement with hypersexual culture as far more complex than conservative understandings. In her analysis of interviews with women concerning their own consumption and feelings about pornography, Ciclitira (2004) described conservative 'porn wars' positions as potentially impinging on women's own complex and individual experiences with pornography. For example, many of the women interviewed by Ciclitira described feelings of excitement, intrigue and curiosity about pornography, but said that these feelings were often obstructed by a deep feeling of awkwardness and guilt at engaging with this material such as Geraldine (42, cohabiting, white, and heterosexual) who explains, “' I feel angry and demeaned by the whole, you know, experience of seeing pornography, and yet also being aroused by it."' (2004, p. 293). Many of the feelings identified by participants were linked in 
their discussions to their knowledge of radical anti-pornography views, which connect porn with rape and the degradation of women in society (Ciclitira, 2004).

At the height of liberal and democratising understandings of the sexualisation of culture is feminist literature which asserts that the linking of the sexualisation of culture to capitalist, neoliberal and postfeminist underpinnings is problematic. Attwood and Smith (2014), argue that within this approach, which focusses its analysis of the sexualisation of culture on notions such as postfeminism and neoliberalism (seen in Gill, 2007, 2007c), sex and the representation of hypersexual femininity become privileged in their power to shape contemporary discourses and interactions. At the same time, Attwood and Smith assert, the discussion of the potential for these sexual representations to "open up new vistas of sexual being, [for] its possibilities of imagining oneself and community, or its possibilities as fantasy and as pleasure" often remain undiscussed (2014, p. 13). Smith (2010) also highlights her frustration at postfeminist and conservative understandings of sex as a form of identity work (for example in Gill, 2007, 2007c) and the overwhelming suspicion of the commercialisation of sex (Levy, 2005). Smith proclaims, "why sex should not be commercialised when every other human endeavour is commercialised is unclear" ( $p$. 107). Smith (2010; see also Attwood \& Smith, 2014) understands postfeminist and neoliberal focussed analyses of women's engagement with the sexualisation of culture as illuminating women's engagement as filled with more potential for agency than conservative positions. However, according to Smith, postfeminist and neoliberal focussed positions still often tend to apply the notion of sexualisation or sexuality as problematic whereby contemporary conditions and cultural shifts seem nonspecifically linked to issues.

As these broad and conflicting perspectives demonstrate, the meanings and understandings of the 'influences' of the sexualisation of culture are highly contested. Importantly, the lack of consensus on the definition and function of this phenomenon within academic circles renders it theoretically and analytically limited (Gavey, 2012; Gill, 2012, 2012b). One of the central issues with the terms sexualisation of culture, pornified, pornification and raunch culture (to name a few of the terms employed) is the disparate but simultaneously all-encompassing use of these terms where scholars and commentators apply these notions to describe a myriad of phenomena, often with different understandings of how they are operationalised (Gill, 2012b, Smith, 2010). Gill (2012b) asserts on the one hand that the struggle over the understanding of 
sexualisation does suggest that "there is something worth struggling over" (p. 492), but on the other, also contends that the notion of sexualisation has become "overloaded with competing meanings as well as an intense affect - particularly (but not exclusively) anxiety" (2012b, p. 492). The broad application of the term sexualisation across feminist commentary can therefore be understood as a conceptual sledgehammer (to borrow from Smith's, 2010 description of 'pornographication') which has slipped easily into 'common knowledge' (Attwood, 2006, 2014; Ciclitira, 2004; Gavey, 2012, Gill, 2012, Gill, 2012b).

Finally, and of particular importance to this thesis, sexualisation is a highly problematic term which can produce certain groups of the population as vulnerable (such as young girls) while simultaneously failing to recognise this phenomenon as occurring within a racialised, classed and gendered society (Gill, 2012, 2012b). A body of recent feminist scholarship has sought to redress this problematic binary within which the notion of sexualisation and sexualised culture, like pornography, have come to be ensnared. The next section turns to the more intersectional and nuanced approach adopted in this recent literature.

Towards a 'nuanced' approach. As highlighted above, feminist debates about the sexualisation of culture have been characterised by conflicting and contrasting views. These debates, specifically those concerning women's engagement with the sexualisation of culture, revolve most prominently around the notion of agency. As the literature highlights, there are significant theoretical discrepancies between feminist academics who understand sexualised culture as devoid of agentic potential (Gill, 2003, 2007; Levy, 2005; McRobbie, 2004, 2007, 2008). At the same time, there are many feminists who engage strongly with notions of agency but who also critique deeply entrenched sexist and patriarchal notions reproduced through women's engagement with contemporary hypersexual identities (Attwood, 2006, 2011, 2011b; Duits \& Van Zoonen, 2006, 2007; Smith, 2010).

The call for a more nuanced feminist approach to the sexualisation of culture aims to provide what Gill (2012b) identified as a much needed:

move away from the generality of 'sexualisation' towards a greater level of specificity; more modest, local, contextually-rooted studies that may not be able to come down on one side or the other in the polemical 'sexualisation wars' but which can inform debates about the meanings, practices and 
experiences of phenomena understood as sexualised in particular settings, among particular groups, at particular moments, with particular consequences. (Gill, 2012b, p. 492)

Critical research from this perspective aims to step outside of binary understandings of women's agency within the sexualisation of culture to produce a more complex account of new femininity. Such complexity might, for example, allow for the transgression of passive femininity (through the expression of empowered and potentially pleasurable sexuality) while at the same time acknowledge its ties to patriarchal and heteronormative constructions of femininity (Gill, 2012b). Critical research which addresses women's engagement with sexualised culture from this perspective is therefore vitally important.

This nuanced approach relies on a conceptualisation of the sexualisation of culture as neither fundamentally damaging nor empowering. Specifically, it may provide the potential to move research on women's and girls' engagement with the sexualisation of culture forward, as it allows for diverse understandings of individual experiences (for example Evans, Riley \& Shankar, 2010; Renold \& Ringrose, 2011). Poststructuralist approaches appear to be particularly useful in avoiding dichotomisation and alternatively attending to the complexity of individual experience. One example of how poststructuralist theory can be used to address participation in the sexualisation of culture, while understanding its cultural power in feminine subjectivity, comes in Evans, Riley and Shankar's (2010) appropriation of Foucault's concept of technologies of the self. Their work responds to critiques of Foucault's proposal of the discursively determined subject who, while still constructed and restrained by available discourses, is endowed with the agentic capacity to actively work on their own, "thoughts, conducts, and way of being, so as to transform themselves in order to attain a certain state of happiness, purity, wisdom, perfection or immortality" (Foucault, 1988, p.18). Drawing on Foucault's conceptualisation, Evans and Riley et al. theorise a technology of sexiness that conceptualises women's engagement with sexualised subjectivities as an agentic expression of self-production, allowing them to produce themselves in a way that liberates them from traditional passive femininity discourses.

In addition, Evans et al. (2010) flesh out their 'technologies of sexiness' theorisation with Judith Butler's work on gender performativity. Butler $(2002,2004)$ asserts that all gender is performance, that there is no inherent or original femininity, 
but rather that all femininity is an imitation of a historically and discursively constituted original. This conceptualisation of gender is mined by Evans et al. for its potential to highlight gendered categories as unstable and therefore potentially transgressive. The notion of a 'technology of sexiness' engages with Butler's theorising of possible resistance by understanding women's hypersexual selfproduction as potentially transgressive, intelligible and agentic acts based on a performance of contemporary femininity. So from this perspective, on the one hand, hypersexuality can be understood as a potentially liberating and agentic performance but, on the other hand the authors contend, such performances are only recognised as transgressive and agentic through their reproduction of normative 'hetero-sexy' femininity. Employing Evans et al.'s approach which is aimed at dismantling the conceptual binary constructed within contemporary feminist theorisation of women's engagement with the sexualisation of culture allows us to move past considering sexualised culture as either liberating or sexist and instead to conceptualise the intricate ways in which women's engagement with sexualised femininity is more helpfully understood as both.

Drawing on the work of Evans et al., this thesis conceptualises performances of contemporary sexuality as potentially subverting traditional passive femininity. However, this transgression is understood as also relying on the performance of normative notions of hetero-sexy femininity, for example porno-chic stylisation. In addition, this research approaches contemporary femininity as plural. Specifically, it acknowledges that there are multiple subjectivities or ways of embodying contemporary feminine desire. While this multiplicity is acknowledged, the media is understood as central to the recuperation and homogenisation of 'ideal' femininities. The following section explores postfeminist media culture and the ways in which contemporary representations of ideal femininity work to standardise the possibilities for ways of being female. This homogenous hypersexual femininity will then be discussed in relation to female pop music celebrity identities, the focus of the current research in relation to pre-teen girls' media practices.

\section{Sexuality as a Postfeminist Phenomenon}

As discussed above, the notion of the sexualisation of culture has been identified in critical feminist literature as a broad and contested term and most importantly as a highly gendered one (Attwood, 2006; Gill, 2007c, 2012b). According 
to Gill (2007c), postfeminist discourse underpins contemporary society's obsession with the representation, commodification and sexualisation of femininity. The saturating representation of, and address to, women is most commonly evidenced (and studied) through a prolific postfeminist media culture (Gill, 2007, 2007c, 2008, 2008b, 2012b). Given the centrality of sexualised femininity within the sexualisation of culture, the reformulation of femininity within postfeminist media culture is of great importance to critical feminist investigations concerning the sexualisation of culture. The proliferation of 'new' postfeminist feminine subjectivities, particularly within popular media thus represents an important topic for continued feminist enquiry.

As has been discussed with regards to the notion of the sexualisation of culture, the term postfeminism has become overloaded with varied and conflicting meanings, each containing a different stance on postfeminism's relationship to feminism and its representation within contemporary media (Gill, 2007c, 2012b; McRobbie, 2004, 2007; Tasker \& Negra, 2005). Postfeminism has been approached positively, as a third wave feminist movement (Genz, 2006), and also with suspicion, as a regressive backlash that historicises the gains of the feminist movement (McRobbie, 2004, 2007, 2008; Whelehan, 2000). As a way forward from slippery definitions and on-going binary debates, this thesis follows Gill (2007c) and attends to postfeminism as a sensibility. Gill's notion of a "postfeminist sensibility" describes postfeminism as a complex, varied and often contradictory phenomenon rather than a political or analytical tool (Gill, 2007c). Particularly, this conceptualisation understands contemporary femininities as departing from a singular understanding of feminism. According to Gill, then, by attending to the complexities of the representation of women within postfeminist media culture, "[t]his new notion emphasises the contradictory nature of postfeminist discourses and the entanglement of both feminist and anti-feminist themes within them" (2007c, p. 149). With this in mind, Gill's approach moves away from notions of a singular and 'true' feminism and instead, using a postmodernist approach, aims to examine the unique and contradictory representations of postfeminist femininity in the media. In particular, the conceptualisation of the postfeminist sensibility pays attention to the construction of postfeminist hypersexual subjectivities, their saturation and their marketing in popular media. Importantly within the current research, this approach addresses the ways in which women might engage with these complex ways of being female. The 
following section then, will explore contemporary representations of femininity within postfeminist media culture, including femininity discourses, subjectivities and ways of being that these culturally saturating representations make available to women and to girls.

The centrality of the female body. Postfeminist media culture prolifically (re)produces hypersexual representations of the female body. In her analysis of contemporary advertising, Gill (2007) identifies the 'midriff' (the exposure and representation of the part of women's bodies between the bottom of the rib cage and the pubis bone) as a key site for the erotic exposure of women's bodies in advertising and postfeminist media culture. As Gill asserts, "in today's media, possession of a 'sexy body' is presented as a woman's key (if not sole) source of identity" (2007, p. 149). Gill continues that within postfeminist media culture, the ownership of a 'sexy' body has replaced traditional feminine characteristics such as 'kindness' or 'nurturing' (2007, 2007c, 2009).

The centrality of the female body within sexualised culture can be seen through a saturation of a 'porno-chic' aesthetic in the celebrity representation of ideal femininity. Evans and Riley (2013) observe that "contemporary representations of female celebrity are characterised by a hyper-feminine (but often 'classy') performance of sexiness within the domain of the fashion and beauty complex" ( $p$. 269). In feminist literature the use of heavy makeup, high heels and revealing outfits are seen as motifs of hyper-femininity and the ever narrowing representation of hetero-sexy postfeminist femininity (Evans \& Riley, 2013; Gill, 2003, 2008b, McRobbie; 2004, 2007, 2008). The eroticisation of the female body within contemporary media has arguably escalated since Gill's (2007) analysis, with every medium (from magazines to music videos) displaying female bodies in an increasing state of undress. More recent hypersexualising of female bodies has moved past the midriff to (almost) full exposure at times. Female pop music, and particularly its music videos, represents a key site in which a sexually desirable, sexually styled and sexually behaving body is frequently produced as essential. For example, Miley Cyrus's "Wrecking Ball" music video features the pop star riding a wrecking ball wearing only a pair of boots, Nicki Minaj shakes her buttocks with an exposed Gstring in her "Anaconda" music video and Rihanna twerks upside down on a throne wearing only a bra and denim G-string in her "Pour it Up" music video (Cyrus, 2013; 
Minaj, 2014; Rihanna, 2013). These hypersexual representations emphasise the possession of a slim but curvaceous, ample breasted and sexually desiring/desirable body as the marker of 'new' postfeminist femininity.

Underpinning representations of the ideal female body within postfeminist media culture is the emphasis on self-pleasing, self-objectification, choice and empowerment (Gill, 2003, 2007c; Lazar, 2009; 2011). The idealised, sexy female body is repeatedly constructed through the guise of women pleasing themselves in its attainment rather than objectifying notions such as pleasing men (Amy-Chinn, 2006; Gill, 2003, 2007, 2007c). The emphasis on hypersexuality and hypersexual performance as pleasing the self is so closely structured around the notion of choice that the production of an aesthetically and behaviourally pleasing female body through the guise of 'choice' has arguably become mandatory. Subsequently, women who do not take up this choice to obtain a sexy body are repeatedly constructed as lazy, uncaring and without value because, as Gill argues, the aesthetics and 'value' of the sexy female body have become intimately linked to social worth and power for women (Gill, 2007c, 2008b, 2009, 2011, 2011b).

In addition, women's agency and choice are often mobilised through the notion of female empowerment. Within postfeminist media culture, empowerment can be understood as an ambiguous term bestowed on women, recuperated from the feminist movement and deployed within postfeminist media, particularly advertising where the purchase of products largely focus on the body (Lazar, 2009). In her analysis of postfeminist beauty advertisements aimed at young Singaporean women, Lazar describes the recuperation of the feminist ideal of female power through the commodification of beauty practices. Lazar asserts, for example, that practices such as buying and using make-up being are constructed within these advertisements as a form of individualised self-asserted female power. Lazar's analysis demonstrations the ways in which agency and female power is radically transformed and emptied of its potentially political agenda and instead intrinsically linked to consumerism, stylisation and transformation of the female body. Individual women who engage in consumerist practices are then endowed with transformative postfeminist empowerment (see also McRobbie, 2007, 2008).

The new desiring subject. Critical to the centrality of the body within contemporary representations of femininity is the move within popular culture from 
objectification to subjectification of the female body - what has been described as the new desiring female (Gill, 2007c). Feminist scholars have identified a marked shift in the representation of women in advertising since the 1970's and 1980's (Gill, 2009; Tasker \& Negra, 2005). Whereas traditional representations of women previously constructed them as objects of the male gaze, postfeminist media culture idealises a 'new' femininity within which women are constructed as (hetero) sexually desiring agents who take up the choice of portraying/displaying sexuality through a process of subjectification (Gill, 2003, 2009). As Gill (2007c) explains, subjectification (selfobjectification), in contrast to objectification, underpins this new version of femininity and is used extensively in contemporary sexualised culture where a (hetero) sexually desiring and empowered version of femininity saturates feminine representation. Such representations also present sexual knowingness and being constantly sexually available or 'up for it' as a mandatory requirement of contemporary femininity (Attwood, 2006, 2011, 2014; Evans \& Riley, 2013; Gill, 2007, 2008b, 2011b; Levy, 2005; McRobbie, 2004, 2007, 2008).

Surveillance (from the self, others and increasingly from the media) is a key feature of the postfeminist sensibility (Gill, 2007c). Idealised, hypersexualised and commodified femininity is presented as available to all females through constant and relentless self-monitoring, discipline of the body as well as participation in a consumer culture obsessed with what has been described as the 'porno-chic aesthetic' (Attwood, 2006, 2014; Gill, 2007, 2007c, 2008b, 2011; Levy, 2005; McRobbie, 2004, 2007, 2008). This aesthetic (as highlighted previously) describes hypersexual dress and stylisation. However, it also describes an increase in and mainstreaming of (through both representation and public participation) sexual practices which have traditionally been associated with the sex industry (Attwood, 2010, 2014; Gill, 2003, 2008b, 2009, 2011; Smith \& Attwood, 2014). Participation in these activities such as pole dancing classes, which have become an acceptable and increasingly popular form of exercise (Attwood, 2014; Levy, 2005; Whitehead \& Kurtz, 2009), is positioned as a way in which females can achieve the ideal hypersexualised feminine status. Sexual knowledge and sexual participation are constructed as the key to female emancipation and empowerment.

Gill $(2007 \mathrm{c})$ posits that underneath the construction of the new agentic and sexually desiring female subject is a change in the structure of regulatory power. The change lies in a shift from the externally policing male gaze, setting the standard of 
desirable femininity for women, to an internalisation of that gaze which has produced a self-imposed monitoring and disciplinary regime. As Gill explains, women in contemporary culture are "invited to become a particular kind of self, and endowed with the agency on conditions that it is used to construct oneself as a subject closely resembling the heterosexual male fantasy" (2007c, p. 152). Amy-Chinn's (2006) exploration of UK television advertising of women's lingerie highlights the connection between the sexy postfeminist body and heterosexual male desire. In her analysis, Amy-Chinn discusses the branding and commodification of women's bodies. She explains that 'new' female sexuality is "a sexuality that understands its power to provoke a specific response in men and to use that power for her own purpose, to generate her own pleasure" (p.159). As Amy-Chinn (2006 see also Gill, 2007c, 2009) explains, the new and empowered femininity that is packaged in postfeminist advertising and other popular culture representations has become irrevocably tied to heterosexual male narratives of female desirability. Empowered postfeminist femininity, though repeatedly constructed within the façade of choice and self-pleasing practises, often works instead to recuperate male attraction as required for subsequent female pleasure.

Not only does the postfeminist 'empowered' woman subjectivity appear to recuperate hetero-male attraction, but also sexualised behaviours commonly associated with heterosexual male behaviour. Popular culture representations of recent times appear to show a reformulation of female sexuality wherein being an agentic and empowered woman means not only controlling men through your sexuality but also controlling other women (Gill, 2003, 2007c, 2008b, 2011; McRobbie, 2007, 2008). This transformation has been repeatedly seen in the construction of a strong female identity in popular music. In Rihanna's music video for her single "Pour It Up" for example, she plays a self-sexualising (through twerking, pole dancing and wearing revealing clothing) pimp, surrounded by women pole dancing while singing/rapping about money and attending strip clubs. Then in the music video for a her single "Bitch Better Have My Money (BBHMM)" Rihanna is seen taking a blonde white woman hostage and terrorising her (including drugging and drowning her) as a ransom for money that the woman's husband owes Rihanna (Rihanna, 2015). These videos both construct the notions of aggressive and assertive sexuality, which has traditionally been applied to the male sex drive (Henriques, Hollway, Urwin, Venn, \& Walkerdine, 1984), as reformulated and directed at female bodies as a sign 
of emancipation and empowerment. While I would agree that these representations do create potential for expressions and feelings of female power and freedom, it is increasingly hard (particularly with the proliferation of the aggressive female subjectivity in popular music) to ignore the irony of a 'new' female sexuality available to women that is not new at all, but can increasingly be read as a reformulation of traditional male desire.

Celebrity as a postfeminist text. From Rihanna singing about her enjoyment of sadomasochistic practices in the music video "S \& M" (Rihanna, 2013), to Katy Perry's cream-squirting candy bra in the music video "California Girls" (Perry, 2013), hypersexuality has become endemic to female pop music and pop music celebrity. While these representations arguably open up many possibilities for the expression of female sexuality which have previously been unavailable, they simultaneously reproduce traditional and male-centric expressions of female desirability.

Female pop music celebrity has become a ubiquitous presence, with an almost obsessive cultural following in magazines, news and online media. Turner (2010) explains the growth in celebrity representations as due in part to the development of new media which "has generated new ways of representing, consuming and producing celebrity while online journalism - especially where it is developed as an additional platform for the mainstream print media - has also had an expansionary effect" ( $p$. 11). The music industry, particularly pop and hip hop genres (which are regularly amalgamated by contemporary female artists such as Beyoncè, Nicki Minaj, Rihanna and Iggy Azalea) is an important site for examining the sexualisation of women within contemporary sexualised culture.

Female pop music artists represent an important phenomena for the study of contemporary hypersexualised femininity, as according to Levande (2008), pop music media is more prolifically distributed that any other media form within contemporary popular culture (Perry, 2003). Levande (2008) puts forward that living in a digital age, these women have an incredibly broad and influential reach that even "when we're not seeing them we're hearing them" (p. 300). Due to their saturating presence and increasingly hypersexual stylisation and embodiment of postfeminist 'up for it' femininity (Evan \& Riley, 2010, 2013), female pop celebrities are understood within this thesis as a conduit of this postfeminist femininity (Evans \& Riley, 2013; Gill, 2007, 2008b, 2011b; Fairclough, 2008; Jackson \& Vares, 2011, 2015b; Whitehead \& 
Kurz, 2009). Despite pop music having an historical relationship with the sexually explicit and shocking (Andsager \& Roe, 2003), contemporary female pop artists' music, performances and celebrity identities are becoming increasingly styled upon 'porno-styled' representations (Evans \& Riley, 2013; Gill, 2012b).

Feminist research has long argued that women are often shown in music videos as objectified and sexualised through the use of revealing clothing. There is a focus on body parts and an increasing representation of women as 'arm candy', sexually submissive and featured specifically to show a male's sexual prowess (Andsager \& Roe, 2003; Conrad, Dixon \& Zyang, 2009; Perry, 2003). Increasingly within a sexualised and postfeminist culture, however, female artists are sexualising and subjectifying their own bodies in their own music videos. In a content analysis using subjectification theory, Frisby and Aubrey (2012) found that within the music that they viewed, women were more often seen sexualising themselves and presenting themselves as desiring sexual subjects than they were seen directly objectified in music videos by male artists (this is also observed by Dixon \& Brooks, 2002; hooks, 1992). The shift from objectification of the male gaze to subjectification of the self within pop music media aligns with Gill's (2007c) description of the sexually desiring postfeminist subjectivity wherein the sexually performative female body is problematically linked to notions of empowerment, choice, and in the case of female artists, often commercial success. Oware (2009) found that while many female artists have messages of empowerment through subjectification in their music and videos, many of these representations are simply re-inscribing and reinforcing traditional and male-centric notions of 'femaleness'. It is worth highlighting here that the selfsexualising female pop celebrity performances cannot be understood as relating to actual celebrity agency (we do not know how much artistic licence a celebrity has over her music video, or even her lyrics). However, this representation, regardless of its authenticity, proliferates a postfeminist hypersexual 'new' femininity used as a tool for selling idealised female pop music identities (Driscoll, 1999; Harris, 2004b; Klein, 1998).

Levande (2008) explores the re-inscription of traditional male hegemony by highlighting the use of female pop stars and their bodies as promotional tools within major marketing campaigns under capitalism. Levande (2008) asserts that, "feminism has been hijacked and its hijackers use female pop stars to sell behaviours and attitudes about sexuality itself. The most popular myth is the equation of stripping, 
prostitution, and pornographic imagery with power" (p. 301). Female pop stars have therefore become regular figures in corporate advertising, highlighting the centrality of capitalism in contemporary culture and also the importance of the commodification of female sexuality in the sale of pop artist identity. Levande (2008) usefully highlights the 2004 PEPSI advertisement starring Britney Spears, P!nk and Beyoncé as an illustration the postfeminist notion of empowerment and the increasing commodification of the sexuality and identity of female pop artists in contemporary advertising and marketing. In the advertisement the women are seen in varying stages of undress performing as entertainment gladiators for the 'king' (played by male pop star Enrique Eglesias). Rather than physically fight, the women are constructed as conquering the empire through their sexuality, toned bodies and ability to distract the emperor.

Aligning with this focus on the female body in the PEPSI advertisement, a shift in focus from the celebrity face to the female pop celebrity body has been identified (Andsager \& Roe, 2003; Gill, 2003, 2008b; Holmes \& Redmond, 2006). The pop star's body has become fundamental to the pop star persona and representation arguably reflecting the postfeminist obsession with the surveillance and attainment of a fit and sexy body as a marker of ideal femininity in contemporary times (Gill, 2007c, 2011b, 2012b). Redmond (2006) posits that previously the celebrity's face was central to their persona and their representation. In contemporary pop music media, however, female pop star representation is almost exclusively about the physical appearance of the body. This shift can arguably also be seen in contemporary song lyrics. Nicki Minaj, for example, released a song in 2014 which playfully remixed the hit song by DJ Sir-Mix-A lot "I Like Big Butts" (Madalina2696, 2009). This song, which is about a man who is sexually attracted, to the point of obsession, to women with large buttocks was remixed by Minaj to feature lyrics (and representations in the music video) that emphasise her own hypersexuality and sexualise her own large buttocks. So unlike the original version of the song, which is a misogynistic surveillance of women's bodies by a man, Minaj's edit (and music video) reformulates the gaze to actively present herself as sexually attractive because of her buttocks, presenting herself as sexually both sexually desiring and desirable (Minaj, 2014).

Alongside an emphasis on the attainment of a (hetero) sexy body and hypersexual behaviour as a marker of ideal femininity, postfeminist discourses draw 
on feminist notions such as empowerment and power for women (Gill, 2007c; McRobbie, 2007, 2008). The use of these notions within female pop music engender a site in which the feminist goals of empowerment and sexual freedom for women are re-appropriated and commodified for marketing gains (Budgeon, 2001; McRobbie, 2004, 2007). The appropriation of feminist values such as empowerment into postfeminist attributes is regularly seen within female popular music and underpins contentious debate amongst feminist scholars and feminist celebrities as to the usefulness (to feminism), and indeed the authenticity, of the increased declarations of feminism from celebrities in contemporary popular music culture.

Feminist-like proclamations of female power and domination by female artists are prolific within popular music. However, these assertions (e.g., example Beyoncé's claim that "Girls run the World" (a Beyoncé song title and lyrics) and Taylor Swift's call for girls and women to work together not against each other in her recent song "Bad Blood") sit somewhat ironically alongside these same female artists' hypersexual performances of hetero-desire. In addition, while artists such as Beyoncé produce representations which present feminist-like narratives, they sit alongside a regular denunciation of feminism by other female pop music artist such as Lady Gaga, Katy Perry and Kelly Clarkson who have all publically distanced themselves from feminism (Hamad \& Taylor, 2015).

The increasing number of pop music celebrity's publically identifying themselves as feminists has been recently debated, for their authenticity within feminist and celebrity studies literature. In a special forum issue exploring celebrity and feminism in the Celebrity Studies journal, Hamad and Taylor (2015) describe the "figure of the self-professed feminist celebrity" as a "recurring feature of Anglophone celebrity culture" (p. 124). In the same celebrity studies issue, Weidhase (2015) discusses an influential performance by Beyoncé at the 2013 MTV awards in which she performed her hit song Flawless in front of a large and brightly lit sign that read "FEMINIST". Beyoncé's performance was met with critique from many feminist scholars and particularly identified by artist Annie Lennox as a politically empty expression of feminism. This critique from Lennox aligns with broader critiques from feminist scholars and feminist celebrities (for example Sinead O' Connor's well documented address to Miley Cyrus) who contend that the notion of 'feminism' is being increasingly appropriated by female celebrities due to the popularisation of the term. Celebrities increased identification as 'feminists' is understood in this critique 
as little more than the artists recognition of 'feminism' as a contemporary marketing strategy in the advertising of their own products.

Postfeminist absences. In addition to the contentious feminist debates concerning the meanings and subjectivities that are included and understood as postfeminist, postfeminist media culture is also usefully understood as a distinctly regulatory phenomenon that is exclusionary in nature. Returning to this chapters earlier discussion of Foucault's theorising of sexuality, Foucault (1978/1980) describes the discursive formation of sex as an explosion of knowledge and technologies concerned with the surveillance and discipline of human behaviour. Foucault discusses his theorisation of sexuality as fundamentally linked to power, wherein the deployment of sexuality must be understood as a contemporary technology of social control. According to Foucault, early sexuality discourses were deployed within which the 'sex drive' or the desire to have sex became hegemonic and normalised (1978/1980). The notion of the 'sex drive' is understood by Foucault as establishing "one of its most essential internal operating principles: the desire for sex - the desire to have it, to have access to it, to discover it, to liberate it, to articulate it in discourse, to formulate it in "truth"' (1978/190, p. 156). The naturalisation of the desire for sex is therefore intricately linked to a construction of sexuality as something which needs to be freed, discovered and can only be done by disobeying its closely related phenomenon, power in the form of sexual repression. According to Foucault (1978/1980), the construction of power (whether it be religious and moralistic discourses) as inherently prohibitionist to sexuality works to obscure the productive and creative relationship that sexuality and power have. Foucault (1978/1980) argues that although sex is positioned as prohibited and repressed by power, power is actually constitutive of sexual discourses, sex is therefore a socially constructed instrument of power. Drawing on Foucault's conceptualisation of sex and power Jess Butler (2013) attends to postfeminism as the most recent deployment of sexuality as a tool of social organisation central to which are the absences and exclusions of individuals from ideal postfeminist femininity.

Postfeminist media culture has been discussed in feminist theory as a profoundly exclusionary discourse based on gendered, classist and racialised ideals that are obscured through constructing notions of freedom, choice and empowerment as available to all individuals (Gill, 2007c; McRobbie, 2004, 2008, 2009). Tasker and 
Negra (2007) address postfeminism's 'taking into account' of inequalities as a way in which this discourse commodifies the previously excluded or oppressed other. According to Tasker and Negra postfeminist discourse "has become so installed as an epistemological framework that in many ways our culture has stopped asking the kinds of questions that it appears to settle" $(2007$, p. 6).

One of the central ways in which postfeminist media cultures exclusion can be seen to be functioning within contemporary pop music media is through the representation of women of colour. Jess Butler (2013) argues that the increasing representation of women of colour within contemporary pop music media means that postfeminism must not be approached as simply inhibiting the representation of coloured bodies. She asserts that not only are these representations increasing, but women of colour who are presented in mainstream popular culture such as pop stars Nicki Minaj and J-Lo,

clearly embody and enact postfeminism: they embrace femininity and the consumption of feminine goods; they espouse a vocabulary of independence, choice, empowerment, and sexual freedom; and they construct themselves (or are constructed by others) as heterosexual subjects. (Jess Butler, 2013, p. 48) According to Butler then, the simplistic assertion that non-white bodies are excluded from postfeminist media leads to an assumption within feminist theorisation of postfeminist media culture that non-white bodies are "somehow unaffected by, postfeminist discourses" (2013, p.48).

As has been discussed earlier in regards to Lazar's (2009) analysis of Singaporean make-up advertisements, postfeminism has been conceptualised by many feminist theorists as appropriating the agenda and demands of the feminist movement and commodifying and redirecting it towards consumption (Gill, 2007c, 2008b, 2011; McRobbie, 2007, 2008, 2009). In regards to race, then, Springer (2007) asserts that postfeminism "takes the feminist demands for racial inclusion and makes race consumable" (p. 74). This commodification according to Springer can be seen through the "mainstreaming the fetishization of a " big, black booty", and "promoting year-round 'bronzed' (brown) skin", all of which is regularly seen through in female pop music media. Pop music media representations from artists such as Nicki Minaj, Rihanna and Beyoncé can be understood as central to the commodification of colour wherein these artists 
regularly draw on the problematic troupes of the black female body including the accentuation of the curvaceous black female body (e.g., Nicki Minaj's "Anaconda" single) and the notion of animalistic hypersexuality (Beyoncé's performance as a caged animal in "Partition", see Knowles-Carter (2014).

\section{Chapter Summary}

The sexualisation of culture has been identified in this chapter as a contested and debated phenomenon in which understandings of the increased sexualisation of popular media and public representations are broad and conflicting. Central to the phenomenon of the sexualisation of culture has been women's involvement, specifically, the saturation of hypersexual representations of women. These representations, which tie female hypersexuality to postfeminist notions of empowerment and freedom, have been shown in this chapter to construct a 'new' idealised female subjectivity. Importantly, however, the new hypersexual and 'empowered' female subjectivity has become a key feature in marketing wherein hypersexual femininity is increasingly linked to neoliberal discourses of individualism and, most importantly, consumption.

As this chapter has highlighted, female pop music media is a site in which the uptake of sexualisation and the new empowered female has been prolific. Female pop music celebrities and their media are understood in this thesis as an important phenomenon for continued feminist enquiry into the sexualisation of culture. As a conduit of hypersexual, desiring and desirable postfeminist femininity with a saturating exposure within popular culture, female pop musicians are understood in this research to be an important resource for girls on ways of being and performing femininity. Postfeminist pop music celebrity and media is also of great importance to this thesis because of its centrality within contemporary debates concerning the sexualisation of girls within Western culture. Within the sexualisation of girls discourse, celebrities are viewed as providing sexual scripts which negatively affect and 'sexualise' girls.

The following chapter instigates an exploration of the sexualisation of girls discourse. The chapter will unpack and explore the ways in which girls are positioned within this discourse and specifically the ways in which girls' engagement with postfeminist pop music celebrity has been constructed. In exploring the contemporary 
theorisation concerning girls' music media consumption, the chapter aims to move past problematic theorisation of girls as passive media consumers, and will instead explore (through a growing body of critical feminist literature) the possibilities of self for girls within postfeminist pop music media.

Chapter Three:

The Sexualisation of Girlhood 
Building on the previous chapter, the following discussion takes the sexualisation of culture as a broad context for its interrogation of contemporary sexualisation claims about pre-teen girls. The chapter focuses on key theoretical conceptualisations used to construct claims about the sexualisation of girls within contemporary culture, in particular the way in which such constructions have come to largely define and recuperate notions of girlhood as an inherently risky developmental period for girls.

The chapter approaches its unpacking of a sexualisation of girls discourse as deeply rooted in socio-historical knowledge about girlhood sexuality rather than as a unique and contemporary phenomenon as it is often constructed within academic and media texts. Doing so takes into account the hegemonic 'knowledge' that underpins the sexualisation of girls discourse. This knowledge includes the highly gendered and classist ideals about childhood and the historically problematic pairing of girls and sexuality which has been dominant since its insertion into social discourse in the Victorian period (Foucault, 1978/1980). In discussing these conceptualisations of girlhood, the chapter is further concerned with the construction of the deviant 'sexualised' girl subjectivity within the sexualisation of girls discourse and her permanent and pathologised subjectivity in Western society. The chapter discusses the notions of agency and victimhood that inflect the sexualised girl subjectivity and explores how feminist academic theorisation might move beyond these binaries to a more comprehensive and complex understanding of girls' relationship with hypersexual postfeminist media culture. This challenge to binary constructions is particularly important in the thesis's analytical chapters which will specifically address girls' pop music media engagement. Through exploring and unpacking girls' pop music media engagement, this chapter aims to complicate and explicate the binaries and frameworks which plague dominant understandings of girls' engagement with the hypersexual representations that characterise contemporary popular music by female artists.

\section{Contextualising the Sexualisation of Girls}

As was explored in the previous chapter, contemporary feminist theorisation about the sexualisation of culture has its roots in the historical feminist 'porn wars'. 
At the beginning of the 1990's, however, debates about women's engagement in pornography diminished as academic and feminist interest began to focus intently on child protection and paedophilia within the context of sexualised culture (Ciclitira, 2004). With this shift came a rapid increase in concerns about the sexualisation of children which has been widely understood in academic theorising and media coverage as a by-product of children's exposure to sexualised culture. It is described as causing children to become sexually precocious and consequently subject to negative behavioural and life outcomes within Western society (Egan, 2013). Although in theory the sexualisation of children applies to all children, contemporary sexualisation concerns are in fact highly gendered whereby girls are most commonly seen as at risk of sexualisation (Egan, 2013; Gill, 2012b; Walkerdine, 1996, 1998). As Levine (2002) highlights, the almost exclusive application of sexualisation to girls is underpinned by "the idea that young minds (and female minds and feeble minds) are vulnerable to bad thoughts that might lead to bad acts" (p. 10). In addition to positioning girls as particularly at risk of sexualisation, the contemporary crisis has been focused specifically on an age category known as the "tween", an elastic term which has been used in mainstream advertising and across academic literature to describe girls anywhere between the ages of 5 and 14 years old (Cook \& Kaiser, 2004; Jackson \& Vares, 2011; Vares, Jackson \& Gill, 2011).

Although discourses of girlhood sexualisation have currency in a contemporary hypersexual culture, problematising discourses of girlhood have a lengthy history. The most recent wave of concern can be located in an increased interest in girlhood that arose in the 1990's, resulting in subsequent literature concerned with the lives of girls (for example, Griffin, 1997; Johnson, 1993; Lesko, 2001; Maxson \& Klein, 2008; Pipher, 2005; Wiseman, 2002; Wyn \& White, 1996). Gonick (2006) explains that with this sudden and startling proliferation of texts came a recurring mobilisation of discourses that present girlhood as a troubling and dangerous time. Whereas previous panics have positioned girls as inherently helpless (Pipher, 2005), and pathologically mean (Wiseman, 2002), the current sexualisation discourse constructs girls as passive media consumers who are being precociously sexualised by media before their time. Rather than a unique phenomenon of our times, the sexualisation of girlhood discourse extends a pattern of contemporary moral panics viewed as a crisis for all girls burgeoning on womanhood (Egan, 2013; Egan \& Hawkes, 2008, 2008b, 2009, 2012; Gonick, 2006; Hawkes \& Egan, 2008). 
As the latest in this series of panics concerning girls, the sexualisation of girls discourse has been described across a range of texts. These texts have included, for example, a publication from the American Psychology Association (American Psychological Association, 2007), mainstream news reports (Kidsfree2bekids, 2009, 2009b); government funded reviews in the UK and Australia (Bailey, 2011; Rush \& La Nauze, 2006, 2006b; Papadopoulos, 2010), academic literature (Bragg, Buckingham, Russell \& Willett, 2011) and popular psychology texts (for example Tankard Reist, 2009; Hamilton, 2009; Levin \& Kilbourne, 2008). Throughout these texts, the sexualisation of girls discourse is overwhelmingly presented as a contemporary problem related to the mainstreaming of sexual representations within popular culture (Carey, 2011; Hamilton, 2009; Levy, 2006; Oppliger, 2008; Tankard Reist, 2009). Specifically, this body of work asserts that the sexualisation of girls is related to the saturating representation of hypersexual femininity and its associated practices in mainstream media. By way of unpacking the sexualisation of girls discourse the following section discusses sexualisation texts, in particular, the assertion that girls are being dangerously and uniformly sexualised by contemporary culture.

\section{Unpacking the Sexualisation of Girls Literature}

The pandemic reach of the sexualisation of girls discourse is evidenced in the proliferation of texts both within academic literature and popular psychology publications that re/produce this phenomenon. This literature which will be examined in this section and throughout this chapter (referred to as 'sexualisation texts') is a body of work that reproduces the sexualisation of girls discourse and constructs contemporary sexualised culture as uniformly damaging and expressly problematic to contemporary girlhood. In critically approaching the sexualisation of girls discourse constructed within these texts I find it important to emphasise my own position. My intention in exploring these texts is to highlight the academic reach and hegemonic strength of the sexualisation of girls discourse and to deconstruct the problematic body of knowledge it produces about girlhood. At the same time, it is also important to highlight the binary operating within critical feminist approaches to the sexualisation of girls. For example, as Ringrose highlights, feminists adopting positions which view sexualisation as inherently dangerous are often accused of overhyping sexualisation at the expense of "real issues" (2011, p. 100) and those feminists 
who adopt more critical understandings of the sexualisation of girls (like myself) are understood as careless and promoting sexual victimisation. With this in mind, my criticism of the works I review should not be understood as a rejection of the importance of studying girls within the sexualisation of culture or as a 'prosexualisation of girls' advocacy. Instead, discussion of this literature serves to trouble (from my own feminist poststructuralist positioning) notions which are taken for granted within sexualisation literature. Sexualisation literature is therefore used in this in this exploration to highlight the ways in which the sexualisation of girls discourse has been repeatedly represented through moralistic and fear-laden dialogue. The literature creates an academic and cultural context within which this discourse has become so controversial yet so taken for granted that, as Egan (2013) asks, "who can be for the sexualisation of young girls?" (p. 19).

Within sexualisation literature, sexualisation is described as affecting girls through a uniform process. The APA Task Force, for example, describes this process as when; i) an individual's "value comes only from sexual appeal or behaviour," ii) individuals are "held to a standard that equates physical attractiveness with being sexy," iii) individuals are "sexually objectified — that is made into a thing for other's sexual use,' iv) and “'sexuality is inappropriately imposed upon another person' (APA, 2007, p. 2). Sexualisation literature as a whole addresses multiple areas of concern such as the psychological 'effects' of premature sexualisation on girls' development, distorted body image, learning difficulties, and sexual promiscuity (APA, 2007; Papadopolus, 2010; Rush \& La Nauze, 2006, 2006b). Sexualisation reports have also described a rise in mainstream marketing which presents young girls as desirable and desiring in the sale of 'adultified' and sexualised products and clothing to girls (Bailey, 2011; Papadopolus, 2010). Referred to as 'corporate paedophilia' by Rush and La Nauze (2006), sexualised products marketed to young girls are identified by these authors as influences that pressure girls to become precociously sexualised while simultaneously inviting the paedophilic gaze.

Sexualisation reports, such as those mentioned above, have been harshly criticised by some feminist academics (for example, Dunschinsky, 2013; Egan \& Hawkes, 2008, 2008b, 2012; Gill, 2012b; Lumby \& Albury, 2010). These critiques have highlighted the reports' generalising observations (APA, 2007), small media samples (Rush \& La Nauze, 2006, 2006b), as well as their lack of definitive meaning and poor operationalisation of 'sexualised media' and 'sexualisation of the 
individual'. In her report on the effects of the sexualisation of culture on girls, for example, Papadopoulos (2010) fails to describe exactly what constitutes 'sexualisation' or 'sexualising' material (see Gill, 2012b for a critique of this report). The difficulty in operationalising sexualisation, and particularly the subjective nature of deciding what constitutes sexual or sexualised material, is seen throughout sexualisation research and has rendered many of these studies methodologically unsound and flawed by unsubstantiated findings (Egan, 2013; Gill, 2012; Lumby \& Albury, 2010).

Following the release of the aforementioned reports and academic publications concerning the sexualisation of girls, a proliferation of pop psychology publications on the subject emerged. These texts, which also emphasise girls as at risk to sexualisation, are aimed primarily at parents and emphasise the need to protect girls from the dangers of contemporary culture. Texts such as The Lolita Effect (Durham, 2009), What's Happening to our Girls? (Hamilton, 2009), Girls Gone Skank (Oppliger, 2008) and So Sexy So Soon (Levin \& Kilbourne, 2008) present an alarming narrative which positions girls as inherently passive and victimised within contemporary culture (Gonick, 2006; Jackson \& Vares, 2015, 2015b; Vares \& Jackson, 2015).

Aligned with the reports, this (largely) feminist body of popular psychology literature relies on an understanding of the sexualisation of culture as inherently dangerous to girls and as leading them to become inappropriately sexualised. Within this construction, girls are understood as unable to resist the messages of hypersexuality that they are exposed to. Concurrently, this media is repeatedly described as initiating their decline into sexualisation, beginning with the mimicry of sexualised feminine identities and resulting in premature, promiscuous and risky sexual behaviour (Levin \& Kilbourne, 2008; Papadopolus, 2010; Tankard Reist, 2010). Levin and Kilbourne (2008), for example, describe pop music as particularly dangerous to girls highlighting that "in an effort to expand its reach, the music industry has turned its attention to creating edgy music for younger children" (p. 46). The author's further claim that hypersexualised music media "lures children into a world of 'hot' songs and sexy behaviour that can be problematic for adolescents and its definitely inappropriate for children. It takes children yet further away from the childhood they should and need to have" (Levin \& Kilbourne, 2008, p. 46). The repeated references to idealistic notions of childhood within Levin and Kilbourne's 
assertion illuminates another problematic feature of sexualisation narratives, the assumption of a clear cut definition of "What's normal?" sexual development for girls and "What's not normal?" or pathological 'sexualised' behaviour (titles taken from So Sexy So Soon, Levin \& Kilbourne, 2008). Within this normal/abnormal sexual development binary, girls are regularly constructed as victimised and endangered (Hamilton, 2009; Levin \& Kilbourne, 2008; Tankard Reist, 2010). Sexualisation, as it is conceived within this binary, is an inevitable and uniform process that is absent of classed, racialised or socio-economic difference (Durham, 2009).

Moralistic narratives in sexualisation texts such as those discussed above are predicated on an assumption that girls are straightforwardly internalising the images and messages that they are exposed to within contemporary hypersexual media. In conceptualising girls as an audience, sexualisation literature often relies heavily on media effects models which propose a causal link between girls' exposure to such media, and girls' internalisation and reproduction of this imagery through their own precocious sexual behaviour (APA, 2007; Rush \& La Nauze, 2006, 2006b; Levin \& Kilbourne, 2008; Hamilton, 2009). The hypodermic model, as it has been termed (Bineham, 1988), underpins this problematic conceptualisation of girls as passive consumers and therefore victims of contemporary hypersexual media (Buckingham \& Bragg, 2004; Lumby \& Albury, 2010). Buckingham and Bragg explain that the media effects model assumes that girls are "powerless to resist the 'messages' to which they are 'exposed'. They [girls] are assumed automatically to believe what they see" (2004, p. 10). Indeed, the employment of a media effects model is evidenced in popular psychology texts such as in So Sexy So Soon (Levin \& Kilbourne, 2008) which asserts multiple times that "children believe what they see" (2008, p. 47). The assumption of girls' desire to copy sexualised representations and behaviours that they are seeing in popular culture is so central to sexualisation literature that, as Jackson and Goddard (2015) highlight, the representation of the 'sexualised girl' on the covers of pop psychology texts often feature girls in adult-styled clothing (see the cover of Oppliger, 2008) and wearing makeup (see the cover of Hamilton, 2009). Girls' sexualisation, then, is regularly described as unfolding through a process of mimesis, whereby sexualised behaviours and representations of femininity are constructed as scripts that teach girls how to perform idealised contemporary hypersexual femininity. 
In sum, the literature which re/produces the sexualisation of girls discourse positions girls as passive in their media reception, internalising the messages that they are seeing, and as compelled to reproduce sexualised behaviour. This discourse, and its associated assumptions and knowledge, is understood in the thesis as one that is widely reproduced and holds significant power within contemporary Western culture. Egan (2013) asserts, for example that "our culture is more concerned with sex acts acted upon or by the child than the risks posed by poverty, neglect and lack of health care" (p. 9). Following this, this thesis adopts a critical feminist stance towards the sexualisation of girls discourse which is underpinned by a socio-historical understanding of the relationship between girls and sexuality as inherently deviant and problematic (Egan \& Hawkes, 2008, 2008b; Hawkes \& Egan, 2008; Renold \& Ringrose, 2013; Ringrose \& Renold, 2008, 2011;Walkerdine, 1998). A formulation of the sexualisation of girls discourse as a dynamic body of knowledge about girlhood informs the following exploration of the historical problematising of the pairing of girls and sexuality.

\section{Girls and Sexuality: A Socio-Historical Account}

Foucault's historical analysis of sexuality in Western society emphasises sexuality as a dynamic body of knowledge which, like all hegemonic discourses, is socially and contextually shaped over time. Contrary to dominant understandings of contemporary sexuality as a stable phenomenon, Foucault's analysis demonstrates the ways in which contemporary sexuality norms and ideals are the products of a long and unstable history of sexuality discourses. As highlighted in the previous chapter, Foucault (1978/1980) describes sexuality being "put into discourse" (p. 11) and becoming an important form of knowledge about the individual, in the Victorian period. Rather than limit the ways in which sexuality was understood in Western culture, Butler asserts that the discursive shift described by Foucault worked to extend, multiply and, importantly, govern "its forms, penetrating individual bodies through a surge of incitements, enticements, and excitement" (Butler, 2013, p. 37). In addition, Foucault (1978/1980) suggests that the governance of childhood sexuality is one of the original forms of "bio-power" which he describes as the governance of 
populations through knowledge about the body and life rather than through prohibition and death ${ }^{1}$.

Central to Foucault's (1978/1980) analysis of sexuality is his understanding of power within society and, specifically, its effects on dominant ideas about sexuality. From a Foucauldian perspective, power is conceptualised as neither good nor bad, but rather examined as a productive force for change and meaning-making. (Foucault's theorisation is examined more thoroughly in Chapter Four of the thesis, p. 75-76). Power can therefore be understood as central to the construction of the sexualisation of girls discourse. While hegemonic discourses such as the sexualisation of girls retain their power through their apparent 'naturalness' and history, they can in fact be understood as forms of social control and social organisation which dictate 'appropriate sexuality' through the process of normalisation and punishment. Also useful to exploring the sexualisation of girls discourse is Foucault's conceptualisation of the power of the norm (Foucault, 1977/1995) which emphasises the invisibility of the exercise of power and also the technique of subtle coercion which works to pressure people to conform to the 'norm' (for example, the pressure on girls and their parents concerning pathological status of sexuality). Foucault posits the relationship between childhood and sexuality as becoming problematic specifically through the development of sexual discourses that conceptualised the child as sexually innocent and inherently naïve to sexual knowledge. He describes early protectionist and disciplinary behaviours, such as masturbatory surveillance of children, as structures that initiated the privileging of sexuality to adulthood and the need to protect children from sexualisation.

Protectionist narratives are inextricably linked to the sexualisation of girls discourse, particularly as they have been identified by a number of feminist academics as underpinning the childhood innocence discourse (Egan, 2013; Egan \& Hawkes, 2007, 2008b, 2010, 2012; Renold, 2005; Renold \& Ringrose, 2013). Within a protectionist discourse, childhood innocence (asexuality) is naturalised and the child is understood as always at the risk of being tainted through exposure to sexualised material (Egan \& Hawkes, 2009, 2010, 2012). Egan and Hawkes (2007, 2012), assert

\footnotetext{
${ }^{1}$ Michel Foucault described the notion of "biopower" as a technology which appeared in the eighteenth century and (similar to disciplinary power which is used to train bodies) is used to govern and manage populations through the control over the birth, life and death of bodies. Foucault explains bio-power as "an explosion of numerous and diverse techniques for achieving the subjugations of bodies and the control of populations" (1977/1995, p. 140).
} 
that during the Victorian period, purity activists produced cautionary narratives of children as corrupted by sexualising influences. They observe that "the discursive production of the corrupt or knowing child, within purity literature, was an attempt to disentangle the ambivalent construction of childhood sexuality within the social purity movement" (2012, p. 274). The authors describe the problematic sexualised child as becoming the scapegoat during this time for anxieties about modernisation and urbanisation whereby, "the child symbolized a site of potential management that could be controlled, shaped and trained, thereby shifting uncertainty and concern onto something else: a pure and civilised future" (2007, p. 456). Extending the understanding of the sexualised child subjectivity as a moral scapegoat, Faulkner (2010) explains that childhood, as it has historically been conceptualised, is "understood as holding the secret to the self - as the nostalgic construction of a simpler past; society's glowing (or degenerate) future" (p.109).

In addition to its underpinnings within concerns about childhood innocence and urbanisation in the Victorian period, sexualisation narratives have also been described by Egan as constructed through fears of middle class 'contagion'. Egan explains that concerns within the middle class about the influence and infiltration of the working class "have been taken for granted as truthful and underpinned social movements (social purity, hygiene, and eugenics), disciplines (hygiene, medicine, criminology, sociology, and psychology) and institutions (public health and social work)...which sought to regulate and normalize the erotic practices of the working class" (2013, p. 81-82). Contemporary fears concerning the sexualisation of girls can therefore be traced to middle class fears about perverse, 'inappropriate' and sexualised behaviours which are associated with 'the distasteful' and the working class which are often conflated (Egan, 2013). Egan and Hawkes (2007, 2010) describe the notions of taste and of manners as pivotal in the construction of class and particularly in the associations between the civilised and uncivilised body. The uncivilised and distasteful behaviours of the working class sexualised girl is therefore understood by Egan (2013) as underpinning many of the contemporary fears about the risk that these representations pose to the young respectable middle to upper middle class girls.

Aligning with Foucault's view of dominant sexuality discourses as taken for granted within contemporary culture, feminist critiques concerning the historical, classed and raced intersections and contextualisation of the contemporary 
sexualisation of girls discourse often go unmentioned within mainstream media and popular psychology texts (Egan \& Hawkes, 2012; Gill, 2012b; Lumby \& Aulbury, 2010; Renold \& Ringrose, 2011). Egan and Hawkes (2012) explain the taken-forgranted nature of the sexualisation of girls discourse in their comment that, "the problem itself [sexualisation] exceeds the need for proof... Sexualised girls are $d e$ facto the walking wounded... To this end, the discourse of sexualisation relies upon a logic of exnomination" (p. 275). Egan and Hawkes's assertion might therefore account for the absence of critiques in sexualisation literature because, as they explain, the sexualisation of girls discourse is so privileged within Western culture that it is always already presumed. This presumption is also described by Lumby and Albury (2010) as allowing the questionable methodological legitimacy of sexualisation literature to be overlooked because the presumed danger and urgent need for help exceeds the need for the substantiation of these deeply problematic claims.

The widespread acceptance of the sexualisation of girls discourse as common knowledge within Western culture also underpins its power in constructing contemporary understandings of girlhood through the problematic binary of the 'sexualised girl' and the successful 'innocent girl' (Harris, 2004; Griffin, 2004, 2004b; Gonick, 2006). This binary has contributed to a simplistic understanding of girlhood that constitutes the asexual 'good girls' in opposition to the sexualised and problematic 'bad girls' (Gonick, 2006; Griffin, 2004, 2004b; Jackson \& Vares, 2015; Renold \& Ringrose, 2011; Ringrose \& Renold, 2012, 2012b). Sexualisation literature repeatedly refers to the sexualised girl using degrading and repulsive language. For example, such literature has labelled girls as "prostitots" (Durham, 2009) and as sexually immoral (for example, engaging in oral sex at birthday parties according to Hamilton, 2009). As well as deploying the construction of the 'slut' to mark the sexualised girl as problematic, these descriptions highlight the separatist language that contributes to the understanding of sexualisation as a personal failing rather than a socially and historically produced discourse which operates as a regulatory device within contemporary culture (Egan \& Hawkes, 2009, 2012; Jackson \& Vares, 2015b; Lumby \& Albury, 2010; Renold \& Ringrose, 2011). These derogatory assertions, which Egan and Hawkes say "in any other context would be deemed problematic at best and definitively anti-feminist, patriarchal and misogynist as worst" (2012, p. 280), can be understood as disempowering the population they claim to be in need of 
protection (Egan, 2013; Egan \& Hawkes, 2009, 2012). The disempowering binary within the sexualisation of girls discourse is evidenced through the representation of the sexualised 'at-risk' girl subjectivity which will be discussed in the next section.

The sexualised 'at-risk' girl. As has been discussed earlier in this chapter, the sexualisation of girls is a deeply problematic discourse within contemporary culture. Within sexualisation literature, the precociously sexualised girl is understood as "at best beyond hope and, at worst, beyond redemption and thus deserving social isolation" (Egan \& Hawkes, 2012, p. 277). The sexualised girl subjectivity is repeatedly represented in both the popular and academic press as an individual whose sexuality is excessive and whose practices violate dominant girlhood norms (Egan, 2013).

Harris's notion of the 'at-risk' girl may be aptly applied to describe the sexualised girl. Harris describes this negative depiction of girlhood as deeply rooted in classist and racist notions, explaining that "not only are these girls unlikely to be middle class, but they are also generally of particular ethnic minorities. These young women are often seen as those either most at-risk or those most likely to be risk takers" (Harris, 2004, p. 25). Class and particularly the construction of the precocious young girl are central to the dissemination of the sexualised girl subjectivity within sexualisation literature. Presented in opposition to the (often white) innocent middle class girl, the working class girls' precocious and promiscuous behaviour is often signalled in sexualisation literature through her barely dressed body (Egan, 2013). Jackson \& Goddard (2015) for example (discussed previously on p. 52 of the thesis), describe numerous covers of sexualisation texts which present the 'sexualised' girl(s) often posed, wearing making up and revealing clothing. Indeed, within sexualisation literature clothing choice (particularly body-exposing styles) is regularly viewed as both influencing and indicative of sexualised behaviour by girls (Hamilton, 2009; Oppiliger, 2008). Oppliger (2008), for example, uses the terms 'Kinderwhore' and 'Prostitots' to describe the sexualised clothing assumed to be worn by girls. Exploring such practices, Egan (2013) describes the underlying classist assumptions of terms such as 'skanky', 'slutty' and other derogatory language used in sexualisation literature. As Egan asserts, such terms are employed as exemplary of tasteless working class behaviours which are described to "signify or predict a girl's decent down the slippery slope towards sexualised activities" $(2013,91)$. 
Constructed within an 'at-risk' discourse which emphasises her passivity and need for protection, the sexualised girl bears close resemblance to the Ophelia girl (Gilligan, 1982; Gonick, 2006, Pipher, 1994). Piphers' (1994) book, Reviving Ophelia: Saving the Selves of Adolescent Girls is the most recent recuperation of the Ophelia phenomenon (see Gonick 2006, for a discussion of previous invocations of this discourse) which positions girls as inherently at risk during adolescence. Pipher, a $\mathrm{PhD}$ and practising therapist, draws on this victimised and vulnerable construction of contemporary girlhood as a problematic stage. Like the sexualised girl, the Ophelia girl is also associated with girls' failure to achieve success in late capitalist society. This failure, in the case of the Ophelia girl, is manifested in girls' apparent loss of self-esteem and difficulty in navigating adolescence as Pipher (1994) argues that contemporary adolescent girls experience a profound loss of 'self'. Within Pipher's argument, girls are described as stripped of their self-esteem, self-knowledge and any sense of an authentic self. Instead girls are positioned as the unwitting victims of a "hostile girl culture" (1994, p. 15).

Alongside the at-risk girl subjectivity is a contradictory address to girls which Harris captures with the term 'can-do' girls. These girls, who are constructed as largely white and middle class, signify a break with the hegemonic construction of girls as passive victims and are instead addressed by an ever-expanding girlhood marketplace within contemporary culture as media savvy and agentic consumers.

The smart, sassy 'can-do' girl. The 'can-do girls' with "the world at their feet" (Harris, 2004, p. 13) is a girlhood subjectivity which is regularly mobilised in governmental and mainstream media within Western culture (Harris, 2004; McRobbie, 2007). As a population these 'can-do' girls are regularly called upon as examples of social change; they are seen as economically and educationally successful individuals worthy of investment within contemporary culture (McRobbie, 2004, 2007). The newfound opportunities for women and girls within a contemporary neoliberal context are central to the conceptualisation of the can-do girl and McRobbie asserts that these girls (and young women) are now "invited to recognise themselves as privileged subjects of social change, perhaps they might even be expected to be grateful for the support they have received" (2007, p. 722). Such neoliberal agendas individualise girls' successes, whereby overall female achievement in education, sport and the workforce comes to stand for the apparent achievement of 
gender liberation and equality (Gonick, Renold, Ringrose \& Weems, 2009; McRobbie, 2007).

The notion of gender equality and female success is also played out within mainstream popular culture that newly addresses 'can-do' girls as sassy, smart, independent and self-reliant consumers within a postfeminist girl marketplace (Harris, 2004; McRobbie, 2004, 2007). Within this marketplace 'can-do' girls are not addressed as in danger of sexualised culture. Instead, they are hailed as active consumers in the growing tween market (Cook \& Kaiser, 2004; Jackson \& Vares, 2011; Vares \& Jackson, 2012). The 'tween' label itself was created as a marketing strategy for selling children's clothing in the 1930's (Cook \& Kaiser, 2004). Cook and Kaiser describe the 'tween' or preteen as an "aspirational social identity... [that] by definition, seeks to move out of 'tween hood' and thus up the age prestige ladder" (2004, p. 205). The success of the girl tween market has resulted in the highly gendered nature of the tween category whereby 'tween' has become synonymous with 'girl' (Aapola, Gonick \& Harris, 2005). Of particular relevance to this thesis, the 'tween' market capitalises on the sale of adult-styled, often hypersexual, new (sexualised) girl feminine identities to pre-teen girls through a growing number of products (Jackson \& Vares, 2011, 2012, 2015).

Much like the postfeminist market described in the previous chapter which commodifies and sexualises contemporary femininity, employing feminist tropes such as empowerment and choice, the postfeminist 'tween' market capitalises on the feminist notion of girl power in its address to girls. Girl power discourse is a complex and contradictory phenomenon which has been recuperated as a central feature of popular cultures address to girls since the early 1990's (Gonick, 2006; Harris, 2004; Taft, 2004). In its original form, girl power was a political movement established by a group of young, mainly white and middle class women in the United States known as Riot Grrrls (Gonick, 2006). This group engaged in acts such as writing on their own bodies with politically loaded and regulatory words such as 'slut', 'shame', and 'rape' as a form of reclamation of such derogatory language typically used against women. This reclamation, along with the performance of punk rock music and employment of the term girl power (originally called grrrl power to denote anger), was a challenge to gendered norms (specifically female passivity) and signified the embracing and encouragement of aggression, fierceness and independence for women and girls (Gonick, 2006; Harris, 2004; Taft, 2004). The movement received immense academic 
and media attention, but despite its political beginnings it was quickly taken up in popular media as a marketing strategy directed towards an emergent young female consumer population (Gonick, 2006).

The individualising and depoliticising effects of capitalist and neo-liberal discourses on girl power through the insertion of a postfeminist discourse has led to the positioning of girls (and women) as ideal neo-liberal subjects within contemporary culture (Gill, 2007c, 2008; McRobbie, 2004, 2007, 2008). This has meant that "while girl power emerged within the economic, socio-political context of the 1990's where girls could be active, in the 2000's they are now expected/demanded to be fully selfactualised neo-liberal subjects" (Gonick, Renold, Ringrose \& Weems, 2009, p. 2).

Within the postfeminist girl market the 'empowered' girl subjectivity is made available to girls through the purchase of products such as magazines, clothing and makeup which are often promoted by and modelled on female pop music artists (for example, Katy Perry's nail polish, and Rihanna as the face and body of Puma clothing). In addition to the marketing of products, behavioural practices such as sexual stylisation are repeatedly seen in the representation of female artists and are produced through a strictly heterosexual lens (Jackson \& Vares, 2011; Renold \& Ringrose, 2008; Ringrose, 2008, 2011; Willet, 2008). Fritzsche (2004) highlights the interaction with stars as distinctly consumer based in contemporary culture. She explains that the purchasing of consumer products allows fans to mimic their idols and transform themselves in a way that may provide them with the experience of what it is like to be a star (see also Redmond \& Holmes, 2006; Rojek, 2001). The consumer-based fandom in contemporary culture positions pop stars as a commodity that fans can (and are encouraged to) make a part of their own consumer subjectivity, rather than a distant idol figure (Fritzsche, 2004; Redmond \& Holmes, 2006, 2007; Rojek, 2001)

Although postfeminist media and its associated marketplace instructs girls on ways of embodying postfeminist girl power(ed) ideals, the very notion of hypersexually desiring and desirable girlhood transgresses contemporary girlhood norms (Griffin, 2004; Renold \& Ringrose, 2011; Ringrose, 2008;Willet, 2008, 2011). Moreover, in practise girls' sexual agency is regulated by a binary between good and bad girls, 'sexy girls' and 'sluts' (Griffin, 2004, 2004b; Renold \& Ringrose, 2011; Ringrose, 2008, 2011; Willet, 2008). The production and performance of a heterodesiring girl subject disrupts the hegemonic notions of childhood innocence discussed 
in the beginning of this chapter. The simultaneous address to young girls by postfeminist media of sexual agency on the one hand, and the consistent monitoring and theorisation of the problematic sexualised girl on the other, has constructed a girlhood binary within which girls are constantly at risk of failing. The contemporary saturation of postfeminist girl power(ed) girlhood, in conjunction with the problematising of girlhood sexuality, produces a "contradictory landscape, strewn with binaries of agency/victimhood, sexuality/asexuality and influence/savviness" (Jackson \& Goddard, 2015, p. 243, see also Jackson \& Vares, 2011, 2012; Vares \& Jackson, 2011; Griffin, 2004, 2004b; Ringrose \& Renold, 2011; Ringrose, 2008, 2011). It is within this contradictory landscape that girls must negotiate (through processes of self-discipline and self-monitoring) contemporary girlhood, where being a sexually innocent 'good girl' within a discourse of childhood innocence requires a failure of postfeminist girl power(ed) girlhood subjectivity. This schizoid nature of girlhood subjectivities has created what Griffin (2004, 2004b) describes as an "impossible space" for girls and young women. Girls' engagement with the postfeminist girl market as either victims to sexualised media, or successful innocents has been a space in which the possibilities for girls' agency within the postfeminist market and media culture are contested and debated amongst feminist scholars.

\section{Complications of Girls' Sexual Agency and Empowerment}

Girls' consumption of sexually styled clothing (which mimics the clothing worn by female celebrities such as short mid-riff shirts) has been a site of contentious feminist debate concerning girls' agency and potential empowerment in their engagement with these products (Duits \& Van Zoonen, 2006, 2007; Gill, 2007, 2012, $2012 b$ ). As has been explored in the previous chapter, the mainstreaming of pornochic stylisation has been a key feature of feminist debates concerning the sexualisation of culture. The increasing representation of female hypersexuality is arguably most regularly seen through the representation of female pop star's bodies. Sexually provocative, body-exposing dress has become increasingly common in female pop stars' media, such as in recent representations of Nicki Minaj shaking her buttocks wearing a visible g-string (Minaj, 2014) and Miley Cyrus's continued public appearances and performances wearing only pasties to cover her nipples (Jimmy Kimmel Live, 2015). Alongside such representations, girls' clothing arguably reflects these hypersexual trends with an increase in adult-styled clothing such as G-strings 
(Willet, 2008) and short skirts marketed to girls (Gill, 2003; Levy, 2005). The adultification of young girls' clothing is a marketing strategy that, as Jackson and Vares highlight, is “designed to engage with girls' desires to appear older and more sophisticated and women's desires to appear younger and girly" (2011, p. 135; see also Cook \& Kaiser, 2004).

In a magazine study addressing girls' consumption practices, Brookes and Kelly (2009) observe that contemporary girls have been raised in a culturally conscious society where the tween market accentuates the importance of consumption. They explain that "tweenies understand the relationship between identity and consumer goods and are aware that a sense of self can be fashioned from the resources to be found in the marketplace" (p. 602). Popular culture's address to girls as sassy and independent consumers, therefore, provides an environment in which, particularly through the representation of female pop music artists within postfeminist media culture, girls are instructed on the importance (and the value) of looking 'hot' and 'sexy' (Brookes \& Kelly, 2009; Jackson \& Vares, 2011; Jackson, Vares \& Gill, 2013; Lamb \& Brown, 2007).

Feminist debate concerning girls' engagement with hypersexualised clothing has not been dissimilar to that concerning women's engagement with postfeminist hypersexual culture (explored in Chapter Two). While some feminist authors have argued that the increase in hypersexual clothing offers limited power to girls (for example Gill, 2003; McRobbie, 2007; Peterson, 2010), others such as Duits and Van Zoonen $(2006,2007)$ argue that girls' clothing consumption can be an empowering tool in their self-making. Arguing against the dichotimisation of girls' clothing consumption as either sexualised (bad) or innocent (good), Duits and Van Zoonen (2006) critique the discourses of decency and morality mobilised within feminist debates which position girls as sexualised by contemporary clothing trends. The authors highlight that within these feminist debates there is a problematic assumption that girls' appropriation of body exposing clothing styles is directly associated with girls' sexuality. In fact, as Duits and Van Zoonen assert, "girls themselves do not necessarily make the connection between nudity and sex. They may choose belly shirts to copy their mums or to imitate idols like Britney Spears, without wanting to adopt the sexual connotations" (2006, p. 107). In attempting to disrupt the dichotomous notion of girls as either sexualised or not by clothing, Duits and Van 
Zoonen (2006) describe clothing consumption as always potentially agentic and empowering for girls.

However, girls' potential for empowerment through engagement with postfeminist media culture remains contested within feminist scholarship. This contestation was played out in a recent succession of articles in a Sex Roles journal forum (2012) where Lamb and Peterson debated the topic drawing on previous publications (Peterson, 2010; Lamb, 2010, 201b). Contrary to Peterson's assertion that girls' empowerment (through engagement with hypersexual postfeminist media) is possible, Lamb questioned whether feeling empowered is the same as being empowered. In response to the 2012 Peterson and Lamb debate, Gill (2012) and Gavey (2012) described such abstract explorations of empowerment as ignoring differences in girls' exposure to media (highlighting for example that there is not one definitively 'good' or 'bad' postfeminist woman) and also as producing girls as either affected or engaged consumers outside of family, schooling and friendship influences. According to the authors, the term empowerment, as well as terms such as 'pornified' and 'sexualised', only work to homogenise individual experience. Gavey (2012) points out that, rather than attending to individualised experience, empowerment is an "umbrella term for referring to the active and positive (in at least some ways) dimensions of girls' choices, actions, and experiences" (p. 720). Gill (2012) similarly asserts that while different people are sexualised (or not) in different ways, the meanings attached to 'sexualisation' are also differing and 'the way that sexualisation is described (particularly) in the moral panic is as if it is outside of other processes of gendering, classing and racialisation as well as taking place within a profoundly ageist, disablist and heteronormative framework" (p. 742).

Overall, despite their different perspectives on girls' potential empowerment, what feminist authors appear to agree on is that the use of the term empowerment, and the search for whether it is absent, present or even possible in girls' engagement with sexualised culture, mobilises problematic, binary constructions of girls and sexuality. As Lamb (2010) asserts, the notion of girls as empowered or disempowered maps neatly onto binaries within the sexualisation of girls discourse which position girls and media as subject vs. object and girls' consumption as active vs. passive. Gavey (2012) takes the view that we should turn our attention away from individual acts which may or may not be 'empowered' and rather look at the discursive 
conditions which allow for the possibilities of girls' sexuality expression and embodiment to be explored. She explains that while the possibility for girls to become empowered through their engagement with sexualised culture, and their positioning within postfeminist discourses is an important subject for feminist consideration, the terms within these debates are too abstract to be of any help. Gill (2012) asserts that rather than providing any insight into girls' engagement with sexualised culture, these debates mirror the binaries that construct contemporary girlhood. In particular, Gill explains, this mirroring is seen through notions of a 'good' empowered sexuality and a 'bad' disempowered sexuality. Instead, critical feminist academics such as Gill and Gavey emphasise the need to move past dichotomous conceptualisations of girls' engagement with popular culture in order to explore the intricacy of girls' engagement outside of such black and white thinking.

In exploring ways in which girls' sexual subjectivity and engagement with hypersexual media can be conceptualised beyond traditional constructions, Tolman $(1994,2005,2012)$ emphasises the need to move past binaries such as those which construct girls sexuality as either negative or positive. In response to Lamb (2010 and the 2012 Lamb and Peterson debate), Tolman asserts the need to move past the "narrow view of pleasure as 'managing orgasms' and 'constituting good sex"” (2012, p. 750). Instead, Tolman calls for further discussion of sexual subjectivity in exploring girls' engagement with and development of sexuality. Tolman identifies sexual subjectivity as a girl's entitlement to "experience herself as a sexual being... sexual pleasure and sexual safety" (2012, p. 749). Tolman's conceptualisation of sexual subjectivity allows for an understanding of girls' engagement with postfeminist popular culture that moves away from traditional conceptualisations of female sexuality as either pleasurable or dangerous.

Given the emphasis on exploring girls' popular culture consumption practices outside of binaries, an increasing body of literature addresses girls' negotiation of hypersexual media and their own sexual subjectivity development as complex. This research has shown, for example, that while hypersexuality is celebrated in postfeminist media culture and girls' consumption of sexualised garments is positioned as on trend and idealised, in practice girls' clothing consumption is a key site for their regulation and they are more likely to be labelled as sluts than as sassy (Griffin, 2004, 2004b; Jackson \& Vares, 2011, 2012; Renold \& Ringrose, 2012, 2013; 
Ringrose, 2008, 2011). Throughout the literature girls' have been shown to use the 'sexy'/‘slutty', sexualised/innocent binaries to regulate their own behaviour and stylisation (Ringrose, 2008, 2011; Ringrose \& Renold, 2011, 2012b). Girls in Ringrose's (2008) study for example constructed revealing too much in their pictures on the social media tool Bebo as undesirable, and constituting girls as sluts through signalling sexual availability and desperation. At the same time, however, girls discussed the importance of successfully navigating the binary of presenting themselves as desirable (for example, one girl commented that she wouldn't post a Bebo picture where she wasn't wearing makeup) and appearing as sexually desiring and 'slutty', described by one girl's comment, "if you put pictures on like that people are just going to think 'oh look you're like a bit of a slut' or you're gagging to have sex, I had to make that choice because I thought I don't want people to see me like that" (Ringrose 2008, p. 106).

Girls' negotiation of the undesirable slutty subjectivity has also been seen in other critical feminist literature where girls' employment of the term slut has been found to function as a discursive tool employed to separate themselves from the undesirable sexual subjectivities of celebrities and of other girls (Jackson \& Vares, 2011, 2012; Renold \& Ringrose, 2008, 2011; Ringrose, 2008, 2011; Vares \& Jackson, 2011). In Renold and Ringrose's (2011) study, for example, two of the girls describe their recuperation of the label slut (following verbal bullying and being labelled a slut by others) as a term of endearment for each other with one of the girls explaining that "she's my whore and I'm her slut" as an example of their own transformation of the traditionally derogatory terms (p. 396).

Girls' complex negotiation of sexualised culture described throughout this chapter is theoretically conceptualised by Renold and Ringrose (2011) as a "schizoid pull". The term schizoid denotes how within contemporary culture 'otherness' is regularly re-appropriated for commercial means, whereby notions such as gender and sexual diversity can be celebrated (eg., in the form of female desire) without troubling traditional norms and discriminatory practices such as homophobia, sexism and racism (Braidotti, 2006). Drawing on Braidotti's understanding, Renold and Ringrose (2011) provide a framework within which to understand girls' engagements with sexualised media as potentially always both positive (empowering) and negative (sexist or disempowering). Renold and Ringrose appropriate the schizoid double pull to theorise an understanding of girls' engagement with sexualised culture which steps 
outside of binaries which position young girls as either sexualised and affected or innocent and media savvy. Using this framework, Renold and Ringrose provide space to move past previous feminist disagreements about girls and empowerment and instead attend to the ways in which girls' media engagements may offer spaces for empowerment, while at the same time produce potentially dangerous or negative effects and reproductions. For example, this approach emphasises the complex (but necessary) negotiation that girls must engage in within contemporary society wherein their bodies are simultaneously inscribed as a sexy (through a commercialised infantilising gaze) and also as naturally innocent.

Using the Deleuzian conceptualisation of subjectivity which approaches it as multiple, constantly shifting, and altered by the bodies, environments, regulations and meanings that it comes in contact with, Renold and Ringrose (2011) complicate the victim/assertive, innocence/hypersexual binaries that construct girlhood through a micro analysis which understands girls' engagement with sexualised culture as 'becomings'. According to Renold and Ringrose, exploring girls' engagement with sexualised culture through the bodily notion of becoming "allow[s] us to connect up girls' feelings of pleasure and power in the becoming-sexual-woman with their experiences of virtual and embodied networks colonized with real and symbolic (hetero)sexualised violence in their everyday lives" (2011, p. 402). This means that through this conceptualisation of the schizoid double pull we can attend to the ways that girls might experience and navigate these contradictions and deal with the objectifying and victimising ways that girls' bodies are represented.

Drawing on the feminist debates and theorisation concerning girls' potential for agency within contemporary popular culture, this thesis understands female popular music media as a significant cultural resource for girls. It recognises the need to move beyond sexualisation and empowerment binaries in theorising girls' engagement with female pop music media, to one that understands girls as variably influenced and agentic in their media consumption and self-making. Female pop music's address to girls (through the postfeminist notions of commodification and sexualisation of the female body) might be understood as informing or influencing girls' bodily practices through the emphasis on sexual stylisation and behaviours it provides them. At the same time, this music media can be understood as a site for girls' negotiation of postfeminist 'sexy' femininity that potentially enables them to exert some agency over their own sexuality. The next section takes up girls' 
engagement with hypersexual pop music media as consumers who actively appropriate, negotiate and reject contemporary postfeminist constructions of femininity.

\section{Girls and Pop Music: A place for Sexual Agency?}

Consistent with the feminist literature described previously in this chapter, contemporary pop music celebrity is approached in this research as a pervasive and complex cultural resource with which girls make meaning of contemporary discourses of femininity for self and others. Although female popular music media is central to hegemonic discourses which position girls as always in danger of sexualisation from popular culture, only a small body of critical feminist literature has examined girls' engagement with popular music celebrities. Central to discussions of girls' engagement with this media has been theorisation of female pop music's prolific employment of postfeminist commodified girl power. The Spice Girls, an all-female pop music group which gained worldwide fame in the 1990's, have been widely discussed as a prominent vehicle for commodified girl power (Driscoll, 1999; Taft, 2004; Whelhelan, 2000) in the 1990's. The group's employment of the girl power discourse has been problematised and discussed within feminist literature, particularly concerning its usefulness for girls.

Fritzsche's (2004) analysis of Spice Girls fans asserts that interpretations of the group's influence over girls may at times be overstated. Rather than conceptualising the Spice Girls as uniformly influential, Fritzsche describes girls' individual subjectivity and meaning making as central to their potential influence by the group's notions of girl power (such as whether this influence is positive or negative for the girls). Driscoll (1999) also moves past questioning whether the group is a helpful force for girls or not and instead discusses the groups' use of commodified girl power as a form of feminism. Providing a comparison between the Spice Girls and politically charged movements such as Riot Grrrls, Driscoll discusses the ways in which "Spice Girls fandom might demand less dramatic changes to girls' positions within established political and social systems than does participation in the riots and resistances of some other forms of girl culture" (1999, p. 188). While debates concerning the Spice Girls' usefulness for girls are outside of the scope of this thesis, the Spice Girls arguably commandeered the commodified girl-powered pop music 
which remains a central theme within contemporary female-performed popular music today (Jackson \& Vares, 2011; Jackson \& Goddard, 2015).

While girls' engagement with pop music media products such as clothing, toys and the consumption of images and music videos has been central to the conceptualisation of girls as passive and victimised consumers, girls' play to pop music has for the most part been ignored or overlooked in research as meaningless play (Kearney, 2013). Furthermore, there is even less literature that has investigated girls' relationships with popular music that involves them as consumers and as producers of music media. Although feminist scholarship has analysed girls' engagement with sexualised celebrity, much of this research has focused on the negative effects. For example, the view that girls are being influenced by their sexualised celebrity idols and emulate their porno chic practices and styles is particularly strong (Sweeney, 2008). Audience studies are therefore critical to interrogating how and whether girls are relating to sexualised celebrities in such ways.

The current research locates itself within a small body of critical feminist psychology which draws on audience studies in its exploration of girls' popular music media viewing practices and the ways in which they understand and negotiate the hypersexual postfeminist messages in this media. This research and its feminist intersection which positions girls as knowledgeable participants departs from the sexualisation and protectionist narratives described in the earlier discussion of sexualisation literature. Within critical feminist literature, girls have been found to be anything but passive in their media reception. Rather, girls have been found to critique celebrities on their representations, often discussing hypersexuality as inappropriate and grounds for no longer engaging with the celebrity (Jackson \& Vares, 2011, 2011b, 2012, 2015; Zaslow, 2009). While hypersexuality has been identified as undesirable in the case of some celebrities (such as Jackson \& Vares's discussion of Miley Cyrus), Zaslow (2009) found that girls in her study identified celebrities being comfortable and confident with their sexuality as an important aspect of girls' engagement with that celebrity. Celebrities' comfort with their sexuality was understood by Zaslow's participants as a sign of female strength where, as one of participants comments, "to be aware of your sexuality and be comfortable with it, you know, like 'This is my body, this is who I am.' I think it's good, and it's strong” (p. 65, Jenna). 
Female pop music's saturation with postfeminist and girl power messages that emphasise sexuality as empowering, can be understood as a site of conflicted meaning-making for girls'. Lowe (2003) identified this conflict in girls' discussions of pop music celebrity Britney Spears. Lowe explains that the girls were able to engage with (and enjoy) constructions of girl-power notions of ambition and power in Spears' media, and even celebrate her postfeminist commercialisation of sexuality, with one of the participants asserting that (in reference to Spears' hetero-desirable body), "if a guy thinks you're sexy, you can get him to do anything” (p. 135, Kara). At the same time, the girls in Lowe's study condemned Spears for her sexualised image on a cover of Rolling Stone magazine (which featured Spears in a bed wearing a push up bra) and on one of Spears' album cover's (Hit Me Baby One More Time) where she is seen straddling a chair, wearing blue jeans, a white crop top (described by Lowe, 2003, p. 136). Although the girls initially used terms such as "slut" and "whore" to describe Spears in these media, Lowe (2003) suggests that the girls were working through their own conflict and highlights that they were able to intelligently "separate their disapproval from their enjoyment of those texts that confuse and anger them" (p. 140).

In addition to identifying sexuality as important in pop music media, critical feminist literature has discussed girls' critique of celebrity representations based on their perceived authenticity, wherein celebrities who are perceived as inauthentic are less likeable than those understood by girls as authentic (Allen \& Mendick, 2013, 2013b; Kennedy, 2014). Girls' judgement of celebrity authenticity highlights their capacity to understand celebrity-commodity (Turner, 2004), which challenges assertions within sexualisation literature that, for example, "children believe what they see" (see p. 51-52 for previous discussion of Levin \& Kilbourne, 2008). Girls' evaluation of celebrities and decisions about whether or not to engage with a particular celebrity highlights their agency and critical ability as media consumers. Aligning with the representation of girls as capable and agentic media consumers, Duits \& Van Romondt (2009) describe the girls in their study as reflexive, critical and agentic in their meaning making and relationship with pop culture. The authors assert that rather than a passive internalisation of sexualised content, girls' media consumption is a complex process within which "girls simultaneously overstate their agency and are aware of (certain) structural constraints" (2009, p. 55). Duits \& Van Romondt (2009) argue against sexualisation narratives and instead assert that 
celebrity culture should be understood as a site which offers possibilities of self and ways of being that girls are able to take up or avoid.

An understanding of popular music as a site of possibility rather than uniform negative influence over girls is also expressed by Jackson and Vares $(2011,2015 b)$ and Jackson, Vares and Gill (2013) who highlight girls' media practices as central to their pop music navigation. Jackson and Vares $(2011,2015 b)$ identify girls' media engagement as so widely monitored and problematised that girls (aware of their own positioning as passive consumers) engage in viewing and discursive practices in an attempt to avoid being positioned as problematic and sexualised. One of the ways in which girls have been shown to regulate their own viewing practises is through the employment of positive/negative binaries in describing celebrities. Jackson and Vares explain that "through critique and expressions of disgust, participants not only positioned themselves in opposition to 'bad girl' or sexual displays but also any association with 'slutty' celebrities" (2015b, p. 564). The authors assert that girls' use of these binaries serve to distance them from the possibility of being mis-recognised as engaging with sexualised celebrity and therefore as inhabiting the undesirable sexualised girl subjectivity. Girls' regulation of their own (and others') viewing practises is understood by Jackson and Vares to be the result of the popularisation of the sexualisation discourses which, according to the authors, limit girls' relations with celebrities as,

the pressure to stop 'liking' and watching Cyrus (a 'slutty' celebrity) means that affective and other dimensions of relationships are ignored and negated. This creates tensions and dilemmas for those girls who either choose to maintain, or are unable to let go of, their relationship with a celebrity who is categorised as 'bad'( Jackson \& Vares, 2015b, p. 564).

Further exploring girls' consumptive media practises, Baker points out that girls' play to music has historically been recorded as 'girly' and meaningless behaviour. She conceptualises mimesis as central to the conceptualisation of girls' play to music as complex and nuanced. Taussig (1993) describes mimesis as the "nature that culture uses to create second nature, the faculty to copy, imitate, make models, explore difference, yield into and become other" (p. xiii). Drawing on Taussig, Baker conceptualises girls' mimesis of hypersexual femininity in pop music as the space from which the notion of the "real (flexible and changing) me" emerges for pre-teen girls. Baker's (2001, p. 368; see also Baker, 2004) conceptualisation of 
play as serious and an important tool in girls' subjectivity development challenges the notion of girls' engagement with popular music as meaningless and silly. She argues that girls' play to music can be understood as a tool for the development of their cultural identities. Aligning with this conceptualisation, Renold and Ringrose's (2011) study of girls' negotiation of hypersexualised culture highlights the importance of music and dance for young girls in the trying on and negotiation of adult sexualised subjectivities. The authors describe a case study in which a young girl, Casey, filmed herself and her friends performing sexualised dancing to a hip hop song while drinking alcohol and smoking. Rather than understanding the performance as representative of sexualisation, the authors highlight aspects of the recording (specifically Casey and her female friend dancing together and rejecting the boys' attempts to dance with them) as evidencing the girls' negotiation of the hip hop woman subjectivity. In this instance the girls' rejection of the boys' advances is conceptualised by the authors as the girls' appropriation of the agentic, independent pop star subjectivity and a resistance to the sexualised female prop subjectivity that is often seen in hip hop music videos. Notably, Renold and Ringrose's analysis highlights the importance of understanding girls' play to music as a complex and contradictory space in which resistance and mimesis can be jointly produced.

\section{Chapter Summary}

This chapter has presented an exploration of the sexualisation of girls discourse. It has unpacked a large body of texts, focussing on government funded, academinc and popular psychology literature, which posit girls as inherently and uniformly sexualised through their exposure to contemporary hypersexual culture. Though contemporary concern regarding the sexualisation of girls is repeatedly constructed as a unique phenomenon and an outcome of the sexualisation of contemporary culture (discussed in Chapter Two), the current chapter has demonstrated this discourse as steeped in an historical problematisation of girls and sexuality. Given this historical context, the construction of girls as passive media consumers has been approached in this chapter as underpinned by the childhood innocence discourse.

Through its emphasis on idealised childhood as defined by sexual innocence and passivity, the contemporary construction of the sexualisation of girls discourse has been approached in the chapter as hinged upon two dichotomous and 
problematising girlhood subjectivities. These subjectivities, the 'at-risk' sexualised girl and the idealised 'can-do' girl are demonstrated in the chapter as creating an 'impossible space' for girls to negotiate in their engagement with contemporary pop culture (Griffin, 2004b).

With this binary in mind, the current chapter discussed the importance of moving past binary understandings of girls as either passive sexualised media victims or agentic unaffected consumers. Following a small body of critical girlhood literature, the chapter explored pop music media as a significant resource for girls. Female pop music has been conceptualised as providing an informative and influential site for girls' negotiation and meaning making of postfeminist femininity while at the same time, through their engagement, offering possibilities for girls to exert agency over their own sexual subjectivity development and self-positioning.

Following this chapter's identification of the importance of critical feminist approaches to girls' media consumption, the research chapters which follow engage with the complexities of girls' engagement with and meaning making of female pop music media in a time in which girlhood is characterised by disadvantageous constructions of girls as passive and victimised media consumers. The methodology chapter which follows will introduce and discuss the key theoretical perspectives which underpin this research, both in its feminist conception and aims and also in the analytical approaches taken in the analysis of a focus group study and a music video study (presented in Chapters Five and Seven). The analysis chapters of this thesis have the broad feminist goal of providing research that not only benefits girls (through the critical contribution to knowledge about their media practices) but also considers them as active and knowledgeable participants in the research. The two studies (presented in Chapters Four and Six) are informed by feminist poststructuralist theory, and importantly, by the thesis's recognition of female pop music as a complex site in which girls' engagement is always potentially passive and agentic, empowering and problematic. In addition, female pop music media will be discussed as a multimeaning site within which girls' engagement is conceptualised as a potential site for their performative trying on of postfeminist 'sexy' femininity. Departing from sexualisation narratives and mainstream psychological perspectives which construct girls as uniformly effected by popular media, the following methodology chapter explores conceptualisation of girls' subjectivity as fluid and dynamic and as 
influenced by such media while simultaneously shifted and shaped by the girls selfpositioning and meaning making. 


\section{Chapter Four:}

\section{Methodology}

This chapter discusses the critical and poststructuralist approaches that guide the research. It details the feminist poststructuralist approach (Burr, 2003; Gavey, 1989; Lazar, 2007; Weedon, 1997) which underpins the conceptual framework of this thesis. Beginning with an overview of the thesis's broad critical approach, the chapter then discusses the central concepts of discourse, power, knowledge and subjectivity within feminist poststructuralist theory. Positioned with critical psychology, this thesis draws on interdisciplinary perspectives. In exploring these perspectives, the current chapter also addresses conceptualisations of the audience, feminist media studies, and the celebrity. To conclude, the chapter explores the ethical and reflexive considerations of this research project paying particular attention to its feminist ethics of practice and care and the importance of transparent researcher reflexivity.

\section{Critical Approaches}

This thesis adopts a critical approach in its investigation into psychological understandings of contemporary girlhood. This approach is understood as stemming from ongoing debates between mainstream humanist psychology scholars and a small group of radical psychology scholars who began to assert the importance of phenomenology and to debate the value of laboratory research in psychology (Parker, 1999). This disagreement continues within psychology and a critical approach has had radical effects on the psychological discipline (Parker, 1998, 1999). However, the critical movement must be understood as influencing disciplines both within and outside of psychology for, as Parker (1999) explains, "there is nothing particularly special about academic psychology that makes it a more worthwhile target of critical work than other disciplines" (para, 2). The critical approach should therefore be understood as part of a broader movement beginning in psychology and stemming more broadly into the human sciences (Gergen, 1985; Tuffin, 2004; Willig, 2013).

In its critical approach to the deconstruction and questioning of psychological knowledge and assumptions, a critical approach does not subscribe to one particular epistemology and instead employs a wide array of perspectives both within the discipline of psychology and across a myriad of other academic approaches (Parker, 1999). Given this broad scope and diversity of epistemological approaches, a critical 
approach is necessarily complex. Parker (1999) sees a critical approach as defined and directed by the following three broad aims:

1. The systematic examination of how some varieties of psychological action and experience are privileged over others, how dominant accounts of 'psychology' operate ideologically and in the service of power.

2. The study of the ways in which all varieties of psychology are culturally and historically constructed, and how alternative varieties of psychology may confirm or resist ideological assumptions in mainstream models.

3. The study of forms of surveillance and self-regulation in everyday life and the ways in which psychological culture operates beyond the boundaries of academic and professional practice.

(Parker, 1999, para, 32)

A critical approach therefore examines and questions mainstream psychology's scientific methods and assumptions. In particular this approach examines the taken-for-granted 'knowledge' asserted in positivist scientific methods (Burr, 2003; Gergen, 1985). A critical approach does not reject the scientific method, rather, it rejects the methods emphasis on a singular truth and instead conceptualises science as one of many 'truths'. As such, the critical approach to psychology employed in the thesis allows for an examination of the construction of knowledge and 'truth' about girlhood and the sexualisation of culture. This perspective enables the thesis to pay particular attention to the ways in which these bodies of knowledge (such as the assertion that girls are sexualised by contemporary media) shape the way that girls are positioned and understood within contemporary society more broadly (Weedon, 1997). A critical approach also rejects the realist notion that dominates positivist research frameworks: the assumption of a predictable, stable and internally dwelling human mind with a set of observable traits and characteristics that can be accessed and investigated through objective testing (Burr, 2003; Gergen, 1985; Parker, 1999; Weedon, 1997). Instead, a critical approach positions the individual as produced and constrained by their socio-cultural world and positions each individual as a unique culmination of a multiplicity of intricate, dynamic and multi-meaning 
social and cultural environments which shape their thoughts and behaviours (Burr, 2003; Weedon, 1997).

A critical approach is central to this thesis, particularly as this approach enables the research to examine and deconstruct contemporary girlhood and girlhood sexuality discourses. This approach can be seen in the previous chapters through the critiques of taken-for-granted understandings of girlhood which dominate psychological and mainstream media understandings of girls as potential victims of the sexualisation of culture. Additionally, the critical approach is reflected through an analytical approach which seeks to bring into question and trouble hegemonic girlhood discourses, both as they are constructed and circulated in academic and media texts, and also as they are negotiated, struggled over and lived out in girls' own experience.

\section{Poststructuralist Theories}

Poststructuralist theories share with critical approaches a rejection of the positivist assertion that universal and stable 'truths' are available and observable through objective scientific measures (Burr, 2003; Edley, 2001, Wetherall, 1999; Willig, 2001). Instead, within poststructuralist theory, knowledge is argued to be socially constructed and 'truth' is understood as constructed and importantly constrained through the outcomes and possibilities produced in the shared use of language (Weedon, 1997).

In approaching language, poststructuralist theorists reject the humanist assertion of predetermined social meanings and knowledge as expressed and reported through language (Burr, 2003; Weedon, 1997; Willig, 2001). Positivist approaches assume that there is an uncomplicated relationship between the world we inhabit and our perceptions and experiences within that world (Edley, 2001; Willig, 2001). In contrast to this assumption, poststructuralist theorists describe language as a productive tool in meaning making and the construction of social knowledge that is deeply entrenched within relations of power (Edley, 2001; Gergen, 1985, Parker, 2005; Potter \& Wetherell, 1987). Following this approach, language is conceptualised in this thesis as productive (rather than descriptive) of an individual's social world and directly shapes the ways in which we understand ourselves (Burr, 2003; Edley, 2001). Language and discourse are understood as closely tied to power (in that dominant knowledge can often be directly related to power structures within society) 
and as the very means with which our worlds and our understandings of the world are created and experienced (Gergen, 1985; Potter \& Wetherall, 1987; Weedon, 1997). Drawing on a poststructuralist perspective enables this investigation to deconstruct and explore the 'naturalness' of dominant knowledge about childhood sexuality and media effects on young audiences. In addition, the intersection of critical psychology and a poststructuralist approach makes it possible to question, and be critical of, dominant psychological knowledge which positions girls as a passive and victimised audience. This approach differs significantly from a positivist perspective which not only considers scientific truth as revealing an observable fact, but as Willig explains, this position suggests "that phenomena directly determine our perception of them and that there is, therefore, a direct correspondence between things and their representation" (Willig, 2001, p. 3). Moving away from empirical approaches which take a dualist approach to the individual and the environment/context within which they are situated, critical approaches have nonetheless struggled over the individual/social dualism (Weeden, 1997; Burr, 2003). While conceptualisations such as Osterkamp's (1999) Marxist-informed approach aim to attend to both sides of the dualism, Wetherall (1999) asserts that a poststructuralist approach, seen particularly in the writings of Foucault which this thesis draws on, moves beyond the binaries of the individual versus the social to explore instead "modes or practices of subjectification, the rituals and routines which produce human natures in the plural and our very sense of "individuality"' (p. 402).

Discourse. Following Parker's (1992) tentative description, discourses are defined within this research as a "system of statements which constructs an object" (p. 5). Discourses are broad meaning-producing concepts which are historically and culturally specific (Parker, 1992; Weedon, 1997). Constructed within shared meaning and language use, discourses both collaborate and compete with each other, offering subject positions or ways of being and understanding the world for individuals within specific socio-historical contexts (Burr, 1993; Weedon, 1997; Willig, 2001). Foucault describes discourses as shared cultural meanings and knowledge which are constructed through the operation of social power (1978/1980, 1977/1995). Discourses are understood as the product of human interaction through language and shared meaning. Given their construction through human interaction, discourses are 
not approached as universal or absolute, but rather, they as bound in cultural and historical specificity and their relationship to other discourses (Weedon, 1997).

While language is understood as central to knowledge production, Foucault highlights discourse as producing and making available the ways that we think and feel about ourselves and our relationship with the world around us. Foucault underlies the importance of historical and social context and institutional power in the construction of discourse. He asserts that the strength of a discourse at any given time is dependent on its relationship to the institutional power in that specific setting (1972, 1978/1980, 1977/1995). The construction of discourses as dominant and 'taken for granted' is central to their dominance within society (Burr, 2003; Foucault, 1977/1995; Weedon, 1997). Constructing hegemonic discourses as logical and reasonable, serves to conceal the effects of dominant bodies of knowledge allowing them to remain unchallenged and therefore unchanged. Weedon (1997) describes the employment of the notion of naturalness in the maintenance of dominant knowledge. She explains that "the appeal to the 'natural' is one of the most powerful aspects of common-sense thinking, but it is a way of understanding social relations which denies history and the possibility of change for the future" (p. 4, italics in original).

Poststructuralist theory rejects positivist psychology's dominant framework of objectivity and validity, and the overarching search for the ultimate 'truth'. Instead objectivity is seen as an impossible feat and the validity or 'truth' of a theory is understood to be not only irrelevant but also a feature and product of the discourses power (Gavey, 1989; Weedon, 1997; Willig, 2001). Knowledge from this perspective, is understood as socially constructed and inextricably bound to the cultural and social conditions from which it is created. Importantly, poststructuralism highlights human understanding and experience of the world as existing only in its cultural and historical context (Gavey, 1989; Gergen, 1987; Willig, 2001). Attending to the historical, cultural and social construction of knowledge enables poststructuralist approaches to deconstruct dominant discourses such as the sexualisation of girls by approaching knowledge as not only plural but as contextually dependent.

Language, knowledge and power. Within poststructuralist theory language is understood not as a reflection of reality but as the very tool that constructs an individuals' reality (Gavey, 1989; Weedon, 1997; Willig, 2001). Language, then, is approached by poststructuralist theorists as an inherently political tool in both the 
construction of the self and the construction of the world around us (Weedon, 1997). Within poststructuralist theory, language and meaning are understood as intricately related (Potter \& Wetherall, 1987; Weedon, 1997). Weedon (1997), for example, describes language as the medium through which "possible forms of social organisation and their likely social and political consequences are defined and contested" (p. 21). Discourse is therefore understood as constructed by and through the process of language. Within this understanding knowledge is not conceptualised as unitary or as neutral (Gavey, 1989). Rather language and shared meaning making are conceptualised as the site of the constant discursive struggle for definition, as 'signs' or dominant bodies of knowledge intertwine, challenge and compete with each other (Foucault, 1977/1995, 1978/1990; Saussure, 1998).

The strength of a discourse is therefore entirely dependent on its relation to the institutional power structures within its social context (Foucault, 1977/1995, 1978/1990). Poststructuralism acknowledges institutional social power as fundamental to the construction of knowledge and also as central to its investigative deconstruction which explores how such power structures and discursive dominance might privilege certain values within a society while marginalising other views. Foucault (1977/1995) put forward the concept of pouvoir savoir, or the knowledge power nexus, an understanding of power which he conceptualises as inextricably connected to subjectivity and discourse. The French translation of the term pouvoir savoir has been described by Spivak (Danius, Jonsson, \& Spivak, 1993, cited in Gavey, 2005, p. 86) as referencing power as a productive and determinative force in the construction of social meaning. Additionally, the conception of the knowledgepower-nexus references individuals and their understanding of themselves as produced within and bound by the available knowledge. What this means is that individuals are tied to discourse wherein actions, ways of being, and understandings of ourselves outside of discourses is not possible (and does not exist) (Gavey, 2005).

In Foucauldian discourse theory, power is seen as a constructive social force which regulates human behaviour through disciplinary techniques. In Discipline and Punish, for example, Foucault (1977/1995) examines how social power is exercised through disciplinary power techniques such as the use of surveillance and normalization. Foucault's conceptualisation of power examines it as a productive force for change and meaning making in society (1977/1995). Normalisation, surveillance and rewards are techniques that Foucault highlights are used to wield 
influence on individuals' self-understanding and practices in contemporary society. Foucault describes the invisibility of the exercise of power through the techniques of normalisation and subtle coercion which work to pressure people to conform to the 'norm' (Foucault, 1977/1978). Identifying the production of 'knowledge' as a site of struggle, rather than as a representation of a singular truth, Foucault illuminates the ways in which alternative (to dominant) productions of knowledge can be conceptualised as resistances to the exercise of social power (Foucault, 1977/1995, 1978/1980).

Subjectivity. Following a poststructuralist approach, the positivist assumption of the fixed, rational individual, described through a stable set of (universal) 'traits' which reflect an inherent and enduring internal 'self' is rejected (Henriques, Hollway, Urwin, Venn, \& Walkerdine, 1984; Wetherall, 1987; Weedon, 1997). The positivist notion of an essential and knowable core of the individual is rejected within poststructuralist theory and, importantly, this dominant understanding of the individual is described as a product of humanist knowledge (Alcoff, 1988). Poststructuralism's central assertion is that there is "no essential core 'natural' to us" (Alcoff, 1988, p. 145). In contrast to the positivist notion of identity, subjectivity does not comprise universal traits. Instead, subjectivity is a fluid and dynamic concept in which the self is actively constructed and performed by the individual, whilst also being shaped and dependent upon the individual's socio-historical surroundings (Gavey, 2005). Henriques et al. explain that the notion of subjectivity is not a 'stand in' for the positivist notion of identity, with its emphasis on traits and an externally dominated world view. Instead, subjectivity should be understood as referring to the dynamic and inherently unstable emotions and self-awareness of the individual, "always positioned in relation to discourses and practices produced by these - the condition of being subject" (1984, p. 3).

Poststructuralist theory aims to "decentre the subject" (Gavey, 1989, p. 465) by rejecting the positivist notion of essential meaning deriving and originating from the subject. Subjectivity is therefore conceptualised as the shifting and dynamic culmination of an individual's interior thoughts and emotions and the "possibilities of self' or ways of being that are available within their specific cultural context (Gavey, 1989; Weedon, 1997; Wetherall, 1987). Composed of multiple, dynamic and even contradictory subject positions through daily interaction with discourses, the taking up 
of a subject position directly influences and affects an individual's understanding of themselves and their relationship with the world around them (Gavey, 1989). This conceptualisation of subjectivity rejects the notion of measurable and universal traits and characteristics which are stable across time, and make up an individual personality. Instead, subjectivity is conceptualised as inherently unstable and dynamic, always bound by the positions made available in the individual's discursive world (Davies \& Harré, 1990; Gavey, 1989). Gavey (2002) refers to subjectivity as a fluid and complex process, one in which subjects are both determining and agentic in their taking up of subject positions, while simultaneously constrained and limited by the uptake of these subject positions and those that are made available to them. This assertion follows Foucault's later works in which he uses the notion of 'technologies of the self' to refer to the individual's agency and ability to negotiate the discourses available to them (while still obviously constrained by the availability of discourses to choose from) (see Foucault, 1988). In this way, an individual's subjectivity and the ways in which they do and can understand themselves, are always culturally and historically bound, making subjectivity an involuntary process (Foucault, 1988, 1978/1980, 1977/1995; Allen \& Mendick, 2013). Here, the subject is continually positioned, re-positioned or excluded within a shifting and dynamic context of discourses and subsequent possibilities of self.

In this research subjectivity calls attention not only to the multiplicity of meanings created around the current moral panic of the sexualisation of young girls, but also the construction of the often contradictory discourses and the limited subjectivities that young girls are afforded within these discourses. Allen and Mendick (2013) describe identity work or subjectivity as "the ongoing process through which people come to understand 'who am I' and their place in the world" (p. 80). Following Allen and Mendick, this research recognises that the taking up of a subject position such as the 'sexualised girl' or the 'passive victim' directly influences and affects girls' views on the world (Allen \& Mendick, 2013, 2013b; Renold \& Ringrose, 2011). In addition, the girls in this research are understood as discursively bound by the subjectivities that are made available to them, but also as agentic and able to negotiate and attempt to resist undesirable subjectivities through their own practices and discursive work. The girls' discussions of and performance to music (as discussed in the following analysis chapters) is conceptualised as their discursive 
negotiation of the available girlhood discourses within which they attempt to position themselves and others.

\section{Feminist Approaches}

The poststructuralist theory employed in this thesis intersects with a feminist approach through its critical deconstruction of contemporary girlhood discourses. Feminist approaches, however, are not singular. Different approaches to challenging and deconstructing dominant patriarchal discourses within society (such as the assertions of women and men as 'fundamentally' different) have resulted in a range of feminist positions and approaches (Weedon, 1997). Weedon describes these approaches as spanning across three broad feminist politics: liberal, separatist and socialist. The central dividing feature of these politics is their approach to challenging and changing the current patriarchal social system. While liberal feminism aims to achieve equality without making any radical political or social changes, separatist feminists believe that a complete social overhaul is necessary in order to ensure a change in which "women will not be subordinated to men and femininity and femaleness will not be debased and devalued" (Weedon, 1997, p. 4). Finally, socialist feminist politics approach gender as a discourse which is socially and historically constructed. Socialist feminists view patriarchy as a social system that is so intricately tied to racism and classist oppressions that it can only be changed with a complete social overhaul (Weedon, 1997). While these three positions have very different approaches to patriarchal discourse, they all find common ground in their emphasis on this discourse as impacting negatively on women and as needing to be challenged and changed in order to improve women's lives and to emancipate them from oppression. Feminist research approaches can therefore be broadly understood through Lather's (1988) assertion that feminist research "is to put the social construction of gender at the centre of one's inquiry" (p. 571).

Feminist approaches to research are therefore directly linked to the goals of the feminist movement which Weedon (1997) describes as "a politics directed at changing existing power relations between men and women in society" (p. 1). This approach to research is therefore deeply rooted in the political feminist movement within which women's participation in (or exclusion from) society, including gender roles and women's experience, is questioned and challenged (Weedon, 1997). Feminist research follows these broad feminist aims by drawing attention to and 
deconstructing a social system of knowledge which not only privileges the male experience, but also has a history of ignoring and/or rejecting the female experience (McRobbie, 2000; Weedon, 1997). In approaching these aims, feminist research involves a critical exploration of how knowledge is produced, and the ways in which access to knowledge is privileged (to males) both historically and within contemporary society. To explore this Weedon asserts that feminist research must "tackle the fundamental questions of how and where knowledge is produced, and by whom, and of what counts as knowledge" (1997, p. 7).

This feminist inquiry into the production of knowledge centres primarily on the critique of positivist mainstream psychological research and assumptions (Gavey, 1989). Gavey contends that positivist psychology "can be understood to fall within the liberal humanist tradition, which is so pervasive in contemporary western society that it is rarely recognized and rarely questioned" $(1989$, p. 461 , italics in the original). In approaching this large body of hegemonic knowledge, then, feminist psychology is critical of many of the fundamental concepts of positivist psychology. Highlighted in feminist critiques are issues such as research validity (particularly of laboratory settings), universality, and researcher/participants power relations, the impossibility of research objectivity and hegemonic positioning of scientific knowledge within contemporary Western society (Gavey, 1989; Weedon, 1997; Wilkinson, 1991; Willig, 2001). In addressing these critiques, feminist research centralises participant experience in research. Gavey (1989) explains that "feminist emphasis on women's experience is important as a political strategy that has given voice to women's oppression by, and resistance to, patriarchal prescriptions" (p. 461). By giving voice to and valuing women's experience, a feminist psychology approach aims to critique mainstream psychological bodies of knowledge which have historically devalued and excluded women's experience from its research (Wilkinson, 1991).

Feminist research is further understood as driven by the basic agreement of women's oppression (Gavey, 1989; McRobbie, 2000; Weedon, 1997; Wilkinson, 1991). The understanding of females as disadvantaged is generally accompanied by a need to uncover and expose what it is that contributes to and maintains this oppression, with the intention of discovering ways in which this might (hypothetically or immediately) be changed or removed for the benefit of females (Gavey, 1989; Weedon, 1997). This thesis rejects positivist psychological conceptualisations and 
theories of girlhood which use empirical research to produce knowledge(s) which repeatedly produce female sexuality (or burgeoning sexuality in girls) as problematic. Psychological understandings of girls as negatively sexualised and affected (e.g., Bailey, 2011; Pipher, 2005; Rush \& La Nauze, 2006, 2006b) are therefore understood and approached in this research as underpinned by problematic, historically and culturally specific knowledge about female sexuality and the positioning of children within society (as discussed in Chapter Two). Importantly, rather than being understood as a universal and observable 'truth' (as it is within sexualisation literature), the notion of girls as inherently at risk of sexualised culture is conceptualised within this thesis as a serious disadvantage for girls in understanding themselves. Gender is central to this investigation both in its conceptualisation of contemporary girlhood theories as profoundly influenced by problematic understandings of gender, and through the understanding of "gender as a basic organising principle which profoundly shapes/mediates the concrete conditions of our lives" (Lather, 1988, p. 571).

Given its focus on the investigation of contemporary girlhood and girls' experience of girlhood, the research employs a critical feminist approach. This feminist approach aims to undermine what Livingstone (2010) describes as the "masculine paradigm" of participant manipulation in favour of methods which focus on "treating them [participants] with respect, checking findings with them to test the credibility of the findings, and designing research so as to be beneficial to interviewees as well as to the (still generally more powerful) interviewer" (p. 2). Following this approach, girls are positioned as active participants in the research process and the research is underpinned by an emphasis on respecting and accurately representing girls' experiences (Livingstone, 2010).

\section{Feminist Poststructuralism}

This thesis employs both poststructuralist and feminist approaches in its analysis of girls' engagement with popular music in the following analytical chapters. The feminist appropriation of poststructuralism has contributed a rich history of research and theory regarding changing ideas of femininity, conceptualisations of female sexuality, and the influence of mass media and investigations of power distribution (McNay, 1992). The works of Foucault are described by McNay as usefully appropriated by feminist theory for his attendance to the plurality of 
knowledge and the productive conceptualisation of power. Foucault's analyses of power and discourse in The History of Sexuality (1978/1990) and Discipline and Punish (1977/1995) provide a theory of the construction of the social body and feminist researchers used this work to engage with and critique women's oppression (McNay, 1992).While Foucault's assertion of sexuality as socially constructed and determined by specific power relations has been usefully incorporated into feminist critiques of the female experience and domination of female sexuality, Foucault's theory has also been understood as problematic to this feminist investigation. Foucault's theory has been critiqued by feminists for not attending to the role that gender plays in the discipline of the body and particularly in the discrimination of women and their historical positioning as the biological 'other' and inherently 'less than' men (McNay, 1992; Weedon, 1997).

A feminist appropriation of poststructuralist theory departs with the problematic notions of 'gender blindness' in Foucault's work and instead addresses questions of how social power is exercised through social discipline and exclusionary tactics and how these problematic gendered discourses can be resisted and transformed. The appropriation of poststructuralism within feminist research has been particularly useful in the deconstruction of gendered 'knowledge' because, as Gavey observes,

dominant conceptions of reality and truth in patriarchal Western society have tended to be male constructions which reflect and perpetuate male power interests. Feminists' explorations of our own realties, as women, have tended to produce different truths, thus casting suspicion on the idea of one reality and one truth. (1989, p. 462)

In regards to the aims of feminist theory, then, poststructuralist conceptualisations of power and its constitution of knowledge are of central importance (Gavey, 1989; Weedon, 1997). A feminist poststructuralist approach provides a framework for the deconstruction of dominant discourses. In doing so, this approach attends to the productive nature of power within the construction of knowledge and importantly the ways in which power relations (particularly patriarchal and institutional power) have contributed to the historical, and continued, production of knowledge which marginalises women (Gavey, 1989; Weedon, 1997). In addition to power and the constitution of knowledge, a feminist poststructuralist approach also emphasises a fluid and dynamic conceptualisation of 
subjectivity. Davies and Harré (1990) explain that within feminist poststructuralist (and many poststructuralist approaches) subjectivities are in a constant state of flux, repeatedly/continually being produced by the subject through the discourses made available to them. The thesis's employment of a feminist poststructuralist approach makes possible an approach to data analysis which recognises the complex phenomenon of girls' sexual subjectivity, while being open to the varied and possible implications of the ways girls' sexuality is constructed. This approach calls attention not only to the multiplicity of meanings created around the current 'moral panic' regarding the sexualisation of girls (as discussed in the previous chapter, The Sexualisation of Girlhood), but also the construction of the limited and often dichotomous subjectivities that girls are afforded within girl sexuality discourses. Through a poststructuralist approach to subjectivity, this research also pays particular attention to the ways in which contemporary femininity is produced through the media and an increasing variety of self-produced and self-employed discourses and technologies such as porno-chic stylisation and beauty practices such as waxing and dieting (Gill, 2003, 2007b, 2007c; Evans, Riley \& Shankar, 2010; Renold \& Ringrose 2011; Ringrose \& Renold, 2012b).

\section{Audience Studies}

According to Kitzinger (2004) "to fully access the media's role in society - its mediation, limitations, and sometimes unexpected implications - we need to study how people read, use, and respond to the media" (p. 167). The use of audience studies gained popularity in the 1980's and 1990's in a time when critical researchers, particularly in cultural and media studies, began to develop paradigms which moved away from positivist methods of subject manipulation and began instead to focus on research which would reflect individuals experience and "give the audience a voice" (Livingstone, 2010, p. 567).

Using an audience approach to study girls' engagement with popular music contrasts with the dominance of positivist and quantitative psychological approaches to the topic which have largely been represented through a media effects model (as discussed previously) and content analysis studies. For example, Sommers-Flanagan, Sommers-Fianagan \& Davis (1993), used a content analysis approach to examining MTV music video content for representations of gender, while Kalof's (1999) media effects study exposed college students to sexually explicit and violent music videos 
and then tested for sexual attitudes, violence acceptance and gender role stereotyping. These studies and many other media effects studies like them (e.g., Downs \& Smith, 2010; Tiggemann \& Slater, 2003) have used quantitative and positivist methods which fundamentally ignore or miss the importance of language and the multiplicity of meaning and knowledge concerning media reception that is enabled through addressing the audience from a feminist poststructuralist approach (Livingstone, 1998, 2010). Fiske (1992) explains that the methodological differences between quantitative and qualitative research methods are primarily defined by the theories' differential understanding and use of the notion of structure. Fiske explains that for positivism, "a structure is a coherent pattern of empirical data that is part of the larger social reality theoretically derived from the data." (1992, p. 356). This means that, while positivist methods such as content analyses generate information about the sexist representation of women in music videos such as quantifying the number of representations of males as sexually dominant and violent, this method is always descriptive. Due to its primarily descriptive nature, the approach is largely limited in its ability to explore or envision any place for change. Fiske (1992) goes on to posit that, unlike qualitative methods such as content analyses, systemic or discursive approaches to media and to the audience:

go further than do positivist ones, for systemic structures such as language are generative... systemic structures generate practises by which they are used and are, in their turn, modified by those practices. Positivist structures, however, have effects, not practices, and the relationship between structure and effect is one-way. (Fiske, 1992, p. 356-357)

In contrast to positivist methods, applying a feminist discursive approach to an audience study is underpinned by an understanding of language and social structures as mutually effecting and thus two-way. The feminist poststructuralist approach to audience studies in the current research therefore conceptualises the audience and the media as mutually constitutive. This means that rather than approaching the girl audience as simply internalising media messages (as has been identified in many sexualisation texts discussed in the previous chapter), the relationship between girls and the media is conceptualised as complexly navigated in girls' consumption and reception. In this way, girls' media practices are not approached as a simple internalisation of hypersexualised media messages, but rather, as a process of potential negotiation, appropriation and resistance to such media messages. 
Underpinning the notion of media consumption as complex, the relationship between the audience and the media is conceptualised as 'two-way' through the poststructuralist attention to language and shared meaning making as central to the construction of discourses. This means that (aligning with critical feminist literature discussed in the previous chapter, see Gill, 2012b) media is not approached as an allpowerful generator of meaning, but rather is reliant on the audience (and vice versa) in the production of shared social meaning.

As a study concerned with girls' engagement with pop music media, insights from the field of feminist media studies are particularly helpful. In exploring the evolution of feminist media research Gill (2007d) asserts that audience studies are "crucially important to feminist media research, in emphasising the polysemic nature of media texts and the complex ways in which they are consumed" (p. 25). Gill discusses early feminist textual analysis work as pivotal in complicating the understanding of women's media reception as potentially positive and problematic in a methodological approach which she terms 'the turn to pleasure' (2007d, p. 13). Gill explains that the 1970's brought about an influx of feminist critique concerning the portrayal of women in the media (particularly to patriarchal representations). According to Gill, 'the turn to pleasure' signals a historical shift in feminist media studies research from identifying and deconstructing problematic and patriarchal understandings of women's representation in and reading of the media, to approaches which complicate women's relationship with the media. This complication is seen particularly in the increased conceptualisation of possibilities for women's pleasure in their media engagement. Early literature concerned with women's pleasurable media consumption has contributed to contemporary understandings of women's engagement with media. Gill highlights, for example, Modleski's book Loving with a Vengeance as having an important impact on the theorisation of women's reading of romance media (see 2007d, p. 14; Modleski, 1982). However, this research repeatedly produced itself within a textually deterministic model where, as Gill explains, "the pleasures were to be found encoded in the text, waiting to be discovered" (2007d, p. 15). The turn to pleasure then, although providing a significant shift in the conceptualisation of media texts as polysemic and audience reception as complicated and always potentially pleasurable, resulted in a gendered focus on audience reception and consumptive practices whilst obscuring a multitude of socio-cultural influences and contexts of the viewer. 
The audience studies movement is described by Gill (2007d) as developing through three central 'moments'. The first moment 'encoding/decoding/interpretation' points to the development of the audience study method by Stuart Hall (1973, cited in Gill, 2007d, p. 17). According to Gill, Hall recognised that media messages contain multiple meanings which, alongside the intended message of the text, can be interpreted differently by individual consumers. This understanding of media messages and media reception signals a move away from the conceptualisation of the passive cultural dupe and the media as an all-powerful entity seen in early media studies work (2007d). Instead, as Ruddock explains, the encoding/decoding theory is often "credited with empowering the audience" (2001, p. 143). This conceptualisation of media engagement was profoundly influenced by poststructuralist understandings wherein the conceptualisation of the dynamic, determined and simultaneously selfdetermining subject became central to the understanding of audience media reception (Gill, 2007c). As such, theorisation of the audience also influenced a shift in feminist research whereby feminist researchers began to explore the cultural and social differences which could influence audience reception. Currie's (2000) study on teenage girls magazine consumption, for example, highlights the positioning of everyday practices as central to women's media reading and, as she explains, in this study "the social texts of femininity were treated as a mediating process through which both the gendered subject and the social world of heteropatriarchy are reconstituted" (p. 290). Currie's study posits an understanding of the audience as not passively positioned by media texts but rather that "'something' outside the text was explored in terms of school culture, although other processes, such as family dynamics, obviously play an important role in the way in which teenzine meanings will, or will not, be taken up by adolescent readers" (p. 290).

Returning to Gill's (2007d) discussion of audience studies, she also looks at the turn to pleasure within audience studies methodologies, in particular in fictional media. Radway's (1984) analysis of women's romantic novel reading is described by Gill as pivotal to this type of audience study. Using interviews, Radway explored women's engagement with, and meaning making of, romantic novels. As Gill explains, Radway's work is notable not only for its contribution to the conceptualisation of women as agentic media consumers, but also for the way it serves as a site for debates about the role of the feminist media critique within feminist studies (Gill, 2007c, p. 18). In illuminating these debates, Gill describes the 
work of Ang $(1985 ; 1990)$ as pivotal both in its contribution to feminist understandings of women's pleasurable media consumption but also importantly, along with Radway's work, contributing to feminist debates concerning the role of the feminist researcher in such research. Gill (2007d, p. 19-20) uses Ang and Radway to highlight two differing positions of feminist researchers, wherein Radway (1984) is understood as taking a stance (positive or negative) concerning women's engagement with fictional characters, while Ang $(1985 ; 1990)$ understands her research as absent of such judgements. Gill highlights that "the debate between Radway and Ang goes beyond the issue of how particular texts and interpretations should be read, to the heart of questions about what feminist media studies should be or should not do, and the nature of the relationship between the feminist critic and women" (2007d, p. 20)

Exploring this, Brunsdon (1993) identifies three feminist approaches to audience critique. The first approach is the transparent one which Brunsdon refers to as a Utopian position, where the researcher posits an equal relationship between herself and the participants. The second mode is the hegemonic approach which is described by Brunsdon (1993 see also Gill, 2007d) as a movement in which "the construction of feminist relation through this relation involves the differentiation of the feminist from her other, the ordinary woman..." (p. 171). This mode is also described by Brunsdon as a position within which the feminist woman intends to make change or enlighten the 'non-feminist' participant. Brunsdon describes the third mode as 'fragmented'. This final mode is understood as an institutional reaction to both the transparent and hegemonic modes within which the "epistemological grounding of the political category 'women' is thrown into crisis" (p. 174). This research, then, examines previously excluded categories of being such as race and class, thereby highlighting "the impossibility of telling stories in which individuals are 'just' gendered” (Brunsdon, 1993, p. 173).

As the preceding review suggests, audience studies, particularly within feminist scholarship, is crucial to gathering knowledge about how girls understand media, how media messages are navigated and circulated (challenging dominant claims about media influence) and girls' everyday participation and media practices (Livingstone, 2010). Given its ability to produce such polysemic and gendered investigations, audience studies has a rich history of feminist scholarship which is of particular value to the current research. Moving past mainstream positivist assumptions of media as an 'all-powerful' influence on girls' development, this 
investigation attends to the ways in which media shapes girls' worlds and vice versa. In this way female pop music media is conceptualised in the research as a widely available resource for girls in ways of being and 'doing' contemporary femininity. Additionally, while female pop music media is understood as a site within which feminine subjectivities are made available (or constrained) for girls, this media (and its presumed 'effects' on girls within sexualisation narratives) is also understood as a site which influences the ways in which girls are constructed and understood as at-risk within contemporary culture (Livingstone, 1998, 2010).

Within the tradition of nuanced approaches to the audience in feminist media studies, the current study rejects positivism's depersonalisation of participants and its methods that generally disregard, universalise, or fail to identify girls' own understandings as an audience. Moreover, the present research is underpinned by a positioning of girls as an active and participatory audience who are capable of critically and insightfully reflecting on their own experience. As such, it reflects the feminist underpinnings of this thesis. The employment of the audience study in this research is guided by two key principles: i) the necessity of paying close attention to girls' experience, respecting it and positioning it as important and informative ii) the rejection of the scientific notion of experimentation which has historically ignored women and girls' experience. This final point can also be applied to the study of children who have long been (and continue to be in many positivist psychological investigations) constructed as 'less than' adults and/or as unable to describe their own experiences (Buckingham, 1993).

Approaching the child audience. Thomson (2008) explains that in conducting research with children we need to step outside of contemporary ideas about children as not yet adults and as half humans. Instead, Thomson asserts that child participants in research must be conceptualized from a position within which "children and young people are capable of providing expert testimony about their experiences, associations and lifestyles" (2008, p. 1). This approach to understanding the child audience is central to the current research.

Buckingham (1993) draws on the works of Plato to describe the long history of the conceptualisation of the child as innocent and always potentially in danger of influence from the media. Whereas Plato highlights poets as negatively affecting impressionable young people, Buckingham describes constructions of the media in 
contemporary Western culture as having "an extraordinary power to penetrate the thin veneer of civilisation and release the anarchic, anti-social forces that lie beneath", a power that children are understood to be particularly vulnerable to (p. 4). Buckingham explains that while theories from cognitive psychology and 'uses and gratification' research have made considerable advances in the conceptualisation of the active child audience these approaches still work to position the child as 'less than' (adult) and as a less than capable consumer who is often conceptualised as divorced from individualised socio-cultural contexts. Buckingham explains that within these audience approaches young people are positioned as "somehow asocial - or perhaps pre-social - beings. They are merely on their way to becoming something else, something finished" (p. 9). Similarly, Livingstone and Drotner (2011) assert that a disconnection concerning children's media culture and potential for agency has resulted in a history of research which poses "disconnected questions about the impacts of particular media (...) often framed in terms of moral panics, and with predominant focus on American children as the implicit prototype for children everywhere" (p. 2, see also, Drotner, 1999).

Livingstone and Drotner (2011) assert that in order to develop the study of children and their media culture and consumption a multidisciplinary approach is necessary. Drawing on the assertion of the importance of a multidisciplinary approach, the current research identifies media and cultural studies as an important framework for studying girls' media engagement. According to Buckingham (1993), a media and cultural studies approach locates young people's media use within individualised socio-historical contexts, taking into account the individual and everyday experiences of young people. Buckingham explains that within this framework “"being an audience' (or a member of an audience) is seen as a social practice, not as a fixed state of existence: it is something you do rather than something you are (p. 13, italics in the original). This conceptualisation of the young audience is particularly useful to the current thesis as it will allow for an understanding of girls' pop music media engagement as an active process rather than an all-powerful transformative (sexualising) phenomenon as this relationship has been conceptualised within sexualisation texts.

In addition to the conceptualisation of media consumption as a variable practice, Livingstone (1998b) discusses the importance of approaching the child audience within its specified context. She explains that without contextualising 
children's media engagement within their socio-cultural context "research on children and young people tends to transform the positives and negatives of their lives into positive and negative children or young people, particularly negative ones (the Internet addict, the screen-zombie, the social isolate)" and in the case of sexualisation literature, the precociously sexualised girl (p. 440). The importance of recognizing the social and cultural contexts of girls' media engagement is thus addressed through this projects intersection with a media and cultural studies approach and the poststructuralist underpinnings of the thesis as a whole. Moving away from cognitive psychology approaches to the child audience, this study pays particular attention to the social context of the audience and to the problematic and limited discourses and subjectivities available to young girls in relation to hypersexual media. In addition, this framework also approaches texts as polysemic in nature. From this perspective, the young audience is understood as active in their potential reading and meaning making of the text and simultaneously, "rather than regarding meaning as something contained within the text, it [a media and cultural studies approach to the child audience] draw attention to the possibility of ambiguity and contradiction" (Buckingham, 1993, p. 15).

Additionally, this conceptualisation of the child audience, allows for an investigation of the relationship between girls and pop music media which moves past the polarisation and causal assumptions within sexualisation literature which position girls as inherently and singularly influenced by media. This polarisation, described by Buckingham as "the power of the reader" position and "the power of the text" position can be seen particularly in sexualisation literature which positions the media as entirely corruptive of girls or conversely, literature which positions girls as entirely agentic and unaffected (1993, p. 14). This approach, then, is central to the current research's aims to complicate the conceptualisation of girls as passive media consumers which has dominated contemporary girlhood literature.

\section{Girls as Media Producers}

The increasing number of girls who are becoming media producers rather than solely consumers is an area that deserves continued interest within feminist literature (Kearney, 2007). The importance of research which examines girls' own creation of media as a medium for the potential disruption of mainstream messages cannot be understated. As Gill (2012) highlights, “In demonstrating children's and young 
people's sophistication and reflexiveness this research offers an important corrective to the psychological tradition and, moreover, a valuable push to policymakers to take young people's voices seriously as participants in (sexualised or otherwise) media culture" (p. 490). Girls' production of media, like girls' consumption of media, has historically been discussed through binaries which position girls' media production (such as learning technological and media literacy skills) as positive (leading to nonsexualised outcomes) against girls' media consumption (leading to sexualisation dangers) (Driver, 2007; Harris, 2004; Kearney, 2006; Mazzarella, 2005). However, literature has also identified that 'media literacy' (e.g., teaching girls that postfeminist representations are not necessarily real or possible) doesn't remove the pressure placed on girls to emulate these representations (Jackson \& Vares, 2011; Jackson, Vares \& Gill, 2013).

Although this thesis emphasises girls' media production as important, production is not privileged over consumption. This is particularly important in the investigation of girls' media engagement where, while girls' consumption has been problematised in contemporary media and academia, the theorisation of production as a means of entirely escaping the proposed influence is also problematic on its own. Rather, as Kearney (2007) highlights, girls' consumption and production are understood in the current research as neither inherently negative nor positive. Analysis of girls' productive performance is instead approached as just one way of understanding girls' meaning making of contemporary hypersexual popular music media and the different ways in which girls might use this media.

\section{Approaching Celebrity as a Discursive Text}

Given the research's focus on girls' consumption of female pop music media/artists, the conceptualisation of 'celebrity' as a discursive text which girls (and contemporary culture more broadly) negotiate and make sense of in their consumption (and productive practises) is important to the thesis's methodological underpinnings. Celebrity has become a central feature of contemporary culture that has increasingly in the last decade been seen to "attract attention and to drive consumption" (Turner, 2010 , p. 11). New media has been central to the spread of celebrity from a largely print and television platform to ever expanding digital sites (Turner, 2010). Turner explains that "the growth of new media has generated new ways of representing, consuming and producing celebrity while online journalism... has also had an 
expansionary effect" (2010, p.11). Within academic disciplines, the study of celebrity has grown exponentially in what Turner (2010) calls the "celebrity of celebrity studies" (p. 12). The analysis of celebrity (particularly the assertion of detrimental effects in relation to celebrity worship) has also been picked up within the social sciences and psychology (Turner, 2010).

From its feminist poststructuralist underpinnings, approaching celebrity as a discursive formation means conceptualising it as a culmination of multi-directional discourses which dually influences and is influenced by the audience, enabling and constraining culturally and contextually specific possibilities for the self (Turner, 2010). Celebrity is conceptualised in this research as operating through a number of discourses within contemporary society (Allen \& Mendick, 2013; Duits \& van Romondt Vis, 2009; Willett, 2011). Consistent with the theoretical framework described earlier in the chapter, these discourses are viewed as historically and culturally specific amalgamations of meaning, value, and possibilities of self for those engaging with them (Foucault, 1978/1980).

This thesis approaches the construction of celebrity as intimately linked to institutional power whereby "distinctions are made and certain relations, behaviours and people are given or denied value" (Allen \& Mendick, 2013, p.78). A poststructuralist approach views contemporary celebrity as intricately linked to neoliberalist notions of commodity, exclusion, and the responsible, self-regulating and consuming individual who is privileged within contemporary Western culture (Allen \& Mendick, 2013). In addition to this, Redmond and Holmes (2006) assert that one of the central functions of celebrity within contemporary culture is the desire that they fuel among individuals to purchase the products and goods that they promote. As a marketing tool, celebrities are widely used in the sale of products which promise the possibility of 'transformation' through the purchase of goods: in effect, 'normal' people are offered the opportunity to live like and 'as' the celebrity (Holmes \& Redmond, 2006; Rojek, 2001). Following these conceptualisations, celebrities are understood to be central proponents of the idealisation of the consuming subject within postfeminist media culture wherein the knowable 'self' is constructed and empowered through consumable products (Giddens, 1991; Gill, 2007c).

In addition to the transformative possibilities offered by celebrity, the public are also said to be attracted to, even obsessed with viewing the 'real and accessible' celebrity (Dyer, 2002). Duits and Van Romondt Vis (2009) describe this feature of 
contemporary celebrity as intimately related to Giddens' (1991) assertion of the self as a reflexive project in modern times, one which must be relentlessly worked upon and improved, generating an identity or understanding of the self as a project to be worked upon and completed. Drawing on Giddens, Duits and Van Romondt Vis (2009) surmise that "celebrities offer audiences the perfect opportunity to engage in questions of authenticity and an ideal of individual autonomy" (p. 43).

The approach to celebrity in the current research does not ignore the transformative nature of celebrity but instead focuses on the female celebrity as a cultural commodity both in its relationship to consumption and its function as a vehicle for how to 'do' contemporary ideal femininity. As such, celebrity is understood as a relationship between the representational qualities of the celebrity individual and the ways in which the celebrity is understood by the audience. In this way, both the presentation and the public reception of the celebrity rely on (some argue are maintained by) the management of both public and private personas. Duits and Van Romondt Vis (2009), for example, assert that "a celebrity is more than a/one person. A celebrity's' image is a discursive construction that does not necessarily match who the celebrity is as a person" (p. 42). As a central attraction to celebrity culture, the search for the 'real' celebrity has been pivotal in contemporary understandings of audience reception of celebrity (Holmes and Redmond, 2006). It has been discussed in the literature as a key factor in regards to celebrity consumption and fundamental to the audiences acceptance (or rejection) of a celebrity (Dyer, 2002; Holmes \& Redmond, 2006, 2007; Rojek, 2001). The search for the 'real' celebrity is illuminated in literature that explores the increasing 'realist' representations of celebrity in reality television (see Holmes, 2004), the 'real' celebrity in gossip magazines (Fairclough, 2008), and, of relevance to the current investigation, audience reception studies with girls in which their attraction to the 'real' 'authentic' celebrity has been described fundamental to their engagement (Duits \& van Romondt Vis, 2009; Zaslow, 2009; Jackson \& Vares, 2011, 2011b, 2012).

In approaching celebrity as a discursive formation, this investigation is also concerned with the gendered representation of contemporary celebrity. Particularly as celebrity studies literature has identified the gap between the supportive and removed public approach to male celebrities and the growing representation of the gendered (female) 'celebrity train wreck' (Holmes \& Negra, 2008). Redmond (2012), for example, describes the contemporary emphasis on shaming and vilifying female 
celebrities as "fame damage", and asserts that "psychosis, madness, depression, drug and sex addition, and suicidal tendencies mark out the representational trajectory of a great many famous people" (p. 34). This assertion by Redmond highlights contemporary celebrity as always in jeopardy and at risk of "falling from grace" (Rojek, 2001, p. 58). Of particular interest within 'train wreck' celebrity media representation is the coverage of hypersexual female teen celebrities (Negra \& Holmes, 2008). Negra and Holmes explain the intense scrutiny of the female celebrity by asserting that "when women struggle or fail, their actions are seen to constitute "proof" that for women the "work/life balance" is really an impossible one" (2008, p.

2). The authors describe female celebrity (and particularly female celebrity in crisis) as mediated through notions of class and traditionalist notions of femininity and motherhood. Further to this point, Negra and Holmes assert that female celebrity is always intrinsically linked to motherhood wherein the choice to have children is regularly presented as the remedy or end to a celebrity's 'bad girl' ways (see also Bell, 2008). In regards to celebrity class, Negra and Holmes draw on the work of Beverley Skeggs (1997) who contends that the working-class woman is often represented as hypersexual, excessive and without taste alongside her sexually controlled and 'demure' middle-class counterparts (Negra \& Holmes, 2008).

To summarise, this thesis conceptualises celebrity as a discursive phenomenon, comprised of a multitude of hegemonic discourses, which may serve as a platform and a resource for young girls in ways of performing contemporary femininity. The intense scrutiny of female celebrities, as discussed earlier, is also recognised as underpinning contemporary conceptualisations of the female celebrity as a potentially dangerous role model for young girls (Negra \& Holmes, 2008). This conceptualisation is particularly emphasised in regards to girls' engagement with pop music celebrities which has a long history of being conceptualised as problematic. Fear concerning girls' infatuation with male celebrities is seen, for example, in research conducted by Davies (1969) which describes 'beatlemania' as a set of behavioural symptoms manifesting through girls' obsession with the pop group The Beatles. While 'beatlemania' emphasises historical concerns about girls' pop music engagement as centred on their infatuation with pop celebrity, contemporary fears shift this concern to the problematised assumption that girls want to inhabit and reproduce celebrity identity (Lumby, 2007; Negra \& Holmes, 2008). Catherine Lumby explains that: 
popular concerns about young women's relationship to fame have been gradually shifting away from concerns about their irrational idealisation of predominately male idols to concerns that they are obsessively fantasizing about becoming famous themselves. Put simply, the new lament about teen girls is not that they're too passive in the face of the fame industry, but that they're too interactive. (Lumby, 2007, p. 342)

In approaching girls' engagement and lived experience with celebrity, the analysis chapters which follow will consider the ways in which discourses of celebrity flow through power structures and the ways in which they privilege certain ways of being. Of particular importance in this research, however, is the recognition of girls as engaging with, but also possibly appropriating and resisting, subjectivities made available to them by celebrity culture.

\section{Ethical Issues in the Research}

The Victoria University of Wellington School of Psychology Ethics Committee (SOPHEC) granted ethical approval for both the focus group and music video studies included in this thesis in March of 2011. As part of the approval, girls were required to have parental and/or caregiver consent in order to participate in the research (see Appendix A: Parental/Caregiver Information Sheet, Appendix B: Parental Consent Form). Confidentiality was another important ethical consideration in conducting this research. In line with SOPHEC's requirements, protection of the girls' personal information included secure storage of their demographic information, focus group and music video material, all of which were accessed only by the project researcher and supervisor. In addition, pseudonyms were used on all written material. Extending beyond the ethical considerations stipulated by SOPHEC, the feminist theoretical frame work of this thesis and the involvement of child participants had particular implications for the way the research was undertaken. These implications will now be addressed.

Feminist Ethics of Practice and Care. Feminist research employs a range of ethical considerations which are central to producing safe, respectful and transparent research (Wilkinson, 1988, 1991). Informed consent is of great importance within feminist research. However, children are widely held to be incapable of giving informed consent (Jackson, 2006). The default position in contemporary research with 
children is to offer children the assent process but require parental approval/consent (as was the case in this study). Assent acknowledges children as capable participants who are able to advocate for their own choices and to some extent this process and acknowledgement may work to dissipate the 'expert' researcher/naïve participant binary that is challenged by critical and feminist approaches to research (Jackson, 2006).

The researcher/participant relationship is a central concern of feminist research (Wilkinson, 1988, 1998). Within the discipline of mainstream psychology, specifically the scientific paradigm, uneven power relations reside in the ability of the researcher to experimentally manipulate the participant (historically described as the 'subject' in quantitative research) for research purposes (Livingstone, 2010). The problematic construction of the 'all-knowing' researcher and the naïve participant within positivist research has been addressed broadly by a critical approach (discussed in the beginning of the current chapter) which seeks to deconstruct and question hegemonic knowledge within the discipline of psychology, moving away from manipulation techniques and unbalanced power dynamics (Parker, 1999). In addition to this, a critical approach emphasises the importance of producing research that benefits both the researcher and the participants through accurate and transparent research processes and representation of the data (Parker, 1999). Aligning with these aims, feminists have long asserted the importance of producing research which centralises women's voices and experiences and directly addresses 'the masculine paradigm' in which the participant is understood as powerless and manipulated by the powerful researcher (Livingstone, 2010; Wilkinson, 1988).

The feminist underpinnings of the current research and the attention to the researcher/participant relationship guided the selection of research methods which enable a respectful approach that emphasises girls' voices as paramount to producing research about their lives and their experiences (Brown \& Gilligan, 1992). Wilkinson (1988, 1998, 1999) describes focus groups as particularly useful in conducting research which provides an open framework that aims to openly explore a topic and to pay particular attention to the participant's voices. Importantly, the focus group method is also identified by Jackson (2010) as aligning with the "social worlds of young people, where much time is spent talking with peers; social lives are made (and un-made) in interaction, making the focus group a microcosm of wider social life" (p. 16). Consistent with this view, focus groups were selected in this investigation as they 
offer a research method that enables a focus on the girls' understandings and unique contribution without over-representing the researchers' conceptualisations, aims or interpretation of their ideas (Wilkinson, 1988).

A semi-structured interview plan (see Appendix G: Friendship Group Interview Schedule) allowed for the girls to be productive participants in the focus groups wherein, rather than being entirely led by the researcher, the girls were also generating ideas, questions and topics that they considered important and relevant while rejecting those ideas that they did not. The use of semi-structured focus groups was also selected to extend the project's aim in respectfully and accurately representing the girls' voices. In their study exploring girls' development during adolescence, Brown and Gilligan (1992) describe their method as open structured (with the broad goal of exploring girls' understandings of themselves and the world around them) and centred on the voices of girls. Centring on girls' voices departs from historical explorations of girlhood which are dominated by clinical and often male-centric understandings of females as 'other'. Instead, as Brown and Gilligan explain that, "by listening to women and to girls and bringing their voices into the centre of psychological theory and research, we are changing the voice, the body and the story about relationships" and placing girls' own understandings as central to the exploration (1992, p. 22).

Finally, the use of focus groups contrasts many of the research methods and methodological assumptions within sexualisation literature (such as Papadopolus, 2010; Rush \& La Nauze, 2006, 2006b) where research rarely addresses young girls directly and instead relies on content analysis. The emphasis on girls as capable and active individuals also underpins the selection of a visual method in the music video study. While the notion of children as providing a specialised or uninfluenced view of the world is problematic, the girls' music videos productions (analysed in Chapter Eight) are conceptualised as providing a somewhat rare insight into girls' media production, complicating the dominant representation of them as solely consumers of media (Kearney, 2007, 2013). By providing a platform for the girls to create and manage their own media productions, the music video study analysis demonstrates the complexity of girls' media engagement and the importance of moving beyond a consumptive focus in exploring girls' relationship with hypersexual media. 
Conducting research with children. In addition to considerations drawn from a feminist ethics of practice, research with children necessitates further ethical considerations. These ethical considerations, particularly consent and confidentiality, have become apparent due to historical (and still current within some quantitative research) conceptualisations of the child as a passive and dependent participant. Jackson (2010), for example, asserts that "research 'with' children values what children and young people have to say, and is concerned with what issues look like from their perspective rather than prioritising adult perspectives" (p. 14). This ethical approach to research with children central to the current investigation wherein girls' active contribution to the research process is considered fundamental to gathering information about and insight into their media consumption and their lives.

In considering this conceptualisation of children within research, Morrow and Richards (1996) discuss how the assumption of children as inherently vulnerable, incompetent, and powerless underpins traditional understandings of children as research subjects, particularly within developmental psychology models. Similarly critical of the ways in which children are treated in research, Burman (1994) explains that:

developmental psychology's commitment to the view of children and child development as fixed, unilinear and timeless is not only ethnocentric and culture-blind in its unwitting reflection of parochial preoccupations and consequent devaluation of differing patternings, but is also in danger of failing to recognise changes in the organisation of childhood subjectivity and agency. (Burman, 1994, p. 59-60)

Addressing assumptions of child vulnerability and incompetence which have plagued research with children, Pam Alldred (1998) describes children as a group who have been socially silenced (like other marginalised groups such as those prejudiced due to race, social status or disability). Alldred (1998) highlights that within psychological research of children, "the focus has been on what happens to them (and the processes they undergo), rather than what they say or do" (p. 4). Rejecting the objectivism which has long positioned children as passive and naïve in psychological research, Alldred instead advocates for a growing body of research which emphasises the importance of 'giving children a voice'. She contends that it is critical that children are understood as playing an active and essential role in research which concerns them. Critical psychology has played a large role in deconstructing 
developmental models of children as incapable consumers. As Thomson (2008) explains, in conducting research with children we need to step outside of contemporary ideas about children as not yet adults and as half humans. She asserts that, instead, child participants in research must be conceptualized from a position within which "children and young people are capable of providing expert testimony about their experiences, associations and lifestyles" (p. 1). In considering the ethics of girls' participation in the current research, then, the conceptualisation of them as experts of their own experience is of great importance.

In addition to conceptualising girls as 'experts' in their own experiences, consideration of girls' potential discomfort in discussions concerning hypersexual material such as body exposing and provocative behaviour in popular music is another aspect of ethics of care. Although these topics might be potentially difficult for any individual, they may be particularly difficult for young girls for whom there are expectations of innocence and asexuality (Harris, 2004; Griffin, 2004). On the other hand, Hoppe, Wells, Morrison, Gillmore, and Wilsdon (1995) discuss focus groups as an important method in the study of sensitive material such as the projects address to sexual exposure and behaviours in pop music in the current research. Hoppe et. al. (1995) highlight the importance of group facilitators or researchers in focus groups being astute and observant of children's comfort in the focus groups and emphasise the importance of a comfortable research environment and for the researcher to be sensitive and respectful to the participants sharing. The ways in which the current research managed considerations of sensitivity, comfort and respect are addressed more fully in Chapter Five (p. 106).

\section{Reflexive Considerations of the Research}

Researcher Reflectivity. Wilkinson (1988) describes reflexivity as an academic discipline which requires "any psychological theory to apply as much to the theorist as to those he or she seeks to study" (p. 493). This assertion highlights the importance of moving away from the construction of the "scientist" as all-knowing and manipulating the lay person through research. Rather, within a feminist paradigm, research is understood as mutually affecting and influencing both parties (researcher and participant). Conversely, positivist paradigms approach the researcher's personal influence as problematic and something that can (and needs to) be overcome in order to produce objective research (Wilkinson, 1988). In contrast to this, feminist 
approaches understand reflexivity as an important resource which highlights the centrality of individual experience within this epistemology.

In approaching this research from a feminist position it is important to acknowledge the personal investment and impact of the researcher in both the analysis and the conceptualisation of the project as a whole (Wilkinson, 1988). Reflexivity can therefore be understood as the open and transparent address of the researcher's power which Alldred usefully identifies as:

operating through multiple levels: through the hegemonic cultural perspective contained in the language we (must) use; through the subject positions we take up and are positioned within (including our deliberate claims to researcher positions); and through our particular individual relationships with participants and to our field of inquiry. (Alldred, 1998, p. 15)

As explained in the preface to this thesis, my interest in studying girlhood and popular music has been greatly influenced by my own experience of girlhood which was saturated with the presence of music and female popular music celebrities. In discussing postfeminism as a phenomenon that permeates contemporary popular culture and popular music it is important to locate my own girlhood within the 1990's. This period has been identified as a time period within which the intensification of the appropriation of postfeminist notions into popular music was initiated (Driscoll, 1999; Whelehan, 2000). Given this cultural context, postfeminist media culture and the appropriation of postfeminist ideals of femininity have saturated popular culture for as long as I have engaged with it. Moving forward into my time in postgraduate learning at university, my engagement in feminist poststructuralist thinking, analysis and the deconstruction of contemporary discourses of femininity has largely shifted and developed. In particular my understanding of postfeminist media culture and the possibilities it offers for women in contemporary culture has shifted and changed along the theorectical continuum which theorises it as a backlash on one end and an emancipatory phenomenon on the other. Despite my development as a feminist researcher, I have never experienced a culture outside of the postfeminist constructions of femininity that proliferate within female pop music. Although I have developed abilities in the critical deconstruction of postfeminist media culture including the opportunities, absences and exclusions which postfeminist discourses impart on my own possibilities for self, my engagement with this media is experienced as both difficult and also as immensely pleasurable. 
Reconciling my self-understanding as a feminist researcher and a young woman in contemporary culture who is on a daily basis bombarded with images, products and representations of the ways I should perform femininity has been difficult and personal work which has occurred in the background of this thesis. In addition to making sense of myself inside and outside of the research, analysis of the music video texts' (analysed in Chapter Eight) has greatly problematised my own engagement with such texts outside of a research context. Analysis of music video texts highlighted to me the ways in which postfeminist discourses are greatly implicated in my life in terms of what I understand as 'valuable' and as feminine. This analysis enabled me to explore the ways in which my own media engagement is complicated by my positioning within feminine subjectivities of gender, class and race and my simultaneous pleasurable enjoyment which is derived from consumption of postfeminist media culture. In addition, this analysis has urged me to question how I can both undertake feminist research while still pleasurably engaging in postfeminist media.

\section{Chapter Summary}

To summarise, this research presents an informative investigation of girls' engagement with female popular music which acknowledges girls as active individuals in their self-making and media engagement. This research deviates from contemporary sexualisation literature (in both the academic and popular psychology texts which have been discussed in Chapter Three) which produces girls as passive and victimised media consumers and contributes to hegemonic conceptualisations of girlhood as a problematic and dangerous developmental period. Addressing girls as capable participants highlights the feminist ethics of the current research which aims (through close attention to reflexivity) to produce research which accurately and respectfully represents girls' voices. The following analysis chapters directly address girls' media engagement through analysis of their discussions of female pop music media and the ways in which they discursively navigate a media terrain which is both pleasurable and laden with problematic sexualisation binaries. The focus group analysis chapter (Six) highlights the ways in which girls make meaning of and negotiate postfeminist media culture and particularly the hypersexualised representations of femininity which saturate such media. Following the Focus Group Chapter, the Girls' Media Production Chapter (Eight) explores both the postfeminist 
discourses in the music videos that girls consume and the ways that girls negotiate, reject or appropriate the song's/videos meanings through their own performance and media production. 


\section{Chapter Five:}

\section{General and Focus Group Study Method}

This chapter documents and describes the details of the method used in the focus group study. The first section pertains to the project as a whole and describes the participant recruitment process and the participants that took part in both the focus group and music video studies. The second section sets out aspects of the method specific to the focus group study. The method for the music video chapter is located in Chapter Seven of the thesis.

\section{Participants}

Recruitment. After obtaining ethical approval from the Victoria University School of Psychology Human Ethics Committee (SOPHEC) to conduct the research, two Intermediate schools within the Wellington region were selected to approach. These schools were selected for their known receptiveness to and interest in research being conducted with their students. They were also chosen for their demographic profiles wherein at the time of the study these schools held similar decile ratings (9 and 10 respectively signalling high socio-economic status) which provides an approximation of the student body as middle to upper middle class. Both schools identified themselves as having a broad representation of ethnicities in their student body. To further protect participant confidentiality (participant confidentiality is discussed in Chapter Four, p. 97), the schools were given the pseudonyms Tahi and school Rua. These are the Māori words for numbers one and two and were assigned based on the order in which schools were recruited into the project.

The selected schools were contacted by telephone to arrange a meeting with principals and deans to discuss the project. Following this meeting, both schools agreed to participate in the study and meetings were arranged with girls selected by the schools (identified as individuals who would potentially interested in participating) to inform them about the project. The initial meetings with both groups of girls generated considerable interest and the girls who expressed interest in participating were given a parental information sheet (see Appendix A) explaining the project, a parental consent form (see Appendix B), and an information brochure for themselves (see Appendix C). Girls who agreed to take part and had parental consent to do so were asked to return their consent forms the following week. 
Participant Descriptions. Twenty-nine girls returned completed parental consent forms by the arranged day and time. The participants were all aged between 11-13 years and were in either year 7 (14 girls) or year 8 (15 girls) of intermediate school. Twenty-two of the participating girls were recruited from school Tahi and seven of the girls from school Rua. A significantly smaller number of participants were recruited from school Rua as the participating girls were drawn from one drama class that the school identified as available to participate in the project (producing their music video and participating in the focus group) during class time.

The girls participating in the study were ethnically diverse. While the majority of the girls described themselves as New Zealanders, 'Kiwis' or 'NZ', there were also many girls who additionally identified themselves as Maori, Assyrian, North American, Nepali or Indian and a small group of girls described their ethnicity as comprising multiple identities including Dutch, Burmese, and Egyptian. All but one of the girls identified themselves as being born in New Zealand. The girls' family structures were also diverse. Although the majority of the girls' identified their family structure as nuclear, a significant group of girls' came from 'reconstituted' families with divorced or separated parents and step and half siblings.

\section{The Focus Group Study Method}

The following section introduces the structure, process and analytical approach for the focus group study which explored girls' meaning making of female pop music artists and their music media. As discussed in Chapter Four (p. 98-99), focus groups have been used widely in feminist research particularly because they enable an open investigative framework which attends to participants' voices (Wilkinson, 1988, 1998, 1999). In this research, the focus group study aimed to explore research questions two, three and four of the project (see Chapter One, pp. 1920 for a list of the research questions) which address the research's aim to explore the ways that girls are understanding femininity discourses within female pop music media and the possibilities of self that these discourses enable (or restrain) for girls. The focus groups were conducted using a semi-structured format which facilitates a research environment that encourages group participation, and most importantly, emphasises the participants' generation of topics and ideas for discussion rather than simply focusing on a predetermined set of questions posed by the researcher (Livingstone, 2010; Wilkinson, 1998, 1999). In addition, the open format of the focus 
groups allowed for flexibility and responsiveness to, for example, celebrities and music videos of interest to the girls. An interview guide was used by the facilitator (researcher) during the focus groups which contained open questions and topics that provided some direction while still allowing space for the girls to lead the discussion and introduce topics (see Appendix G for interview guide). The interview guide included, for example, topics on female pop music artists that the girls liked, girls' favourite and least favourite artists and videos, popular songs and artists at their schools, clothing styles stemming from pop music media representations, their own engagement with pop music media at home, their understandings of the messages within this media, and their parent's role in mediating their consumption.

Facilitation of the focus groups involved consideration of how questions were posed by the researcher in each group. Specifically, it was important that the questions were framed as open (to encourage discussion amongst the girls) and as non-leading or non-inferential. For example, asking the girls how a certain media representation 'affects' them infers that there is an effect from this representation and can therefore be understood as a leading question. The use of open-ended and nonleading questions was also important in facilitating the focus groups in a way that encouraged group cohesiveness and contributions from all of the girls in each group. This involved encouraging girls to present individual (and possibly contrasting) opinions to their peers while also monitoring the girls' discussions in order to keep them respectful (of other's opinions) which was particularly important due to the potentially sensitive subjects (such as body exposure and hypersexual behaviour) that were discussed in the focus groups. The comfort and emotional safety of the girls was of great concern to focus group facilitation. The specific ways in which this was addressed will be explained in the following focus group process section.

\section{Focus Group Study Process}

Five focus groups took place across the study (four from school Tahi and one from school Rua). The focus groups were conducted in a quiet room in each school which was assuredly free of interruptions and lasted between 45 and 60 minutes. In school Tahi the focus groups included between three and eight girls. The focus groups (which were referred to as friendship groups) were composed of groups of friends that were participating in the study. These groupings were organised by the dean of school Tahi as she had knowledge of the girls' friendship groups and was also aware of the 
girls' school timetables and when they were able to participate in the focus group interviews together. Although it was requested (by the researcher) that each focus group have a minimum of five girls and a maximum of ten girls, there was one group of three girls and one group of four girls arranged from this school to take part in the interviews. In addition, despite requesting that the girls be organised into groups of friends for the focus group study, there was one focus group in school Tahi which incorporated two separate groups of friends. This focus group was the only one within which there was an instance of behavioural issues which had to be addressed by the researcher. Specifically there was an instance of teasing (a younger girl was laughed at by three older girls) in one group where girls of differing ages from two separate groups of friends were incorporated into one focus group. This instance is notable in the research because it arguably highlights the importance of the composition of the focus groups, specifically when discussing sensitive topics. At school Rua, all the participating girls took part in one focus group interview. On arrival to school Rua it was found that a scheduling error had been made and girls' allocated focus group time was reduced to 45 minutes rather than 60 minutes as originally discussed.

Confidentiality was of great importance in the focus group study and it was explained to girls that they must keep all information shared in the focus groups confidential. At the beginning of each focus group the girls were given assent forms (see Appendix D) which outlined the terms of participation in the research including the girls' confidentiality and the purposes and uses of the data which would be gathered from the girls. An opportunity to ask questions was provided and, following this, the girls were invited to give assent to participate in the research. As part of the assent process, the girls were also asked to fill out a form identifying who they would be participating in the music video study with (or indicating that they would be participating alone) (see Appendix E). Following assent, the girls filled out an "About me" information sheet (Appendix F). On this sheet they answered general contact information (such as their home and email address) as well as demographic information about their ethnicity, their parents' jobs and their favourite activities. These sheets were kept for basic demographic information.

As well as filling out an "About me" information sheet at the beginning of each focus group, a group exercise was conducted in which, beginning with the researcher, each individual was asked to say their name and something interesting about themselves. This exercise was recorded and used for voice identification 
purposes for the researcher in the transcription phase of the research and was also undertaken to create group cohesion by encouraging each girl to speak. The researcher's participation in this activity through disclosing information about herself and listening to the girls' information addresses feminist and child research ethics in which it is important to attempt to balance the researcher/participant power relations (discussed in the ethical considerations in Chapter Four, p. 95-96, see also Wilkinson, 1988, 1998). Establishing comfort and group cohesiveness was an important task in the beginning of the focus groups. In order to address this, the researcher discussed the importance of respect and confidentiality within the groups with the girls. Finally, in an effort to increase the informality and comfort, the friendship groups were provided with a snack during the interviews.

\section{Transcription}

The focus groups were recorded on a Kingston audio recorder and transcription (for analysis) began immediately after the first focus group. Transcribing while conducting further interviews enabled a focus on topics across groups that were well-received (or not) and also allowed for topics which had been generated by the girls and of interest to one group to be introduced by the researcher in other groups.

All transcription was performed by the researcher and therefore understood as informing the first stages of thematic and discursive analysis. Having a background in conversation analysis was greatly beneficial in the transcription of the focus groups. A simplified version of Jefferson's (1985) transcription techniques were used in the transcription process. The focus groups were transcribed with the intent of providing a clear representation of what had been said and little emphasis was placed on irrelevant talk features or specifics such as minor intonation or pauses. Overlaps in the girls' speech were recorded to show the progression of the conversation. Brief descriptions of the transcription notation used in the extracts in Chapter Six are included where relevant. Following the importance of the confidentiality in the projects ethical considerations, each girl was given a pseudonym at the time of transcription which was used for the remainder of the data collection and analysis. All recorded and transcribed material from the focus groups was stored in a locked file and/or in password protected computer files. 


\section{Focus Group Analysis}

Thematic Analysis. The analytical process began with the thematic analysis of the data which broadly followed the procedures described by Braun and Clarke (2006) and involved four phases (some of which were repeated for further clarity of the themes). The first step of the thematic analysis involved becoming familiar with the data, a process that began with transcription which is recognised as an important familiarisation step in the thematising process (Braun \& Clarke, 2006). Following transcription, the transcripts for each focus group were read and re-read to continue the process of familiarisation. The reading and re-reading of the transcripts was an active process of recording ideas about the data set as a whole.

Following this, the next stage of thematic analysis involved the generation of initial codes within the data set as a whole. This was achieved through further 'active reading' of the transcripts and marking (on the transcripts) features of the data which were identified by the researcher as relevant, surprising, common, or interesting specifically in relation to the research questions. Each instance that was found was coded. At this stage of the analysis codes were both specific (e.g., the use of a word, eg., "flaunt”) and broad (eg., "girls' descriptions of music video storylines"). Coded words and phrases were highlighted and briefly described on the transcript where they occurred. During this process a list of all the codes found in the data was compiled. Following Braun and Clarke (2006) the search for themes firstly involved grouping the already identified codes based on their likeness to each other (such as instances which are about girls describing "knowing the celebrity" or girls talking about "clothing"). Secondly, the entire data set was re-read to check for any instances that might have been missed. In this stage of the analysis, individual codes were lifted from the original transcripts as an extract paragraph (each extract was assigned a name and a locational marker, e.g., "Girls describe Lady Gaga as "Crazy"- Tahi, Focus Group 3, p. 25" for future reference) and placed into individual digitalised documents for each theme.

As part of the process of bringing these initial themes together, the extracts within each theme were considered alongside each other whereby the ways in which each extract described the theme was examined (or if it did not, it was removed). The result of examining the themes in this way was that in many instances an extract was found to be 'weak' (meaning that it didn't describe the theme) or a theme was found to be unsubstantiated (which could describe a weak set of extracts, a lack of extracts 
or a lack of coherence between extracts). In the case of unsubstantiated themes, these were collapsed (and the extracts were reorganised into new or existing themes) or abandoned (e.g., the theme Knowing the Celebrity was collapsed and split into two sub-themes, Maturity and Celebrity Authenticity. The overarching theme Sexualised Clothing was split into Body Shame, Exposure and The Sexy Celebrity Body. These were later disbanded and Exposure extracts with other texts were incorporated into the Responsibility theme). This process was extremely important in coming to define the themes that were generated across the research and instrumental in beginning to explore the broader relationships between the themes across the project as a whole (Braun \& Clarke, 2006). Additionally, this process allowed for the first level themes to be refined and importantly defined as to specifically what each theme was describing. The process of theme refinement is extremely murky wherein themes which have been previously described as important might be later abandoned and reorganised as a different theme. Importantly, the notion of the themes 'strength', following Braun and Clarke (2006), is not dependent on a quantifiable 'significance'. Rather, the strength of a theme within thematic analysis is dependent on a multitude of factors including the prevalence of extracts on that theme (though there is no quantifiable number which makes a theme more significant), the pervasiveness of the theme across the data as a whole and also, the relevance of the theme in answering the research questions.

Thematic Outcomes. Thematic analysis identified a number of themes and sub-themes which as a whole described the data set. Across the themes instances of overlap were seen, for example Role Modelling and Celebrity Influence, Responsibility, and Exposure included examples of extract overlap. However, Braun and Clarke (2006) highlight that homogeneity across thematic maps is expected and these overlaps were not concerning as the thematic analysis was a precursor to discourse analysis of the data. The first of the themes found through this process was, Knowing the Celebrity, which incorporated texts that emphasised the girls' relationships with female pop music celebrities, the girls' knowing the 'real' celebrity, and particular emphasis on celebrity authenticity (see Chapter Six, Extract Two, p. 115). The second theme, Exposure, dominated the data cohort as a whole (being highly prevalent), it incorporated discussions of celebrity body exposure, sexualised clothing and hypersexual behaviour all of which was framed within differing critiques 
of such representations. The third theme, Role Modelling and Celebrity Influence, incorporated girls' discussions of celebrities as influential to girls, including through their clothing choices, product consumption and behaviour. The final theme, Responsibility, (closely related to Role Modelling and Celebrity Influence), incorporated discussions of girls as consumers of sexualised content, it included girls' media viewing practices and discussions of danger and risky outcomes in the case of irresponsible media use and celebrity emulation (e.g., see Chapter Six, Extract Nine, p.135-136) and also girls' uncomfortable media consumption (e.g., see Chapter Six, Extract Ten, p.137).

Discourse Analysis. The methodological assumptions that underpin the discursive analysis undertaken in this thesis have been addressed in Chapter Four. The process of discursive analysis focused on the previously identified themes as a starting point and was informed by recommendations within feminist poststructuralist literature (Burr, 2003; Gavey, 1987; Weedon, 1997; Willig, 2001). The data, which had been organised into thematic categories, was addressed from a 'top down' discursive approach which broadly pays attention to social processes, the construction of knowledge and discursive practices that the participants used in their shared meaning making (Edley \& Wetherell, 1997). Undertaking discourse analysis of the focus group material from a feminist poststructuralist approach to knowledge involved paying attention to the gendered constructions that girls used in describing their navigation of pop music media. In particular, this involved noticing girls' descriptions of the ways in which they navigated/made meaning of hypersexual pop music media and how these consumption practices and meanings could be related (or not) to girls repeated positioning within hegemonic problematic girlhood discourses. Discourse analysis, then, enabled an approach to the girls' focus group data which explored the ways in which girls were positioned by discourses such as the sexualisation of girls or postfeminist femininity discourses and also paid attention to the girls' navigation of these discourses through their talk.

The process of discourse analysis reflects many of the same stages that were described in the thematic analysis section above. The work began with the process of becoming familiar with the data (achieved primarily through the thematic analysis process). Next, coding, note-taking and comparative reading (across themes, extracts and relevant literature) took place in order to build narratives and readings of the data 
drawn on in this thesis. Central to the process of discourse analysis is 'active' reading of the texts which Willig describes as "reading for action orientation (what is this text doing?) rather than simply reading for meaning (what is this text saying?)" (2001, p. 93).

The following chapter presents the analytical work produced from the focus group study. The organisation of the discursive analyses is split into broad sections which draw on the thematic outcomes described above. The first section The Real Celebrity draws on material from the Knowing the Celebrity and Exposure themes. The discursive analyses in this analysis section focuses on girls' constructions of hypersexual celebrity. The second section, Girls' Negotiation of Consumer Subjectivities in Sexualised Pop Music Media, draws of material from the Role Modelling and Celebrity Influence and Responsibility themes. This analysis section focuses on girls' negotiation of sexualisation discourses. Specifically, this section explores the subjectivity work that is performed by girls in their self-positioning as consumers of hypersexualised pop music media. 


\section{Chapter Six:}

\section{Girls Negotiating Female Pop Music Media: Construction and Consumption}

Postfeminist pop music media (lyrics, videos, and celebrity identities) were identified as ubiquitous in the girls' talk about their everyday lives. Girls described their engagement with popular music from perspectives of both pleasure and discomfort. Across the focus groups, girls presented themselves as savvy media consumers, confidently discussing the highest trending songs, female music celebrities and intricate details of popular music videos. Female pop music media influenced the girls' fashion, stylisation, and consumer choices and also forged an important bond between them as they watched music videos together or shared music files via cell phones, email files and social media platforms. The purpose of this chapter is to show how these girls engaged with postfeminist music media, their relationships with the artists/celebrities, and the ways in which they negotiated and made sense of the contemporary discourses of femininity within postfeminist music media which were explored in Chapter Two of the thesis.

Analysis of girls' talk in the chapter is organised around three key aspects of the study's findings. These are; i) the ways that girls constructed hypersexual celebrities and representations within pop music media through an acceptable/unacceptable binary using discourses of authenticity and maturity; ii) the ways that girls positioned themselves and others in relation to female pop music media and artists drawing particularly on discourses of the sexually knowing, responsible consumer and; iii) how girls' self-positioning as capable consumers was mediated through the sexualisation of girls discourse in the context of parental surveillance. Taken together, the analyses of girls' talk about female pop music media in this chapter shows girls' media consumption to be a complexly negotiated process encompassing both moments of rupture and appropriation of problematic sexualisation discourses.

\section{Constructing the 'Real' Celebrity}

The analyses in this section explore the ways that the girls in this study constructed acceptable and unacceptable representations of femininity in female pop music media. The girls used an acceptable/unacceptable binary in their decision to engage with or 'like' an artist and, simultaneously, in doing so, to construct 
themselves as critical media consumers capable of identifying 'harmful' media. Girls employed two discourses: an authenticity discourse which referenced the 'realness' of sexualised representations and a maturity discourse in which the age of the celebrity was salient to acceptable sexual representation. These constructions will now be discussed.

Authenticity. Giddens (1991) describes the idea of crafting an individual and self-possessed identity as central to the reflexive project of the self in modernity. Authenticity or "being true to oneself" is at the centre of the project of self-knowledge where coming to know ones true's self through a myriad of self-actualising process has become a mandatory process (Giddens, 1991, p. 78). Giddens's asserts that in modern culture, authenticity and discovering and coveting a true self, has become a key mode through which notions of the authentic and idealised celebrity becomes knowable to the celebrity audience (Giddens, 1991; Rojek, 2001).

Kennedy (2014) discusses the pervasive use of discourses of authenticity and 'being true to yourself' within tween girls popular culture. In particular she demonstrates the ways in which The Hannah Montana Show strategically adopts an authenticity discourse wherein the shows storylines repeatedly link back to the character Miley Cyrus learning to connect with and maintain a 'true' sense of self in the process of growing up. Kennedy observes more broadly that "tween popular culture is heavily invested in authenticity and selfhood, and it claims that an authentic self (which exists inherently within the girl) needs to be revealed and maintained if the tween is to successfully become appropriately feminine" (2014, p. 230). Aligning with Kennedy's claim, studies with girls have found authenticity to be a key aspect of their talk about celebrity. For example, Duits and Van Romondt Vis (2009) found that girls identified authenticity as a key factor to achieving fame. Girls in their study constructed authenticity as signifying a "fit between person and image" (p. 53). Similarly, in her research about girls' understandings of female celebrity sexual representation, Zaslow (2009) identified consistency as an important marker of celebrity authenticity for girls. In addition, girls in Zaslow's study described change (particularly from little to overt sexual representation) as a sign of an inauthentic and manufactured celebrity identity.

In the current study, authenticity was fundamental to girls' engagement with female pop music artists, and consistency was a key feature through which girls 
constructed and judged celebrity authenticity. Specifically, girls understood the common trajectory of increasing 'sexualised' representation during a female pop celebrity's career as change and therefore a sign of inauthentic identity. On the other hand, girls judged celebrities with a consistent hypersexual image as authentic. Girls also used individuality as a measure of celebrity authenticity. For the girls, 'being yourself', exhibiting 'true' artistic expression, being original and unique were understood as indications of celebrity authenticity. In the focus groups the girls described 'being yourself' as requiring consistency between the public (performance identity) and private persona of an artist (personal identity). As with sexual representations, such consistency was critical to girls' engagement with, and 'liking' of, an artist. The girls constructed being original as a celebrity's expression of their inherent, natural, self. Additionally, girls constructed celebrities doing what they want to do as authentic. However, the notion of authenticity was primarily constructed through celebrity dress, specifically body-exposing styles. In the case of body exposure, girls deemed celebrities to be authentic provided that their representation was understood as consistent with what the girls perceive to be the artist's true self. In the following extract, the girls describe how they would feel about a hypothetical 'change' (an idea introduced by the researcher) in the performances of artist Katy Perry. Katy Perry is as well-known for the sexualised lyrics in songs such as "I Kissed a Girl (and I liked it)" (Perry, 2008), as she is for her outfits which fuse girlish candy colours with hypersexual, body-exposing styles. Earlier in the discussion, Perry had been identified by the girls as an artist whose representation can be "a bit inappropriate" (meaning hypersexual).

S:

Isabella: $\quad$ - It wouldn't be as interesting

S: $\quad$ Because Katy Perry's music videos are always so bright and colourful and exciting aren't they?

Group: $\quad$ Yeaah

Sophie: If she changed I wouldn't listen (Group: *laughter*) to be honest but that's just me

Isabella: I would think like she's not exposing herself enough or - or she's not she not being who she is 
[Extract 1: Tahi School, mixed ethnicity group of 7 girls. (Transcription notes: S represents the researcher throughout the extracts in this chapter. Bracketed and italicised text represents background talk or laughing.]

In the extract above the hypothetical change to a less hypersexual performance identity for Katy Perry is met with Sophie's denunciation, "if she changed I wouldn't listen". Girls' strong disapproval and resistance to change is consistent with Duits and Romondt Vis (2009) finding that, for the girls in their study, "radical style changes are [also] unacceptable and evoke guaranteed disapproval. Personality and performance of self are not to be changed overnight" (p. 53). Isabella's assertion that, "I would think like she's not exposing herself enough or - or she's not being who she is" orients to the celebrity body as a key site for the production and performance of identity (Holmes \& Redmond, 2006; Rojek, 2001). Following Isabelle's comment, inconsistency between Perry's performance identity and her (perceived) 'true' hypersexual self is considered a sign of an inauthentic identity. Rather than something to be changed or shunned however, the girls in this extract construct Katy Perry's hypersexual stylisation and displays as evidence of authenticity and key to their engagement with her music.

Throughout the focus groups girls most often discussed authentic celebrity identity in relation to Lady Gaga. Gaga's attempts at avant-garde styling (she wore a dress made entirely out of raw beef to the 2010 MTV awards, see Mapes, 2010) and performances (she performed her hit song "Paparazzi" at the American Video Music Award show the previous year which ended with her faking her own death in a pool of blood, see Kaufman, 2009) have led her to be well known for her music and for creating a spectacle. Lady Gaga has received much attention from feminist scholars and critics (see Geerts, 2013, Halberstam, 2012; Paglia, 2010) for her attempts at deconstructing traditional notions of femininity and female attractiveness. For example, her outlandish costumes and music video depictions such as her "Alejandro" video (Gaga, 2010) where she performs as a BDSM styled nun and "Judus" video (Gaga, 2011c) which Geerts (2013) describes as "destabiliz[ing] the whorish connotations that are attached to the Maria Magdalene character [Gaga] plays in the video (...) by transforming her into a tough biker chick" (p. 4). At the same time Gaga has been inconsistent in her self-representation. Alongside Gaga's potentially gender destabilising performances she has also asserted that she is not a feminist and celebrates American hyper-masculinity (Geerts, 2013; Paglia, 2010). Despite a 
number of her performances publicising marginalised identities (for example her gender bending performance as Jo Calderone, her male alter ego, at the 2011 American Video Music Awards, Eduardo, 2012), Gaga's denunciation of feminism has resulted in many feminist scholars taking issue with her inconsistent persona (Geerts, 2013; Paglia, 2010). The girls in the following extract, however, describe Gaga as an example of being and doing who she is through her dress.

Grace: I thin- you have to get to know - I think you have to get to know the artist like really well and like like them and - and then I think it's ok for them to change like- like go in a direction they want because if you like really like them (Group: $\mathrm{mmm}$ ) then you would let them do that (Group: yeah) whereas sometimes they change too early or at the wrong time and that's just yeah (Group: yeah)

S: $\quad$ How do you get to know the artist?

Group: $\quad$ Through their music/videos

S: $\quad$ Through the music you feel it's like you kind of get to know them a little bit?

Grace: $\quad$ Yeah like if Lady Gaga like - when I saw some of her videos I thought you know well ok it looks like she's just being herself I mean (Group: $\mathrm{mmm}$ )

Sophie: $\quad$ At first I thought Lady Gaga was crazy

Isabella: $\quad$ Like they're kind of like -

Charlotte: Like with her first CD like with the "Just Dance" and "Poker Face" and all that like she's still pretty crazy and stuff

Sophie: $\quad$ She's kind of like a bad girl

Brooke: $\quad$ Mmm but she still seems like herself though

Isabella: $\quad$ But she hasn't changed

Grace: $\quad$ She just like kind of $\underline{\text { is who she is }}$

Isabella: $\quad$ She didn't start off being good to get the attention and then start going crazy but I mean she started off who she was and she's still who she is

Charlotte: $\quad$ Yeah she was never a good girl like -

[Extract 2: Tahi School, mixed ethnicity group of 7 girls. Transcription note: Underlined text represents vocal stress/emphasis.]

The girls in this extract construct themselves as knowing media consumers, capable of identifying and judging an artist's 'true' identity. Grace's assertion that you can "get to know the artist like really well" can be understood not only as 
constructing this knowing subjectivity, but also speaks to the closeness that is felt by girls to their favourite artists. Girls' identification of the music video as a key mode of celebrity consumption and the development of a 'relationship' with celebrities is consistent with Rojek's (2001) suggestion that advances in communications technologies (such as social media platforms and interactive media websites) have increased the exposure and illusory availability of celebrities. Furthermore, Rojek asserts that these increases in celebrity exposure create a heightened sense of closeness between the celebrity and fans (2001). The increased possibilities for the girls' visual connection with contemporary celebrities and their music media can be inferred to create a sense of uniqueness and intimacy in their consumption (Holmes \& Redmond, 2006). With respect to the intimacy of video format viewing Redmond (2006), for example, points out that "when shot in close-up, for example, it is as if the star is looking at you, into your eyes, and when he smiles he is smiling at and for you" (p. 37, italics in original). Rojek (2001) identifies this celebrity/fan intimacy as inherently flawed, and a form of commodified desire through its lack of face-to-face contact. However, Redmond (2006) argues that these relationships are "as 'real' as anything", producing "surplus emotionality that cannot be easily channelled or 'sucked up' by capitalism” (p. 38).

In the extract, Grace constructs knowing and liking the artist as a factor which can make changes in celebrity representation acceptable. She explains that once you get to know the artist really well and come to like them "it's ok for them to change like - like go in a direction they want". In this way, changes in celebrity identity, including an increase in sexualised representation, may still be read by the girls as authentic provided that the changed identity is perceived as an agentic expression of the celebrity's 'true' self. Additionally, Grace's assertion that celebrity identity changes need to be going in the direction "they want" draws attention to the importance of celebrity performance identity mirroring the private persona or the 'true' self of the celebrity rather than a manufactured identity built with the purpose of attracting fans and making money.

Many of the girls in Extract Two use the notion of a true self and consistency across time in judging the authenticity of Lady Gaga. For example, Isabella's comment, "she started off who she was and she still is who she is" might be interpreted as her judging the controversial and hypersexual performances of Lady Gaga as authentic due to the consistency and expression of Gaga's (perceived) 'true' 
self. In addition, discussing Lady Gaga, Charlotte and Sophie deploy the term "crazy" to describe Gaga's performance identity. Two of Lady Gaga's early singles, "Just Dance" and "Poker Face", are identified by Charlotte as being "pretty crazy and stuff'. The singles, from the album The Fame mark Gaga's first major appearance on the pop music scene in 2008. Both songs and their corresponding music videos incorporate ideas of partying, excessive alcohol consumption, "I love this record baby but I can't see straight anymore” (Just Dance, see Gaga, 2009) and (hetero) hypersexuality, "I'll get him hot, show him what I've got" (Poker Face, see Gaga, 2009b). "The Just Dance” music video depicts a house party in which Gaga dances around intoxicated young people. The video has some key hypersexual elements, including an up-close shot of Gaga suggestively licking her finger to the lyrics, "wish I could shut my playboy mouth" and repeated cross cuts to one scene showing Gaga in a paddling pool with two men draped across her and another where she is straddling a blow-up whale. "Poker Face", which followed the release of "Just Dance", has been described in the media and by Gaga herself, as promoting ideas of bisexuality and women engaging in 'cock teasing', an insulting slang term used to describe an individual who behaves sexually to provoke sexual interest from men without intending to engage sexually with them.

One interpretation of the girls' assertion of Gaga as "crazy" might be approached as a description/reflection of the hypersexuality which has been incorporated into Gaga's performance identity consistently throughout her career. Isabella's comment about Lady Gaga, "she didn't start off being good to get the attention and then start going crazy", reflects the idea of this hypersexual consistency as a marker of Gaga's authenticity, as discussed by girls in regards to Katy Perry in Extract One (p. 115-116). Similarly, Sophie labels Gaga as "kind of like a bad girl" which, like "crazy", signals the representation of hypersexuality in Lady Gaga's performance identity. One reading of Sophie's employment of the term "bad girl" and Charlotte's reference to the "good girl" (both as descriptions of Gaga) could be the girls' employment of the good/bad girl binary which has been described by Griffin (2004, 2004b) as regulating contemporary girlhood (see Chapter Three, p. 58-59).

Although the girls in this extract describe Lady Gaga as "crazy" and a "bad girl", her hypersexual image is simultaneously constructed as acceptable. Brooke's response to the assertion that Lady Gaga is a bad girl, "mm but she still seems like herself though" constructs hypersexuality or "bad" girl-ness as acceptable provided 
that this representation is perceived as reflecting the artist's true identity. The girls' talk following Brooke's comment reinforces the idea of "bad" girl-ness as acceptable for Lady Gaga because, "she hasn't changed” (Isabella), "she just kind of is who she is" (Grace) and "yeah she was never a good girl" (Charlotte).

The girls in the following extract also construct Lady Gaga as having an authentic celebrity identity. The song and music video being discussed, "Born This Way" have been described by Gaga as a celebration of LGBT sexualities (Gaga, 2011b). The girls in this extract, however, make no reference to the LGBT community. Instead, they understand the lyrics as touting authenticity. In the video, Lady Gaga is seen singing and dancing in leather lingerie. Gaga is also wearing multiple face-and-body altering prosthetics adding to the notion of individuality and being "born this way". Flesh coloured cheek and brow prosthetic horns give Gaga's face a reptilian or alien aesthetic. Prosthetic horns on her shoulders also give her body a sharp and angular outline. Ironically, while her face and shoulder bones are visually outlandish, the rest of her body, from her long blonde hair to her pert breasts, toned abdomen and legs, conform to contemporary postfeminist ideals of female beauty discussed in Chapter Two (p. 34- 40, see also Gill, 2007c).

S: [What's it about - what's] "Born This Way" about?

Marissa: [I think its "Born This W]ay" um being like [ ( ??? ) being t]he way you are

Nicole: [It's just like being yourself] yeah that was [kind of like m]y point because she wears what she wants because she's happy with who she is

Courtney: $\quad$ Yeah and she says like -

Nicole: $\quad$ Cause you were Born This Way so just -

Courtney: $\quad$ Stay that way

Alexis: $\quad$ And I think like -

Marissa: $\quad$ Be happy

[Extract 3: Tahi School, mixed ethnicity group of 4 girls. Transcription notes: Bracketed question marks represent talk that was unclear in the focus group recording. Square bracketed text represents an overlap (simultaneous) in talk.]

Marissa understands "Born This Way" as being about authenticity, in her words, "like being the way you are". Nicole's assertion that Lady Gaga, "wears what she wants because she's happy with who she is", highlights the construction of 
authenticity as existing through the celebrity body. Her comment aligns with Holmes and Redmond's (2006) explanation that within contemporary popular culture there is a growing detraction from the celebrity face and increasingly the body has become central to the representation and consumption of celebrity.

Nicole's construction of Lady Gaga's body as a source and sign of happiness emphasises one of the central elements of Gill's (2007c) theorisation of the postfeminist sensibility (unpacked in Chapter Two, p. 34- 40). Gill argues that the possession and ownership of a toned and sculpted body has become the marker of new successful femininity (2007c). In the above extract, the wearing of revealing clothing legitimates Lady Gaga as someone who is happy with who she is. For the girls, Gaga's exposure of her slim body functions as an expression of Gaga's (presumably fit and healthy) inner self (Gill, 2007c). Within postfeminist discourse, the relentlessly self-monitored and self-regulated female body, such as the body of Lady Gaga in the "Born This Way" video, has come to signify a pathway to becoming happy and healthy.

Moreover, achieving ideal femininity within the postfeminist sensibility involves a mandatory disavowal of the (often painful) process of self-discipline and regulation (Gill 2007, 2007c; McRobbie 2008, 2009). In addition to the prosthetics which Gaga wears in the "Born This Way" music video (which she was obviously not born with), Gaga's body is extremely thin and toned. One possible reading of Gaga's proclamation of being "born this way", an assertion which sits in stark contrast to Gaga's obviously highly disciplined body in the music video, is through the notion of the postfeminist disavowal (of self-discipline and regulation). While the idea of selfacceptance within the lyrics of the song seem like a positive message for the girls, it's hard to ignore the potential reading of irony in the idea of loving a highly disciplined body because it was "born this way". In this sense the idea of being happy with your 'natural' 'inner self' is contradictory and constructs the notion that some bodies (that are disciplined) are a source and reflection of happiness, while others are not.

Maturity. Maturity is another element that the girls used to judge the authenticity of hypersexual celebrity representation. The girls employed strict boundaries of age and (perceived) experience in judging the appropriateness and authenticity of sexualised celebrity representations. The maturity discourse is closely tied to the notion of change, and was employed particularly in relation to artists that 
the girls feel have become (or become more) sexualised at an age deemed outside of what the girls perceived to be 'old enough' to behave sexually. On the one hand, the girls constructed hypersexuality outside of maturity (celebrities being too young) as unacceptable, but on the other hand, they constructed the hypersexual representation of artists that they deemed to be mature as acceptable, authentic and a reflection of the artists 'true self'.

P!nk (Alicia Moore), aged 32 at the time of the focus groups, is a longstanding pop artist who was introduced (by the researcher) to the girls as a 'bad girl'. P!nk is widely regarded as an important pop music artist whose vocal talent and daring style changed the "cookie cutter" image of female pop music in the early 2000's ("Pink is always going to do things her way", 2015). P!nk's public image fuses a tough tomboy look with feminine styles of dress and music seen for example in her single "U +Ur Hand" (P!nk, 2009). The girls in the extract below construct P!nk's celebrity representation as acceptable and authentic not only because of the consistency of her 'bad' girl image but also because of her (adult) age.

S: Do you guys listen to P!nk? (Group: yes) (Emily: $\mathrm{mmm}$ )

Lucy: She's my favourite artist

S: $\quad$ What do you guys think about P!nk because she's a - a bit of a bad girl

Group: $\quad$ Yeah

Charlotte: Yeah but -

S: $\quad$ She's not like a Taylor Swift type girl?

Emily/Sophie: [No definitely not]

Charlotte: [But she can be b]ecause she's like old enough (Group agreement: $\mathrm{mmm}$ ) and like and she's - she's been doing the music thing for a long time so everyone just kind of knows her (Lucy: yeah)

Group: $\quad$ Yeah

S: $\quad$ So like cause she's older its fine that she's doing that stuff?

Charlotte: $\quad$ Yip

Sophie: [I mean it's not fine*whisper*]

Isabella: [But she talks more ab]out (.) um 


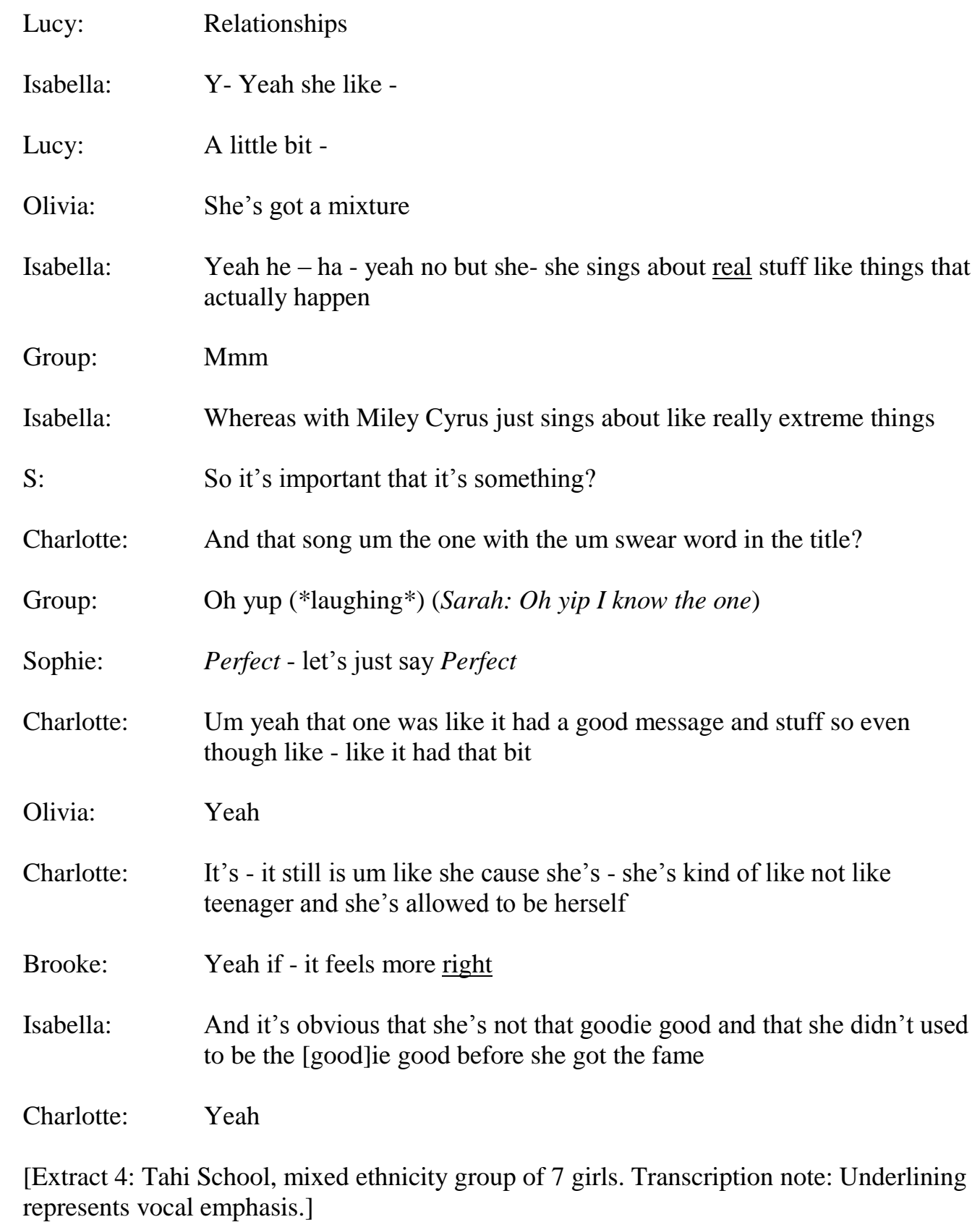

One approach to the assertion that P!nk is "like old enough" to have a more sexualised representation is that the girls are using age to construct hypersexual celebrity representation as acceptable. P!nk's age is central to the girls' construction of her representation and song lyrics as grounded in authenticity, despite the fact that they cannot know the true background of the singer's song production. The notion of the 'true' artist being revealed to the girls through music and representation can also be seen in this extract in Isabella's claim that P!nk "sings about real stuff like things that actually happen". Brown (2012) discusses the commodification of 'truth' or authenticity in contemporary pop artists' lyrical content. She asserts that, "the notion that a musician is relaying her 'true self' through her lyrics is one that carries a strong 
affective pull for fans, and thus carries a great deal of commercial significance" ( $p$. 166). In line with Brown's assertion, girls in this extract use ideas of lyrical 'truth' to construct $\mathrm{P}$ !nk as an authentic celebrity.

The girls' comparisons of P!nk's 'real' lyrics to younger singer Miley Cyrus who "just sings about like really extreme things" re-emphasises how the girls use maturity to construct acceptable vs. unacceptable sexualised celebrity representation. The maturity discourse in this extract can be read as constructing a binary which demarcates P!nk's mature sexual representation as legitimate and Cyrus's immature sexual representation as illegitimate. The construction of a maturity discourse in girls' celebrity critique might also be understood as aligning with a childhood innocence discourse. For example, one possible reading of Charlotte's assertion that P!nk is, "not like teenager and she's allowed to be herself" is as the mobilisation of a childhood innocence discourse. Within this discourse, which is almost exclusively applied to girls, all forms of girlhood sexuality and expression are considered dangerous and illegitimate (see Buckingham \& Bragg, 2003, 2004; Egan, 2013; Egan \& Hawkes, 2008, 2008b; Walkerdine 1998). The girls in this extract might be understood as deploying this discourse in their construction of P!nk as "allowed" to have a more sexualised expression due to her being outside of childhood. Cyrus on the other hand, is constructed by the girls as within childhood (too young) which, consistent with a childhood innocence discourse, positions her expressions of sexuality as illegitimate and unacceptable. The strength and common sense status of the childhood innocence discourse can arguably be seen in Brooke's agreement that, "Yeah if - it feels more right" for P!nk to have a sexualised representation rather than Cyrus.

Miley Cyrus was of particular concern for the girls in regards to celebrity acceptability and was identified as having an unacceptable and inappropriate hypersexual representation in every focus group in this project. Specifically, when Cyrus was discussed, girls repeatedly constructed her as inauthentic due to a change in her image (from innocent to hypersexual) which, despite the artist being twenty years old at the time of the focus groups, was constructed by the girls as occurring during childhood. As the following extract shows, Cyrus's 'change' from an innocent Disney "GIRL" (see Extract Five below) to a hypersexualised adult woman was identified by the girls as particularly negative, leading many of them to reject her as a role model and discontinue engaging with the media she produces. 
S:

Do you guys listen to Miley Cyrus?

Group: Noooo!

All: $\quad$ I don't like her

S: $\quad$ Why don't you like her?

Olivia: $\quad$ She's too like really slutty (Group: yeah *laughing*)

S: $\quad$ What like - what do you mean by that?

Brooke: $\quad$ She used to be like -

Grace: $\quad$ Like Can't Be Tamed

Brooke: $\quad$ Really nice but her -

Sophie: $\quad$ Like this sweet little girl

Olivia: $\quad$ But her video like Can't Be Tamed like that's when that's when I didn't li- like I really used to look up to (Group: yeah) her -

Isabella: $\quad$ And she acts older than what she is

Grace: $\quad$ I used to look up to her

Olivia: $\quad$ And I saw that video and I just don't like her anymore

S: $\quad$ She acts older than she is like wha- what's -

Isabella: I dunno if she was say twenty five-ish I would say oh yeah that's cool but she's not and so it's- it's like what are you doing that for?

S: $\quad$ You think that's important that girls act their age?

Olivia: $\quad$ She's not being herself

[Extract 5: Tahi School, mixed ethnicity group of 7 girls.]

Olivia describes the "Can't Be Tamed" video as a point in which a change in the identity of Cyrus was seen (Olivia: but her video like "Can't Be Tamed" like that's when that's when I didn't li- like I really used to look up to (Group: yeah)). Prior to the release of this song and music video, Miley Cyrus had been known as the wholesome young heroine Hannah Montana performing in the extremely successful children's musical comedy The Hannah Montana Show on the Disney Channel. In the show, Cyrus played Miley Stewart, a teenager living a double life as schoolgirl by day and famous recording artist Hannah Montana by night. At the age of 17 after finishing with The Hannah Montana Show, Cyrus released her first independent album in 2010 Can't Be Tamed. 
The "Can't Be Tamed" music video begins with Cyrus (aged 17 at the time) wearing a black leather leotard and heavy makeup, 'trapped' inside a huge bird cage while spectators flock around her and take pictures (Cyrus, 2010). The video continues as Cyrus escapes from the cage and runs wild through a museum with her backup dancers. It shows multiple jump cuts to Cyrus wearing a peacock-inspired bodice, lying on the ground and staring up at the camera singing. The song reproduces ideas of uncontrollable female (hetero) sexuality and postfeminist notions of female power achieved through sexual subjectification with lyrics such as, "I go through guys like money" and "If you try to hold me back I might explode". While far from the hypersexuality seen in other artists' videos (for example Gaga's "Just Dance" and "Poker Face" videos, Gaga, 2009, 2009b described previously), for the girls, "Can't Be Tamed" is evidence of a significant shift in identity for Cyrus from someone to look up to, to someone who is "kind of slutty".

Olivia's description of Miley Cyrus as a slut and the unanimous agreement from the rest of the group shows that the girls find Cyrus's identity change unacceptable. In line with Jackson and Vares (2011) the girls' use of the word "slutty" in their construction of Miley Cyrus can possibly be understood as regulation of the hypersexualised femininity that Cyrus performed in the "Can't Be Tamed video" and has since continued throughout her career. The girls' focus on Miley's age in relation to her hypersexual performance (see the previous extract) might also be understood within the context of a contemporary culture within which there has been an increase in the surveillance and regulation of girl's sexual behaviour mobilised specifically through sexualisation moral panics (Egan, 2013; Egan \& Hawkes, 2010). In Extract Five the girls' use of a maturity discourse when judging Miley Cyrus as unacceptable mirrors the focus on age-appropriate sexual behaviour in girls seen in contemporary sexualisation moral panics (Ringrose \& Renold, 2011).

Brooke and Sophie's description of Cyrus as previously a "really nice" (Brooke), "sweet little girl" (Sophie) highlights the change seen in the performance identity of Miley Cyrus. Sophie's identification of Cyrus as a "girl” positions Cyrus as outside of the maturity discourse, underlining her sexual representation as unacceptable. These ideas are implicit in notions of Cyrus's change from a "sweet little girl" to Isabella's explanation of Cyrus's performance (in "Can't Be Tamed") as "really slutty", a change which the girls construct as inappropriate due to the singer's age. Isabella explains that Cyrus's sexualised representation is unacceptable because 
"she acts older than she is". Interestingly Isabella's insistence "if she was say twenty five - ish I would say 'oh yeah that's cool" introduces the idea of a definitive age boundary of acceptable hypersexual representation for artists (such as P!nk, see Extract Four, p. 123) who are understood as adult. Furthermore, Isabella's assertion which follows, "but she's not and so it's- it's like what are you doing that for?" constructs Cyrus's sexuality as not only unacceptable but also as inauthentic and potentially manufactured.

This section of the chapter illustrates the ways in which girls understood and constructed female pop music celebrity through the discourses of authenticity and maturity that dichotomously categorised hypersexual representation as acceptable or unacceptable.

\section{Negotiating Pop Music Consumption}

The chapter now moves from girls' constructions of hypersexual representations in pop music, to the ways in which girls' positioned themselves through agentic consumer discourses. Girls' negotiation of hypersexual pop music representations and celebrities was repeatedly discussed in relation to girls' selfpositioning as sexually knowing and responsible media consumers. Underpinning girls' self-positioning within these agentic consumer subjectivities (which will be discussed below) was a construction of pop music celebrities as influential role models for girl audiences. The notion of celebrity influence was discussed by girls as leading to potentially dangerous and risky outcomes for 'other' girls. The girls' selfpositioning within these consumer subjectivities is therefore seen alongside their positioning of 'other' girls as at risk of influence by the same hypersexual media and celebrity representations.

The sexually knowing consumer. As discussed earlier in the thesis, a sexualisation of girls discourse positions girls as at risk of precocious sexualisation through the internalisation of hypersexualised femininity representations in popular culture (for example, Hamilton, 2009; Levin \& Kilbourne, 2008; Oppliger, 2008, discussed in Chapter Two, p. 50-54). Mainstream media and psychological literature repeatedly construct girls as passively mimicking female celebrities, particularly in reference to the hypersexual displays that saturate contemporary pop music media. Girls' supposed emulation of hypersexual behaviour is problematised within this 
literature and regularly constructed as causing an endless number of negative outcomes for girls (Durham, 2009; Papadopoulos, 2010).

Aligning with notions of influential pop stars and influenced girls, discussions concerning female pop stars as role models took place in every focus group throughout the project. Given the wide circulation and repetition of the sexualisation of girls discourse within academic literature and mainstream media publications, it was not surprising that girls regularly employed this discourse in their own talk and understanding of pop music consumption. Girls repeatedly constructed celebrities through the binary of a 'good' or 'bad' role model. They described celebrities who engaged in hypersexual displays as "inappropriate" and as bad role models whereas those who did not perform in such ways were considered good role models. Of particular interest to the girls were celebrities who were identified as 'bad' role models due to their 'unacceptable' hypersexual representation (see the analyses of Extracts Four and Five in the previous section, p. 122-125). Importantly, throughout the focus groups, all discussion of role modelling and celebrity influence was predicated on the girls' repeated assertions that they themselves were not influenced by such role models/representations. In the following extract the girls discuss the role model potential of artists Lady Gaga and Katy Perry and explain the artists' sometimes 'inappropriate' representations.

Brooke: I think it's cool that she's [Lady Gaga] original but like she might have to go in a different way because I agree that some things are quite inappropriate (Group: yeah) like a little bit ehh -

Charlotte: Same with Katy Perry I think she's a bit, she's really good but she's it's inappropriate

Olivia: It's inappropriate sometimes

S: $\quad$ What do you mean by inappropriate?

Isabella: $\quad$ Well like clothing -

Grace: $\quad$ Showing too much maybe - I don't know well I mean I dunno cause -

Sophie: $\quad$ You don't really concentrate on that you more concentrate on the music (Charlotte: yeah) rather than what they're wearing

Charlotte: $\quad$ Yeah I don't really mind about that (Group: yeah) cause it's kind of like everywhere these days and you're going to get exposed to it anyway

[Extract 6: Tahi School, mixed ethnicity group of 7 girls.] 
In the extract Brooke highlights Lady Gaga's originality as "cool” but explains that Gaga might have to change (be less hypersexual) because "some things are quite inappropriate" with which the whole group agrees. Charlotte also uses the notion of "inappropriate" to describe the hypersexual representation of Katy Perry. When asked what inappropriate means Isabella identifies clothing and Grace asserts that "showing too much" is what makes these celebrities inappropriate. One way of reading the girls' use of "inappropriate" is that it constructs them within a mature and sexually knowing consumer subjectivity. At the same time, girls' description of artists as inappropriate mobilises a widely accessible moral discourse which reproduces contemporary fears about the effects and influence that sexualised pop music media may have on young girls (Egan \& Hawkes, 2007, 2008, 2008b, 2012; Jackson \& Vares, 2015b; Renold, 2005; Renold \& Ringrose, 2013).

Although this media is described as inappropriate, Sophie's statement "you more concentrate on the music rather than what they are wearing" might be read as distancing Sophie from a passive and easily influenced girl subjectivity, constructing her instead as capable consumer who is knowing about the 'dangers' of sexualised media influence. Sophie's assertion that "you concentrate on the music" rather than the hypersexual representations might also be read as disrupting contemporary sexualisation discourses which present girls as strongly driven to copy the visual elements of hypersexual culture. Charlotte's statement that she doesn't "really mind about that [sexualised media] it's kind of like everywhere these days and you're going to get exposed to it anyway" might also be read as aligning with the knowing consumer subjectivity. Although Charlotte initially describes hypersexual media (specifically Katy Perry's hypersexual representation) as "inappropriate" in her first comment, her subsequent description of exposure to sexualised material as inevitable and ubiquitous might be read as her self-positioning (similarly to Sophie) as a knowing media consumer in a sexually saturated media culture.

Whereas Gaga and Perry's body exposure was deemed inappropriate but not a concern to the girls in Extract Six, Miley Cyrus received considerably harsher treatment by the girls in regards to her hypersexual representation and particularly her role model status. As discussed in the previous section, Cyrus was described as unacceptable and inauthentic in her hypersexual representations following her departure from the Hannah Montana character. Aligning with the project wide disapproval of Cyrus's hypersexual media representations, the artist was also 
discussed repeatedly as an example of a bad role model. The following extract presents some of this discussion (and follows on from the girls' previous discussion of Cyrus in Extract Five, p. 125). Importantly, rather than refocus on Cyrus, the inclusion of this extract serves to demonstrate the girls' use of the role model discourse and specifically their discussion of the potential 'effects' (a term introduced by the research) of bad role models on a girl audience. The girls discuss bad role models as having negative consequences on girls who consume such media. Girls' use of the role model discourse may also be read as a further positioning of themselves as sexually knowing consumers who are aware of the 'dangers' of sexualised influence for girls.

Marissa: $\quad$ Like Miley Cyrus she's like Hannah Montana she's like a role model but like -

Nicole/Alexis: Yeah

Marissa: $\quad$ When she turns into Miley Cyrus

Jennie: $\quad$ But now she's kind of all -

Alexis: $\quad$ Yeah

Courtney: So many kids look up to her and then she goes and does all those things

Nicole: $\quad$ She was in like rehab I think

Marissa: $\quad$ Yeah

Alexis: $\quad \mathrm{mm}$ and stuff

Sarah: $\quad$ How do you think that effects. Is it like younger people or like your age?

Alexis: $\quad$ It's kind of like our age cause like

Courtney: Our age and maybe younger

Alexis: $\quad$ And like a bit older in like some kids my sisters watch (Courtney: *laughs*) Disney channel

S: $\quad$ Does it make you think like that what- what effect do you think that would have on younger people?

Nicole: I think it might make them dress that way before they're like old (Alexis: $\mathrm{mm}$ ) - enough to understand what it means when you dress that way

Alexis: $\quad$ And you're kind of like - 
S:

Alexis:

Nicole:

Marissa:

Nicole:

Marissa:

Nicole:

S:

Alexis:

Courtney:

Alexis:

Nicole:
Mmm? What does it mean when you dress that way?

Kind of slutty

Kind of sending out the wrong message to people

To old - er men

You know yeah kind of like to guys and stuff

It's like dangerous

They don't understand

It's - h- how is it dangerous? What do you mean by dangerous?

Because you know - you don't know whose wandering around and -

And who's watching you

And if you wear like really short clothes (Group: Yeah) yeah and if your kind of just like trying to grab attention (Sarah: Mmm)

But in the wrong type of way like -

[Extract 7: Tahi School, mixed ethnicity group of 4 girls.]

In line with other critical feminist literature which explores the sexualisation of girls discourse, girls frequently identified 'other girls' as at risk or victims to hypersexual media while simultaneously producing themselves within the knowing consumer subjectivity (Jackson \& Vares, 2011; Jackson, Vares \& Gill, 2013; Jackson \& Goddard, 2015; Renold \& Ringrose, 2011; Ringrose, 2011). Nicole's comment reflects the notion of 'othering' as she highlights early on in the discussion that "it [sexualised music media] might make them [younger girls] dress that way [sexualised dress styles]" and later in the discussion "they don't understand" the dangers of dressing provocatively. Here Nicole's talk constructs younger [than her] girls as naïve to the 'effects' and dangers of sexualisation. Nicole's comment may be read as positioning herself as a knowledgeable and uninfluenced media consumer within a discourse in which she (as a young girl) is regularly constructed as a passive and objectified victim. Within a sexualisation of girls discourse young girls are seen as not only socially naïve but also as subconsciously and uncontrollably vulnerable to internalising the sexualised femininity scripts that they are repeatedly exposed to in pop music media (Buckingham, 1992; Egan \& Hawkes, 2008, 2012). Nicole's comment "it might make them dress that way before they're like old enough to understand what it means" might therefore be read as an appropriation of a 
sexualisation of girls discourse. Further, Nicole's assertion that younger girls do not understand the 'meaning' of dressing in a sexually provocative way might be read as constructing girls' engagement with hypersexual pop music as passive and potentially victimizing.

When asked (by the researcher) for meanings of dressing "that way", Alexis draws on the term slutty to describe sexualised stylisation among young girls. Employment of the term slutty not only describes precocious sexuality (a central concern in the sexualisation of girls discourse, Egan, 2013), it has also been described in girlhood literature as a term used by girls to regulate female sexuality and behaviour that is deemed inappropriate (Griffin, 2004; Jackson \& Vares, 2011, 2015; Ringrose, 2008, 2011; Renold \& Ringrose, 2012b). Alexis's use of the term slutty can be read as appropriating the sexualisation of girls discourse which positions girls' provocative stylisation as an example of sexualisation and subsequent sexual availability (Hamilton, 2009; Papadopolus, 2010).

Nicole's comment that dressing in that way is "kind of sending out the wrong message to people" connects with the fears within the sexualisation of girl's discourse where 'evidence' of sexualisation is often located on the body of the girl. Nicole's comment aligns with Ringrose's (2011) discussion of the complex stylistic choices that girls must make in order to present themselves appropriately and, more specifically, the inferred consequences if girls fail to do so. Nicole's comment might therefore be read as mobilising a sexualisation of girls discourse wherein a girl dressed in a hypersexual or 'age inappropriate' way is read as indicative of her precocious sexuality (Oppliger, 2008; Hamilton, 2009; Levin \& Kilbourne, 2008).

The girls' constructions of 'other' girls as "slutty" also interweaves with notions of the predatory male and the paedophilic gaze. Marissa for example expands on Nicole's assertion that dressing in a sexualised manner is "sending out the wrong message" "to old-er men" and Nicole specifies "to guys and stuff", both of which are consistent with predatory male and paedophilic discourses. It can be argued that the girls' comments implicitly construct male (heterosexual) desire as normative and girls as responsible for covering their bodies in order to keep the male sex drive at bay (Walkerdine, 1998). That they are required to do so, emphasises girls' sexuality as organised around the discourses of danger and sexual victimisation (Fine, 1988; Fine \& McClelland, 2006; Vance, 1984). Thus when Marissa explains that dressing in 'that way' is dangerous, Nicole's assertion that "they [young girls] don't understand" the 
dangers of attracting the male predatory eye through their dress might be read as emphasising the construction of girls' as sexually vulnerable. Egan (2013) describes the paedophilic gaze or predatory discourse as highly gendered, "paradoxically naturalising the assumed asexuality of the girl child while also constructing her as utterly irresistible and even enticing to the predatory, aggressive male sexuality" ( $\mathrm{p}$. 62). This notion of the girl child as asexual while also at risk of hetero-male interference underpins the sexualisation discourses where parents, teachers and even governments are positioned as responsible for protecting girls from the 'effects' of precocious sexuality and knowingness (Bailey, 2011; Egan, 2013; Egan \& Hawkes, 2008, 2008b; Rush \& La Nauze, 2006, 2006b).

The construction of parents as protectors, shielding girls from the paedophilic gaze peppered much of girls' talk across the focus groups. This was incorporated into constructions of girls as needing parental protection (in the form of media surveillance) from the inevitable 'effects' of sexualised media. However, girls positioned themselves as responsible media consumers for whom parental control was unnecessary because they were competent and able to self-survey and monitor their own media consumption. The next section elaborates on girls self-positioning as responsible media consumers.

The responsible media consumer. Parental control and surveillance featured frequently in girls' discussions of their pop music media consumption. Within their discussions, girls repeatedly positioned themselves as knowing consumers, mature and responsible enough to regulate their own viewing and adhere to their parents' rules. Responsibility in this case included being able to identify 'inappropriate' content and being sensitive (at times hyper-sensitive) to parental concerns about sexualised media. Adherence to parental media consumption rules seemed, in part, to underpin the girls' self-positioning within a responsible consumer subjectivity. Although the rules were prescribed by more knowledgeable (according to the girls) parents, the girls' talk suggested an internalisation of parental norms around appropriate vs. inappropriate content, an emphasis on self-surveillance (described as mature behaviour), and the ability to "make the right choices" about media viewing.

In the next extract the girls discuss the restrictions that their parents have set on appropriate and inappropriate media content for them to watch. The responsible consumer subjectivity is inhabited by all the participating girls. Interestingly, in 
drawing on the responsible consumer discourses, specific content restrictions by the girls' parents are not described but, rather, these rules are discussed as something that the girls understand as important to enforce upon themselves.

Charlotte: $\quad$ My mum doesn't really mind me watching like Lady Gaga and stuff she just doesn't want me to get like distracted with my like other stuff

Brooke: $\quad$ But my mum she kind of trusts me like if I know that she wouldn't want me to watch it then I will just like exit the tab (*miming computer use*) or whatever cause I know that it's not the right thing to do

S:

Is that the same for you girls?

Lucy: $\quad$ A little bit like what Brooke said (Olivia: Mmm kind of I guess)

S: $\quad$ Is there some stuff that you're not allowed to watch?

Group: $\quad$ yessss

S: $\quad$ In terms of music videos? Music videos though? Or do you just know when it's like no I'm not watching that? Um (Group: yeah yeah)

Brooke: $\quad$ Something that you go to and it's like woop *accidental*

Isabella: $\quad$ I don't know m- my parents don't really restrict me from watching (Grace: yeah) I know not to watch it

Grace: If it's like - yeah if it's over the top something you know something that isn't too great or something like then yeah my parents - like cause I mean i- i- yeah I mean like same thing with Charlotte my parents just you know they don't mind me watching Youtube or whatever

Charlotte: $\quad$ My parents don't really mind me watching like they just kind of trust me to not go onto like the -

Grace: $\quad$ Yeah to make the right choices and stuff

[Extract 8: Tahi School, mixed ethnicity group of 7 girls. Transcription note: Capitalisation and underling indicate loud speech and emphasis respectively.]

Girls in this extract position themselves as knowledgeable and responsible consumers. Charlotte's knowledge that her mother doesn't want her to get "distracted" by pop music media (such as the raunchy Lady Gaga music videos she is watching) could be read as Charlotte's understanding and negotiation of the sexualisation discourse which positions media as dangerous and Charlotte (as a young girl) as potentially at risk of 'distraction'/sexualisation. The responsible consumer subjectivity is also shown through the girls' adherence to parental media viewing rules and self-enforcement of these rules by not watching media that is "over the top something (...) that isn't great" (Grace). 
The responsible consumer subjectivity is reinforced through the notion of trust from parents and the girls' ability, when watching certain media, to discern when it is "not the right thing to do" (Brooke) and instead "to make the right choices and stuff" (Grace). The girls' emphasis on making the 'right choices' might be understood within the context of problematic contemporary girlhood subjectivity dichotomies (Gonick, 2006; Harris, 2004). Within this dichotomy, girls' emphasis on obtaining trust from parents and being self-surveying in regards to media consumption could be read as demonstrating the importance of avoiding at-risk and problematic girlhood subjectivities (Harris, 2004). The notion of trust highlights that achievement of the responsible media consumer subjectivity is contingent on girls' constant selfsurveillance and makes the risk of 'failing' omnipresent. The 'choice' to produce oneself as a responsible and unaffected consumer might therefore be understood as constrained. McRobbie highlights that within the contemporary postfeminist subjectivity, choice becomes a constraint rather than an empowering option, asserting that "the individual is compelled to be the type of subject that makes the right choices" (2004, p. 261). The girls' assertion that they choose to not watch sexually explicit media is an example of this constrained choice as their alternative option (to watch sexually explicit media) means that they fail at positioning themselves within the responsible consumer subjectivity and are likely to be positioned as irresponsible and at-risk by parents.

The importance of surveillance and making the right choices also relates to neoliberal concepts of self-regulation and self-responsibility. The girls in this extract constructed themselves as ideal neo-liberal subjects by displaying their ability to make the "right" choices through rigorous self-monitoring. Within individualised neoliberal discourses, external disciplinary power is replaced by an internalisation of this regulatory force. Rather than being externally monitored, the subject is now seen as responsible and active in self-monitoring and self-regulation of the prescribed ways of being; "the responsibility to be a 'good' citizen now lies within the individual" (Evans \& Riley, 2010, p. 116). Compulsory 'choice' is at the heart of neoliberal discourses, whereby active citizenship is defined by an individual's ability to make apparently free but realistically pre-prescribed 'choices'(Gill, 2007b, 2009). Thus, one way of reading the girls' emphasis on self-monitoring and making the right choices is as an internalisation of prescribed parental media consumption rules, rules that somewhat paradoxically are reinforced through the active notion of choice. Girls' 
appropriation of neoliberal discourse can also be seen in their assertions that they can make "the right choices". Through employing the mature viewer discourse in the extract, girls are able to resist the passive affected girl subjectivity and instead occupy the responsible consumer discourse through constant self-surveillance. Isabella, who says her parents do not restrict her from any media, for example, inhabits this responsible consumer as she explains that although she is not externally regulated she still knows (internalisation) the media that she must avoid.

Alongside girls' discursive positioning of themselves within sexually knowing and responsible consumer subjectivities within the focus groups, was a construction of awkwardness concerning media consumption in the presence of parents. While girls' repeatedly emphasised that they were self-surveying media consumers in the absence of parental figures, girls' media consumption in the presence of parents was particularly difficult. In regards to co-watching sexualised media, an 'awkward' affect was repeatedly constructed in girls' discussions. This awkward affect further demonstrates the complex negotiation that is required from girls in relation to hypersexual media consumption and is discussed in the next section.

The awkward viewer. The previous section underlined the importance of context in mediating girls' pop music media consumption, specifically the mediating effects that parental surveillance can have on this process. This final analysis section will further illuminate the mediating effects of parental surveillance through exploring girls' discussion of their affective experiences (particularly of discomfort and awkwardness) when viewing hypersexual celebrity media in the presence of parents. Additionally, the girls' assertions of discomfort will be addressed as they were found to be structured around age-based boundaries to being seen (or to describing themselves) as enjoying the consumption of sexualised pop music media.

Girls' described affective responses such as awkwardness, embarrassment or even shame (to be seen viewing such content) in their discussions of co-viewing material with their parents. The notion of an affective relationship with media is insightfully captured in the work of Rebecca Coleman (2008; see also Ringrose \& Coleman, 2013). Her work encourages us to focus not on 'good' or 'bad' media representations for girls, but rather, the possibilities that "the relations between bodies and images limit or extend" (2008, p. 168). Coleman uses the Deleuzian notion of 'becoming', to describe a way of understanding girls' relationship with media that 
attempts to escape the mainstream dualism of the affected versus unaffected consumer. Approaching the relationship between the physical and the representational body as relational rather than causal allows the research to attend to the "knowledges, understandings and experiences of bodies are produced through images" (Coleman, 2008, p. 168). The following analyses attend to the 'affects' that arise for girls in their navigation of pleasurable consumption coupled with their negotiation of "capable savvy postfeminist girl consumer' and 'at-risk sexualised girl' subjectivities.

In the following extract, girls described 'awkwardness' when watching sexualised media in the presence of parents. This awkwardness can be understood as one aspect of girls' affective relationship to sexualised media, in this instance it could be read as linked to the mediating effect of parental presence and girls' knowledge (or assumption) of parental anxiety about sexualised media.

Nicole: $\quad$ Yeah like it makes me feel awkward - you - like last night we were watching MTV Classic and then there was like this song and there was like this girl pole dancing and cause it was like on the TV and I saw it and I was just like turning around cause like we were at the dinner table and it's like she's not wearing very much

S:

How? Why? What about that makes you feel awkward? Like I get what you mean I just mean like -

Alexis: $\quad$ Yeah

Courtney: It's just like if your parents or family

Nicole: $\quad$ Yeah if your parents see it (Alexis: $I-I$ )

S: Why does that make it awkward?

Marissa: $\quad$ I don’t know (Alexis: because -)

Nicole: It's like if you're watching it

Marissa: Cause like if you're watching it with your parents then like-

Courtney: Because only your parents can tell you what to do and what not to do and then when they see you watching those kind of things they might get the wrong idea

Alexis: $\quad$ I just like yeah

Nicole: and like especially like for me, I don't, cause like my dad you know like for my mum she would probably understand more watching it but like my dad if I saw something like that he probably - I don't know

[Extract 9: Tahi School, mixed ethnicity group of 4 girls.] 
Nicole describes watching the White Stripes “Don't Know What to do With Myself" music video (Q8Painkiller, 2014), which features model Kate Moss pole dancing in leather underwear throughout the entire music video. This music video mirrors many of the hypersexual makers of both the sexualisation of culture (Attwood, 2006, 2014; Gill, 2007) and postfeminist femininity which have been explored in Chapter Two of this thesis (p. 32-38; Gill, 2007c). Despite Nicole's previous positioning of herself as both knowledgeable of the dangers of sexualised media (to other girls) and responsible in her own media consumption (see Extract Seven, p. 129), in the presence of her parents, Nicole describes this media as making her "feel awkward" (which is met with agreement from the other girls in the group).

When questioned about the source of such awkwardness, the girls in this extract find it difficult to explain their affective response. Courtney's explanation that parents might "get the wrong idea" can possibly be interpreted as grounded in girls" awareness of the highly publicised and widely circulated sexualisation of girls discourse. In this way, one reading of the girls' feelings of awkwardness in the presence of parental figures could be their concern that their parents will read such consumption as 'signs' of sexualisation. In addition to this reading, Courtney's description of parents as authority figures might be read as informed by anxiety about the possible consequences of violating parental media rules/expectations. This reading however is not particularly supported by the data. Despite the notion of awkwardness being widely reported, there was no instance of a girl identifying specific media rules prescribed by her parents. Rather, girls' self-surveillance was constructed as a 'knowledge' or internalisation of what was acceptable for them to watch and what was not. However, an 'awkward' feeling was repeatedly described in relation to what parents might think during co-watching or instances of parents overseeing girls watching certain content. Girls' feelings of awkwardness also align with Jackson \& Vares (2015b) finding of girls' concern about being discovered (by parents) consuming sexualised media. Following Jackson \& Vares (2015b) analysis, girls' awkwardness might be read as their concern of parental misrecognition as irresponsible media consumers and/or as evidence of sexualisation and the desire to mimic sexualised behaviours (Jackson \& Goddard, 2015; Jackson \& Vares, 2015b; Jackson, Vares \& Gill, 2013; Griffin, 2004b; Harris, 2004 ).

Nonetheless, evidence of strategies to avoid/manage their awkwardness in the presence of parents was seen throughout girls' discussion. The next extract illustrates 
one group's discussion of strategies that they use to attempt to avoid the feeling of awkwardness when their parents discover them watching sexualised media. In this extract, the girls' descriptions of (presumably) hypothetical parental reactions to their consumption of sexualised media, the assumption that they should know to "turn it off' (Georgia), emphasises the girls' discomfort in being potentially misrecognised as irresponsible consumers.

India: $\quad$ I just find it awkward (Group: yeah) just pretend you're not - not watching it

Georgia: Especially if your parents come in its like why didn't you turn the TV off? Cause that's gross or something (Sarah: yeah)

Madeleine: I find it more awkward if it's like -

India: $\quad$ Your da $\left({ }^{*}\right.$ laughing*)d

Group: $\quad$ *Laughter* YEAH!

India: I'm just like I'm not watching that

Madeleine: I'm more likely to switch it over if my parents are there than my brother

Group: $\quad$ Yeah

S: $\quad$ Wh- why do you reckon that is? Cause of what they're doing? Or?

India: $\quad$ I don't know it's just like I just find it weird if they're watching it's just like ehh yeah nah

S: $\quad$ Because of what they're doing and how they're dressing and stuff?

India: $\quad$ Mmmm yeah

Elisa: $\quad$ You don't want your parents to think that you know - that you enjoy watching that sort of stuff

Group: $\quad \underline{\text { YEAH }}$

Elisa: $\quad$ Because that would be quite embarrassing

S: $\quad$ Yeah so you just change it over so it like you don't even [care about it] and don't wana watch it ohh ok

India: [Care about it]

Elisa: $\quad$ Or you could say oh that's a bad song - it's not

[Extract 10: Tahi School, mixed ethnicity group of 6 girls.] 
As in the previous extract, the girls describe feeling awkward consuming sexualised media in the presence of parents. Specifically, girls identify that the sexualised representations of "what they're doing and how they're dressing" in the presence of their parents evoked feelings of awkwardness and embarrassment. As highlighted earlier, one way of reading this awkwardness is through the notion of possible misrecognition. For example, Elisa explains that "you don't want your parents to think that you know - that you enjoy watching that sort of stuff'. This comment is followed by the eruption of laughter (which could be interpreted as recognition and tension by the other girls participating) and agreement by all of the girls in the focus group. The girls' feelings of awkwardness when faced with parental co-viewing and particularly parents' discovery of girls watching sexualised media, suggests that girls' concern that being 'caught out' (despite possible intentions to discontinue watching such media) might be viewed by parents as a failure to be a responsible media consumer.

Interestingly, when discussing awkwardness Madeleine asserts that "I find it more awkward if it's like" to which India continues "Your da(*laughing*)d" and the group erupts in laughter and agreement. One reading of the identification of an intensification of awkwardness in the presence of fathers but not necessarily their brothers (asserted by Madeline and agreed on by the group) or their mothers (identified by Nicole in Extract Nine, p. 135-136) is a gendered intersection where perhaps to be identified as inappropriately sexualised, promiscuous and/or sexually available by their adult fathers is particularly embarrassing. Although, another reading of the heightened awkwardness in the presence of the girls' fathers might due to the authoritative position of their fathers in the home and their ability to ban girls from media consumption.

In the Extract Ten (above) girls' identify strategies to avoid co-viewing and feeling awkward in the presence of parents including turning the media off, ("I'm just like I'm not watching that", Madeline and India) and pretending not to like it, ("you could say 'oh that's a bad song' - it's not", Elisa). These strategies may reflect an attempt to negotiate or position themselves as responsible consumers in the presence of parents. The girls' reluctance to consume this media in front of their parents could also signal the difficulty, and possibly the inability, for the girls be seen to be consuming such media (thereby potentially constructed as influenced by sexualised media) and maintain their self-positioning as capable media consumers. 
Although awkwardness and embarrassment about parental presence was common in girls' discussions, the age of the girls was also a significant factor in the extent to which girls expressed enjoyment in engaging with sexualised pop music material. Whereas older girls appeared to be more comfortable engaging with and discussing sexualised representations, younger girls were found to use more affective responses such as disgust and even anger at such representations. A discussion of Beyoncé's hypersexual representation in her music videos among girls at school Tahi below (Extract Eleven) provides an example of this where the youngest girl in the group Jasmine comments on the singer's body, "its kind of disturbing to watch sometimes I kind of have to turn it off', the older girls India and Madeline were seen to reflect positively on such representations.

\footnotetext{
Madeleine: she probably knows that she can wear that kind of stuff though cause she's got the body for it

India: $\quad$ yeah she's got the body (Elisa: also you don't want to (???))

India: she's just flaunting what [she] has and that's not always]a bad thing

Madeleine: $\quad$ [yea]h [you gotta flaunt] (Sarah: $\mathrm{mmm}$ )

India: like if you've got it then (Sarah: $\mathrm{mmm}$ ) India: like if you've got it then
}

[Extract 11 Tahi School, mixed ethnicity group of 6 girls. Transcription note: Question marks in brackets indicate speech as unclear.]

In contrast to Jasmine's assertion of discomfort and avoidance, India and Madeleine draw on a postfeminist discourse, mobilising the notion that the idealised hypersexual, desiring and desirable female body is endowed with the privilege and ability to "flaunt it". 'Flaunting it' can be understood as capturing the notion of subjectification of the female body which, within postfeminist media culture, is constructed as leading to female power and 'empowerment' (for a discussion of the 'new desiring subject' within postfeminist media culture see Chapter Two, p. 35; Gill, 2007c, 2008, 2011; Mc Robbie, 2009).

\section{Chapter Summary}

Taken together, this chapter has demonstrated girls' navigation and meaning making of postfeminist discourses of hypersexuality as complex and as challenging linear and causal assumptions within sexualisation discourses. The analyses in this 
chapter highlight girls' negotiation of sexualised media as a complex process wherein they use the discursive resources available to them in different ways to achieve different effects. In consuming pop music media, for example, sexualised representations were not constructed as straightforwardly 'good' or 'bad', rather, girls' appraisals of celebrities were mediated by discourses of authenticity and maturity which were often interrelated with a childhood innocence discourse (such as the celebrity being too young to have a sexualised representation). As well as for celebrities, the mediating effects of age were also seen in relation to girls' consumption of sexualised media wherein as well as highlighting awkwardness/embarrassment under the parental eye, girls' comfort in engaging with sexualised representations was complicated by their age. The limited possibilities of self for girls as consumer's was found to be particularly difficult wherein girls were seen to navigate (with much discomfort and awkwardness) the problematic binary of sexualised/innocent girlhood subjectivities.

The following chapter continues the thesis's work of exploring girls' understanding and navigation of hypersexual pop music media. Moving from girls' discussion of hypersexual celebrity and consumer subjectivities in the current chapter, the focus now shifts from consumption to girls' navigation of pop music through practice and production of choreographed performances. The chapter which follows discusses the method of the Music Video Study which follows in Chapter Eight. 


\section{Chapter Seven:}

\section{Music Video Study Method}

The previous chapter presented ways in which girls made sense of their consumption of sexualised pop music celebrities and music media through talk. This chapter introduces the method of the music video study which follows in the next chapter. First, the music video study is discussed, then, the process for analysing both the girls' music videos and the corresponding professional/original music videos is detailed. The music video study which follows this chapter approaches the analysis of professional music videos as providing a social and cultural context to the postfeminist messages and hypersexual representations that girls are exposed to. Importantly the analysis of the girls' videos approaches the girls' performance to female pop music as a potential site for identity work and negotiation of postfeminist gendered messages. The girls' performances are therefore addressed as visual examples of their navigation, in particular their understanding of these messages and the possibilities of self that this media makes available or unavailable to them.

Analysis of the girls' videos provides a unique (and rarely explored) research approach to girls' sexualised media consumption and navigation through performance rather than talk. The video approach discussed in this chapter also provides the kind of new directions in research concerning girls and sexualisation which addresses girls' engagement with sexualised media without immediately problematising and positioning this engagement as dangerous to girls' development as advocated by McClelland and Fine (2008).

\section{Music Video Study Process}

The music video recording groups were self-selected by the girls during the preliminary sign up phase. When the girls signed up to participate in the study they were asked to fill out a 'Recording Group' form where they listed the other girl(s) that they would participate in the music video study with (or alternatively indicated that they would be participating in the study alone). Six groups opted to make videos, the largest group (from Rua School) containing eight members and the smallest (Tahi School) an individual participant.

Following the completion of the focus group study, recording meetings were set up at each of the schools with the participating groups of girls. In these meetings 
the music video study was discussed in depth and each group was assigned a video camera and given a short lesson on how to operate the cameras. Groups were provided with a copy of the 'Filming Rules' (see Appendix: H) which was included in each camera bag. The filming rules stated that the girls were not to record anyone who was not a consenting participant in the study, anyone outside of their filming group, and that they were not to film in any location other than at home or at school. These rules were put in place to protect the girls' privacy (as filming in public could lead to interest and interruption from children or others outside of the project) and to protect the confidentiality of others outside of the project.

In describing the music video study to the girls it was explained that they were to perform and record a music video to a song by a female pop music artist. The girls were told that they were not to edit or delete any takes from their videos for the final product (as this might have risked the data being lost or damaged) but to record the music video through as many different takes as they liked. In addition to this, during the filming meeting the girls' confidentiality was addressed again and it was stressed that the only people who would see the music videos were the other participants in their filming group (in the follow up interviews), my supervisor and I. Stressing the importance of confidentiality to the girls was also an attempt to make them feel more comfortable performing in front of the camera. Additionally, in consideration of the girls' comfort on camera, it was also explained that the music video task would not be judged or compared in any way and that the girls could not 'fail' at this task. In an attempt to emphasise to the girls that the task would not be judged, it was explained that the project was intended to be fun and that they should try and enjoy the process. The girls were not given any instructions concerning the format of their music video (e.g. a story telling or choreography format). They were given two weeks to produce the music videos and were instructed to drop the recorded disc (inside the camera and the camera bag) to the school office for me to collect. Following collection of the girls' music videos, preliminary analysis (viewing the music videos and identifying the corresponding professional music videos which would be analysed) began.

The professional music videos analysed were the corresponding/original videos produced for the songs which the girls performed to in their own videos. In Chapter Eight which follows, three of the girls' music videos are analysed (selection of these videos is discussed briefly later in this chapter) which are performed to three songs: Katy Perry's “Hot and Cold”, Lady Gaga's "Edge of Glory” and Jessie J's 
"Who's Laughing Now?". The professional music videos for each of these songs have been analysed using semiotic and discursive analytical tools. The professional music videos were found on YouTube (www.youtube.com). YouTube was used for the viewing of the professional music videos both because it is known by the researcher as a reliable source for free viewing of professional music videos and also because it was identified by the girls in the focus group study as a website that they used for viewing pop music media content.

Regarding the analysis of professional music videos, Railton and Watson (2011) usefully suggest that explorations of popular culture and particularly music videos need to step away from making comparisons between music videos and 'reality'. Railton and Watson (2011) assert that music videos are not made to reflect reality, rather, they should be approached as a resource with which audiences may make sense of pop star's and of themselves. Accordingly female pop music videos are approached in the following analysis as a resource that young girls might use to inform them about idealised hypersexual femininity. Specifically, the analysis presented in the following chapter considers the possibilities for self these music video texts enable or constrain for the girl audience and the ways in which the girls in this study make sense of these subjectivities through their own performance to music.

\section{Music Video Analysis}

Six music videos were submitted by the girls (one video was not completed on time due to the girls' school commitments). Following the collection of the girls' music videos, the performances were downloaded into VLC format so they could be watched on a computer and the original disks were kept in a locked filing cabinet. The girls' performance files were downloaded and saved onto a secure password protected computer for later description and analysis.

Thematic Analysis. In commencing the music video analysis, first, a detailed description of all the music video data in the project (including the professional and the girls' videos) was carried out. Producing the detailed descriptions of each video enabled the researcher to become familiar with all of the videos and this process, much like the transcription process in the focus group study, was an important and dynamic first step in the analysis of the music videos. 
Description of the girls' videos involved multiple viewings and note taking of various aspects of focus in each video including the girls' clothing, choreographed movements, their interpretation of the song lyrics/original music video, and features of the girls' videos which were consistent across the data set or those which were unique and/or surprising. Following completion of the detailed description, each of the girls' videos were thematically analysed using a modified version of the procedures described by Braun and Clarke (2006), appropriate to video data. During this phase annotation was used to mark occurrences within the video descriptions that were particularly interesting and/or addressed the thesis's research questions. These aspects included dance movements; clothing; the format of the video (e.g., was it narrative, full choreography, stage performance etc.) the presence or absence of 'common' hypersexual and/or hyper feminine representations (such as sexualised display of the body through movements or clothing), and unique performances such as girls' original interpretations of song lyrics and choreography that did not follow the hypersexual representations which saturate contemporary popular culture. Following this preliminary generation of ideas across the data, this material was coded and assigned a name which reflected what the phenomenon was about, for example; the girls' reproduction of storylines from the original music videos such as their use of 'party scenes'; the use of posing and mouthing the song lyrics at the camera; and their unique choreographed movements. These themes were broad and noted on the video descriptions as aspects of each video for semiotic and discursive analysis.

Descriptions of the professional music videos followed the same process as the girls' videos described above. Differences were seen in the generation of the professional music video descriptions however, specifically, the themes and ideas in these videos seemed more accessible possibly due to the fact that these videos were created for the purpose of advertising the song. This made the description process much faster for the professional music videos than for the girls' videos. In addition, descriptions of the professional music videos were not approached as 'interpretations' of the song but rather as performances which signalled broader trends in the representation and idealisation of postfeminist femininity more broadly within popular culture. Descriptions of the professional music videos also incorporated descriptions of the song lyric which were used to generate themes within the professional music video data. 
Semiotics and Discourse Analysis. As discussed in Chapter Five, the thematic data from the girls' videos was discursively analysed using a feminist poststructuralist approach. Through this approach the performances (including the storylines, choreography, and clothing) were understood as providing information about the girls' understanding and navigation of 'sexualised' pop music media. Girls' performances were approached as discursively informed sites where girls' were able to negotiate (through taking up, appropriating or resisting) the subjectivities and ways of being that are made available to them in the original music video and in popular culture more broadly. Particular attention was paid to the ways in which girls' performances could be understood as negotiations of discourses which were mobilised in the girls' talk in the focus group study. For example, the absence of sexualised representation in the girls' performances was approached in the analysis as highlighting the girls' navigation of the childhood innocence discourse.

In contrast to the large body of sexualisation literature explored in Chapter Three (p. 48-52), the research approach to the analysis of the girls' performances follows a small body of critical feminist literature which addresses girls' performance to music (see Baker, 2004, 2004b; Bloustein, 2003; Jackson \& Vares, 2015; Ringrose, 2008). Following these authors, the girls' performances are conceptualised as potentially productive sites within which girls could explore the postfeminist femininity subjectivities which are represented in the original music video and, more broadly, saturating media representations within contemporary popular culture.

In light of the visual focus of the music video study, semiotic analysis is a key analytical tool used in the analysis. Semiotics is a tool which works to deconstruct images and investigate how these images construct/and or signal broader systems of meaning (Rose, 2007). Central to semiotics is the analysis of 'signs'. Rose (2007) explains these two concepts, the signified and the signifier as "only distinguishable at the analytical level; in practice they are always integrated into each other" (p. 79). Semiology asserts that "human culture is made up of signs, each of which stands for something other than itself and people inhabiting culture busy themselves making sense of those signs" (Rose 2007, p. 75). Semiotics therefore facilitates an analysis of signs which are presented within images, paying attention to the ways in which these signs privilege certain systems of meaning and power dynamics within society. In the current study, with its focus on gender, semiotics enabled a deconstruction of the production and presentation of femininity in girls' performances. Specifically, 
through deconstructing the girls' performances through stills of poses, clothing choice and choreography for example, semiotics attends to the ways in which 'postfeminist signs' are used to construct gender within these texts. Corresponding to Rose's (2007) discussion of analysing visual texts, various 'signs' in the girls' performances were identified through multiple viewings of the text and noted on the video description. Identification of the 'signs' (through the signified and the signifier) through this process centred on the researcher's repeated viewing of the videos asking at each section or interesting moment of the video "what is being signified in the text?". For example, the image in one video of a girl standing with her hand on her hip, legs posed, hip jutted, pointing to the camera with her head raised, mouthing the lyrics of the song with her eyes closed is identified as a sign. In this case the signified concept (through her positioning) is identified by the researcher as the performance of the signifier 'female pop star' due to its alignment with the visual representation of these movements within professional music videos and female pop performances within contemporary society.

The presentation of the following analyses of girls' music video performances adopts a case study approach. The case study approach enabled a clear presentation of the data in the analysis chapter which Rose (2007) highlights as an important feature of semiotic analysis, this format provides a descriptive element to the analysis which allows the reader to imagine the images being analysed. This approach was therefore selected for its ability to enable an in-depth analysis of the data that also provides more context and descriptions of the performances as a whole. Due to the size restraints of the thesis, only three of the six music videos were selected for case study analysis. These videos, Hot and Cold by Ashleigh, Jade, Kaylee and Paige, Who's Laughing Now by Abigail and Jordan and The Edge of Glory by Charlotte, Gemma, Issabella, Jamie and Sophie were chosen because of their analytical richness and ability to represent the themes seen across the music video data as a whole. The three videos analyses which are not presented in the thesis included the Do it like a dude by Jessie J, Love you like a love song by Selena Gomez and Last Friday night by Katy Perry. Importantly, these performances were not identified as lacking analytical potential or as representing different or contrasting themes than the videos selected; rather, the videos selected simply represented the themes in a more in-depth way.

To contextualise analysis of the case studies, corresponding professional music videos were analysed together with each case study. Presenting the girls' and 
professional music video analyses alongside each other strengthens the music video chapter as it provides context to the girls' performance of the song and also highlights the postfeminist discourses of femininity (and possibilities of self) which girls are exposed to within contemporary female pop music media. The professional music videos were also analysed using semiotic and discourse analysis following the same process described above. The analysis from both music video data sets (girls' videos and professional videos) are presented in the following analysis chapter in a case study format.

\section{Follow up Group Interviews}

Follow up interviews at the schools took place with each recording group following the completion and submission of their video. The follow up interview employed a semi-structured format using a short interview guide (see Appendix I). The follow up sessions were designed as a final meeting with the girls not only to go through their music videos but also to serve as a closing of the project. The girls were provided with a small snack during the sessions and were presented with a movie voucher to thank them for their participation in the project.

In these focus groups the girls watched their music videos and discussed the music video production process they used as well as the things that they enjoyed about the production. Given that the analysis of the girls' music videos had already begun, the follow up interviews also enabled further questions to be asked (by the researcher) about the content of the music videos, such as why they had chosen certain representations. Unexpectedly, the sessions also served as a place for girls to talk not just about their performance, but also about the (often) uncomfortable feelings that they had while watching the playback of their performance.

The follow up interviews were significantly shorter than the initial focus groups lasting around 20-30 minutes. In one instance (at school Rua), the shorter running times of the focus groups was the result of a misunderstanding with the teacher which left the group with only 30 minutes to participate. In the other focus groups however, the shorter running times of the follow up focus groups was largely due to a relatively low level of discussion input by the girls during this final meeting. Although the girls all responded to watching their own videos (mostly with embarrassment and awkwardness), for the most part girls provided very little dialogue or explanation about the video process. The follow up focus group therefore provided 
a very little analytical data, the majority of which was gathered from one focus group (which is discussed in the following analytical chapter). Some implications of the lack of data produced in the follow up focus groups is discussed in the Conclusion Chapter (p. 187 of the thesis). Due to the minimal discussion in the follow up focus groups, the interviews were recorded and transcribed for analysis but this material was primarily used as an opportunity to round off the project and thank the girls for their participation rather than analysis.

\section{Chapter Summary}

This chapter has described the method of the music video study as a prelude to the following chapter which presents the discursive and semiotic analysis of the girls' music video data and corresponding professional music video data. The analysis presented in the next chapter adopts a case study format using three of the girls' videos which were selected as they were found to be analytically rich and representative of the data set as a whole. Preceding each of the analyses of the girls' videos is an analysis of the corresponding original music video. Although presented side by side, these two analyses which make up each case study are not intended to be comparative. Rather, the original music video analysis should be approached as providing a context to the song and associated media selected by the girls' for their own performance and also to highlight the types of representations which are seen across postfeminist pop music media more broadly. 


\section{Chapter Eight:}

\section{Girls' media production: Appropriation, Regulation and Rupture}

The following analysis chapter uses a case study approach drawing on a corpus of five music videos, which, were produced, performed, and filmed by girls who participated in the focus group section of the research. The girls were responsible for the selection of the female pop song for the performance and for the choreography they performed in the video.

Of the five music videos produced by the girls, three videos were selected for in-depth analysis based on their analytical richness and their ability to represent the music video data as a whole. Overall, the three case studies show a broad representation of the ways in which the girls in the study were seen to use/perform to pop music. The research understands the girls' videos as providing insight into the ways these girls make sense of female pop music stars, lyrics, and videos. From resistance to the official music videos' postfeminist themes and discourses to the appropriation and narration of these postfeminist themes, the girls' videos construct a picture of the complex ways in which girls are engaging with female pop music.

The selected girls' videos sit alongside analysis of the corresponding professional music videos (the commercial videos produced by the artist to advertise the song) which the research views as potentially informing the girls' own music video performances. The three videos "Hot and Cold” by Katy Perry (Perry, 2008b), "Who's Laughing Now” by Jessie J (J, 2011), and “The Edge of Glory” by Lady Gaga (2011) present a range of contemporary postfeminist discourses and representations of 'ideal' femininity. Analysis of these professional music videos, via their representations and postfeminist discourses, provides a context for understanding the kinds of music media that the girls in the study are engaging with. The analysis of the girls' videos and the professional videos thus provides the opportunity for the recognition and deconstruction of the postfeminist discourses which girls are exposed to. At the same time, the analysis highlights the girls' careful work in appropriating, transforming and negotiating these messages as active participants in their own media production.

As discussed earlier in this thesis, many of the contemporary discourses explaining girls' media consumption (such as the sexualisation of girls discourse) are constructed through dichotomous constructions of girls as influenced (Hamilton, 
2009; Levin \& Kilbourne, 2009; Oppliger, 2008; Papdopolus, 2010) or as empowered (Duits \& Van Zooneen, 2006; Lamb, 2010, 2010b; Lamb \& Peterson, 2012; Peterson, 2010) consumers. But, as Willet (2008 see also Gill, 2012b; Renold \& Ringrose, 2011) highlights, these binaries put us (as researchers) at risk of over-simplifying girls' media consumption. Willet (2008) explains that on the one hand, conceptualising postfeminist media as empowering for girls (see Lamb, 2010; 2010b) discounts and overlooks the many negative implications of self-surveillance, selfdiscipline and the limited possibilities of self that contemporary femininity discourses offer for women and girls (Gill, 2003, 2007, 2007b, 2011, 2012; McRobbie, 2004, 2007, 2008, 2009). On the other hand, Willet (2008) continues, constructing media as entirely negative for girls means that we may "overlook times when girls express awareness and critique of the ways they are being positioned by the media" (p. 422). With these cautions in mind, this analysis explores girls' engagement with media as a labyrinth of possibilities for their own consumption and creation of media. This conceptualisation will allow for an exploration of girls' relationships with pop music media that attends to the complexities of their taking up, rejection, or transformation of postfeminist subjectivities. Approaching girls' relationships with pop music will offer an important contribution to the small body of critical feminist literature (Baker, 2001, 2004, 2004b; Jackson \& Vares, 2011, 2012, 2015b; Renold \& Ringrose, 2011; Willet, 2008, 2011) which offers an insights that unpack and challenge traditional 'media effects' models and dichotomous assumptions.

Although video analysis of both the girls' videos and the professional videos offers contextualised insights into postfeminist discourse and girls' potential appropriation of it, it is also important to appreciate, that like any text, these videos (particularly the official music videos) operate at plural levels with multiple and often contradictory possible understandings (Curry, 1990). The professional music videos take place within a very specific cultural context. Therefore, while professional music videos can be approached as saturating pop music culture within contemporary times, they must also be conceptualised as just one of a number of mediums through which pop music is presented. Though the ubiquitous presence of the pop artist 'personality' and the multimodal nature of contemporary celebrity, spanning from radio, television, magazines, social media and even personal appearances is outside of the realm of this thesis its influence must be acknowledged. 


\section{Case Study One}

Katy Perry, "Hot and Cold" official music video analysis. Katy Perry was liked by the majority of the girls in the project, and girls discussed her at length in all of the focus groups. In these discussions Perry's identity was constructed as contingent on and defined by her body exposing practices such as Sophie's assertion that, "If she changed I wouldn't listen" and Isabella's comment, "I would think she is not exposing herself enough" while at the same time her hypersexual identity was constructed elsewhere as "inappropriate" (Charlotte) and "showing too much" (Isabella) (Chapter Six, Extract One, p. 113). The girls' discussions of Perry as an artist and celebrity demonstrate their complex and sometimes contradictory understanding of female pop star identities, Perry's identity, for example, can be understood as constructed both within postfeminist (hypersexual) and moralistic (good girl) discourses. These contradictory discourses are common in female pop artists' representations (Baker, 2004b) and have been identified in the literature as leading to struggles when it comes to girls' sense making of these performances and images (Lowe, 2003, discussed in Chapter Three, p. 66).

The official video for "Hot and Cold" opens with a wedding scene which takes place in a church with Perry playing the bride. In this opening scene Perry recites her vows in front of a large crowd then waits for her groom to also say "I do". The music to the song starts as the groom hesitates and then runs from the church and out onto the street. As the groom runs an angered Perry takes chase. The next sequence shows repeated shots of Perry chasing the groom whilst becoming increasingly disheveled. Perry's appearance quickly changes from being extremely feminine - with pastel colored makeup emphasising her bright blue eyes, pink cheeks and lips - to a face streaked with black makeup, a ripped dress and a fascinator in complete disarray as she screams at the groom.

Throughout the music video there are repeated cuts to Perry and her posse of bridesmaids on bikes chasing after the groom while angrily lunging at him and singing the lyrics. These shots of the disheveled bride (and bridesmaids), and Perry's anger and quick breakdown, can be understood as portraying what has become a popular female representation within contemporary culture: the vengeful woman (Gill, 2008). In her article examining new femininity representations within contemporary advertising, Gill highlights the vengeful woman as one of a number of new standard representations (2008). Gill explains that the key feature of the vengeful 
woman is the representation of a woman seeking revenge on a man who has harmed her in some way. In the Katy Perry video, this vengeful character is seen in the chase to punish the fleeing groom.

Perry's aggression and physical deterioration throughout this scene might be approached as exemplary of the contradictory construction of the vengeful woman subjectivity. Perry's portrayal of the vengeful subjectivity highlights its construction of 'new' postfeminist strength (a move away from traditional passive representations of femininity) alongside a simultaneous presentation of female aggression as vulgar and psychotic. In explaining the contradictory nature of the vengeful subjectivity, Gill (2008) asserts that rather than representing a shift in gender relations, the repeated representation of this trope in popular culture "has little or nothing to do with contemporary girl power, but rather its opposite: powerlessness" (p. 47). Rather than Perry's demonstration of strength and aggression showing a widening in gender relations, this scene serves to reemphasise the traditional gender binary. As such, the portrayal of the vengeful woman contributes to shutting down any other possibilities for men and women to relate through anything but conflict (Gill, 2008).

During the chase Perry's representation of female aggressiveness is also reminiscent of the construction of the ladette (Jackson \& Tinkler, 2007). The ladette is often associated with crude and aggressive behaviour in working and middle-class women (Skeggs, 1997, 2005). Additionally, ladettes are often described as having masculine traits and participating in masculine activities and domains such as alcohol consumption and fighting (Jackson \& Tinkler, 2007). The contrast between the hyperfeminine white bridesmaids dresses and the (traditionally) masculine BMX bikes and baseball bats works to construct female violence not only as masculine and problematic (seen through the ripped dresses and smudged makeup) but also as dangerous and uncontrollable. According to Jackson and Tinkler (2007) the construction of the ladette as dangerous and out of control is used regularly by the media, especially in reference to women's participation in traditionally male dominated areas. Within male dominated areas/activities, the ladette is regularly produced as dangerous to the women and to the rest of society.

The second sequence in the official video shows the groom sneaking into an underground night club to hide from bride Perry. Instead, the groom finds Perry on stage as the lead singer of a rock band, dressed in leather hot pants, a leather jacket and aviator sunglasses singing the lyrics (of "Hot and Cold") to a huge crowd. In the 
final sequence the groom lays on the ground exhausted from the chase as 'hip hop' Perry dances around him wearing different hot pants, a leather jacket and high top Converse shoes.

The use of multiple characters all performed by a single female pop star as seen in the current video is common within pop music videos. In her analysis of the music video by Beyoncé, "Check On It” (Knowles-Carter, 2009), Durham (2011) discusses the representation of "flat femininities" (p. 45). Flat femininities in this context refers to the multiple and increasingly narrow definitions of femininity made visible in female music videos. According to Durham these flat femininities offer one dimensional caricatures of different types of femininity and point to the impossibility (for girls and women) of negotiating and inhabiting these subjectivities. The Katy Perry video portrayal of the three different Katy Perry characters might therefore be understood as showing three versions of shallow femininities, from the bride to the rock star, and finally the hip hop girl. Discursively, the bride, rock star, and hip hop characters present alternative subjectivities for girls to emulate, transform or reject. As Ringrose (2008) identifies in her analysis of pop star Avril Lavigne's music video Girlfriend (2007), these multiple (but shallow) feminine identities also present the possibility that all of these 'characters' or ways of being reside in all women and girls.

Girls' music video analysis: performing 'the bitch'. Ashleigh (11), Jade (12), Kaylee (11) and Paige (12) from school Rua worked together to produce and perform a music video to the song "Hot and Cold" by Katy Perry. During the initial focus group the girls' friendship was readily apparent as they all sat together giggling and whispering to each other and expressed excitement to the rest of the group about filming together. The girls' video is set in the performance room at their school. The girls are seen standing in an empty classroom-like space and dancing together in casual and comfortable-looking clothing (sweat pants, hoodies and shorts etc). The girls perform to two different versions of the song "Hot and Cold". The first is the original version sung by Katy Perry and the second is a cover by the Chipettes. The Chipettes are a children's animated musical trio of female chipmunks who are in a band together. The trio form the 'girl version' of the male animated group The Chipmunks. The Chipettes perform covers of pop songs many of which are seen in Chipmunk movies and released on Chipmunks albums (such as Alvin and the Chipmunks movie and Chipwrecked the album). 
Ashleigh, Jade, Kaylee and Paige's performance to "Hot and Cold" shows no obvious incorporation of postfeminist discourses represented in the official Katy Perry video. For example, there are no 'sexualised' or sexually suggestive movements seen in this video. However, marked differences in the girls' movements, energy levels and filming style were seen between their two performances of the Katy Perry song. During the girls' first performance (to the official version of the song) they stand in a line facing the camera mouthing the lyrics while performing choreographed movements. For example to the lyrics "You change your mind, like a girl changes clothes. You PMS like a bitch, I would know", the girls point to the camera ("You"), point to their heads ("change your mind"), point to themselves ("like a girl") motion up and down their bodies ("changes clothes"), swing their arms limply at their waists ("You PMS like a bitch") then pointing to themselves again ("I would know"). The sharp and intermittent enactment of the lyrics continues throughout the performance and is particularly noticeable during the lyrics "You PMS like a bitch, I would know". The girls act out these lyrics by swinging their arms at their sides which does not represent the words PMS or bitch in the manner that other lyrics were literally acted out. One way of understanding the change from movements which literally act out the lyrics to movements that do not, could be that the girls are uncomfortable with the topic of PMS and/or the song's use of the word bitch. If this were to be the case, this restrained performance could be read as the girls' awkwardness in the performance of the adult Katy Perry identity.

As has been discussed in Chapter Six (see also Jackson \& Goddard, 2015) girls' awkwardness has been found to be an affective response to the consumption of pop music, especially when viewing representations of hypersexual femininity. To recap, the girls in the focus groups reported awkwardness in seeing sexualised representations in pop music media particularly in the presence of an adult or authority figure. Applying this idea to the girls' movements to the lyrics in their music video, the perceived awkwardness might be linked to the girls' concern or discomfort with enacting "PMS" or "bitch" as both may be considered as outside the boundaries of 'appropriate' girlhood.

As the girls' next performance, to the Chipettes cover of "Hot and Cold", starts there is immediately a noticeable difference in their movements and energy levels. The girls perform the same movements which act out (most of) the lyrics as in their previous performance, however immediately the emphasis and energy put into 
these movements is significantly elevated and almost excessive. Following Bloustein (2003, see also Bloustein \& Baker, 2003), the girls' Chipettes performance can be understood as a type of mimetic excess. The girls use excessive and over the top 'feminine' movements, such as hip swinging and posing their legs, almost to the point of mockery as they act out the ideas of love and lust in the song. In her study exploring girlhood through video diaries, Bloustein highlights that girls, "sometimes used mimetic excess as a way of exploring possibilities and simultaneously rejecting them through play" (2003, p. 62). The girls' over the top performance to the Chipettes version of the song might then be read as their employment and simultaneous rejection (through mockery) of hyper-feminine movements which are often seen in pop music videos.

Alternatively, the girls' employment of mimetic excess in performing the movements such as posing their legs and bouncing their hips side to side, could be read as the girls trying on this hyper-feminine adult identity. The use of mimetic excess allows the girls to navigate this potentially inappropriate identity by appearing to not be seriously engaging in it. Additionally, the girls' choice to employ hyperfeminine movements in the Chipettes performance, rather than in their performance to the original version of the song, could be read as allowing the girls to play with, and try on, adult feminine identity, whilst keeping this play firmly rooted within the bounds of childhood through the use of children's music. In this way, the fusion of childishness (The Chippettes) with 'adult' constructs such as love and relationships in the song allows the girls to try out these movements which in other contexts are constructed as inappropriate and problematic (see Levin \& Kilbourne, 2009; Oppliger, 2008). For example, in a sexualisation of girls discourse the girls rolling their hips and posing their legs to these lyrics might be interpreted as signaling premature sexualisation and its proposed effects.

These aspects of the girls' second performance therefore highlight the ways in which the girls' performance might be understood as more than evidence of internalisation of hypersexual identity as is often produced and proposed by moralistic discourses and media effects models (Hamilton, 2009; Papadopoulos, 2010). Instead the differences seen in the girls' performances could be read as emphasising the girls' careful navigation of the 'appropriate' and 'inappropriate' feminine identities seen in pop music. Specifically, this highlights girls' performance to music as their own trying on and exploration of postfeminist female subjectivities, while at the same time 
evidences girls' awareness of the navigation necessary to manage problematic subjectivities that these pop representations present for girls.

Walkerdine (1998) highlights that pop music and dancing to pop music is a space where girls can move outside of rigid notions of appropriate girlhood namely the space of being a 'good girl'. An example of pop music functioning in this way can be seen in the girls' performance to the lyrics "You PMS like a bitch, I would know" in their Chipettes rendition of the song. During the girls' Chippettes rendition of the song, they rewind to the first verse and just before they press play Paige says "Ok, who is going to be the bitch?" In taking the word 'bitch' from a lyric to a word that can be used unsung and characterised in the girls' performance, it can be argued that the girls' play and performance provides a space where they are free to transgress norms of 'good girl' femininity; specifically the norm that 'good girls' don't swear. The girls' use of the word bitch also sits in contrast with their awkwardness in the previous performance. This dramatic change from not really engaging with or acting out the word bitch in the first rendition, followed by the characterisation of the word bitch in the Chippettes rendition could be understood as emphasising the girls being able to step outside appropriate girlhood through incorporation of childhood signifiers (the Chipettes).

The girls' apparent characterisation of the word bitch might also be understood through the work of Renold and Ringrose (2008, p. 337) in their exploration of girls" navigation of "slut subjectivities". In their analysis, Renold and Ringrose highlight girls' recuperation of the term slut, particularly the re-signification of the term by actively taking on this label. Taking on the label of slut is understood by Renold and Ringrose as allowing the girls to take back the power associated with the term and re-signify it to a status symbol rather than an insult. Returning to the "Hot and Cold" performance, the girls enthusiastically point to Taylor who is the "bitch" and they all (including Taylor) laugh along. I would argue that rather than taunting or teasing, the assignment of Taylor as the "bitch" in this performance shows the girls' navigation of this insult. The girls' assigning of the 'bitch character' might be read as a kind of re-signification as the girls take up and transform the notion of bitch from an insult to a character in their own performance.

More broadly, the girls' use of the word bitch might also be understood within the context of bedroom culture. McRobbie and Garber's (1976) seminal essay highlights bedroom culture as an important space for girls in trying on adult identities. 
Furthermore, Willis (1990) describes girls' bedrooms as a key location for the constitution of identities and similarly Baker's (2004) study of girls' play to music illustrates girls' use of the bedroom for the private consumption of music. Bedroom privacy is also described by these authors as providing a safe space (outside of parental regulation) for girls to try on and experiment with female subjectivities outside of those deemed appropriate for girls (Baker, 2001, 2004, 2004b; McRobbie \& Garber; 1976; Willis, 1990). Though the girls in the current music video are not performing in a bedroom, their use of the word bitch occurs in a safe space (i.e. away from adults) where they can explore the meanings of the 'bitch' without fear of transgressing boundaries of appropriate girlhood which are strictly regulated, particularly in a school setting (Ringrose, 2008, 2010, 2011).

The girls' relationship to me as the researcher might also be a salient context in understanding their use of the 'adult' word bitch. This relationship, which was developed during the initial meetings, and the focus groups, allowed me to connect with the girls in a way that did not position me as an authority figure. Although this authoritative position can never really be fully avoided (Frith, 2000; Thomson, 2008) I was able to position myself more as a sister during the focus groups which could possibly have influenced the girls' comfort in using the word bitch.

\section{Case Study Two}

Jessie J, “Who's Laughing Now” official music video analysis. The official music video for "Who's Laughing Now" is set in a primary school (J, 2011). The video narrates the song's lyrics in which artist Jessie $\mathrm{J}$ remembers being bullied as a child and in light of her subsequent fame is able to address her bullies, who now want to be her friends saying “Who's Laughing Now?" (that Jessie has become a successful pop star). The video narrates a day in the life of 'child' Jessie J (played by British teen actress Adrianna Bertola) being bullied by a clique of girls at school.

The video shows repeated shots of Jessie $\mathbf{J}$ as a child sitting in a classroom next to adult/current Jessie $J$ who sings to both her child self and the camera/audience. These shots suggest a connection between adult and child Jessie, where child Jessie is positioned as in trouble and adult Jessie is comforting her (through song and showing their eventual success) while also admonishing the bullies that torment child Jessie. The opening sequence shows child Jessie $\mathbf{J}$ walking down a school corridor while a group of white, blonde girls all dressed in pink stand by their lockers whispering to 
each other as well as pulling faces at child Jessie $\mathbf{J}$ as she walks by. This opening sequence mobilises a mean girl discourse which is one of the latest in a succession of problematising girlhood discourses (Bjorkquist \& Niemela, 1992, 1994; Gonick, 2006; Ringrose, 2006). The discourse positions girls as socially (and sometimes physically) aggressive towards each other particularly in a school setting.

The mean girl discourse circulates widely within contemporary culture. Although girls' violence is considered morally repugnant within contemporary society, it is repeatedly conceptualised as a normal part of girls' development within developmental literature (Crick, 1995; Crick \& Grotpeter, 1996; Garbarino, 2006) where it is described as 'relational aggression', an indirect form of bullying involving passive aggressive behaviour including manipulation, spreading rumors, exclusionary techniques and friendship withdrawal (Crick \& Grotpeter, 1996; Geiger, ZimmerGembeck, \& Crick, 2004; Simmons, 2002).

Ringrose (2006) asserts that the normalisation of the 'mean girl' within contemporary culture serves as a new developmental model, "constitutive of the shift from a universalised vulnerable girl to a universalised aggressive/mean girl” (p. 406). The mean girl discourse adds to the postfeminist rhetoric of girlhood as problematic (Ringrose, 2006). The shift from the passive vulnerable girl (Pipher, 2005) to a contemporary mean girl, and even more recently the sexualised girl (Hamilton, 2009; Tankard Reist, 2009), points to the potential for understanding these concerns and moral panics as examples of a wider social concerns about contemporary girlhood (Egan, 2013) rather than the 'existence' of a constantly evolving and problematic girlhood. Focusing on the mean girl reveals how this discourse, like the other moral panics mentioned above, works to construct girlhood as complex, incomprehensible for adults (a problem that the multitude of self-help books aimed at parents and teachers claim to solve), and a stage where girls are constantly in danger and vulnerable to the world.

Egan (2013) views this discourse as politically motivated to protect middle class white girls. This politically motivated discourse, according to Egan, highlights a fear of a hypersexualised and 'out of control' female middle class if girls within this demographic are not controlled and contained. Returning to the video, the physical representation of the mean girls might be understood as emphasising this component of the mean girl discourse: the social concern for the middle class white girl (Egan, 2013; Ringrose, 2006). The 'mean girls' in the video all fit within the physical 
characteristics of the innocent white, middle class girl. Particularly, the physicality seen in the girls playing 'mean' draws attention to the problematic mean girl, by playing up notions of girliness through the use of honey blonde, braided hair and the adornment of bright pink clothing, hair decorations, and a pink mirror.

The official video includes some scenes in which child Jessie $\mathrm{J}$ is seen acting out and taking revenge on the mean girls. In the first of these scenes, child Jessie is in the classroom and enduring the indirect and relational bullying described above, including being excluded and being called names by the group of mean girls. As the scene progresses Jessie presumably has had enough and stands up from her desk, swinging the classroom door open and storming out. What follows is an aggressive rampage where Jessie is seen smashing over a model universe with her school bag, ripping notices off the notice board, pushing over a Hollywood sign and throwing food at the cafeteria lady (who will be discussed later in the analysis). In the final revenge scene Jessie walks back into the classroom with a fire extinguisher and begins laughing and spraying down the girls who have been bullying her while the rest of the class looks on in disbelief. Jessie's acts of aggression around the school, and her retaliation against the bullies, are far from indirect and relational. Jessie's behaviour might therefore be understood as transgressive of contemporary 'normative' female aggression.

Although Jessie's transgression of normative (passive) female aggression is celebrated in the music video, particularly in a shot of Jessie's classmates standing behind her dancing and cheering for her after she has 'defeated' the mean girls, her transgression from normative girlhood is represented and made noticeable through her appearance. Jessie wears a pair of dark blue baggy jean shorts, which are rolled at the bottom, a black t-shirt and a black and white letterman jacket. Jessie also has very straight, jet black hair styled in a short bob. Jessie's hair can be attributed to producing a similarity between her and adult Jessie $\mathrm{J}$ (who has the same haircut and colour). At the same time, Jessie's baggy clothing further constructs Jessie's transgressive aggression as outside of normative girlhood femininity (Hadley, 2003; Ringrose, 2006). Taken together, the two mean girl subjectivities in the "Who's Laughing Now" video, the mean girl (using indirect-relational aggression) and violent child Jessie (using outright aggression), reiterate contemporary society's obsession with problematic girlhood subjectivities. 
The adult characters in the official music video (the teacher, janitor and lunch lady) are all played by adult Jessie J. These characters are seen throughout the video engaging in various levels of sexualised behavior, which could be understood as reproducing the hypersexualisation of women within contemporary postfeminist culture (Gill, 2007, 2007c, 2008b, 2009, 2011). In particular the teacher and lunch lady show sexual subjectification throughout the video. "Who's Laughing Now" also has a 'making-of' video (Getmusicasia, 2011), which is aimed at showing fans behind the scenes during the filming of the official video. The 'making-of' video functions differently to the official music video. Rather than a narration or promotion of the song, the 'making-of' format is constructed as allowing the viewer an insight into the meanings in the video and lyrics, as well as into the artist's reflections and feelings about the song. The making of "Who's Laughing Now" shows shots from behind the camera and includes multiple mini interviews where Jessie $\mathrm{J}$ explains individual characters and themes of bullying and redemption, which are reflective of her own experience of bullying whilst at school.

Returning to the adult characters in the official music video, the teacher is portrayed as a woman who is more concerned with her looks and sexual attractiveness than she is with teaching Jessie's class. She is seen sitting at the front of the classroom either asleep at her desk, swiveling suggestively in her chair with a pencil in her mouth, licking her shoe, or rubbing her chest in a hypersexual manner. Jessie J describes this teacher as someone who "thinks she's hot but she's NOT" in an interview in the 'making-of' video and explains that she herself "had a few of them [teachers who were uninterested and only concerned with their looks] at my school" (Getmusicasia, 2011, 6:16).

Given this insight by Jessie J, who presumably has some artistic power in the making of the official video and therefore the representation of the teacher (and lunch lady), these female representations are also usefully understood as a commentary or critique of contemporary femininity by the artist herself. The teacher wears a fitted pink tweed jacket over a white shirt and tie, with matching pink tweed underwear (only visible very briefly) over opaque stockings. Her hair is pulled back into a very tight bun that sits high on her head and she wears heavy make-up and pink high heels. Her hypersexual behaviour in these classroom scenes emphasise Jessie J's critique of hypersexual femininity through the deconstruction (and mockery) of the postfeminist subject as it is defined by bodily display and 'up for it' hyper-heterosexuality (Gill, 
2003, 2007; 2007c; Attwood, 2006). One way to read the hypersexual school teacher is through the notion of Jessie $\mathbf{J}$ (the artist), producing the text as a mockery of hypersexual culture and contemporary society's obsession with female sexuality and the postfeminist subject (Gill, 2007c, 2008, 2010).

Similarly to the teacher, the lunch lady character engages in hypersexual display. Although she is featured only a few times and in very short segments, the lunch lady's presence and representation of femininity is significant. The lunch lady character wears a high neck, bright orange top with purple track pants underneath a bright blue ill fitted apron dress with a purple hat, presumably designed to keep her long, voluminous blonde hair out of the food. She also wears large (fake) gold chains including a dollar sign and multiple rings. In the initial segment the lunch lady is seen sitting on the counter where the food is prepared with her legs open, hunched over, picking her teeth with her long nails and stretching the gum in her mouth out and around the same finger. In the 'making-of' video Jessie $\mathrm{J}$ names the lunch lady Tina Fish (a play on tuna fish). When Jessie briefly introduces Tina Fish in this video she uses a lower class (cockney) accent to introduce herself as the character, despite there being no dialogue for this character in the official music video. In continuing this performance Jessie J describes Tina Fish's week, working Tuesday - Friday at the school and then looking after dogs on Monday. This performance of Tina Fish, through the accent and reference to multiple low-paid jobs, coupled with the emphasis on a lack of hygiene, manners and a display of excessive femininity (Skeggs, 1997, 2004) through her loud clothing, big hair and large cheap looking jewelry in the official video signals the representation of (working) classed femininity (Skeggs, 2004).

The work of Beverly Skeggs traces the long history of the working class woman's representations through excess and disgust. While taste and modesty have been identified as key to the signification of middle class, Skeggs $(2004,2005)$ explains how the image of the "loud, white, excessive, drunk, fat, vulgar, disgusting" woman has come to signify the socially problematic and uncontrollable working class woman (2005, p. 965). Following Skeggs, the emphasis on excessive femininity in the signification of the working class can be seen in the lunch lady's clothing, jewelry and behaviors as a picture of bad taste and excess. Simultaneously, her open legs, sitting on a cooking bench, picking her teeth and playing with her gum, constructs the working class woman as unhygienic, vulgar and unaware of 'proper femininity' traits 
such as manners. This construction of working-class femininity aligns with Ringrose and Walkerdine's (2008) discussion of the 'abject other'. Following Ringrose and Walkerdine, the representation of the lunch lady as unhygienic and loud can be read as Jessie J's critique of "the abject working class woman who fails as subject/object of desire" and is therefore constructed as disgusting and tasteless (presumably) compared to upper-class and successful Jessie (2008, p. 228).

Girls' video analysis: performing 'pop star'. Abigail (13) and Jordan's (12) music video was filmed at Jordan's house while the girls were spending time together over the weekend. Abigail and Jordan, from school Tahi, were the only girls who filmed as a pair and, as has been described in the previous case study, their friendship was apparent from our first meeting. During the initial focus group the girls sat together and were very quiet and reluctant to speak to the group. For this reason watching their video performance was surprising due to the unexpected confidence that the girls exuded while performing in front of the camera.

Abigail and Jordan's performance to the song "Who's Laughing Now?" stood out as the most narrative focused video across the project. Rather than a dance performance to music (as was seen in the majority of the girls' videos) Abigail and Jordan chose to appropriate the narrative music video format. Railton and Watson (2011) describe the narrative format as one of four genres of music videos currently circulating. Narrative format uses visualisation to narrate the song's lyrics and, according to Railton and Watson (2011), to "variously illustrate, complement or extend the lyrical content of the song, or, on the other hand, function independently of it" (p. 55).

As well as adopting a narrative format, Abigail and Jordan's music video recreated some of the themes from the song's lyrics and official music video. In their opening sequence Abigail and Jordan wear their school uniforms, which would seem to reference the official video's setting in a school and the child Jessie character. Abigail performs arriving home from school (as child Jessie J) by walking in the front door of Jordan's home in her school uniform, dumping her school bag at the door and running upstairs. Other ideas from the song and official music video that are reproduced in this video include the girls alternately playing adult Jessie and also the girls who bully child Jessie. Rather than choreographed dance moves, the girls take 
turns performing as these characters, moving and posing in front of the camera while mouthing the lyrics.

The girls' video stood out in the research as a particularly theatrical performance of the pop star identity. For example, to end the arriving home from school segment (discussed above). Abigail playing child Jessie J, Abigail disappears through a wooden sliding door and in a new shot reappears through the same door now wearing blue skinny jeans, a light blue round cut t-shirt with buttons down the front, and her hair in a side ponytail. Following this costume change, Abigail performs as adult Jessie $\mathbf{J}$ for the remainder of the video.

In her pop star performance Abigail uses her body to communicate the Jessie $\mathrm{J}$ pop star identity through her movements. There are repeated shots of Abigail standing in front of a plain white wall mouthing the lyrics (sung by adult Jessie $\mathrm{J}$ in the official video) at the camera. For example, Abigail stands facing the camera, closing her eyes at times as she sings "have you forgotten how you would make me feel when you drag my spirit down?" and also looking up at the ceiling as she mouths "who's laughing now?" Abigail's legs are posed and move between a left and a right 'hip jut' as she sings, while the top half of her body moves her shoulders from left to right. Abigail's elbows remain fixed to her side for the majority of the shots by herself and she regularly rolls her hips and body to the side and shimmies with her hand out to the side and a pointed finger, emphasising talking to the bullies. Rose explains that the relationship between the signified and the signifier is important in semiology because "it means that the relation between meanings (signifieds) and signifiers is not inherent but rather is conventional, and can therefore be problematised" (p. 80). This kind of performance to the music makes visible the movements that the girls used to signify 'pop star identity' (in other music videos) including posed legs, bouncing hips and hands on the hips. The image of a woman facing the camera with her hip jutted out to one side, hand on hip and one arm raised is a very common representation in female pop music to the extent that these movements can be described as signifiers (Rose, 2007) of the female pop star.

What is most striking about Abigail's choice of movements in performing the pop star Jessie J's identity is that these movements are not seen in the official music video. In the official music video, adult Jessie is seen in the classroom sitting at a desk singing to the camera. Her top half is covered in a beige top with a collar that is buttoned up at the neck. In contrast to many of her other music videos, Jessie is seen 
in this video dressed and dancing very modestly. Abigail's performance of the Jessie J pop star identity might then be understood not as a simple reproduction of that seen in the official video, but rather as an integration and amalgamation of the movements that she may have seen Jessie J perform in other videos and live performances. For example, in "Domino", another of her songs which was very popular at the time of the focus groups, Jessie $\mathbf{J}$ can be seen throughout the video dancing with her hands above her head, dipping down to the ground with her legs spread and swinging her hips ( $\mathrm{J}$, 2011b)

Finally, in addition to the girls' performances as Jessie J (adult and child) and as the bullies, they also narrate some of the songs themes throughout their videos, such as Jessie $\mathbf{J}$ going to Hollywood in search of fame and feeling like people (previously her bullies who now want to be her friends) are using her now that she has achieved career success. The girls include a segment where Abigail (playing adult Jessie $\mathbf{J}$ ) is seen walking through a garden gate which has a handmade sign on it saying "HOLLYWOOD". The girls' use of the sign can be clearly linked to the lyrics at this point in the song, which describe Jessie's move to Hollywood to seek fame. Additionally, in the official music video child Jessie $\mathrm{J}$ is seen pushing over a large Hollywood sign, perhaps representing adult Jessie J's eventual conquering of Hollywood through her fame. A second sign used in the girls' video as part of their narrative says "INDISPOSED" and is shown after the "Hollywood" section. Again the sign is home-made, but this time Abigail is seen standing beside it facing the camera mouthing the lyrics "so now because I'm signed, you think my pockets lined, four years and now I'm still waiting in line". The girls' meaning of the word indisposed is not entirely clear, however it shows that they are not just reproducing what they are seeing and hearing on the surface of the song (e.g. song lyrics and the music video) but that their interaction with the song goes beyond imitation. They are trying to engage with, make sense of, and produce this song in their own way.

\section{Case Study Three}

Lady Gaga, "The Edge of Glory" official music video analysis. Lady Gaga was discussed repeatedly in the focus groups. The girls described Gaga as outrageous and even crazy in reference to her live performances, clothing and particularly in her music videos. Gaga's music videos and live performances have led her to become known for her bizarre, outrageous and often hypersexual display, seen regularly 
through performing in revealing clothing. Gaga's costumes range from dancing in her underwear while wearing body altering angular prosthetics in "Born This Way" (Gaga, 2011b) to her almost naked body wrapped in police "CRIME SCENE- DO NOT CROSS" tape draped in a prison cell in Telephone (Gaga, 2010b) and her gender-bending performance in "Alejandro" which involved S\&M depictions (Gaga, 2010).

The official music video for Lady Gaga's "Edge of Glory" opens with a shot of a classic New York street. The street is set with a stoop, fire escape balcony with a ladder outside of an apartment building and a fire hydrant. The set is minimal and lit to represent night time. In the opening shots choral voices 'hoot' to the beat of the music. As Lady Gaga sings the first lyrics "There ain't a reason you and me should be alone tonight yeah baby, tonight yeah baby", Gaga is seen emerging from the apartment window, slowly drawing back the curtains and climbing out onto the fire escape. It is worth mentioning at this point that in multiple interviews about "Edge of Glory", Gaga explained that the lyrics refer to a tear-filled night she spent with her father as her grandfather passed away (Vena, 2011). Despite this apparent insight, the music video, from Gaga's clothing to the self-touching and dancing (which will be explored next), does not seem to represent this experience. Instead, the music video is hypersexual and I would argue that a viewer unaware of Gaga's explanation would assume this song is about sex, possibly about a one night stand. The choice to represent this song in a hypersexual manner immediately highlights the importance of sexuality, not only in the performative identity of Lady Gaga but more broadly within pop music in the context of contemporary sexualised culture.

In the "Edge of Glory" music video Gaga wears a black leather S\&M-inspired studded leotard. It is low cut at the front, revealing a lot of her bust. She wears ripped mesh stockings under her leotard and matching studded leather cowboy boots. Gaga's hair and makeup includes a black and white wig styled in a short bob and eye makeup which runs far below her eye line. It seems to box out around her eyes, creating a very dramatic effect combined with her bright red lipstick. Gaga's outfit can be located within a sexualisation of culture discourse. In exploring the sexualisation of culture, McNair (1996) posits a contemporary pornification of culture in reference to the substantial increases in pornographic representations and the mainstreaming of softcore pornographic styling that have become commonplace in art and most prominently in popular culture. Gaga's outfit highlights this shift in sexual 
representations; specifically, it points to the emphasis within postfeminist media culture on hyper-(hetero)-sexuality as central to 'new' femininity (Gill, 2007c). Gaga's highly sexualised outfit lends itself to ideas of S\&M and bondage, all sexual activities which were previously considered taboo and are now regularly a part of mainstream public discourse of sex and central to debates in feminist sex wars (Attwood, 2006, 2014; Hunter \& Duggan, 1995).

As discussed in Chapter Two, the mainstreaming of sex, particularly through porno-chic (Gill, 2003, 2011, 2011b) styling, is at the heart of problematic conceptualisations of women's and girls' engagement with sexualised culture (Gill, 2003, 2011; Duits \& Van Zoonen, 2009; Evans \& Riley, 2013; Jackson \& Vares, 2011, 2012). In their study examining the controversy around women's dress, for example, Duits and Van Zoonen highlight the ways in which girls' (and women's) bodies have come to be understood as the nexus of problematic female subjectivities within sexualisation of culture arguments. These authors describe 'porno-chic' as evident in popular culture and also as infiltrating mainstream fashion. Indeed, the S\&M type stylisation seen in the "The Edge of Glory" video is not just evidenced in popular culture but is also a very fashionable style within underwear and lingerie marketed to women and more problematically, to young girls (Duits \& Van Zoonen, 2009 Gill, 2003, 2007b, 2012b; McRobbie, 2008, 2009).

Returning to the video, after Gaga emerges from the window, the next shot shows her on the street strutting slowly towards the camera (with the camera focused on her face and also her chest). As Gaga walks towards the camera she holds her head up high making eye contact as she addresses the audience singing "I've got a reason that you should take me home tonight". Gaga's outfit and address to the camera highlight what Gill (see also Atwood, 2014) identifies as the commodification of female sexuality and female bodies. In her exploration of female representations in contemporary advertising Gill (2008) explains that there has been a shift in the representation of women from passive objects for the male gaze to contemporary representations where women are "frequently depicted as active, independent and sexually powerful” (p. 35). Gaga's strutting towards the camera wearing an S\&Mstyle leotard while addressing the audience with a potentially sexual 'come on' reemphasises this idealised active, independent and sexually 'up for it' postfeminist subjectivity (Evans \& Riley, 2010; Gill, 2007b). 
Although some feminist authors (Attwood, 2014; Attwood \& Smith, 2014; Smith, 2010) have celebrated this new sexual permissiveness available to women, Gill (2007c, 2009 and McRobbie, 2007, 2008) highlights this supposed choice as problematic. Both Gill and McRobbie posit hypersexuality as less of a choice and more of a mandatory ideal that women must engage with whilst maintaining the rhetoric of choice. So, although postfeminist discourses are often presented as empowering and choice driven, women who do not choose to 'please themselves' by making themselves a (hetero)sexually desiring subject are often excluded from ideal feminine subjectivity (Gill, 2007b, 2011, 2011b, 2012; McRobbie, 2008, 2009).

In another of the video's sequences Gaga climbs the ladder extending from the fire escape balcony. As she climbs, the camera follows her up and maintains a low angle shot, viewing her from below for the remainder of the shots which feature her on the ladder. While on the ladder, Gaga strips off the baggy shirt that she is wearing in the opening shot to reveal the leotard. In another shot she moves up and down the ladder thrusting her hips and throwing her head back, displaying her body. In a final shot Gaga is seen squatting down towards the camera, while shaking her buttocks and thrusting her hips, looking down at the camera suggestively. The camera angle of these shots of Gaga on the ladder is reminiscent of the type of angle from which a stripper might be seen dancing on a pole. Looking up at Gaga allows the audience to see Gaga's legs and buttocks moving seductively to the music while slightly obscuring her face. I would argue that the ladder, on which Gaga strips and displays her body on for the audience to view from below, functions as a kind of stripper pole upon which Lady Gaga performs.

Pole dancing in contemporary culture has changed from being an activity solely associated with sex and the sex industry to being a widely acceptable and popular fitness exercise for women (Whitehead \& Kurtz, 2009). Additionally, within this postfeminist, hypersexualised context, pole dancing is not only sold as a form of exercise but also as a form of choice and empowerment for women. The popularity of pole dancing for women emphasises Evans and Riley's (2010) assertion that sexual agency and sexual practices have not only become normative, but have been harnessed and reworked by postfeminist forces to be reproduced as domesticated into everyday activities for contemporary women. The mainstreaming of pole dancing and the hypersexuality and sexiness typified by Gaga's performance in the current video are now seen to be replacing traditional idealised feminine traits such as innocence 
and passivity (Gill, 2003, 2011, 2011b, 2007b). Gaga's representation of this hypersexualised femininity not only works to present her as a picture of feminine perfection, it also emphasises the requirement for women (and increasingly girls) to actively engage in hypersexual displays allowing them to be read as powerful and sexually liberated (Evans \& Riley, 2010; Gill, 2007b, 2008, 2012; Lamb, 2010, 2010b; Lamb \& Peterson, 2012;).

\section{Girls' music video analysis: performing 'more extreme versions of} ourselves". Charlotte (12), Gemma (12), Isabella (12), Jamie (12), and Sophie (12) from school Tahi, worked together to produce a music video performance to the hit song "Edge of Glory" by Lady Gaga. In the follow-up focus group the girls said that they got together multiple times to brainstorm their song selection and choreography, and then filmed over one afternoon at Charlotte's house. The five girls made up the largest filming group and were all close friends which was evidenced through the girls' comfortable interaction with each other. The girls' data from the follow-up focus group will be used in addition to their music video in this case study, because it added insight to the girls' performance where many other post-focus group data did not. The girls' performance involved choreographed dancing to the Lady Gaga song with some lip synching. It stands out from previously discussed case studies as highly choreographed and the most stylised music video across the project. Like the official music video, the girls' video does not use a narrative structure.

In the opening sequence of the girls' music video Jamie is seen standing at the top of a garden deck wearing black pants, a white t-shirt and a black vest with her hair partially pulled back. As the opening lyrics to the song begin Jamie walks across the deck and down a flight of stairs while maintaining eye contact with the camera and lip synching to the song. As Jamie comes to the bottom of the stairs she meets Gemma who is standing still (statue-like). As Jamie leans on the handrail and comes to a standstill, Gemma moves and twirls in a circle with her hands in the air, landing posed with one hand on her hip and the other lowered down from her head to touch Sophie, who is knelt down on the ground also holding still. As Gemma touches her and comes to a standstill, Sophie starts to move and begins strutting across the shot with her legs crossing exaggeratedly (seen in the official video) and her hands on her hips. When she is halfway to Isabella, Sophie stops and does a Marilyn Monroe-type pose (the common representation of Marilyn Monroe holding her dress down while standing in 
the street), crossing her legs and bending over forwards with her hands on her hips and (possibly) puckering her lips. She then struts around Isabella and poses with one hand on her hip and one hand flicked out to the side in a hyper-feminine way, which signals Isabella to move. Isabella then spins across the shot with her hands in her hair. As she reaches the left of the shot Gemma and Sophie move in next to her and they all walk forward together (as if on a stage) and form a line, where they roll their hips then spin and walk to the back of the 'stage' and pose, crouching on the ground.

This type of group choreography is seen a number of times throughout the video, as well as in individual dances by each of the girls. The girls' use of the statue standing and movements upon being touched by another member in their choreography is reminiscent of the children's game statues (a childhood game in which a person starts out as the 'Curator' and stands at the end of a field. Everyone else playing stands at the far end. The object of the game is for a 'Statue' to tag the Curator, thereby becoming the Curator and resetting the game). The incorporation of statues with the performance of the Lady Gaga pop star identity highlights (as seen in previous case studies) the girls' collaborative use of childhood and appropriate girlhood markers, which function as a method of securing their potentially problematic performances within the realms of childhood.

In the follow up focus group Gaga's video was mentioned by the girls as influencing the individual dances and poses. Jamie explained that "All I could think of through all our choreography was common pose hahaha so we decided we wanted to do some posing". It is unclear exactly what Jamie means by "common posing" but one understanding might be that she is referring to the common pop star pose of one hand on jutted hip and hand behind the head, in the air or other variations. The posing that the girls used in segments of their performance looked very similar to the Lady Gaga hypersexual posing that is seen in the official music video. Despite the posing similarities, the girls did not use any makeup or sexualised clothing. Their performance as whole includes many childhood signifiers (such as the statues game). These signifiers also include having the family dog in the background of multiple dance sequences and an entire section of the song where the girls are seen jumping on the trampoline and laughing together.

The use of childhood signifiers can be seen particularly well through Sophie's performances. In the opening group piece (described above) Sophie's part of the dance involves exaggerated hyper-feminine walking (crossing her legs and swinging 
her hips just like Lady Gaga walks down the street in the official video) and hands flicked out and Marilyn Monroe pose. In the follow-up focus group Sophie described much of the group dancing as "strutty" and, when asked, she indicated that she would not want anyone else to see their video because it would be embarrassing to be seen behaving that way. In her individual piece in the Lady Gaga performance, however, Sophie is seen facing the camera in a mid-shot from the belly button up. She stands in one spot and rapidly pumps her arms out to the side and then above her head, then puts her hands together in front of her body doing a stirring/circular motion, all the while having a huge smile on her face. When describing her individual performance Sophie explained that "for my thing I do this thing where I go like chink *smile and thumbs up* and it's like kind of like The Wiggles haha". The Wiggles are a popular children's singing and acting group (for children much younger than Sophie). This reference might be understood as Sophie grounding her adult-like "strutting" performance within a good girl/appropriate girlhood discourse, therefore lessoning the chance of her play with the adult identity in the music video being viewed as problematic.

Distancing from the more adult/sexual movements that the girls performed in their video was evident on multiple occasions in the follow up focus group. While Charlotte described the girls' regular hair flipping as "a bit weird", Sophie described it as "we were like weeee" which again references childhood and girliness.

Additionally, the girls described their video performances which involve posing and hair flicking as "not really us". The girls' conversation about their music video demonstrates their careful negotiation of girlhood and adult femininity discourses. Although the girls had previously said that they enjoyed the experience of making the music videos, their talk points to an awareness that some people might understand this play as problematic. Distancing themselves from the performances, specifically describing them as "not ourselves" and "a more extreme version of ourselves", works to construct the girls as 'good' girls and not as 'bad' sexualised girls.

\section{Chapter Summary}

The three case studies presented above show the ways in which girls engage with female pop music media through their performance and play. The case studies of the professional music videos highlight the saturating representation of postfeminist discourses within this media and the repeated representation of 'new' idealized, 
sexualised and empowered femininity. This summary will firstly discuss the postfeminist discourses identified across three female pop music videos and then discuss girls' use of these discourses in their own productions.

Analysis of the official music videos highlighted the saturating appropriation of postfeminist discourses within female pop music media. Within these discourses, the portrayal of the vengeful women and repeated performance of hypersexuality underscore central features of contemporary postfeminist 'new' femininity. The representation of the vengeful woman in the Katy Perry music video can be contextualized within the contemporary emphasis on women as strong and assertive, which moves away from passive constructions of femininity. Hypersexuality was also seen in the official music videos wherein behaving sexually was constructed as powerful (physically) for women as in the performance by Lady Gaga. These representations which have been described in the literature (such as Gill, 2003, 2007b) can be understood as representative of the centrality of postfeminist discourses within contemporary media.

Despite the plethora of sexualisation literature (discussed in Chapter Three) which positions girls as passively and uniformly emulating the messages, especially within postfeminist pop music media, the girls' music videos were not found to show any sexual representations. Rather than reproducing the postfeminist notions of hypersexuality that are regularly seen in female pop music media, the girls drew on their own understandings of their selected songs and each video produced by the groups was individual and different from the others.

The analytical work in Chapter Six highlighted girls' repeated positioning of themselves as responsible and critical consumers. In the focus group study, the girls' discursive work in positioning themselves within critical and responsible consumer discourses was understood as their own negotiation, and distancing, from an influenced/sexualised girlhood subjectivity. The analysis within the current chapter also found girls distanced themselves from the sexualised girl subjectivity as a key part of their performances. However, their tool for distancing was not only their use of words (such as the post - video discussion, Case Study Three, p. 169) but also the use of childhood signifiers which were paired with movements that could possibly be interpreted as problematic or 'sexualised' as a way of securing this performance of adult identities safely within the bounds of childhood. In this way, girls' performance 
to music might be understood as a reflexive and critical process accomplished through the body.

The following and final chapter presents a synthesis of the findings drawn from analyses presented in the focus group and music video chapters. It will construct a narrative to consider the research as a whole and discuss the ways in which it can be applied to contemporary understandings of girls and popular music media. 


\section{Chapter Nine: \\ Synthesis: Girls' Negotiation and Rupture of Pop}

This concluding chapter aims to weave together the insights gathered from the work of the thesis. It highlights girls' understandings of female pop music media from two studies focussed respectively on the girls' discussion of and performance to this music. Beginning with a synthesis of the findings from the two analytical chapters, the chapter discusses the discursive work that girls were seen to do in their talk about, and performance to, female pop music media. The closing sections of the chapter reflect on the im/possibilities for self for girls as consumers of contemporary popular culture. The reflection also considers girls' complex and contradictory navigation through a myriad of problematic girlhood discourses and the cost at which girls' navigation often comes. The final section discussed the contributions and implications of the thesis's findings and the possibilities for future research and developments within the area of girlhood studies.

\section{Girls, Pop Music and 'Sexualisation'}

This research addresses girls' media consumption in a socio-historical period which is dominated by conceptualisations of girls as uniformly and passively sexualised by popular music media (and popular culture more broadly). Contrary to this view, girls in the current research were found to critically engage with female popular music media, challenging the notion of them as straightforwardly influenced by sexualised media consumption, a finding which is consistent with a growing body of feminist girlhood literature (see Baker, 2004, 2004b; Duits \& van Romondt Vis, 2009; Jackson \& Vares, 2015b).

Also consistent with a small body of critical feminist literature, girls in the current study were seen to navigate the sexualised/innocent girlhood binaries which have been identified as foundational to contemporary problematic understandings of girlhood (Gonick, 2006; Griffin, 2004, 2004b; McRobbie, 2004; Ringrose, 2008). The girls' navigation of pop media messages within a web of regulatory girlhood discourses highlighted girls' engagement as both rupturing traditional/regulatory discourses through agentic engagement while simultaneously mobilising regulatory discourses of appropriate female and girlhood sexuality. At times, girls' engagement with this media ruptured postfeminist discourses which idealise hypersexuality 
through the increased representation of sexually desiring and desirable female bodies. So too were there occasions where girls' talk/performances ruptured sexualisation discourses which position girls as passive media consumers, for example through positioning themselves as knowing and non-sexual in their talk and performances. At the same time, and often in close succession with instances of rupture, girls also drew on regulatory discourses, often distancing themselves from the undesirable sexualised and influenced girl subjectivity through regulating the 'inappropriate' sexual behaviour of others (both celebrities and other girls) critiquing age, maturity and authenticity. This heterogeneous engagement with contemporary hypersexual culture is consistent with findings by Renold and Ringrose (2008) who assert that examining moments of rupture within discourses that regulate possibilities for girls enables insight into girls' unique engagement and "significant spaces of 'doing girl differently"' (p. 313). However, notions of regulation and rupture should not be approached as 'positive' or 'negative' media engagement or understood as a binary or opposing form of engagement. The following discussion alternatively draws on Foucault's conceptualisation of discourses as dynamic and power as a productive force. Approaching girls' engagement with hypersexual media through the notion of rupture and of regulation through power attends to the poststructuralist notion of girls as simultaneously subjected and self-positioning within these protectionist discourses. This approach underscores the thesis's findings that, despite much evidence of girls' mobilisation of regulatory discourses concerning girls and sexualisation, mobilisation does not always point to negative outcomes or indeed to evidence of sexualisation. The following sections are organised to highlight the importance of considering girls' engagement with sexualised media through the notions of re-appropriation and rejection of girlhood discourses within a framework of regulation and rupture.

Girls' negotiating sexualised pop music. The framework of rupture and regulation in this chapter draws out the ways in which girls' engagement (even small moments) can be approached as moments of disruption and transgression of hegemonic discourses. Girls' critiques of female artists' performances of 'sexualised' subjectivities commonly drew on a moral discourse to construct a binary that deemed celebrity sexuality to be either un/acceptable. Within this binary girls used notions of authenticity and maturity to critique and position celebrities within the dichotomy of 'acceptable' and 'unacceptable' celebrity. Where celebrities were critically appraised 
by the girls as authentic (linked to the girls' understanding of a 'true' celebrity identity) or mature, their sexualised representations assumed a status of appropriateness and acceptability. Additionally, girls' use of a maturity discourse meant that when a celebrity was deemed 'old enough' (by the girls) to perform hypersexuality, that performance/identity was appraised by the girls not only as acceptable but also as 'evidence' of the celebrity's individuality and authenticity (e.g. P!nk). On the other hand, and aligning with the notion of regulation, girls' construction of celebrities as 'too young' to have a sexual representation resulted in the celebrities sexuality being labelled as illegitimate, where girls mobilised sexualisation discourses such as childhood innocence and, in some instances, regulatory terms such as 'slut' to denounce that behaviour, a finding which is consistent with previous feminist literature (such as Baker, 2004, 2004b; Jackson, Vares \& Gill, 2013; Ringrose, 2011; Renold \& Ringrose, 2011; Zaslow, 2009). So, for example, whereas the girls constructed artists such as Lady Gaga as authentic and therefore acceptable in her hypersexual representations, Miley Cyrus, although twenty years old at the time, was constructed by the girls as a celebrity whose sexuality was deemed unacceptable. Cyrus's sexuality was discussed by the girls as occurring inappropriately during childhood leading the girls to label Cyrus (and others like her) as a 'bad role model' (a notion which will be explored further later in this chapter).

In addition to maturity, girls' critique of celebrities un/acceptable sexuality was also linked to their appraisal of celebrity authenticity. Central to authenticity was the girls' discussion of and dislike of celebrity changes in identity. The girls' distrust of celebrity change is consistent with Zaslow's (2009) identification of girls as distrustful of 'change' in celebrity identity more broadly. However, in the current research the girls' dislike of change was specifically linked to their distrust and disliking of celebrity change from a childish representation to a hypersexual 'adult' one. As well as aligning with Zaslow's research, the girls' distrust of change can also be understood as highlighting that, rather than simply accepting all representations they are exposed to, girls evaluations of celebrities were not fixed but rather subject to ongoing evaluation in determining whether they 'liked' or 'disliked' them. In this way, girls' engagement with certain artists can be understood as just as important to explore as their selective disengagement with other artists.

Miley Cyrus was regularly described by the girls as disliked for her change from a child star to a 'hypersexual' one which is consistent with research by Jackson 
and Vares (2011) and also Vares and Jackson (2015). In their research, Jackson and Vares found that girls regularly employed the term 'slut' when describing the inappropriateness of Cyrus's hypersexual image change. In the current research the girls also used the regulatory term 'slut'. Consistent with the girls' identification of sexuality as inappropriate for young celebrities in the focus groups, the girls did not incorporate signifiers of sexuality in their own music video performances (discussed in the next section of this chapter).

In addition to critiquing celebrity sexuality based on age and authenticity/consistency, a role model discourse also functioned to regulate hypersexual celebrities within a good/bad binary. Within this discourse, celebrities whose sexual representations were judged as acceptable (via authenticity and maturity) were described as 'good' role models and those who violated the girls' acceptability norms in their hypersexual representation were deemed to be 'bad' role models. The emphasis on inappropriately (according to the girls) sexualised female pop music celebrities as 'bad' role models appropriates a sexualisation of girls discourse by mobilising the notion that girls passively reproduce the sexualised behaviours that they are exposed to. This construction of the 'bad' role model is found in the large body of sexualisation literature within which girls are positioned as in danger of hypersexuality because of their assumed desire to mimic celebrity behaviour (Levin \& Kilbourne, 2008; Hamilton, 2009).

Central to the mobilisation of the role model discourse was the girls' assertion of the negative effects of 'bad' role models affecting 'other' girls. Whereas the girls mobilised a girlhood sexualisation discourse to repeatedly position young, naïve girls as mimics who internalise hypersexual female celebrity representations, they simultaneously distanced themselves from this undesirable subjectivity by emphasising pop music media as damaging for other girls but not themselves. Doing so functioned to position themselves as knowing and capable therefore resisting the undesirable subjectivity.

The 'othering' was also structured around the girls' maturity wherein the other girls were largely described as younger girls. Additionally, while the younger girls in the study expressed dislike and even disgust at many sexualised celebrity representations, older girls in the study showed more willingness to engage with hyper-sexuality under particular conditions (e.g., the girls' discussion about Beyoncé's hypersexual representation in Chapter Six, Extract 11, p. 139). Despite the 
age difference in apparently comfortably engagment with hypersexual representations, a discourse of dangerous/ risky sexuality that inflects a sexualisation of girls discourse nonetheless had a significant presence in girls' talk across the study (both in relation to celebrities and to girls). This at-risk discourse was especially evident in girls' discussions of dress, with some girls producing narratives of danger particularly structured around the notion of a 'paedophilic gaze' in their comments. The girls' construction of 'inappropriate' dress and behaviour as inherently dangerous for girls underscores the regulatory effects that discourses such as the sexualisation of girls have on expressions of sexual subjectivity particularly in regards to their dress, public appearance, and behaviour. In addition, the girls regular positioning of other girls as always potential victims to the predatory eye also calls attention to the regulation of girls' sexuality as functioning in tandem with constructions of girls as sexual innocents. Such regulation is evident in what Fine and McClelland (2008, see also McClelland \& Fine, 2008) theorise as a "missing discourse of desire" which posits an invisibility of girls' sexuality and constructs girls' sexuality through discourses of danger and victimisation.

The preceding discussion has demonstrated girls' negotiation of their participation/engagement with hypersexualised media through the mobilisation of regulatory discourses. While some of these examples of mobilisation re-appropriate relationships between girlhood and hypersexual contemporary culture as a dangerous and problematic relationship, the girls' mobilisation of these discourses is also regularly seen as a position from which girls can assert themselves as critical consumers and resist being positioned within the problematic sexualised girl subjectivity. Importantly, however, girls' discursive negotiation is not straightforward and discourses can also be used to structure alternative positions for themselves (e.g. as knowing and savvy). Girls' navigation of these discourses in this way emphasises the work required of girls in the negotiation and management of their own pleasurable participation in and consumption of female pop music media and celebrity culture (Harris, 2004; Griffin, 2004, 2004b; Gonick, 2006).

Girls' discursive rupture of sexualisation discourses. Interwoven with girls' mobilisation of regulatory girlhood sexuality there was also much evidence of girls' negotiation of hypersexual pop music media in unique and transformative ways which can be understood as rupturing the same moral and regulatory discourses they deploy. 
Exploring these ruptures in the current section serves to highlight not only the ways in which girls are transforming the problematic discourses in a contemporary context which is saturated with concern about girls, but also to emphasise these discourses as actively managed and negotiated by girls rather than solely problematic and negative constructions from which girls have no escape.

Contrary to the hypersexual, overly made-up, body-exposing image of the 'sexualised girl' constructed within sexualisation literature, the visual representation of the girls in their music videos was significantly different and importantly absent of such 'sexual markers' (e.g. Hamilton, 2009; Levin \& Kilbourne, 2008; Oppliger, 2008). The absence of sexualised 'markers' in the girls' performances could possibly be read through the notion of rupture in that they performed a 'non-sexual' version of girlhood and anchoring themselves within the realm of childhood in their performances, although the matter of the 'audience' (the videos were made for the researcher to view) necessarily tempers such a reading.

Nonetheless, a distinct absence of the 'sexual' by way of dress and movement formed part of a wider picture within which girls included 'childhood markers' in their performances to pop music songs. Such markers, that included filming the family dog, themselves jumping on the trampoline, the use of childhood games and children's music and media references, could be read as an appropriation of a childhood innocence discourse (through emphasising non-sexual childhood), but, alternatively, these representations could be read as rupturing postfeminist discourses of hypersexuality. From this perspective, rather than being approached as an example of girls as regulated by sexualisation discourses, the girls non-incorporation of hypersexual messages in the music that they were performing to can alternatively be seen as them actively distancing themselves from hypersexual femininity and discursively anchoring themselves within the domain of childhood. Their use of childhood markers is argued here as a further demonstration of the complexity of their engagement with this media (Renold \& Ringrose, 2008).

Whereas in the girls' talk a sexual taboo operated for those who were deemed immature, the girls were also seen to navigate this taboo themselves in their own performances. The finding of childhood markers in girls' performances of pop music appears to be somewhat novel within critical feminist girlhood studies. Sexualised messages in song lyrics and music videos were for the most part replaced with childhood representations thereby rupturing the notion of girls as passively emulating 
their pop music idols (Durham, 2009) As part of the complexity of girls' media engagement, although childhood markers were often used in the girls' performances, hypersexuality within female pop music media was not necessarily always constructed by the girls as 'taboo' or unacceptable in their own engagement. Specifically, girls' ages structured the lines of permissibility and appropriateness concerning their own pleasurable engagement with and understanding of hypersexual postfeminist texts wherein greater acceptance and comfort in engaging with hypersexual representations was seen in the older girls' discussions. Although older girls displayed more comfort in engaging with sexualised representations, girls' selfpositioning as capable consumers who are able to self-regulate and identify what was in/appropriate content for their consumption was seen across the study regardless of age. However, girls' self-regulation may be read less as a rupture and more of an 'anxious awareness' concerning their consumption of sexualised media (Duits \& Van Zoonen, 2006, 2007; see also, Jackson \& Goddard, 2015).

Such 'anxious awareness' is readily understood in a context of girls' sexuality as so predominantly centred on discourses of risk and victimisation (Fine $\&$ McClellend, 2006; McClelland \& Fine, 2008). Thus, in the case of producing themselves as responsible, girls' 'management' of their consumer identity emphasises the burden of responsibility that girls must negotiate (of not becoming 'sexualised' or victimised by contemporary media) alongside their pleasurable engagement. Arguably, the girls' construction of themselves as responsible self-monitoring consumers functions to distance them from the undesirable sexualised girl, a subjectivity which was mobilised particularly in their discussion about the dangers of girlhood sexuality. At the same time, the responsibility discourse speaks to their necessary work and endless self-monitoring of their media consumption to make the 'right' (non-sexualised) consumer choices under the threat of failure that risks being positioned as a passive, victimised and immature consumer. So, girls' pleasurable engagement with female pop music media can be understood as inextricably intertwined with their required management and mitigation of discourses of risk and danger. Nonetheless, such management positions them as agentic individuals. Girls' discursive management of their own pleasurable consumption in light of their simultaneously overwhelming positioning within contemporary culture as either 'unaffected' or 'at-risk' aligns with previous literature (Egan, 2013; Egan \& Hawkes, 2008, 2008b, 2009; Gonick, 2006; Griffin, 2004, 2004b; Harris, 2004; Jackson \& 
Vares, 2012b; Ringrose, 2007, 2008; Renold \& Ringrose, 2011; Willet, 2008, 2011). This literature has identified girl' engagement with sexualised media (and in turn broader understandings of girlhood sexuality) as narrowly defined within a binary of either 'sexualised' or 'innocent'.

\section{Final Reflections}

The research presented in this thesis offers important insights into girls' engagement with hypersexual female pop music media and more broadly with the sexualisation of culture. It builds on a small body of empirical, feminist poststructuralist literature which addresses how girls are making their way through a sexualised media landscape in a time in which their consumption is highly problematised. Consistent with this body of work the current thesis troubles and challenges the binaries that characterise contemporary hegemonic discourses that construct girlhood as an inherently unstable and problematic developmental period.

In the exploration of this concern, the thesis presented the analysis of three qualitative studies. These studies have shown girls' active negotiation of the limited subjectivities offered in sexualisation discourses to be a necessary part of their own pleasurable media consumption. Through the use of three methodological approaches to the study of girls' pop music media engagement, the research in the thesis expands current understandings of girls' discursive practises in navigating the 'sexualised' or 'innocent' girlhood binary. Specifically, the research has produced insights into girls' discursive practices about critiques of acceptable/unacceptable celebrity sexuality grounded in regulatory discourses that work through maturity and authenticity. It has emphasised girls' strategies for negotiating a sexualised industry in their distancing from sexualised performances through their use of 'childhood markers' and the mobilisation of a responsible consumer discourse.

McClelland and Fine (2008) assert that it is necessary for researchers to find a way in which girls' sexuality expressions “"on release' are not 'eaten up by commercials, predators and shame, but could loiter a bit, in talk and body" (p. 100). Following this, selecting qualitative methods for the research acknowledged the importance of gathering knowledge about girls' media engagement with and by the girls themselves. From a feminist perspective, then, the research achieves the important goal of undertaking research which positions girls' voices, understandings and actions as central to exploring their lives and experiences. Of the three studies, the 
girls' music video study has been a particularly novel and key contribution to the literature.

Through these qualitative methods, the research contributes important findings concerning girls' navigation of contemporary sexualised culture and how they are living in a cultural context which dually and simultaneously hails them as ideal consumers and positions them as passive and 'at-risk'. Firstly, girls' use of childhood markers to anchor themselves within a childhood (non-sexual) domain is a hitherto unexplored aspect of discursive practices that girls use to navigate undesirable subjectivities. Second, the girls' mobilisation of a role model discourse contributes to theorisation concerning the ways in which this discourse is employed by the girls in a regulatory fashion in their accounts about the relationship between girls and hypersexual media (appropriating protectionist discourses).

Although valuing girls' views, the research also recognises the considerable role that culture and society (through dominant and available discourses for girls) play in the girls' lives, namely through the limited set of possibilities for self made available to girls in regards to media consumption and sexuality within contemporary western culture. Therefore, the research recognises the argument put forward by Tolman (1994, 2005, 2012) and McClelland and Fine (2008) that girls' talk (and behaviour) is necessarily constrained by the available discourses through which they speak. By grounding the research in girls' talk (within which possibilities of self are enabled and constrained) and production of media the current research was able gather rich and complex insights into the ways in which girls are engaging with and understanding the messages and representations that saturate contemporary culture.

While the current research can be understood as complicating the sexualisation of girls discourse through its representations of ways in which girls' engagement with pop music media challenged and contradicted its assumptions, it provides no grand 'evidence' to dismiss this body of knowledge. Rather, the study contributes to a small but growing body of feminist literature which undermines this sexualisation discourse through nuanced feminist research explorations. The current research cannot be understood as removing, 'fixing' or 'defeating' the sexualisation of girls discourse (nor can this be the aim of poststructuralist research). Instead, the research with girls has called into question the claims of this protectionist discourse and revealed it to be restrictive in its construction of a narrow binary of 'sexualised' or 'innocent' girlhood subjectivity which girls must negotiate alongside their media engagement. 
All research has limitations in that it is contextually bound to the situation within which it was conducted. For the research presented in this thesis, the school based setting, specific age group, and exploration of a very specific part of girls' lives bound the findings. How girls of different ages, in different social contexts (e.g., home, leisure activities) talk about and perform pop music media may vary considerably from this research context. Moreover, girls in the study from school Tahi were pre-selected by the school Dean, meaning that only a specific group of girls from this school were given the opportunity to participate. It is possible to hypothesise that girls were selected as 'good' representatives of the school while other 'less desirable' candidates were not given the opportunity.

In addition to the limitations related to the participant selection process, the raced and classed intersections within girls' engagement with postfeminist female popular music media are not specifically analysed in the focus group or girls' music video studies. Although this research has understood girls' engagement with female pop music media as always negotiated within the intersection of race and regulatory notions of 'acceptable' and 'unacceptable' female sexuality, girls' discussions in the focus groups did not engage with the ethnically diverse bodies of contemporary pop music celebrities. Even when expressly asked about their engagement with ethnically diverse female celebrity embodiment, the girls responded by explaining that there were no racial differences in the music that girls at their school listened to or in the bodies of the celebrities that they were exposed to. Rather than indicating an absence of race as a mediating factor in girls' meaning making and engagement with female pop music media engagement, the implication of this finding in the research is understood as highlighting the limited possibilities of self that were available in relation to racial identities, within postfeminist female pop music media at the time of the focus groups. Reflecting on contemporary culture since completion of this research, the female pop music media landscape (and more broadly Western society) has shifted, particularly in relation to the discussion and representation of race. Whereas in 2011, when the data in this thesis was collected, music media and representations by artists such as Beyoncé, who is African American, paid a startlingly small amount of attention to the stars ethnic heritage. In 2016, however, racial politics are not only at the centre of contemporary public and political debate (seen through campaigns such as \#blacklivesmatter for example) they are also becoming increasingly centralised within female pop music media. Beyoncé for 
example, released her latest album titled Lemonade in 2016 which, departing from her emphasises on feminist proclamations (seen in the previous album), has been hailed as "a love letter to black women" (Hunt, 2016). Although not explored in the research data in this thesis, the intersections of race within postfeminist female pop music media (and the possibilities for self that this intersection enables and constrains) is an important topic for future consideration and research. In addition, given the vastly different pop music media context which girls are engaging with in 2016 (and likely in the years ahead) future research concerning girls' engagement with female pop music media (and the sexualisation of culture more broadly) must examine the ways in which girls' understandings of self and others are navigated and produced in this context. Moving forward, analysis of girls' media consumption specifically concerning the ethnicities of the pop stars that they are seeing is an important consideration for future research.

Acknowledging these contextual limitations and intersectional absences in the literature, this thesis does not make any generalising claims about girls' engagement with popular culture. Rather, the research in the thesis presents insights from girls from a very specific cultural, classed and raced context. Specifically, drawing on the decile rating of the participating girls' schools, most of the girls could be expected to be middle to upper middle class and although there was a distribution of ethnicities, the majority of the participants were white. The participants' socio-cultural backgrounds can therefore be understood as contextualising some of the girls' understandings about 'appropriate' and 'inappropriate' sexualised behaviour for celebrities and for young girls themselves. Thus, future research concerning young girls and their engagement with sexualised culture must consider and explore the understandings (and possibilities for self) for working class girls and other than Pakeha ethnicities in New Zealand such as Maori and Pacific Island girls.

Given that the participants in the study were drawn from a specific (and arguably privileged social background), the analyses that have been discussed in the thesis, while consistent with other research about girls' negotiation of popular culture, can only be understood as providing insight into how these particular girls, within a specific research setting, discussed and negotiated their participation in/engagement with female pop music celebrities and media.

Another aspect of the research which warrants attention is the video visual methodology deployed. This method arguably offers a relatively new approach to the 
investigation of girls' engagement with and performance to music, as in several other influential feminist studies which have used video data to explore girls' play to music (e.g., Baker, 2004, 2004b). Whereas Baker's (2004, 2004b) research centred around girls play to music, in the music video study presented in this thesis, the nature of the videos (specifically that they were practiced, planned and presented for a research project) suggests a different kind approach to the data than has been seen in the previously cited studies about girls' play to music. Visual data of this kind needs to be considered through the notion of girls processes of production and reflection, wherein, the planning and practicing of performances means that they must be approached possibly mediated by girls knowledge of the researcher audience for which they were produced. This kind of visual data brings to light questions about how we (as researchers) approach such performances which have been created for us as a specific audience. Although the video method employed in this research warrants further explorations and potentially offers important research opportunities for exploring girls' media engagement, the 'limits' of the video methodology in general must also be considered. For example, despite the researcher being absent, certain dynamics, particularly of surveillance, must be understood as always at play and possibly influencing the data. In addition, despite the absence of the researcher, Baker and Bloustein (2003) contend that the tendency to approach visual methods of research as providing more 'real' or raw must be avoided.

Finally, the lack of data drawn from the follow up focus groups is an important limitation within the thesis research. Although the follow up focus groups were approached as a method which would provide insights to girls' music video production, disappointingly, with the exception of one focus group, very little discussion about the music videos made by the girls took place (this data was used in the music video analysis, p. 172). While the reasons for so little discussion are unknown, a number of possibilities can be considered. Firstly, the follow up focus groups took place at the end of the girls' school year. During this phase of the research the atmosphere in the school as a whole was markedly less focussed. For example, a girl in one of the focus groups commented that with the holidays only days away, school had become less focussed and they spent more time watching movies and playing than doing 'work'. A lack of focus at the end of the school term coupled with the end of the project may explain the girls' limited participation in their followup discussion groups. Another possible explanation is that the girls felt too 
uncomfortable to participate after watching their videos as a group. This process of viewing the girls' music videos uniformly sparked responses of discomfort from the girls where, in the most extreme case, one of the girls refused to watch her group's video entirely. Interestingly, however, in the most engaged follow-up focus group, the girls displayed far less embarrassment. It is possible to hypothesise, then, that the girls' general discomfort in seeing themselves performing prevented them from fully participating in the follow up focus group. This possibility also represents an area which could be explored in future research. The reasons behind the girls' embarrassment in seeing themselves perform these identities could arguably provide further insights into their navigation of this media and the possibilities of self it enables and constrains. The girls' embarrassment (or flat out rejection of watching the videos) might be explored through the possibility that these performances challenge the girls' understandings of appropriate play and performance to this music for example. Exploring girls' discomfort in consuming their own performances to pop music might therefore extend the understandings of the complexities of girls' media engagement which have been explored in the thesis.

This thesis sought to explore girls' pop music media consumption through their understandings, experiences and practices which they employ in their engagement with such media. Despite the proliferation of sexualisation literature which presents problematic and increasingly negative views of girls' engagement with contemporary culture, the research presented in this thesis has not found evidence to support these claims. Rather, the thesis has presented findings which highlight girls' media engagement as a complex process within which many of the complexities and contradictions could be understood as stemming from the regulatory discourses deployed in much of the sexualisation literature. The research has shown that regulatory discourses (such as the sexualisation of girls) simultaneously function as regulators of girls' behaviour, positioning them as passive and victimised media consumers, while at the same time functioning as discursive tools used by girls to distance themselves from the undesirable subjectivity.

The research presented in this thesis aligns with much previous critical feminist research that describes girls' sexuality and female sexuality more broadly as increasingly commodified, hypersexualised and depoliticised within postfeminist culture (Gill, 2003, 2007, 2007b, 2008b; McRobbie, 2007, 2008;). Within this problematic cultural landscape, and in the years since the beginning of this project, 
girls' engagement with postfeminist hypersexual culture has revealed itself to not be an entirely depressing and hopeless situation. In fact, despite the continued production of texts of concern about girls and contemporary popular culture, critical feminist research has produced literature which highlights the ways in which girls' unique navigation of contemporary media at times can be seen to transform the hypersexualised idealised femininity at the centre of sexualisation moral panics. The current research, however, does not, and did not intend to provide answers to a key question within sexualisation literature - is hypersexual culture 'bad' for girls? Instead, this research recognises the limited and problematic assumptions within this question as central to understanding the contemporary relationship between girls and postfeminist media culture. While the author agrees in many respects that the proliferation of hypersexualised images of celebrities does function negatively for girls' subjectivity work (in particular sexual subjectivity), providing extremely narrow possibilities for achieving 'ideal femininity' and increasingly harsh 'punishments' for failure, this relationship is far from black and white or causal. Rather, the proliferation of texts aimed at 'discovering' whether media is 'good' or 'bad', sexualised or not and the simultaneous positioning of girls as 'good' or 'bad', sexualised or not is far more harmful to girls' sexual subjectivity development. Instead, the author contends that in approaching girls' hypersexual media consumption, the moments of rupture and regulation, the points in which girls' actively negotiate postfeminist messages, need further exploration.

As a final point and possible way forward for critical feminist girlhood research, it is important to consider the powerful effects that the sexualisation of girls discourse has not just on the lives of girls at a micro level, but also more broadly on the macro level influencing their social positioning as helpless victims and girlhood itself as an inherently problematic developmental time in contemporary Western culture. As has been discussed in regards to postfeminist discourse, academics have repeatedly contended that the sexualisation of girls discourse attends to a contemporary fear for white middle class girls, but feminist analysis and investigation has tended to stop there. It is the authors belief that in continuing research which explores the ways in which girls are living and experiencing contemporary culture it is imperative that we examine not just the girls who are positioned within this discourse but also those who are excluded, absent and deemed unaffected by this hegemonic discourse. Exploration of the girls who are afforded such attention and 
those who are not might also reveal something about the ways in which society, through ethnic and classist prejudice, structures the positioning and 'worthiness' of its girl citizens. 


\section{References}

Aapola, S., Gonick, M., \& Harris, A. (2005). Young femininity: Girlhood, power and social change. New York: Palgrave Macmillan.

Alcoff, L. (1988). Cultural feminism versus post-structuralism: The identity crisis in feminist theory. Signs, 13(3) 405-436. doi: 10.1086/494426.

Alldred, P. (1998). Ethnography and discourse analysis: Dilemmas in representing the voices of children. Retrieved from http://dspace.brunel.ac.uk/bitstream/2438/1507/3/Chil dren'sVoicesDilemmas.pdf.

Allen, K., \& Mendick, H. (2013). Keeping it real? Social class, young people and 'authenticity' in reality TV. Sociology, 47(3), 460-476. doi: 10.1177/0038038512448563.

Allen, K., \& Mendick, H. (2013b). Young people's uses of celebrity: Class, gender and 'improper' celebrity. Discourse: studies in the cultural politics of education, 34(1), 77-93. doi: 10.1080/01596306.2012.698865.

American Psychological Association. (2007). Task force on the sexualization of girls. Report of the APA Task Force on the Sexualization of Girls, 7. Retrieved from https://www.apa.org/pi/women/programs/girls/report-full.pdf

Amy-Chinn, D. (2006). This is just for me (n) how the regulation of post-feminist lingerie advertising perpetuates woman as object. Journal of consumer culture, 6(2), 155-175. doi 10.1177/1469540506064742.

Andsager, J., \& Roe, K. (2003). “What's your definition of dirty, baby?”: Sex in music video. Sexuality and culture, 7(3), 79-97. Retrieved from http://web.b.ebscohost.com/ehost/pdfviewer/pdfviewer?sid=f3370a9a-36ab4bc1-bbd3-8ab833e9b030\%40sessionmgr104\&vid=0\&hid=116 
Ang, I. (1985). Watching Dallas: Soap opera and the melodramatic imagination. London: Methuen.

Ang, I. (1990). Melodramatic identification: Television fiction and women's fantasy. In E. M. Brown (Eds.), Television and Women's Culture. London: Sage Publications.

Aswad, J. (2008, April 27). Miley Cyrus apologised for racy photos, 'artistic' vanity fair spread: 'I feel so embarrassed'. Retrieved from http://www.mtv.com/ news/1586342/miley-cyrus-apologizes-for-racy-photos-artistic-vanity-fairspread-i-feel-so-embarrassed/.

Attwood, F. (2006). Sexed up: Theorizing the sexualization of culture. Sexualities, 9(1), 77-94. doi: 10.1177/1363460706053336.

Attwood, F. (2010). Sexualization, sex and manners. Sexualities, 13(6), 742. doi: $10.1177 / 1363460710384553$.

Attwood, F. (2011). The paradigm shift: Pornography research, sexualization and extreme images. Sociology Compass, 5(1), 13-22. doi: 10.1111/j.17519020.2010.00356.x.

Attwood, F. (2011b). Through the looking glass? Sexual agency and subjectification online. New Femininities, 203-214. Retrieved from http://eclass.uoa.gr/modules /document/file.php/MEDIA118/postfeminism/Ross\%20Gill__New_Femininiti es_Postfeminism_Neoliberalism_and_Subjectivity.pdf\#page $=226$.

Attwood, F. (Eds.). (2014). Mainstreaming sex: The sexualization of western culture. New York: IB Tauris.

Attwood, F., \& Smith, C. (2014). Porn studies: An introduction. Porn Studies, 1(1-2), 1-6. doi: 10.1080/23268743.2014.887308. 
Bailey, R. (2011). Letting children be children: Report of an independent review of the commercialisation and sexualisation of childhood. The Stationery Office. Retrieved from https://www.gov.uk/government/uploads/system/uploads/attachment_data/ file/ 175418/Bailey_Review.pdf.

Baker, S. (2001). 'Rock on, baby!': Pre-teen girls and popular music. Continuum: Journal of Media \& Cultural Studies, 15(3), 359-371. doi: 10.1080/10304310120086830.

Baker, S. (2004). 'It's not about candy' music, sexiness and girls' serious play in after school care'. International Journal of Cultural Studies, 7(2), 197-212. doi: 10.1177/1367877904043236.

Baker, S. (2004b). Pop in (to) the bedroom popular music in pre-teen girls' bedroom culture. European Journal of Cultural Studies, 7(1), 75-93. doi: 10.1177/136754940 4039861 .

Banet-Weiser, S. (2004). Girls rule!: Gender, feminism, and nickelodeon. Critical Studies in Media Communication, 21(2), 119-139. doi: 10.1080/07393180410001688038.

Barnes, B. (2008, April 28). Revealing photo threatens a major disney franchise. Retrieved from http://www.nytimes.com/2008/04/28/business/media/28hannah.html.

Beck, U. (1992). Risk Society: Towards a new modernity. London: Sage Publications.

Bell, E. (2008). From bad girl to mad girl: British female celebrity, reality products, and the pathologisation of pop-feminism. Genders, (48), 1-20.

Bineham, J. L. (1988). A historical account of the hypodermic model in mass communication. Communications Monographs, 55(3), 230-246. doi: 10.1080/0 3637758809376169. 
Bjorkqvist, K., \& Niemela, P. (1992). New trends in the study of female aggression. In K. Bjorkqvist \& P. Niemela (Eds.), Of Mice and Women: Aspects of Female Aggression (pp. 3-15). London: Academic Press.

Bloore, J. (2011, April). Growing up too fast? The sexualisation of girls. Grapevine, 4. Retrieved from http://www.grapevine.org.nz/archive/2011/4_11/templates/ GV_11_4_Growing_Up_Too_Fast.pdf.

Bloustien, G. (2003). Girl making: A cross-cultural ethnography on the processes of growing up female. London: Berghahn Books.

Bloustien, G., \& Baker, S. (2003). On not talking to strangers: Researching the micro worlds of girls through visual auto-ethnographic practices. Social Analysis, 64-79. Retrieved from http://www.jstor.org/stable/23170096.

Boyle, K. (2000). The pornography debates: Beyond cause and effect. Women's Studies International Forum, 23(2),187-195. doi: 10.1016/S02775395(00)00077-7.

Bragg, S., Buckingham, D., Russell, R., \& Willett, R. (2011). Too much, too soon? Children, 'sexualization' and consumer culture. Sex Education, 11(3), 279292. doi: 10.1080/1 4681811.2011.590085.

Braun, V., \& Clark, V. (2006). Using thematic analysis in psychology. Qualitative research in psychology, 3(2), 77-101. doi: 10.1191/1478088706qp063oa.

Brookes, F., \& Kelly, P. (2009). Dolly girls: tweenies as artefacts of consumption. Journal of youth studies, 12(6), 599-613. doi: 10.1080/13676260902960745.

Brown, A. (2012). 'She isn't whoring herself out like a lot of other girls we see': Identification and "authentic" American girlhood on Taylor Swift fan forums. Networking Knowledge: Journal of the MeCCSA Postgraduate Network, 5(1). 
Brunsdon, C. (1993). Identity in feminist television criticism. Media Culture and Society, 15, 309-309. Retrieved from http://www.samfeder.com/PDF/19_IdentityInFeministT_Cr iticism.pdf.

Buckingham, D. (1993). Reading audiences: Young people and the media. New York: Manchester University Press.

Buckingham, D., \& Bragg, S. (2003). Young people, media and personal relationships. Retrieved from http://ofcom.org.uk/static/archive/itc/uploads/Young_P eople_Media_and_Personal_Relationships.pdf.

Buckingham, D., \& Bragg, S. (2004). Young people, sex and the media: The facts of life?. New York: Palgrave Macmillan.

Budgeon, S. (2001). Emergent feminist (?) Identities young women and the practice of micropolitics. European Journal of Women's Studies, 8(1), 7-28. doi: 10. $1177 / 135050680100800102$

Burman, E. (1994). Deconstructing developmental psychology. New York: Routledge.

Burr, V. (2003). Social constructionism ( $2^{\text {nd }}$ Ed.). New York: Routledge.

Butler, J. (2002). Gender trouble. London: Routledge.

Butler, J. (2004). Undoing gender. New York: Routledge.

Butler, J. (2013). For white girls only?: Postfeminism and the politics of inclusion. Feminist Formations, 25(1), 35-58. doi: 10.1353/ff.2013.0009.

Carey, T. (2011). Where has my little girl gone?. London: Lion Books. 
Charles, C. E. (2012). New girl heroes: The rise of popular feminist commentators in an era of sexualisation. Gender and Education, 24(3), 317-323. doi: 10.1080/09540253.20 12.666233.

Ciclitira, K. (2002). Researching pornography and sexual bodies. The Psychologist, 15(4), 191-194. Retrieved from http://search.proquest.com/docview/211854226?accountid= 14782 .

Ciclitira, K. (2004). Pornography, women and feminism: Between pleasure and politics. Sexualities, 7(3), 281-301. doi: 10.1177/1363460704040143.

Clark, J.L. (2006). The early sexualisation of girls and by the media: An examination of fashion. (Master's thesis, University of Canterbury, Christchurch, New Zealand). Retrieved from http://library.canterbury.ac.nz/services/ref/apa/thesis.shtml

Coleman, R. (2008). The becoming of bodies: Girls, media effects, and body image. Feminist Media Studies, 8(2), 163-179. doi: 10.1080/14680770801980547.

Conrad, K., Dixon, T. L., \& Zhang, Y. (2009). Controversial rap themes, gender portrayals and skin tone distortion: A content analysis of rap music videos. Journal of Broadcasting \& Electronic Media, 53(1), 134-156. doi: 10.1080/0883815080264379 5.

Cook, D. T., \& Kaiser, S. B. (2004). Betwixt and be tween age ambiguity and the sexualization of the female consuming subject. Journal of Consumer Culture, 4(2), 203-227. doi: 10.1177/1469540504043682.

Cook, S. (2006, October 15). Outcry at girl's 'lost youth'. The New Zealand Herald. Retrieved from http://www.nzherald.co.nz/nz/news/article.cfm?c_id=1\&objectid =10405978. 
Cooke, H. (2015, September 7). Racy teen novel into the river banned after family first complaint. Stuff.co.nz. Retrieved from http://www.stuff.co.nz/entertainment/books/71 797069/Racy-teen-novel-Intothe-River-banned-after-Family-First-complaint.

Cox, L. (2013, September 13). Raunchy, hypersexualised popstars like Miley Cyrus and Rihanna damage girls' self-esteem - and could harm education and job prospects - says leading academic. The Daily Mail. Retrieved from http://www.dailymail.co.uk/f email/article-2419993/Miley-Cyrus-Rihannadamage-girls-self-esteem--harm-education-job-prospects--says-academic.html.

Crick, N. (1995). Relational aggression: The role of intent attributions, feelings of distress, and provocation type. Development and Psychopathology, 7, 313-322. doi: 10.1017/ s0954579400006520.

Crick, N. R., \& Grotpeter, J. K. (1996). 'Children's treatment by peers: Victims of relational and overt aggression'. Development and Psychopathology, 8(2), 367-80. doi: 10.1017 /s0954579400007148.

Currie, D. (2000). Girl talk: Adolescent magazines and their readers. Toronto: University of Toronto Press.

Currie, D., Kelly, D. M., \& Pomerantz, S. (2009). 'Girl power': Girls reinventing girlhood ( $4^{\text {th }}$ ed.). New York: Peter Lang.

Curry, R. (1990). Madonna from Marilyn to Marlene_-pastiche and/or parody?. Journal of Film and Video, 15-30. Retrieved from http://www.jstor.org/stable/20687895.

Cyrus, M [MileyCyrusVEVO]. (2010, May 5). Miley Cyrus - Can't Be Tamed [Video file]. Retrieved from https://www.youtube.com/watch?v=sjSG6z_13-Q. 
Cyrus, M. [MileyCyrusVevo]. (2013, September 9). Miley Cyrus - Wrecking Ball [Video file]. Retrieved from https://www.youtube.com/watch?v=My2FRPA3Gf8.

Danius, S., Jonsson, S., \& Spivak, G. C. (1993). An Interview with Gayatri Chakravorty Spivak. Boundary 2, 20(2), 24-50. Retrieved from http://www.jstor.org/stable/pdf/30 3357.pdf?acceptTC=true.

Davies, E. (1969). Psychological characteristics of Beatle mania. Journal of the History of Ideas, (2), 273-280. doi: 10.2307/2708439.

Davies, B., \& Harré, R. (1990). Positioning: The discursive production of selves. Journal for the theory of social behaviour, 20(1), 43-63. Retrieved from https://www.researchgate.net/profile/Rom_Harre/publication/227980244_Posi tioning_The_Discursive_Production_of_Selves/links/00b4951d26bd3122b200 0000.pdf

Dines, G. (2010). Pornland: How porn has hijacked our sexuality. Boston: Beacon Press.

Dines, G. (2012). A feminist response to Weitzer. Violence against women, 18(4), 512-520. doi: 10.1177/1077801212452550.

Dines, G., \& Jensen, R. (2005). Pornography is a left issue. Znetcommunications. Retrieved from http://www.feministes-radicales.org/wp-content/uploads/2010 /11/DINES-JENSEN-Pornography-is-a-Left-Issue.pdf.

Dixon, T. L., \& Brooks, T. (2002). Rap music and rap audiences: Controversial themes, psychological effects and political resistance. African American Research Perspective, 8, 106-116. doi: 10.1177/1367877904043236.

Donnerstein, E., Linz, D., \& Penrod, S. (1987). The question of pornography: Research findings and policy implications. New York: Free Press. 
Downs, E., \& Smith, S. L. (2010). Keeping abreast of hypersexuality: A video game character content analysis. Sex Roles, 62(11-12), 721-733. doi: 10.1007/s11199-009-9637-1

Driscoll, C. (1999). Girl culture, revenge and global capitalism: Cybergirls, riot grrls, spice girls. Australian Feminist Studies, 14(29), 173-193. doi: 10.1080/08164649993425.

Driver, S. (2007). Queer girls and popular culture: Reading, resisting, and creating media. New York: Peter Lang.

Drotner, K. (1999). Dangerous media? Panic discourses and dilemmas of modernity. Paedagogica Historica, 35(3), 593-619. doi: 10.1080/0030923990350303.

Duggan, L., \& Hunter, N. D. (2006). Sex wars: Sexual dissent and political culture. New York: Taylor \& Francis.

Duits, L., \& Van Zoonen, L. (2006). Headscarves and porno-chic disciplining girls' bodies in the European multicultural society. European Journal of Women's Studies, 13(2), 103-117. doi: 10.1177/1350506806062750.

Duits, L., \& Van Zoonen, L. (2007). Who's afraid of female agency?: A rejoinder to Gill. European journal of women's studies, 14(2), 161-170. doi: $10.1177 / 1350506807075820$.

Duits, L., \& Van Romondt Vis, P. (2009). Girls make sense girls, celebrities and identities. European journal of cultural studies, 12(1), 41-58. doi: 10.1177/1367549 408098704 .

Dunleavy, T. (2005). Ourselves in primetime: A history of New Zealand television drama. Auckland: Auckland University Press. 
Dunschinsky, R. (2013). What does sexualisation mean?. Feminist Theory, 14(3), 255-264. doi: 10.1177/1464700113499842.

Durham, M. G. (2009). The Lolita effect: Why the media sexualize young girls and what you can do about it. Woodstock, New York: Overlook Press.

Durham, A. (2012). "Check on it” Beyoncé, southern booty, and black femininities in music video. Feminist media studies, 12(1), 35-49. doi: $10.1080 / 14680777.2011 .558346$.

Dworkin, A. (1985). Against the male flood: Censorship, pornography, and equality. Harvard Women's Law Journal, 8, 1. Retrieved from http://heinonline.org/HOL/Page?handle $=$ hein.journals $/$ hwlj8\&div=5\&g_sent=1\&collection=journals.

Dworkin, A. \& McKinnon, C. (1988). Pornography and civil rights, a new day for women's equality. Retrieved from http://www.feministes-radicales.org/wpcontent/ uploads/ 2012/05/Catharine-A.-MacKinnon-Andrea-DworkinPornography-and-Civil-Rights-A-New-Day-for-Women\%E2\%80\%99sEquality-1988.pdf.

Edley, N. (2001). Unravelling social constructionism. Theory \& Psychology, 11(3), 433-441. doi: 10.1177/0959354301113008.

Eduardo, M. (2012, July 1). Lady Gaga - You and I (Live at 2011 mtv VMAs) HD [Video file]. Retrieved from http://www.youtube.com/watch?v=SkWoA25V4tQ.

Egan, R. D., \& Hawkes, G. L. (2007). Producing the prurient through the pedagogy of purity: Childhood sexuality and the social purity movement. Journal of Historical Sociology, 20(4), 443-461. doi: 10.1111/j.1467-6443.2007.00319.x. 
Egan, R. D., \& Hawkes, G. L. (2008). Endangered girls and incendiary objects: Unpacking the discourse on sexualization. Sexuality \& culture, 12(4), 291311. doi: 10.1007/ s12119-008-9036-8.

Egan, R. D., \& Hawkes, G. L. (2008b). Girls, sexuality and the strange carnalities of advertisements: Deconstructing the discourse of corporate paedophilia. Australian Feminist Studies, 23(57), 307-322. doi: $10.1080 / 08164640802233278$.

Egan, R. D., \& Hawkes, G. L. (2009). The problem with protection: Or, why we need to move towards recognition and the sexual agency of children. Continuum: Journal of Media \& Cultural Studies, 23(3), 389-400. doi: 10.1080/10304310902842975.

Egan, R. D., \& Hawkes, G. L. (2010). Theorizing the sexual child in modernity. New York: Palgrave Macmillan.

Egan, R. D., \& Hawkes, G. L. (2012). Sexuality, youth and the perils of endangered innocence: How history can help us get past the panic. Gender and Education, 24(3), 269- 284. doi: 10.1080/09540253.2012.666232.

Egan, R. D. (2013). Becoming sexual: A critical appraisal of the sexualization of girls. Cambridge, UK: Polity Press.

Evans, A., Riley, S., \& Shankar, A. (2010). Technologies of sexiness: Theorizing women's engagement in the sexualization of culture. Feminism \& Psychology, 20(1), 114-131. doi: 10.1177/0959353509351854.

Evans, A., \& Riley, S. (2013). Immaculate consumption: Negotiating the sex symbol in postfeminist celebrity culture. Journal of Gender Studies, 22(3), 268-281. doi: 10.108 0/09589236.2012.658145.

Fairclough, K. (2008). Fame is a losing game: Celebrity gossip blogging, bitch culture and postfeminism. Genders, (48). Retrieved from 
http://go.galegroup.com/ps/i.do?id=GA

LE\%7CA194279234=\&2.1\&=vuw\&it=r\&p=AONE\&sw=w\&asid=b71415c86 a601s875c23b83eb92922403.

Faludi, S. (1992). Backlash: The undeclared war against women. London: Chatto \& Windus.

"Far too much, far too young: Outrage over shocking images of the 10-year-old model who has graced the page of vogue". (2011, August 10). The Daily Mail. Retrieved from http://www.dailymail.co.uk/femail/article-2022305/ThylaneLena-Rose-Blondeau-Shocking-images-10-YEAR-OLD-Vogue-model.html.

Fine, M. (1988). Sexuality, schooling, and adolescent females: The missing discourse of desire. Harvard educational review, 58(1), 29-54. Retrieved from http://search.proquest.com/docview/212286954?accountid=14782.

Fine, M., \& McClelland, S. (2006). Sexuality education and desire: Still missing after all these years. Harvard Educational Review, 76(3), 297-338. Retrieved from http://search.proquest.com/docview/212259433/fulltextPDF?accountid=14782

Fiske, J. (1992). Audiencing: A cultural studies approach to watching television. Poetics, 21(4), 345-359. doi: 10.1016/0304-422X(92)90013-S.

Foucault, M. (1995). Discipline and Punish: The Birth of the Prison (A. Sheridan, Trans.). New York: Vintage Books. (Original works published in 1977)

Foucault, M. (1972). The archaeology of knowledge (1989). London: Tavistock.

Foucault, M. (1980). The history of sexuality, Vol. 1: An introduction. New York: Vintage Books. (Original works published 1978).

Foucault, M. (1988). 'Technologies of the self'. In L.H. Martin, H. Gutman \& P. Hutton (Eds.), Technologies of the Self: A Seminar with Michel Foucault (pp. 16-49). Amherst: The University of Massachusetts Press. 
Frisby, C. M., \& Aubrey, J. S. (2012). Race and genre in the use of sexual objectification in female artists' music videos. Howard Journal of Communications, 23(1), 66-87. doi: 10.1080/10646175.2012.641880.

Frith, H. (2000). Focusing on sex: Using focus groups in sex research. Sexualities, 3(3), 275-297. doi: 10.1177/136346000003003001.

Fritzsche, B. (2004). Spicy strategies: Pop feminist and other empowerments in girl culture. In A. Harris (Eds.), All about the girl:Culture, power and identity (pp. 155-162). New York: Routledge.

Gaga, L [LadyGagaVEVO]. (2009, June 16). Lady Gaga - Just Dance ft Colby O'Donis [Video file]. Retrieved from https://www.youtube.com/watch?v=2Abk1jAONjw.

Gaga, L [LadyGagaVEVO]. (2009b, December 19). Lady Gaga-Poker Face [Video file]. Retrieved from https://www.youtube.com/watch?v=bESGLojNYSo.

Gaga, L [LadyGagaVEVO]. (2010, June 8). Lady Gaga - Alejandro [Video file]. Retrieved from https://www.youtube.com/watch?v=niqrrmev4mA.

Gaga, L [LadyGagaVEVO]. (2010b, May 15). Lady Gaga-Telephone ft. Beyoncé[Video file]. Retrieved from https://www.youtube.com/watch?v=EVBsypHzF3U.

Gaga, L [LadyGagaVEVO]. (2011, June 16). Lady Gaga - Edge Of Glory [Video file]. Retrieved from https://www.youtube.com/watch?v=QeWBSOJBNzQ.

Gaga, L [LadyGagaVEVO]. (2011b, February 27). Lady Gaga - Born This Way [Video file]. Retrieved from https://www.youtube.com/watch?v=wV1FrqwZyKw. 
Gaga, L [LadyGagaVEVO]. (2011c, May 3). Lady Gaga - Judus [Video file]. Retrieved from http:// www.youtube.com/watch?v=wagn8Wrmzuc.

Garbarino, J. (2006). See Jane hit: Why girls are growing more violent and what can be done about it. New York: Penguin Press.

Gavey, N. (1989). Feminist poststructuralism and discourse analysis: Contributions to feminist psychology. Psychology of women quarterly, 13(4), 459-475.

Retrieved from http://web.b.ebscohost.com/ehost/pdfviewer/pdfviewer?sid=74e605a1-91d1457c-b63f-fa2360c3f0e6\%40'sessionmgr115\&vid=0\&hid=116.

Gavey, N. (2002). To and beyond the discursive constitution of subjectivity. Feminism \& Psychology, 12(4), 432-438. Retrieved from http://fap.sagepub.com/content/12/4 /432.full.pdf.

Gavey, N. (2005). Just sex. The cultural scaffolding of rape. Hove, Brighton: Routledge.

Gavey, N. (2012). Beyond "empowerment"? Sexuality in a sexist world. Sex roles, 66(11-12), 718-724. doi: 10.1007/s11199-011-0069-3.

Geerts, E. (2013). Singing sirens. Contemporary pop and rock goddesses and their potentially feminist acts of »chanter hystérique «. Retrieved from http://www.pop-zeitschrift.de/ wp-content/uploads/2013/06/aufsatz-geertssinging-sirens.pdf.

Geiger, T. C., Zimmer-Gembeck, M. J., \& Crick, N. R. (2004). The science of relational aggression. In Girls and Aggression (pp. 27-40). Springer US. Retrieved from https://www.researchgate.net/profile/Melanie_ZimmerGembeck/publication/ 29451861_The_Science_of_Relational_Aggression_Can_we_guide_interventi on/links/0f3175369f9b3359bb000000.pdf. 
Genz, S. (2006). Third way/ve the politics of postfeminism. Feminist Theory, 7(3), 333-353. doi: 10.1177/1464700106069040.

Gergen, K. J. (1985). The social constructionist movement in modern psychology. American psychologist, 40(3), 266-275. Retrieved from http://www.swarthmore.edu/Docmen ts/faculty/gergen/Social_Constructionist_Movement.pdf.

Getmusicasia (2011, August 30). Jessie J - Who's Laughing Now Behind The Scenes [Video file]. Retrieved from https://www.youtube.com/watch?v=FZ8slnGojVs.

Giddens, A. (1991). Modernity and self-identity: Self and society in the late modern age. Cambridge: Polity.

Gilbert. J. (2010, August 8). Sexualisation of girls makes them ill. Stuff.co.nz. Retrieved from http://www.stuff.co.nz/the-press/news/3983393/Sexualisationof-girls-makes-them-ill-author.

Gill, R. (2003). From sexual objectification to sexual subjectification: The resexualisation of women's bodies in the media. Feminist media studies, 3(1), 100-106. Retrieved from http://www.tandfonline.com/doi/pdf/10.1080/1468077032000080158.

Gill, R. (2007) 'Supersexualize me! Advertising, (post)feminism and "the midriffs" '. In F. Attwood., R. Brunt \& R. Cere (Eds.), Mainstreaming Sex: The Sexualisation of Culture. London: I.B. Tauris.

Gill, R. (2007b). Critical Respect: The difficulties and dilemmas of agency and 'choice' for feminism. European Journal of Women's Studies, 14(1), 69-80. doi: 10.1177/1350506807072318.

Gill, R. (2007c). Postfeminist media culture elements of a sensibility. European journal of cultural studies, 10(2), 147-166. doi: 10.1177/1367549407075898. 
Gill, R. (2007d). Gender and the media. Cambridge: Polity.

Gill, R. (2008). Culture and subjectivity in neoliberal and postfeminist times. Subjectivity, 25(1), 432-445. doi:10.1057/sub.2008.28.

Gill, R. (2008b). Empowerment/sexism: Figuring female sexual agency in contemporary advertising. Feminism \& Psychology, 18(1), 35-60. doi: $10.1177 / 0959353507084950$.

Gill, R. (2009). Beyond the 'sexualization of culture' thesis: An intersectional analysis of 'six packs', 'midriffs' and 'hot lesbians' in advertising. Sexualities, 12(2), 137-160. doi: 10.1177/1363460708100916.

Gill, R. (2011). Sexism reloaded, or, it's time to get angry again!. Feminist Media Studies, 11(01), 61-71. doi: 10.1080/14680777.2011.537029.

Gill, R. (2012). Media, empowerment and the 'sexualization of culture' debates. Sex Roles, 66(11-12), 736-745. doi: 10.1007/s11199-011-0107-1.

Gill, R. (2012b). The sexualisation of culture?. Social and Personality Psychology Compass, 6(7), 483-498. doi: 10.1111/j.1751-9004.2012.00433.x.

Gilligan, C., \& Brown, L. M. (1992). Meeting at the crossroads: Women's psychology and girls' development. London: Harvard University Press.

Gonick, M. (2006). Between "Girl Power" and "Reviving Ophelia": Constituting the neoliberal girl subject. NWSA journal, 18(2), 1-23. Retrieved from http://www.jstor.org/stable/pdf/4317205.pdf

Gonick, M., Renold, E., Ringrose, J., \& Weems, L. (2009). Rethinking agency and resistance: What comes after girl power?. Girlhood Studies, 2(2), 1-9. doi:10.3167/ghs.2009.020202. 
Goode, L. \& Zuburi, N. (2004). Media studies: Switching on. In L. Goode \& N. Zurberi (Eds.), Media Studies in Aotearoa/New Zealand (pp. 2-15). Auckland: Pearson.

Griffin, C. (1997). Troubled teens: managing disorders of transition and consumption. Feminist review, 4-21. Retrieved from http://www.jstor.org/stable/139 5785.

Griffin, C. (2004). Good girls, bad girls: Anglocentrism and diversity in the constitution of contemporary girlhood. In A. Harris (Eds.), All About the Girl: Culture, Power, and Identity (pp. 29-43). London: Routledge.

Griffin, C. (2004b). 'Impossible spaces? Femininity as an empty category'. ESRC Research Seminar Series: New Femininities. Retrieved from http://www. lse.ac.uk/collection s/newFemininities.

Hadley, M. (2003). Relational, indirect, adaptive, or just mean: Recent work on aggression in adolescent girls-Part I. Studies in Gender and Sexuality, 4(4), 367-394. doi: 10.1080/15240650409349235.

Hageman, G. (2014, June 28). My life as a pregnant teenager. The New Zealand Herald. Retrieved from http://www.nzherald.co.nz/lifestyle/news/article.cfm?c_id=6\&object $\mathrm{id}=11283247$.

Halberstam, J. J. (2012). Gaga feminism: Sex, gender and the end of normal. Boston: Beacon Press.

Hall, S. (1973). A world at one with itself. In S. Cohen \& J. Young. (Eds.), The manufacture of News, Deviance and Social Problems. London: Hutchinson.

Hamad, H., \& Taylor, A. (2015). Introduction: Feminism and contemporary celebrity culture. Celebrity Studies, 6(1), 124-127. doi: 10.1080/19392397.2015.1005382. 
Hamilton, M. (2009). What's happening to our girls?. London: Penguin.

Harris, A. (2004). All about the girl: Culture, power, and identity. London: Routledge.

Harris, A. (2004b). Future girl: Young women in the twenty-first century. New York: Routledge.

Harrocks, R. (2004). Studying New Zealand television: Themes, methods, perspectives. In R, Harrocks \& N, Perry (Eds.), Television in New Zealand: Programming the Nation (pp. 5-19). New York: Oxford.

Hartley, J. (1998). Juvenation: News, girls and power. In C. Carter., G. Branston \& S. Allan (Eds.), News, gender and power (pp. 47-70). London: Routledge.

Hawkes, G. L., \& Egan, R. D. (2008). Landscapes of erotophobia: The sexual (ized) child in the postmodern anglophone West. Sexuality \& culture, 12(4), 193203. doi: 10.1007/s12119-008-9038-6.

Henriques, J., Hollway, U., Urwin, C. C., Venn, C., \& Walkerdine, V. (1984). Changing the Subject: Psychology, social regulation and subjectivity. London: Methuen.

Henry, A. (2004). Not my mother's sister: Generational conflict and third-wave feminism. Bloomington: Indiana University Press.

Holmes, S. (2004). “Reality goes pop!" Reality TV, popular music, and narratives of stardom in pop idol. Television \& New Media, 5(2), 147-172. doi: $10.1177 / 1527476403255833$.

Holmes, S., \& Redmond, S. (Eds.). (2006). Framing celebrity: New directions in celebrity culture. New York: Routledge.

Hooks, B. (1992). Black looks: Race and representation. Boston: South End. 
Hoppe, M. J., Wells, E. A., Morrison, D. M., Gillmore, M. R., \& Wilsdon, A. (1995). Using focus groups to discuss sensitive topics with children. Evaluation review, 19(1), 102-114. Retrieved from http://erx.sagepub.com/content/19/1/102.full.pdf.

Hunt, E. (2016, April 29). Beyonces Lemonade Album explained, from beginner to 'beyhive'. Retrieved from https://www.theguardian.com/music/2016/apr/29/beyonce-lemonade-jay-zexplainer.

J, J [JessieJVEVO]. (2011, August 10). Jessie J - Who's Laughing Now [Video file]. Retrieved from https://www.youtube.com/watch?v=KsxSxF3JKeU.

J, J [JessieJVEVO]. (2011, December 26). Jessie J - Domino [Video file]. Retrieved from https://www.youtube.com/watch?v=UJtB55MaoD0.

Jackson, C., \& Tinkler, P. (2007). 'Ladettes' and 'modern girls': 'Troublesome' young femininities. The sociological review, 55(2), 251-272. doi: 10.1111/j.1467-954X.2007.00704.x.

Jackson, S. (2010). Lifespan Development: New Zealand Perspectives. In J. Low \& P. E. Jose (Eds.), What do the they think? Qualitative research with children and young people. New Zealand: Pearson Education.

Jackson, S. J., \& Andrews, D. L. (1999). Between and beyond the global and the local American popular sporting culture in New Zealand. International Review for the Sociology of Sport, 34(1), 31-42. Retrieved from http://irs.sagepub.com/content/34/ 1/31.full.pdf.

Jackson, S., \& Goddard, S. (2015). 'I'd say 14 is too young': Pre-teen girls' negotiations of 'sexualized' media. Continuum, 29(2), 241-252. doi: 10.1080/10304312.2015.1022944. 
Jackson, S., \& Scott, S. (2004). Sexual antinomies in late modernity. Sexualities, 7(2), 233-248. doi: 10.1177/1363460704042166.

Jackson, S., \& Vares, T. (2011). Media “sluts": "Tween” girls' negotiations of postfeminist sexual subjectivities in popular culture. In R. Gill \& C. Scharff (Eds.), New femininities: Postfeminism, neoliberalism and subjectivity (pp.134-146). London: Palgrave MacMillian.

Jackson, S., \& Vares, T. (2015). 'Perfect skin', ‘pretty skinny’: Girls' embodied identities and post-feminist popular culture. Journal of Gender Studies, 24(3), 347-360. doi: 10.1080/09589236.2013.841573.

Jackson, S., \& Vares, T. (2015b). Too many bad role models for us girls': Girls, female pop celebrities and 'sexualisation. Sexualities, 18(4), 480-498. doi: $10.1177 / 1363460714550905$.

Jackson, S., Vares, T., \& Gill, R. (2013). 'The whole playboy mansion image': Girls' fashioning and fashioned selves within a postfeminist culture. Feminism \& Psychology, 23(2), 143-162 doi: 10.1177/0959353511433790.

Jefferson, G. (1985). “An exercise in the transcription and analysis of laughter”. In T. van Dijk (Eds.), Handbook of Discourse Analysis, Vol. 3: Discourse and Dialogue (pp. 24-34). London: Academic.

Jimmy Kimmel Live. [Jimmy Kimmel Live]. (2015, August 27). Miley Cyrus' Boobs Made Paul McCartney Uncomfortable [Video file]. Retrieved from https://www.youtube.com/watch?v=ePCxz76qzr8

Johnson, L. (1993). The modern girl: Girlhood and growing Up. Buckingham: Open University Press.

Juffer, J. (1998). At home with pornography: Women, sex, and everyday life. New York: NYU Press. 
Kalof, L. (1999). The effects of gender and music video imagery on sexual attitudes. The Journal of Social Psychology, 139(3), 378-385. doi: 10.1080/00224549909598393.

Kaufman, G. (2009). Gaga lets it bleed during eye-popping VMA performance. Retrieved from http://www.mtv.com/news/1621395/lady-gaga-lets-it-bleedduring-eye-popping-vma-performance/.

Kearney, M. C. (2007). Productive spaces: Girls' bedrooms as sites of cultural production. Journal of Children and Media, 1(2), 126-141. doi: 10.1080/17482790701339126.

Kearney, M. C. (2013). Girls make media. New York: Routledge.

Keller, J., \& Ringrose, J. (2015). 'But then feminism goes out the window!': Exploring teenage girls' critical response to celebrity feminism. Celebrity Studies, 6(1), 132-135. doi: 10.1080/19392397.2015.1005402.

Kennedy, M. (2014). Hannah Montana and Miley Cyrus: 'Becoming' a woman, 'becoming' a star. Celebrity Studies, 5(3), 225-241. doi: $10.1080 / 19392397.2013 .839349$.

Kidsfree2bekids (2009, August 13). 60 Minutes - little women part 1 [Video file]. Retrieved from https://www.youtube.com/watch?v=2J7vKjR45OA.

Kidsfree2bekids (2009b, August 13). 60 minutes - little women part 2 [Video file]. Retrieved from https://www.youtube.com/watch?v=2J7vKjR45OA.

Kitzinger, J. (2004). Audience and readership research. In J. Downing., D. McQuail., P. Schlesinger \& E. Wartella (Eds.), The Sage Handbook of Media Studies. Thousand Oaks, California: Sage Publications.

Klein, B. (2008). In perfect harmony: Popular music and cola advertising. Popular Music and Society, 31(1), 1-20. Retrieved from 
http://web.b.ebscohost.com/ehost/pdfviewer/p dfviewer?sid=c046f028-4ce946cd-903a 91578f9b8dbf\%40'sessionmg r111 \&vid =0\&hid=116.

Knowles-Carter, B. [beyonceVEVO]. (2009, October 2). Beyoncé-Check on it ft Bun B, Slim Thug [Video file]. Retrieved from https://www.youtube.com/watch $? \mathrm{v}=\mathrm{Q} 1 \mathrm{~d}$ UDzBdnmI.

Knowles-Carter, B. [beyonceVEVO]. (2011, May 11). Beyoncé- Run the World (Girls) [Video file]. Retrieved from https://www.youtube.com/watch?v=VBmMU_iwe6U.

Knowles-Carter, B. [beyonceVEVO]. (2014, February 25). Beyoncé- Partition (Explicit Video) [Video file]. Retrieved from https://www.youtube.com/watch?v=p Z12_E5R 3qc.

Knowles-Carter, B. [beyonceVEVO]. (2014, November 14). Beyoncé - ***Flawless ft. Chimamanda Ngozi Adichie [Video file]. Retrieved from https://www.youtube.com/w atch?v=pZ12_E5R3qc.

Kutchinsky, B. (1991). Pornography and rape: Theory and practice?: Evidence from crime data in four countries where pornography is easily available. International Journal of Law and Psychiatry, 14(1), 47-64. doi: 10.1016/01602527(91)90024-H.

Lamb, S. (2010). Feminist ideals for a healthy female adolescent sexuality: A critique. Sex Roles, 62(5-6), 294-306. doi: 10.1007/s11199-009-9698-1.

Lamb, S. (2010b). Porn as a pathway to empowerment? A response to Peterson's commentary. Sex Roles, 62(5-6), 314-317. doi: 10.1007/s11199-010-9756-8.

Lamb, S., \& Brown, L. M. (2006). Packaging girlhood: Rescuing our daughters from marketers' schemes. New York: St. Martin's Press. 
Lamb, S., \& Peterson, Z. D. (2012). Adolescent girls' sexual empowerment: Two feminists explore the concept. Sex Roles, 66(11-12), 703-712. doi: 10.1007/s11199-011-9995-3.

Lather, P. (1988, December). Feminist perspectives on empowering research methodologies. In Women's Studies International Forum, 11(6), 569-581. doi: 10.1016/0277-5395(88)90110-0.

Lazar, M. M. (2007). Feminist critical discourse analysis: Articulating a feminist discourse praxis 1. Critical Discourse Studies, 4(2), 141-164. doi: 10.1080/174059007014 64816.

Lazar, M. M. (2009). Entitled to consume: Postfeminist femininity and a culture of post-critique. Discourse \& communication, 3(4), 371-400. Doi: 10.1177/1750481309343872.

Lazar, M. M. (2011). The right to be beautiful: Postfeminist identity and consumer beauty advertising. In R. Gill \& C. Scharf (Eds.), New Femininities (pp. 3151). doi: 10.10 57/9780230294523_3.

Lesko, N. (2001). Act your age!: A cultural construction of adolescence. New York: Routledge Falmer.

Levande, M. (2008). Women, pop music, and pornography. Meridians: Feminism, race, transnationalism, 8(1), 293-321. Retrieved from http://muse.jhu.edu/journals/mer idians/v008/8.1levande.pdf.

Levine, J. (2002). Harmful to minors: The perils of protecting children from sex. Minneapolis: University of Minnesota Press.

Levin, D., \& Kilbourne, J. (2008). So sexy, so soon. New York: Ballantine.

Levy, A. (2005). Female chauvinist pigs: Women and the rise of raunch culture. New York: Free Press. 
Livingstone, S. (1998). Audience research at the crossroads the 'implied audience' in media and cultural theory. European journal of cultural studies, 1(2), 193-217. Retrieved from http://ecs.sagepub.com/content/1/2/193.full.pdf.

Livingstone, S. (1998b). Mediated childhoods a comparative approach to young people's changing media environment in Europe. European journal of communication, 13(4), 435-456. Retrieved from http://ejc.sagepub.com/content/13/4/435.full.pdf.

Livingstone, S. (2010). Giving people a voice: On the critical role of the interview in the history of audience research. Communication, culture \& critique, 3(4), 566-571. Retrieved from http://eprints.lse.ac.uk/48832.

Livingstone, S., \& Drotner, K. (2011). Children's media cultures in comparative perspective. Retrieved from http://eprints.lse.ac.uk/48953/.

Livingstone, S., \& Drotner, K. (2011). Children's media cultures in comparative perspective. In V. Nightingale (Eds.), The Handbook of Media Audiences. Global media and communication handbook series (IAMCR). Oxford: WileyBlackwell Publishing.

Lowe, M. (2003). Colliding feminisms: Britney Spears, "tweens" and the politics of reception. Popular Music \& Society, 26(2), 123-140. doi: 10.1080/0300776032000095477.

Lumby, C. (2007). Doing it for themselves? Teenage girls, sexuality and fame. In S. Holmes \& S. Redmond (Eds.), Stardom and celebrity: A Reader (pp.341-352). London: Sage Publications.

Lumby, C., \& Albury, K. (2010). Too much? Too young?: The sexualisation of children debate in Australia. Retrieved from http://web.b.ebscohost.com/ehost/pdfviewer /pdfviewer?sid=c00b4a45-0a1947c5-bd51-c189b39d35f3\%40'sess ionmgr111\& vid=0\&hid=116. 
MacKinnon, C. A. (1987). Feminism unmodified: Discourses on life and law. Harvard University Press.

Madalina2696. [madalina2696]. (2009, August 14). Sir Mix-A-Lot - I like big butts (official music video) [Video file]. Retrieved from https://www.youtube.com/watch? v=2ImZTwYwCug.

Mapes, J. (2010). Gaga explains her meat dress: It's no disrespect. Retrieved from http:// http://www.billboard.com/articles/news/956399/lady-gaga-explainsher-meat-dress-its-no-disrespect.

Maxson, C. L., \& Klein, M. W. (1997). Responding to troubled youth. New York: Oxford University Press.

Mazzarella, S. R. (2005). Claiming a space: The cultural economy of teen girl fandom on the web. In S.R. Mazzarella (Eds.), Girl wide web: Girls, the Internet, and the Negotiation of Identity (pp. 141-160). New York: Peter Lang Publishers.

Mazzarella, S. R. (2005b). Girl wide web: Girls, the internet, and the negotiation of identity. New York: Peter Lang.

McClelland, S. I., \& Fine, M. (2008). Writing on cellophane: Studying teen women's sexual desires, inventing methodological release points. In K. Gallagher (Eds.), The Methodological Dilemma: Creative, Critical and Collaborative Approaches to Qualitative Research (pp. 232-260). London: Routledge.

McNair, B. (1996). Mediated sex pornography and postmodern culture. New York: St Martins Press.

McNair, B. (2002). Striptease culture: Sex, media and the democratization of desire. London: Routledge.

McNay, L. (1992). Feminism and foucault. Cambridge: Polity Press. 
McRobbie, A. (2000). Feminism and youth culture. (2 ${ }^{\text {nd }}$ ed.). New York: Routledge.

McRobbie, A. (2004). Notes on postfeminism and popular culture: Bridget Jones and the new gender regime. In A. Harris (Eds.). All about the girl: Culture, power and identity (pp. 3-14). London: Routledge.

McRobbie, A. (2007). Top girls? Young women and the post-feminist sexual contract 1. Cultural Studies, 21(4-5), 718-737. doi: 10.1080/09502380701279044.

McRobbie, A. (2008). Young women and consumer culture: An intervention. Cultural Studies, 22(5), 531-550. doi: 10.1080/09502380802245803.

McRobbie, A. (2009). The aftermath of feminism: Gender, culture and social change. London: Sage Publications.

McRobbie, A., \& J. Garber. (1976). 'Girls and subcultures'. In S. Hall \& T. Jefferson (Eds.), Resistance through Rituals: Youth Subcultures in Post-war Britain (pp. 209-22). London: Hutchinson.

McRobbie, A., \& Thornton, S. L. (1995). Rethinking 'moral panic' for multi-mediated social worlds. British journal of sociology, 46(4), 559-574. doi:

$10.2307 / 591571$.

Minaj, N. [NIckiMinajAtVevo]. (2014, August 19). Nicki Minaj - Anaconda [Video file]. Retrieved from https://www.youtube.com/watch?v=LDZX4ooRsWs.

Ministry of Education (2015). Sexuality education: A guide for principals, boards of trustees and teachers. Retrieved from http://health.tki.org.nz/Teaching-inHPE/Policy-guidelines/Sexuality-education-a-guide-for-principals-boards-oftrustees-and-teachers.

Modeleski, T. (1982). Loving with a vengeance: Mass-produced fantasies for women. New York: Routledge. 
Morgan, R. (1980). Theory and practice: Pornography and rape. In L. Lederer (Eds.), Take back the night: Women on pornography (pp. 134-140). William Morrow: New York.

Morrow, V., \& Richards, M. (1996). The ethics of social research with children: An overview1. Children \& society, 10(2), 90-105. doi: 10.1111/j.10990860.1996.t b004 61.x.

Munford, R (2009). Bust-ing the third wave: Barbies, blowjobs and girlie feminism. In F. Attwood (Eds.), Mainstreaming Sex: The sexualisation of Western Culture (pp. 55-76). London: I.B. Tauris.

New Zealand Legislation (1993). Films, videos and publications act. Retrieved from http://www.legislation.govt.nz/act/public/1993/0094/latest/DLM312895.html.

“New Zealand named best place for working mothers". (2015, July 17). Retrieved from http://www.nzherald.co.nz/business/news/article.cfm?c_id=3\&objectid=11487 541.

NZME (2015, June 4). Abortion: Rights group weighs in on teen pregnancy. The New Zealand Herald. Retrieved from http://www.nzherald.co.nz/nz/news/article.cfm?c_i d=1\&objectid=11459930.

Oppliger, P. A. (2008). Girls gone skank: The sexualization of girls in American culture. New York: McFarland.

Osterkamp, U. (1999). On psychology, ideology and individuals' societal nature. Theory \& Psychology, 9(3), 379-392. Retrieved from http://tap.sagepub.com/content/9/3/3 79.full.pdf.

Overell, R. (2014, January 21). Lorde makes feminism a class issue. New Zealand Herald. Retrieved from http://www.nzherald.co.nz/entertainment/new s/article.cfm?c_id=150 1119\&objectid=11194512. 
Oware, M. (2009). A “'man's woman'? Contradictory messages in the songs of female rappers, 1992-2000. Journal of Black Studies, 39(5), 786-802. doi: $10.1177 / 0021934707302454$.

P!nk [P!nkVEVO]. (2009, October 24). P!nk-U+Ur Hand [Video file]. Retrieved from https://www.youtube.com/watch?v=YUtHjOvPKT0.

"P!nk is always going to do things her way" (2015, November 22). Retrieved from http://faze.ca/faze-interview-with-pink/.

Paasonen, S., Nikunen, K., \& Saarenmaa, L. (2007). Pornification: Sex and sexuality in media culture. New York: Berg Publishers.

Paglia, C. (2010, September 12). Lady Gaga and the death of sex. The Sunday Times. Retrieved from http://www.thesundaytimes.co.uk/sto/public/magazine/ar ticle389697.ece.

Papadopoulos, L. (2010). Sexualisation of young people review. Retrieved from http://dera.ioe.ac.uk/10738/1/sexualisation-young-people.pdf.

Parker, I. (Eds.). (1992). Discourse dynamics: Critical analysis for social and individual psychology. London: Routledge.

Parker, I. (1999). Critical psychology: Critical links. Annual Review of Critical Psychology, 1(1), 3-18. Retrieved from http://www.radicalpsychology.org/vol1-1/Parker.html.

Parker, I. (2005). Lacanian discourse analysis in psychology seven theoretical elements. Theory \& Psychology, 15(2), 163-182. doi: 10.1177/0959354305051361.

Parker, I. (Eds.). (1998). Social constructionism, discourse and realism. London: Sage Publications. 
Pepsi, 2010 [GlassworksLon]. (2010, July 22). Pepsi Commercial HD - We Will Rock Youft. Britney Spears, Beyonce, Pink \& Enrique Eglesias [Video file]. Retrieved from https://www.youtube.com/watch?v=W7jkygJ_QNo.

Perry, I. (2003). Who(se) am I? The identity and image of women in hip hop. In G. Dines \& J. Humez (Eds.), Gender, Race, and Class in Media: A Text Reader (pp.136-48). Thousand Oaks, CA: Sage Publications.

Perry, K [CapitolMusic]. (2008, June 10). Katy Perry - I Kissed A Girl [Video file]. Retrieved from https://www.youtube.com/watch?v=tAp9BKosZXs.

Perry, K [CapitolMusic]. (2008b, October 13). Katy Perry - Hot N Cold [Video file]. Retrieved from https://www.youtube.com/watch?v=kTHNpusq654.

Perry, K. [emimusic]. (2014, June 14). Katy Perry-California Gurls ft. Snoop Dogg [Video file]. Retrieved from https://www.youtube.com/watch?v=F57P9C4SAW4.

Peterson, Z. D. (2010). What is sexual empowerment? A multidimensional and process-oriented approach to adolescent girls' sexual empowerment. Sex Roles, 62(5-6), 307-313. doi: 10.1007/s11199-009-9725-2.

Pipher, M. (1994). Reviving ophelia: Saving the selves of adolescent girls. New York: G.P. Putnam \& Sons.

Potter, J., \& Wetherell, M. (1987). Discourse and social psychology: Beyond attitudes and behaviour. London: Sage Publications.

Q8Painkiller (2014, July 29). White Stripes - I Just Don't Know What To Do With Myself. [Video file]. Retrieved from https://www.youtube.com/watch?v=fC7PEQnjK14.

RadioNZ (2015, October 8). Melissa Tankard-Reist - The impact of sexualised imagery. Retrieved from 
http://www.radionz.co.nz/national/programmes/sunday/a udio/201770434/melinda-tankard-reist-impact-of-sexualised-imagery.

Radway, J. (1984). Reading the romance: Women, patriarchy and popular literature. [E-reader version]. Retrieved from http://site.ebrary.com/lib/vuw/detail.actio $\mathrm{n} ? \mathrm{doc} \mathrm{ID}=10355395$.

Railton, D., \& Watson, P. (2011). Music video and the politics of representation. London: Oxford University Press.

Redmond, S. (2006). Intimate fame everywhere. In S. Holmes \& S. Redmond (Eds.), Framing celebrity: New directions in celebrity culture (pp. 27-43). New York: Routledge.

Redmond, S., \& Holmes, S. (Eds.). (2007). Stardom and celebrity: A reader. London: Sage Publications.

Renold, E. (2005). Presumed innocence: Young children, sexualities and schooling. In E. Renold (Eds.), Girls boys and junior sexualities: Exploring children's gender and sexual relations in the primary school (pp. 17-39). doi: $4324 / 9780203561584$.

Renold, E., \& Ringrose, J. (2008). Regulation and rupture Mapping tween and teenage girls' resistance to the heterosexual matrix. Feminist Theory, 9(3), 313-338. doi: 10.1177/1464700108095854.

Renold, E., \& Ringrose, J. (2011). Schizoid subjectivities? Re-theorizing teen girls' sexual cultures in an era of 'sexualization'. Journal of Sociology, 47(4), 389409. doi: 10.1177/1440783311420792.

Renold, E., \& Ringrose, J. (2013). Feminisms re-figuring 'sexualisation', sexuality and 'the girl'. Feminist Theory, 14(3), 247-254. doi: $10.1177 / 1464700113499531$. 
Revealing photo threatens major Disney franchise (2008, April 12). The New York Times. Retrieved from http://www.nytimes.com/2008/04/28/business/media/28ha nnah.html?_r=0. Rihanna. [RihannaVevo]. (2011, January 31). Rihanna $-S \& M$ [Video file]. Retrieved from https://www.youtube.com/watch?v=KdS6HFQ_LUc.

Rihanna. [RihannaVevo]. (2013, October 2). Rihanna - Pour It Up [Video file]. Retrieved from https://www.youtube.com/watch?v=ehcVomMexkY.

Rihanna. [RihannaVevo]. (2015, July 1). Rihanna - Bitch Better Have My Money [Video file]. Retrieved from https://www.youtube.com/watch?v=B3eAMGXFw1o.

Ringrose, J. (2006). A new universal mean girl: Examining the discursive construction and social regulation of a new feminine pathology. Feminism \& psychology, 16(4), 405-424. doi: 10.1177/0959353506068747.

Ringrose, J. (2008). "Every time she bends over she pulls up her thong" Teen Girls Negotiating Discourses of Competitive, Heterosexualized Aggression. Girlhood Studies, 1(1), 33-59. doi: 10. 3167/ghs.2008.010104.

Ringrose, J. (2010). 12 Sluts, whores, fat slags and playboy bunnies: Teen girls' negotiations of 'sexy' on social networking sites and at school. Girls and Education. Retrieved from https://www.researchgate.net/profile/Jessica_Ringrose/publication/ 274067832_Sluts_whores_fat_slags_and_Playboy_bunnies_Teen_girls_negoti ations_of_sexy_on_social_networking_sites_and_at_school/links/5513d0f90cf 283ee083491b1.pdf.

Ringrose, J. (2011). Are you sexy, flirty, or a slut? Exploring 'sexualization' and how teen girls perform/negotiate digital sexual identity on social networking sites. In R. Gill \& C. Scharf (Eds.), New femininities: Postfeminism, neoliberalism and subjectivity (pp. 99-116). UK: Palgrave Macmillian. 
Ringrose, J., \& Coleman, R. (2013). Looking and desiring machines: A feminist deleuzian mapping of bodies and affects. In J. Ringrose \& R. Coleman (Eds.), Deleuze and Research Methodologies (pp. 125-144). Edinburgh: Edinburgh University Press.

Ringrose, J., \& Renold, E. (2012). Teen girls, working-class femininity and resistance: Retheorising fantasy and desire in educational contexts of heterosexualised violence. International Journal of Inclusive Education, 16(4), 461-477. doi: 10.1080/13603116.2011.555099.

Ringrose, J., \& Renold, E. (2012b). Slut-shaming, girl power and 'sexualisation': Thinking through the politics of the international Slut Walks with teen girls. Gender and Education, 24(3), 333-343. doi:10.1080/09540253.2011.645023.

Robin, M. (1974). Going too far: The personal chronicles of a femininst. New York: Vintage Books.

Rojek, C. (2001). Celebrity. London: Reaktion.

Rose, G. (2007). Visual methodologies: An introduction to researching with visual materials. Thousand Oaks, California: Sage Publications.

Ruddock, A. (2000). Understanding audiences: Theory and method. London: Sage Publications.

Rush, E., \& La Nauze, A. (2006). Corporate paedophilia: Sexualisation of children in Australia. Australia Institute. Retrieved from http://tai.org.au/documents/dp_fulltext/ DP90.pdf.

Rush, E., \& La Nauze, A. (2006b). Letting children be children: Stopping the sexualisation of children in Australia. Australia Institute. Retrieved from http://www.tai.org.au/ documents/dp_fulltext/DP93.pdf. 
Russo, A. (1987). Conflicts and contradictions among feminists over issues of pornography and sexual freedom. Women's Studies International Forum, 10(2), 103-112. doi: 10.1016/0277-5395(87)90019-7.

Saussure, F. (1998). Nature of the linguistic sign. In D. H. Richter (Eds.), The Critical Tradition: Classic Texts and Contemporary Trends (pp. 832-835). Boston: Bedford/St. Martin's Press. Retrieved from http://sites.davidson.edu/spa270bf all13/wpcontent/uploads/2013/08/Saussure_Nature_of_the_Linguistic_Sign.pdf.

Segal, L. (1998). Only the literal: The contradictions of anti-pornography feminism. Sexualities, 1(1), 43-62. doi: 10.1177/136346098001001003.

Seto, M. C., Maric, A., \& Barbaree, H. E. (2001). The role of pornography in the etiology of sexual aggression. Aggression and violent behaviour, 6(1), 35-53. doi: 10.1016/S135 9-1789(99)00007-5.

Simmons, R. (2002). Odd girl out: The hidden culture of aggression in girls. Boston: Houghton Mifflin Harcourt.

Skeggs, B. (1997). Formations of class \& gender: Becoming respectable. London: Sage Publications.

Skeggs, B. (2001). The toilet paper: Femininity, class and mis-recognition. Women's Studies International Forum, 24(3), 295-307. doi: 10.1016/S02775395(01)00186-8.

Skeggs, B. (2004). Class, self, culture. London: Routledge.

Skeggs, B. (2005). The making of class and gender through visualizing moral subject formation. Sociology, 39(5), 965-982. doi: 10.1177/0038038505058381. 
Smith, C. (2010). Pornographication: A discourse for all seasons. International journal of media and cultural politics, 6(1), 103-108. doi:

10.1386/macp.6.1.103/3.

Smith, C., \& Attwood, F. (2011). Lamenting sexualization: Research, rhetoric and the story of young people's 'sexualization' in the UK home office review. Sex Education, 11(3), 327-337. doi: 10.1080/14681811.2011.590314.

Smith, C., \& Attwood, F. (2014). Anti/pro/critical porn studies. Porn Studies, 1(1-2), 7-23. doi: 10.1080/23268743.2014.887364.

Sommers-Flanagan, R., Sommers-Flanagan, J., \& Davis, B. (1993). What's happening on music television? A gender role content analysis. Sex roles, 28(11-12), 745753. doi: 10.1007/BF00289991.

Springer, K. (2007). Divas, evil black bitches, and bitter black women: AfricanAmerican women in postfeminist and post-civil Rights Popular Culture. In D. Negra \& Y. Tasker (Eds.), Interrogating Postfeminism (pp. 72-92). Durham, N.C: Duke University Press.

Swift, T. [TaylorSwiftVEVO]. (2015, May 17). Taylor Swift-Bad Blood ft. Kendrick Lamar [Video file]. Retrieved from https://www.youtube.com/watch?v=QcIy9NiNbmo.

Taft, J. K. (2004). Girl power politics: Pop-culture barriers and organizational resistance. In A. Harris (Eds.), All About the Girl: Culture, Power, and Identity (pp. 69-78). London: Routledge.

Tankard Reist, M. (2009). The pornification of girlhood: We haven't come a long way baby. In M. Tankard Reist (Eds.), Getting Real: Challenging the Sexualisation of Girls (pp. 5-40). North Melbourne: Spinifex.

Tasker, Y., \& Negra, D. (2005). In focus: Postfeminism and contemporary media studies. Cinema Journal, 44(2), 107-110. doi: 10.1353/cj.2005.0012. 
Taussig, M. T. (1993). Mimesis and alterity: A particular history of the senses. New York: Routledge.

The law around abortion. (2016). Family Planning. Retrieved from http://www.familyplanning.org.nz/advice/abortion/the-law-around-abortion

Thomson, P. (2008). Doing visual research with children and young people. New York: Routledge.

Tiggemann, M. (2003). Media exposure, body dissatisfaction and disordered eating: Television and magazines are not the same!. European Eating Disorders Review, 11(5), 418-430. doi: 10.1002/erv.502.

Tolman, D. L. (1994). Doing desire adolescent girls' struggles for/with Sexuality. Gender \& Society, 8(3), 324-342. Retrieved from http://gas.sagepub.com/content/8/3/324.full. pdf.

Tolman, D. L. (2005). Dilemmas of desire: Teenage girls talk about sexuality. London: Harvard University Press.

Tolman, D. L. (2012). Female adolescents, sexual empowerment and desire: A missing discourse of gender inequity. Sex Roles, 66(11-12), 746-757. doi: 10.1007/s11199-012-0122-x.

Tuffin, K. (2004). Understanding critical social psychology. London: Sage Publications.

Turner, G. (2010). Approaching celebrity studies. Celebrity studies, 1(1), 11-20. doi: 10.1080/19392390903519024

Vance, C. S. (1984). Pleasure and danger: Exploring female sexuality. Boston: Routledge. 
Vares, T., Jackson, S., \& Gill, R. (2011). Preteen girls read 'tween' popular culture: Diversity, complexity and contradiction. International Journal of Media \& Cultural Politics, 7(2), 139-154. doi: 10.1386/macp.7.2.139_1.

Vares, T., \& Jackson, S. (2015). Reading celebrities/narrating selves: ‘Tween’ girls, Miley Cyrus and the good/bad girl binary. Celebrity Studies, 6(4), 553-567. doi: 10.1080/ 19392397.2015.1021822.

Vena, J. (2011, May 17). Lady Gaga says ‘Born This Way' is my answer to many questions. Retrieved from http://www.mtv.com/news/1664019/lady-gagametro-editor/.

Walkerdine, V. (1998). Daddy's girl: Young girls and popular culture. London: Harvard University Press.

Walkerdine, V. (1998). Popular culture and the eroticization of little girls. In H. Jenkins (Eds.), The children's culture reader (pp. 254-64). New York: New York University Press.

Walter, N. (2011). Living dolls: The return of sexism. London: Virago.

Weedon, C. (Eds.). (1997). Feminist practice and poststructuralist theory. London: Wiley-Blackwell.

Weidhase, N. (2015). 'Beyoncé feminism' and the contestation of the black feminist body. Celebrity Studies, 6(1), 128-131. doi: 10.1080/19392397.2015.1005389.

Wetherell, M. (1999). Beyond binaries. Theory \& Psychology, 9(3), 399-406. doi: 10.1177/09 59354399093009.

Whelehan, I. (2000). Overloaded: Popular culture and the future of feminism. London, Womens Press Ltd. 
Whitehead, K., \& Kurz, T. (2009). 'Empowerment' and the pole: A discursive investigation of the reinvention of pole dancing as a recreational activity. Feminism \& Psychology, 19(2), 224-244. doi: 10.1177/0959353509102218.

Wilkinson, S. (1988). The role of reflexivity in feminist psychology. Women's Studies International Forum 11(5), 493-502. doi: 10.1016/0277-5395(88)90024-6.

Wilkinson, S. (1991). Feminism \& psychology: From critique to reconstruction. Feminism \& Psychology, 1(1), 5-18. Retrieved from http://fap.sagepub.com/content/1/1/5.full.pdf.

Wilkinson, S. (1998). Focus groups in feminist research: Power, interaction, and the co-construction of meaning. Women's studies international forum 21(1), 111125. doi:_10.1016/S0277-5395(97)00080-0.

Wilkinson, S. (1999). How useful are focus groups in feminist research. In R. Barbour \& J. Kitzinger (Eds.), Developing focus group research: Politics, theory and practice (pp. 64-78). New York: Sage Publications.

Willett, R. (2008). 'What you wear tells a lot about you': Girls dress up online. Gender and Education, 20(5), 421-434. doi: 10.1080/09540250701797242.

Willett, R. (2011). An ethnographic study of preteen girls' play with popular music on a school playground in the UK. Journal of Children and Media, 5(4), 341-357. doi: 10.1080/17482798.2011.587146.

Willig, C. (2001). Foucauldian discourse analysis. In C. Willig (Eds.), Introducing qualitative research in psychology: Adventures in theory and method (pp. 106124). Buckingham, PA: Open University Press.

Willis, P. (1990). Common culture: Symbolic work at play in the everyday cultures of the Young. Milton Keynes: Open University Press. 
Wiseman, R. (2002). Queen bees and wannabees: Helping your daughter survive cliques, gossip, boyfriends, and the new realities of girl world. New York: Crown Publishers.

Wyn, J., \& White, R. (1996). Rethinking youth. London: Sage Publications.

Zaslow, E. (2009). Wanna get dirty?: Determining authentic sexual subjectivity. In E. Zaslow (Eds.), Feminism Inc. Coming of age in girl power media culture (pp. 57-82). New York: Palgrave MacMillan. 
Appendix A: Parental/Caregiver Information Sheet

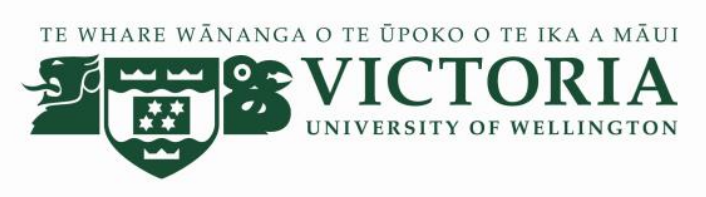

\section{Girls, Music and Identity}

Sarah Goddard

PhD Student

sarah.goddard@,vuw.ac.nz

\author{
Dr. Sue Jackson \\ Senior lecturer \\ sue.jackson@,vuw.ac.nz \\ 4635233 ext 8232
}

\section{What is the project about?}

Music is a highly accessible and popular form of media that is used by young people, especially young girls. With the expansion of online media tools, music, especially music videos have become a medium which saturate girls' lives. With the increase of postfemininity and consumerism in contemporary culture, music has become a vehicle for the messages of the new femininity to be carried out especially to young audiences. The number of female pop artists has also increased dramatically with interactive media tools and music videos allowing girls to have a pseudo friendship with the celebrities/artists that they like. Contemporary female pop music is largely based around postfeminist messages of choice, independence, consumerism and girl power. This project will endeavour to shed light on not only the messages that are being delivered about contemporary femininity but also how the girls that are consuming pop music interpret, understand and possibly apply these messages in their own identity development. Contrary to popular belief which highlights a "reproduction" of these messages by girls, my own previous research has found strong evidence to suggest that girls are not passive consumers, rather they are instrumental in negotiating and transforming messages about femininity when applying them to their own development.

For this reason I believe that further research needs to be done to shed light on girls' relationship to music and its contemporary messages. We are interested not only in the girls' opinions about contemporary pop music and videos but also the kinds of ideas or messages they may use in the creation of their own music videos. We want to learn about the various resources that girls draw on to create their musical identities. This research, specifically the girls own performance aspect will produce a very different and very important perspective to studies about girls' consumption of music.

\section{What is involved if my daughter participates?}

Participation in this project would involve two parts, firstly your daughter participating in producing and performing in a music video with a small group of other participating girls. The recording equipment will be provided for each group. The music video recordings will be transcribed and analysed for themes. Secondly, your daughter participating in a small focus group with myself and the same group of 
girls she was with for the music video task. The discussion will be approximately one hour long and would involve us discussing topics such as music preferences, artist preferences and their own music video performances. This discussion would be transcribed and analysed for themes. Participation in both sections of this study is completely voluntary; your daughter would be free to cease participation at any point of the performance or the focus group without having to give any reason.

\section{How are privacy and confidentiality protected?}

The information that the girls provide would be kept strictly confidential. This means that any information that they provide will not be shared with any person outside of this study. The only record of the girls' names will be on the consent forms; these are also confidential and will be stored in a locked file in my supervisors' research office at Victoria University of Wellington.

Video and audio recordings will only be listened to by my supervisor and myself. These recordings will be wiped following transcription.

All written material (including consent forms, assent forms and written transcriptions) will be stored in my supervisors' office for five years. After this time they will be destroyed.

\section{What happens with the information that is provided?}

Findings will be written up and form part of a PhD Thesis project that will be submitted for assessment. Overall finding may be submitted for publication in a professional journal, or presented at professional conferences.

If you agree to your daughter taking part in this research project please fill out the consent form on the next page. If you have any further questions please do not hesitate to contact me or my supervisor. 
Appendix B: Parental Consent Form

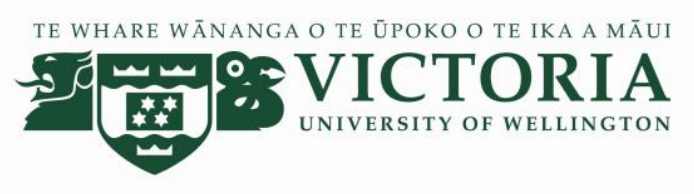

Girls, Music and Identity

I have read the information sheet describing the study. I agree to allow my daughter to participate in this study.

I understand completely what is required of my daughter if she participates and understand that she may withdraw from the study at any time no questions asked.

I understand that all the information that my daughter gives will be kept in strict confidentiality to anyone outside of this study. I understand that all written material in the project will keep my daughters identity confidential. I agree to the focus group being audio-taped and I understand that the audio-tape will be destroyed one the discussion has been transcribed. I agree to the performance being video-taped and I understand that the video-recording will be destroyed once analysis has taken place.

Name of participant:

Name of participants guardian:

Guardians' signature:

Date:

If you would like to receive a summary of the research findings please provide an email or postal address below.

Email Address:

Postal Address: 
Appendix C: Girls Information Brochure

\begin{tabular}{|c|c|}
\hline $\begin{array}{c}\text { How to contact us: } \\
\text { If you have any questions regarding } \\
\text { this research please feel free to contact: } \\
\text { Sarah Goddard (Researcher) } \\
\text { Email: } \underline{\text { sarah.goddard @ vuw.ac.nz }} \\
\text { Supervisor) Senior Lecturer } \\
\text { Email: } \underline{\text { sue.jackson@ vuw.ac.nz }} \\
\text { Phone: } 4635233 \text { ex. } 8232\end{array}$ & $\begin{array}{l}\text { What happens with the information } \\
\text { that you provide? } \\
\text { J The audiotapes of the friendship group } \\
\text { interviews will be transcribed into a written } \\
\text { form. Pseudonyms will be used on all written } \\
\text { material } \\
\text { J I will write up the project to produce a thesis } \\
\text { which is like a book about the project that is } \\
\text { marked by examiners. } \\
\text { J The report may also be used in conference } \\
\text { presentations, or in articles published in } \\
\text { academic journals } \\
\text { J You may request a summary of the main } \\
\text { findings in this project by ticking the } \\
\text { appropriate box and supplying an email or } \\
\text { postal address on your assent/consent form. }\end{array}$ \\
\hline
\end{tabular}

\section{GIRLS AND POPULAR MUSIC}

A research project to be conducted

by Sarah Goddard 


\begin{tabular}{|c|c|c|}
\hline $\begin{array}{l}\text { Hi Girls!! } \\
\text { My name is Sarah Goddard and I am a } \\
\text { Psychology PhD student at Victoria } \\
\text { University of Wellington. As part of my } \\
\text { course I am doing a research project under the } \\
\text { supervision of Dr. Sue Jackson. } \\
\text { I am interested in girls like you and also in } \\
\text { music, particularly music made by female } \\
\text { musicians. So for this project I would like to } \\
\text { know your opinions about popular music, } \\
\text { including the songs and videos clips that you } \\
\text { like to watch and the ones that you don't! } \\
\text { However, I don't just want you to tell me } \\
\text { about what you like about music I also want to } \\
\text { give you the opportunity to create and perform } \\
\text { your own music videos to any female pop } \\
\text { song that you like alone or with a small group } \\
\text { of your friends. } \\
\text { So why do I want to research these topics? } \\
\text { Because I think that music is a very important } \\
\text { part of girl's lives yet we know very little } \\
\text { about what you think about popular music. } \\
\text { Sometimes music and media get blamed for } \\
\text { all the things thought to be 'wrong' with } \\
\text { young people but we actually know little } \\
\text { about what girls like you think about popular } \\
\text { music and music celebrities. We know even } \\
\text { less about how girls use popular music in their } \\
\text { own creative performance and play. }\end{array}$ & $\begin{array}{l}\text { What is involved if you choose to } \\
\text { participate? } \\
\text { J Friendship group interviews will take } \\
\text { place involving you and a small group of } \\
\text { other participating girls. In this discussion we } \\
\text { will talk about popular music and your likes } \\
\text { and disliked about it. This discussion will last } \\
\text { approximately one hour. } \\
\text { J You will also be lent a video recorder to } \\
\text { record a music video either by yourself or in } \\
\text { small groups. You may record your music } \\
\text { video in your homes or school. You may not } \\
\text { record in public and people who are not } \\
\text { participating in the study may not be filmed. } \\
\text { The music video will only be watched by my } \\
\text { supervisor and me. } \\
\text { J Finally, you will be asked to take part in a } \\
\text { friendship group interview with the group } \\
\text { that you did the music video task with. In this } \\
\text { interview we will talk about how you made } \\
\text { the video and what you liked about it. You } \\
\text { will also be presented with a cinema voucher } \\
\text { to thank you for your time. } \\
\text { J There are no right or wrong answers to the } \\
\text { questions that I will ask in the friendship } \\
\text { group interviews, I am interested only in your } \\
\text { own individual opinions. The same goes for } \\
\text { the music video- I'm not interested in how } \\
\text { 'good' it may be but how you use the chosen } \\
\text { song to express yourself. }\end{array}$ & $\begin{array}{l}\mathcal{J} \text { The friendship group interviews will be } \\
\text { recorded audiotaped, transcribed and } \\
\text { analysed for themes. The music videos will } \\
\text { be transcribed and analysed for themes. } \\
\text { Privacy and Confidentiality } \\
\text { J The information that you and your } \\
\text { group give will not be discussed with any } \\
\text { outside persons e.g. family and schools. } \\
\text { J The only record that I will have of your } \\
\text { names will be on the consent forms. } \\
\text { Consent forms are confidential and are } \\
\text { stored in a locked file in my supervisors' } \\
\text { office at Victoria University of Wellington. } \\
\text { J The tape recordings of the friendship } \\
\text { group interviews and music video } \\
\text { recordings will only be listened to and } \\
\text { viewed by me and my supervisor. } \\
\text { J You will not be identifiable in my } \\
\text { research or in any publication or } \\
\text { presentation as each participant will be } \\
\text { assigned a pseudonym (a made up name) } \\
\text { which will be used in all written material } \\
\text { throughout the project. Confidential } \\
\text { information such as consent forms and } \\
\text { assent forms, will be stored in my } \\
\text { supervisor's office for five years, after } \\
\text { which they will be destroyed. After } \\
\text { transcription, the audio recording of the } \\
\text { discussion will be wiped. }\end{array}$ \\
\hline
\end{tabular}


Appendix D: Girls' Assent Form

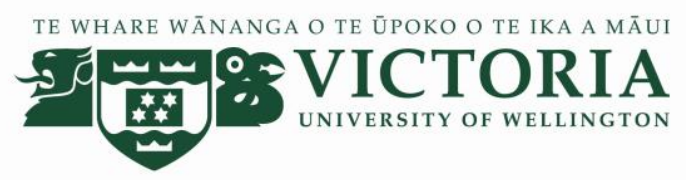

\section{Girls, Music and Identity}

J I have read the brochure describing the study

$\mathcal{I}$ I understand what is expected of me in terms of participation in this study.

JAny questions that I may have had have been answered.

J I understand that I may stop participating in the study at anytime, no questions asked.

J I agree to the focus group being audio-recorded and understand that this recording will be destroyed once it has been transcribed.

I I give Sarah and her supervisor permission to watch the group music video.

J I agree to participate in this research project.

Name:

Signed:

Date:

If you would like to receive a summary of the research findings please provide an email or postal address below.

Email Address:

Postal Address: 
Appendix E: Girls Filming Group Form

\section{gigning trp:}

My name is:

I am in room:

I would like to take part in this project with (please tick one):

just $M E$

With a group of friends who are also participating in the project. Their names are: (write them below, no more than five)

1.

2.

3.

4.

5. 
I would like to get to know you a bit better

I would like you to tell me a few things about yourself

My name is:

Mry dert'e of birtih is:

(dery)/____(mont'_h)/

(yeare)

I would describe msy ethnicitys as:

Mry school jear is:

I am in room:

Myy Geacher is:

I live at:

Mey home phone number is:

My emeil Address is:

Please tick which is the best' way for me to stery in contact with sou dureing the project.

Gell ne albout'́ soure

family. 
Mny Math's work is:

My Derd's work is:

my fervourite thing to do in mas sperre time is: 
Appendix G: Friendship Group Interview Schedule

\section{Girls, Music and Identity}

Friendship Group Interview Schedule:

Duration: $1-1 \frac{1}{2}$ hours

\section{Introductions:}

-Self introduction

-Confidentiality explained

-Questions and assent forms collected

\section{Music Preferences:}

-Favorite music videos. What makes them your favorite?

-Favorite female musicians

-Themselves

- Friends and others at school.

-What makes the most popular video so popular?

-What do your parents or siblings think of the videos that you like?

\section{Music:}

-What are the popular components of a music video?

-How similar are the videos for any individual artist? (e.g., the ones that they have already mentioned)

-What is the most popular music in your school?

-What is the most popular music video in your school?

-Do you think different music appeals to different age groups? Why?

-What is the best way to access music videos?

- How much time would you spend watching music videos in a week?

-Do you prefer to watch music videos while you listen to the song? Why/ or why not?

-What is the most popular topic for a song or music video?

\section{Celebrities:}

- What makes a celebrity popular within different age groups?

-What do you think about the fashion that you see in videos?

-Do you like the fashion, how much does that influence what you choose to wear?

-How does a celebrity 'fall from grace'?

-How much can you identify with the musicians in the videos?

-How much would you like to be like some of the musicians in the videos? 
Appendix H: Filming Rules

It's time to start filming! These rules are an important part of the project and are aimed at keeping you safe so please make sure you know them and stick to them at all times during your participation in the project.

1. No filming anyone who is not a participant in this project. This means that you are only allowed to film the girls who are participating in your group. No family members or friends please.

2. Allowed places to film are in your home (or the home of someone in your group) OR at school in a private room. No filming in public or in spaces where there are likely to be other individuals.

3. Do not remove the recording disc from the camera. This is just to make sure nothing gets deleted accidentally!

4. Please return the camera, inside the camera bag to the school office.

THANKS AGAIN FOR YOUR PARTICIPATION! HAVE FUN!

- SARAH 
Appendix I: Follow Up Interview Schedule

\section{Girl, Music and Identity}

Interview schedule for final friendship group interview:

Duration: 30-40mins

\section{Song Selection:}

-Why did you choose the song to perform to?

-What do you think of the artist and their video performance to this song?

-What are some of the things that you see in the professional videos clips by this artist?

-What do you think the song is about?

\section{Performance:}

-How did you come to choose/decide about the kind of performance you would do? -What ideas from the original performance did you use and what did you change?

\section{Clothing/Costume:}

-How did you decide on your outfits? In what ways were the outfits important to what you wanted to do in the performance?

\section{Likes and Dislikes:}

-Once you made the video what did you think of it?

\section{Conclusion:}

-Girls thanked for their time and given a movie voucher. 